University of Louisville

ThinkIR: The University of Louisville's Institutional Repository

Electronic Theses and Dissertations

$5-2005$

\title{
Legacy children : whose legacy are they?
}

Pamela Nolley Tungate 1968-

University of Louisville

Follow this and additional works at: https://ir.library.louisville.edu/etd

\section{Recommended Citation}

Tungate, Pamela Nolley 1968-, "Legacy children : whose legacy are they?" (2005). Electronic Theses and Dissertations. Paper 1468.

https://doi.org/10.18297/etd/1468

This Doctoral Dissertation is brought to you for free and open access by ThinkIR: The University of Louisville's Institutional Repository. It has been accepted for inclusion in Electronic Theses and Dissertations by an authorized administrator of ThinkIR: The University of Louisville's Institutional Repository. This title appears here courtesy of the author, who has retained all other copyrights. For more information, please contact thinkir@louisville.edu. 
LEGACY CHILDREN: WHOSE LEGACY ARE THEY?

\author{
by \\ Pamela Nolley Tungate \\ B.S., Campbellsville University, 1989 \\ M.S.W., University of Kentucky, 1991

\begin{abstract}
A Dissertation
Submitted to the Faculty of the

Graduate School of the University of Louisville in Partial Fulfillment of the Requirements

for the Degree of
\end{abstract} \\ Doctor of Philosophy \\ Raymond A. Kent School of Social Work \\ University of Louisville \\ Louisville, Kentucky \\ and \\ College of Social Work \\ University of Kentucky \\ Lexington, Kentucky
}

May 2005 
LEGACY CHILDREN: WHOSE LEGACY CHILDREN?

by

Pamela Nolley Tungate

B.S., Campbellsville University, 1989

M.S.W., University of Kentucky, 1991

A Dissertation Defense Approved on

April 27, 2005

by the following Dissertation Committee:

Anita Barbee, Ph.D.

Ruth Huber, Ph.D.

Thomas Lawson, Ph.D.

Pamela Yankeelov, Ph.D.

Thomas Clark, Ph.D. 


\begin{abstract}
LEGACY CHILDREN: WHOSE LEGACY ARE THEY?

Pamela Nolley Tungate
\end{abstract}

April 27, 2005

The Adoption and Safe Families Act created specific outcomes for permanency for children in foster care. The purpose of these outcomes is to decrease the number of children in long term foster care. Seven years have passed since ASFA was signed into law. Audits completed in each state by federal reviewers have found that no state has meet ASFA's primary outcome of permanency and stability of placement for foster children. A number of foster children are still spending long periods of time in foster care. This project sought to identify barriers to permanency for a sample of Kentucky's long term foster care population. Regression analysis and path modeling were used to identify seven direct predictors and nineteen indirect post ASFA predictors of long term care for the children in this study. Number of days between case planning conferences was the strongest predictor of long term foster care. Ethnographic interviews completed with twenty current foster children gathered their perspectives regarding permanency and satisfaction with foster care post ASFA. For these children, stability of placement was the foremost concern. 


\section{ACKNOWLEDGEMENTS}

I would like to thank my husband, Kerry Tungate, for his support and faith. He has spent many nights and weekends changing diapers, attending sporting events and doing homework with our children while I attended class and completed this dissertation. I would also like to thank my children, Alex, 13, Spencer, 10 and Maddie, 6 . Knowing that each of you are proud of me is the best reward I could ever be given. The spirit, energy and hope you bring to my life everyday are my driving forces.

I would be remiss if I did not thank members of my committee and others who helped with the writing process. Dr. Anita Barbee, has been my cheerleader, advocate and mentor through this process. Without her words of wisdom I would not have completed this dissertation. I would like to thank Dr. Ruth Huber for always being available for guidance and encouragement. I would also like to thank Dr. Thomas Lawson, Dr. Pamela Yankeelov and Dr. James Clark for their insights and encouragement and for agreeing to serve on my committee. Last, but not least, I would like to thank Dr. Michael Cunningham for his assistance with data analysis. 


\section{TABLE OF CONTENTS}

TITLE PAGE.

APPROVAL OF DEFENSE .

History of Permanency.............................................. 8

Child Abuse Prevention and Treatment Act (CAPTA) of $1974 \quad 12$

Indian Child Welfare Act of 1976 .......................................... 13

Youakim vs. Miller............................................ 13

Adoption Assistance and Child Welfare Act of $1980 \ldots \ldots \ldots \ldots . \quad 13$

Family Preservation and Support Initiative of $1993 \ldots \ldots \ldots \ldots . . .14$

Multiethnic Placement Act (MEPA) of 1994 ................... 14

Adoption and Foster Care Analysis Reporting System ........ 15

Interethnic Adoption Provisions Act of 1996 ................... 15

Adoption and Safe Families Act (ASFA) of 1997.............. 15

Rationale for Study................................................ 16

Study Design..................................................... 17

Study One - Quantitative Data Collection..................... 18

Study One - Sample.................................. 19

Study One - Variables.............................. 19

Study Two - Ethnographic Study of Legacy Children.......... 20

Research Questions.................................................. 23 
CHAPTER 2: Literature Review....................................... 24

Families Variables .............................................. 25

Visitation.................................................. 32

Parent's Participation in Case Planning...................... 34

Risk Factors Present Specific to Adult Family Mmbers........ 38

Parental Physical Health................................. $\quad 39$

Parental Mental IIIness and Emotional Problems.... $\quad 39$

Chronic Substance Abuse............................. 41

Domestic Violence...................................... 42

Lack of or Inappropriate Extended Family Support...... 43

Parental Intellectual Functioning........................ 44

Title IV-E Eligibility.......................................... 44

Recidivism............................................... 45

Differences in Investigating Abuse Reports on Open... 46 Cases

Differences in Definitions of Indicated Reports of........ 46 Abuse

Differences in the Availability of Alternatives to Foster Care

Number of Children.......................................... 48

Number of parents in the Home............................. 49

Type of Abuse Child Suffered................................ 49

Neglect............................................. 50

Physical........................................... 51

Sexual................................................. 52

Summary of Family Variables................................ 52

Child Variables.......................................................... 53

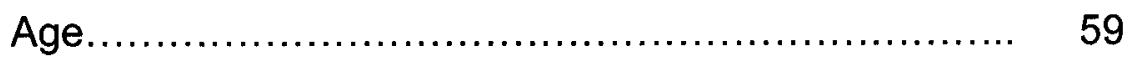

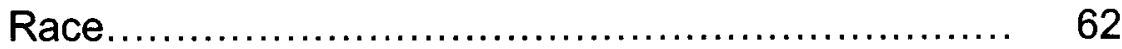


Gender............................................. 64

Children's Behavior Checklist Level..................... 65

Well Being Rating ..................................... 66

Child's Level of Attachment............................... 68

Summary of Child Variables.............................. $\quad 70$

Social Worker Variables......................................... 71

Number of Moves.......................................... 76

Regularity of Case Planning Conferences..................... 77

Permanency Goal of Child................................... 78

Worker Attitude Toward Attachment.......................... $\quad 80$

Social Worker's Educational Degree........................... 81

Experience Level of Social Worker............................ 83

Number of Visits to Parents.................................... 83

Number of Visits to Child .................................... 85

Summary of Social Worker Permanency Indicators............. $\quad 87$

System Variables.................................................. 87

Proximity of Placement...................................... 91

Number of Workers Assigned to Case......................... $\quad 92$

Amount Spent on Child's Placement.......................... 93

Type of Foster Placement..................................... 94

Court System................................................ 96

Legal Status of Child ....................................... 98

Service Array .............................................. 99

Summary of Macro Variables................................. 101

Conclusions................................................... 102

CHAPTER 3: Methodology.............................................. 104

Participants................................................... 104 
Research Design .............................................. 105

Variables Operationalized............................................ 105

Procedures for Data Collection..................................... 109

Instruments..................................................... 112

Child Behavior Checklist ....................................... 112

Survey of Macro Related Influence on Permanency................... 113

Procedures for Data Analysis........................................ 115

CHAPTER 4: Results.................................................... 118

Static Group Comparison Design .................................. 118

Data Analysis.................................................... 119

Family Variable Findings.................................. 120

Family Variables Predictive of Legacy Group................. 126

Legacy Group Predictor - Sibling Group............... 127

Legacy Group Predictor - Lack of Positive Family and 127 Community Support

Predictors of family and community support rating...... 128

Legacy Group Predictor - Parent/Child Visitation........ 129

Predictors of Parent/Child Visitation...................... 131

Legacy Group Predictor - Sexual Abuse and Neglect... 132

Family Variables That Were Not Predictive of Legacy Group.. 133

Extent and Severity of Abuse .......................... 133

Adult Risk Issues...................................... 134

Participation in Case Planning......................... 136

Summary Findings of Family Variables................ 137

Child Variable Findings....................................... 137

Child Variable Predictors of Legacy Group................... 142

Legacy Group Predictor - Child Development Rating... 143

Predictors of Child Development Rating........... 143 
Legacy Group Predictor - Race of Child ................ 144

Child Variables That Were Not Predictive of Legacy Group... 145

Auchenbach/Children's Behavior Checklist.............. 145

Gender and Age at Entry............................. 148

Summary of Findings Related to Child Variables........ 149

Social Worker Findings..................................... 149

Social Worker Variables Predictive of Legacy Group........... 154

Legacy Group Predictor - Days Between Case.......... 155 Planning Conferences

Predictors of Number of Days Between Case.... 157 Plans

Legacy Group Predictor—Number of Foster Care...... 159

Placements

Predictors of Number of Placements............. 160

Social Worker Variables That Were Not Predictive of Legacy.. 161 Group

Permanency Goal.................................... 162

Social Worker Contacts with Child and Family........ 162

Experience Level of Social Worker.................... 164

Educational Degree of Social Worker................. 164

Summary of Social Worker Variable Findings................ 165

System Variable Findings.................................. 166

System Variables Predictive of Legacy Group.............. 171

Legacy Group Predictor - Number of Social Workers 171

Assigned to case ......................................

Predictors of Number of Social Workers $\quad 172$

Assigned to the Case............................

Legacy Group Predictor - Type of Placement......... 173

Predictors of Type of Placement................ 174 
Legacy Group Predictor - Average Monthly Cost of

Care.

Predictors of Average Monthly Cost of Care... 175

Legacy Group Predictor - Termination of Parental

Rights

Predictors of Termination of Parental Rights...

System Variables That Were Not Predictive of Legacy

Group

Educational Degree of Supervisor

Proximity of Placement.

Summary of System Variable Findings

Integrated Regression Model

Integrated Legacy Predictor Path Model.

Ethnographic Interviews

Perceptions of Permanency.

Placement Stability.

Suggestions for Improvement of Foster Care.

CHAPTER 5: Discussion

Summary of Findings by Predictor Variable

Level of Family and Community Support............. 194

Siblings in Foster Care....................................... 196

Race of the Child....................................... 197

Number of Foster Care Placements....................... 198

Cost of Care............................................... 201

Days between Case Plans.................................. $\quad 202$

Termination of Parental Rights............................. $\quad 209$

Limitations of Research........................................ $\quad 214$ 


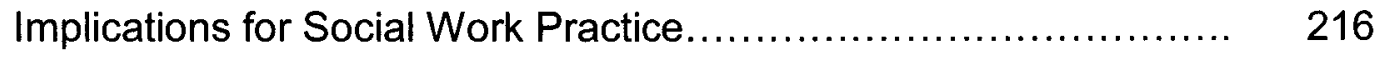

Usefulness for Department for Community Based Services........ 217

Implications for Policy........................................ 218

Directions for Future Research ............................. $\quad 219$

Conclusions...................................................... 221

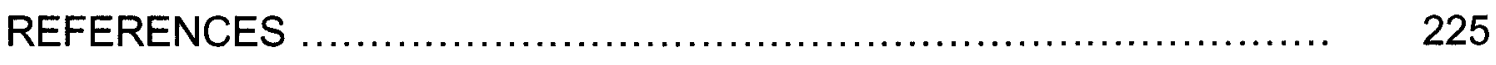

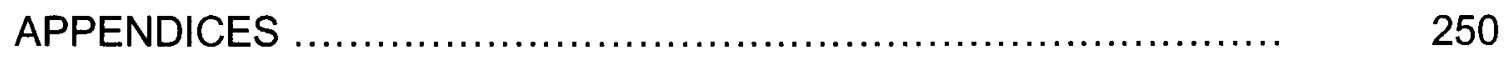

CURRICULUM VITAE ................................................. 286 


\section{List of Tables}

1 Study One Variables................................................. 19

2 Significant Findings - Families' influence on duration of foster care... 27

3 Significant Findings - Child's influence on duration of foster care...... 54

4 Significant Findings - Worker's influence on duration of foster care... 73

5 Number of Parents and Social Worker Visits by Parent and 84 Frequency

6 Significant Findings - Macro influences on duration of foster care... $\quad 89$

7 Variables Operationalized ............................................ 105

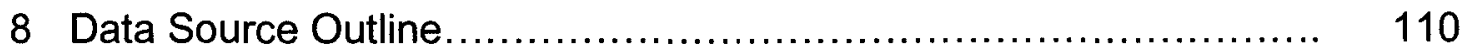

9 Family Variable Descriptive Statistics............................... 121

10 Family Variable and Legacy Group Correlation Table................ 123

11 Family Variable Model Summary................................... 124

12 Family Variable ANOVA Table...................................... 124

13 Family Variable Coefficients .......................................... 125

14 Child Variable Descriptive Statistics................................ 138

15 Child Variable Correlation Table ...................................... 139

16 Child Variable Model Summary...................................... 140

17 Child Variable ANOVA Table ...................................... 140

18 Child Variable Coefficient Table....................................... 141

19 Social Worker Variables Descriptive Statistics........................ 150

20 Social Worker and Legacy Group Correlations....................... 151

21 Social Worker Model Summary ...................................... 153 
22 Social Worker ANOVA Table....................................... 153

23 Social Worker Coefficient Table..................................... 154

24 System Variables Descriptive Statistics............................. 165

25 System Variable and Legacy Group Correlations..................... 167

26 System Model Summary .......................................... 168

27 System ANOVA Table............................................... 168

28 System Coefficient Table........................................... 170

29 Integrated Model Summary ....................................... 182

30 Integrated Model ANOVA Table.................................. 182

31 Integrated Model Coefficient Table........................... 183

List of Figures

1 Thousands of Children in Foster Care by Year........................ 3

2 Family Predictor Path Model........................................... $\quad 132$

3 Child Predictor Path Model........................................... 148

4 Social Worker Predictor Path Model.................................... 160

5 System Predictor Path Model....................................... 176

6 Integrated Legacy Predictor Path Model................................ 191 


\section{CHAPTER 1}

\section{PROBLEM STATEMENT}

Each year in America, tens of thousands of children are removed from their parents or caretakers due to abuse, neglect or delinquency (United States Department of Health and Human Services [USDHHS], 2003a). Public agencies become legally responsible for the care and control of these children, who are typically referred to as foster children. In most states, the legal system, usually in the form of a judge, makes the final determination as to whether a child should be removed from its caretakers and how long the child will reside in foster care. While a child is in foster care, states are responsible not only for addressing the problem which brought the child into foster care, but also for meeting the child's basic needs for the future. This includes ensuring the safety of the child, and meeting the child's educational, physical and behavioral needs. In addition, states are also now responsible for ensuring permanency, or a permanent family, should the child not return home, to prevent lengthy foster care stays.

Decades of "foster care drift" and other less than positive outcomes for children in America's foster care system, have served as catalyst for the development of new laws and policies specifically designed to obtain permanent families for 
foster children. The most current of these laws is the Adoption and Safe Families Act (ASFA) of 1997 (P.L.105-89). ASFA sets national standards for safety, permanency and child well being for children in the American child protection system. States that do not meet these standards face significant reductions in their federal child welfare funding. Currently, over 550,000 children live in foster care in America (USDHHS, 2003a). Many of these children have spent lengthy periods of time in foster care. ASFA proposes an end to foster care drift by requiring states to obtain permanent placements for a majority of foster children within a two-year time frame.

Prior to ASFA and other recent legislation that will be discussed further later in this chapter, philosophies regarding foster care were much different. Few standards existed for permanency of children in foster care and those that did were more similar of recommendations than requirements for child welfare agencies. Long term foster care was considered a viable and preferable option for children due to an emphasis on family preservation. These practices led to many children remaining in foster care indefinitely. Figure 1 (USDHHS, 2003a) shows the growth of foster care in previously documented years. 


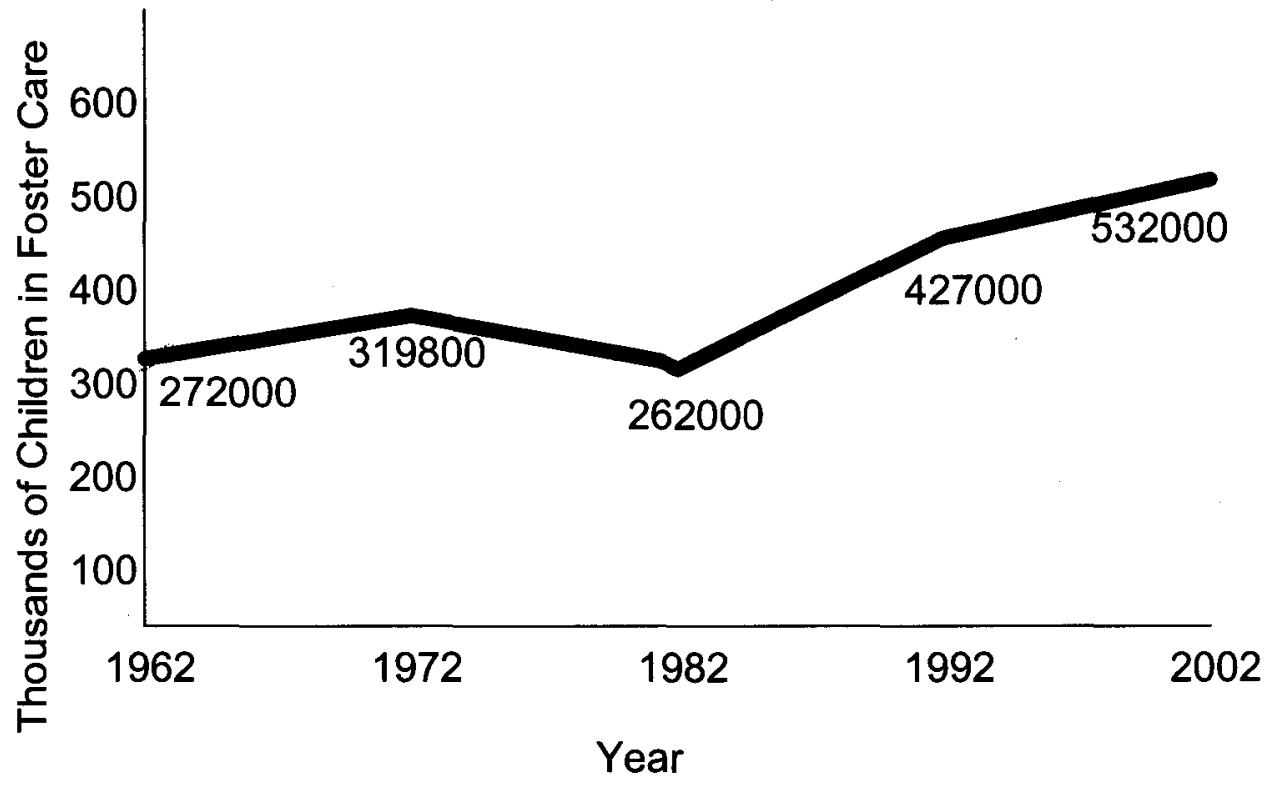

Figure 1 Thousands of children in foster care by year.

Median lengths of time in care for these children ranged from 29 months in 1977 to 19 months in 2001 (USDHHS, 2003a). Mean length of time for these same years was much longer (1977: 47 months; 2001: 33 months) reflecting those children who lingered in the foster care system longest (USDHHS, 2003a). Current foster care philosophies and practices support the notion that foster care is meant to be temporary and balance family preservation and permanency for children. Permanency planning is intended to begin even prior to a child's entry into foster care through efforts to reduce recidivism and develop relative and community support systems. If removal of children cannot be prevented, family or family-like placements within their communities that can become legally permanent, should the children not return to their parents, are the placements of choice. This type of thinking is different from philosophies and practices of the past that encouraged long term foster care. Under ASFA, adoption, reunification with parents, and permanent custody with relatives are the permanency goals 
that are considered as positive legacies for foster children. These are the only placements which meet ASFA's definition of a permanent placement:

1. Legally intended to be permanent, lasting through the child's minority and continue with lifetime family relationships,

2. Secure from modification,

3. Binding on the adult(s) who are awarded the care, custody and control of the child,

4. Provides the caregiver with the legal responsibilities for the child that a birth parent would have, and

5. Clarifies that the state will no longer act as parent for the child; court and agency intervention in the case has ended (National Council of Juvenile and Family Court Judges, 1999).

Long term foster care is no longer considered as beneficial for foster children because of children's needs for permanent connections to family and community. Specific time frames for permanency are now established to prevent children from remaining in foster care indefinitely. For the majority of children, a permanent exit from the foster care system is expected within two years. To achieve this outcome, states must redefine and expand social work practice to provide greater child and family participation, involvement of communities and extended families and methods for evaluation and accountability. These practices are viewed through ASFA as predictors of positive permanency outcomes. 
To evaluate current practices related to ASFA mandated outcomes, states receive quantitative and qualitative federal reviews every two years. Children and Family Services Reviews (CFSR) are a two-tiered process comprised of a statewide assessment and an on-site review (USDHHS, 2003b). Prior to the statewide assessment the Children's Bureau of the United States Department of Health and Human Services prepares a state data profile including aggregate data pertaining to the state's foster care and other child protection service populations. The data profile provides an overall picture of the state's performance using data from1999 through 2001. This information is then forwarded to the state to assist in completion of the statewide assessment.

The second step to the CFSR involves an on-site review conducted by a joint federal and state team. During the on-site review, 50 cases are reviewed at three locations throughout the state. Along with quantitative reviews, qualitative data collection occurs on each of 50 cases through interviews or focus groups with stakeholders including, but not limited to, children, parents, foster parents, all levels of child welfare agency personnel, collaborating agency personnel, service providers, court personnel, and attorneys. To receive substantial compliance ratings, states must meet national standards in both their aggregated data and the 50 cases reviewed during the on-site visit.

To date, no state has passed the entire CFSR. All 50 states, Puerto Rico and District of Columbia were reviewed from 2001 to 2004. None met standards for the first of two permanency related outcomes (USDHHS, 2003c). Permanency Outcome 1 titled: Children have permanency and stability in their 
living situations monitors (a) foster care re-entries, (b) stability of foster care placement, and (c) establishing and achieving appropriate permanency goals for children. Permanency Outcome 2 is titled Children have continuity and preservation of family relationships and connections. Measures for this outcome include (a) proximity of placement, (b) placement with siblings, (c) parental and sibling visitation, (d) use of relatives for placements, and (e) preserving connections and relationships with parents and others with the child in care. Of the states reviewed from 2001 to 2004 , seven received ratings of substantial conformity on this outcome (USDHHS, 2003c).

Findings from the CFSR suggest that there is a need to obtain greater understanding of the factors associated with permanency achievement. Variables previously associated with duration of stay in foster care that are now utilized as indicators of permanency for CFSR have not shown significant relationships to permanency and other child welfare outcomes. Particular findings that suggest the need for further study include:

1. The least likely permanency indicator to be achieved was adoption even though ASFA has dramatically increased the number of children available for adoption (USDHHS, 2003d). According to 2001 AFCSARS data, 65,000 children were legally free and awaiting adoption (USDHHS, 2003a).

2. Findings in some states were that older children and infants were 
among those children most likely to leave care within the national time frames. Previously, these groups experienced longer stays than children of other ages (USDHHS, 2003a).

3. Nationally aggregated CFSR data showed that achieving permanency was not associated with race/ethnicity, especially when the permanency outcome was adoption (USDHHS, 2003d).

4. During the CFSR, seven states met the outcomes for continuity and preservation of family relationships and connections, but did not meet outcomes for timely permanency (USDHHS, 2003c). In previous studies, maintaining family relationships and connections through visitation had been found to have a strong relationship with timely permanency outcomes for children in foster care (Benedict \& White, 1991; Davis, Landsverk \& Newton, 1997; Fashel, 1975; Fanshel, 1982; Fanshel, Finch \& Grundy, 1990; Fanshel \& Shinn, 1978; Lawder, Poulin \& Andrews, 1986; Leathers, 2002; Milner, 1987; Oyserman \& Benbenishty, 1992; Proch \& Howard, 1986; Seaberg \& Tolley 1986; White, Albers \& Bitonti, 1996).

Child welfare researchers now have the ability to incorporate research findings with day to day practice to discover what factors are barriers to all children achieving permanency. Children who do not receive timely permanency are often considered as legacies of an inadequate foster care system. Terms such as Foster Care Drift and Throw away children have long been synonymous with children in foster care and the system that serves them. Within that system, 
many subsystems have shown correlations with timely permanency outcomes. For example, past studies have shown that child protection social workers, parents, and the courts can all heavily influence children's permanency outcomes, and that children themselves may influence their permanency outcomes as well. The child's beliefs regarding permanency, behavior problems or other idiosyncratic needs that are not consistent with the services delivered to the majority of the foster care population may affect timely permanency.

Variables associated with these systems are now assessed through the CFSR to determine child welfare budgets. Since ASFA was passed in 1997, few studies have focused specifically on the relationship of these systems on the group of children who wait the longest for permanency. All children entering foster care since ASFA should be experiencing improved outcomes if the current philosophy regarding permanency is correct. To better understand the development of current policies a history of permanency practices in America's child welfare system is being provided. It is important to discuss past practices to demonstrate the relationship of policy and practice on children's permanency outcomes.

\section{The History of Permanency}

Throughout time, permanency as well as other goals of child welfare has been shaped by political, economic and social forces of the time. In the 1600 s and 1700 s child welfare in America mirrored that of Elizabethan Poor Laws (Webb \& Webb, 1927). Under the principle of parens patriae (Areen, 1975), local townleaders had the authority to remove children from their parents and place them in alternative arrangements. In America, many of the children who were 
removed were from the poorest families, or from families of immigrants. Placements for children included adult almshouses, adult mental asylums, or indenturement to wealthy families. In most cases, these removals were permanent as no services were provided for reunification. During this time and into the early 1800 s, child rescue was seen as the philosophy of child welfare. Religion or moral obligation and social control were used as justification to remove children from parents who were seen as unworthy. Few financial services were available for families as poverty was seen as an individual moral matter. If services were provided they were to be lower then the lowest paid laborer.

Beginning in the mid 1800 s, child welfare began its first paradigm shift relating to the placement of children in foster care. In 1853, the New York Children's Aide Society formed with the Rev. Charles Brace as its first secretary (Bremner, 1971). Brace and his organization began the "Placing Out Movement". This movement was in direct response to increased immigration in New York . City, deterioration of Almshouses and public criticism of past removal practices. Services were developed for children who were removed from their parents to promote character building. One of the ways character building was to be accomplished was through work for and placement in new homes. In 1854, Brace led the first group of children to be taken from New York and placed with families in the Western and Southern states (Bremner, 1970). These placements were considered permanent, but had no legal status attached to them. During this time few services continued to be available for families. Disdain for families 
who had children removed was evident in works such as Braces' The Dangerous Classes of New York, (1872) which popularized family foster care as a method of rescuing dependent children from their families. Within this time period, other political factors including the Civil War began to unknowingly contribute to the development of child welfare practices.

At the end of the Civil War, many of those who had fought in the war and their families were in need of assistance. Distinguishing the worthy from the unworthy, however, turned out to be a difficult task. Several states developed tax laws to provide for needy families. In 1886 the Freedman's Bureau (United States Statutes at Large, Treaties, and Proclamations of the United States of America, 1886), was established as the first federal law to provide financial assistance for needy families. With the increase of families who needed assistance and the growing acceptance of providing services to these families, the view of permanency for children in foster care also changed. In 1886 , Charles Birtwell and the Boston Children's Aid Society began to use family foster care as a means to restore the family (Kadushin \& Martin, 1988). Services for families were developed and the new philosophy of child welfare was that child rescue was best accomplished by rescuing the entire family. This philosophy was also apparent at the 1909 first White House Conference on Children, which declared that every child had the right to a secure and loving home. Children were to only be removed from their homes as a last resort and if removal was needed, quality out of home placements should be provided. This conference helped established a national, but private, child placement network, which focused on return to 
parent as the permanency goal for children in foster care. This philosophy continued during the hard times of the Great Depression and both World Wars, with the government's role as overseer. By the 1950 s numerous placement options for children existed, including (a) boarding homes, where children worked and paid a portion or all of the cost of their board, family foster homes and (c) orphanages or group homes, where a number of unrelated children lived together.

The evolution of permanency continued into the 1960 s and 1970 s when several movements and reports influenced another reconsideration of child welfare's definition of permanency. Some of these included (a) mental health and mental retardation's deinstitualization movement, (b) the civil rights movements, and (c) reports such as those of Maas and Engler's (1959) Children in Need of Parents and the Oregon Project (Pike, 1976) which did not show positive outcomes for children in foster care. From these reports it became evident that child welfare was not practicing its philosophy of family maintenance. Maas and Engler (1959) reported that most children in foster care had at least one parent living, but there was little to no work being done with parents to return children home and no planning with the children or family for permanency. The Oregon Project (Pike, 1976) was a landmark federally funded demonstration project between the Oregon State Department of Human Resources and the Portland State University School of Social Work which showed that many of the children in foster care could return home safely if services were in place. 
Permanency planning has undergone several revised definitions since it began in the 1970s. Initial goals for permanency planning were to declare the intent of the placement and keep a permanency plan alive for the child. Services were focused on preventing children from entering foster care unnecessarily and avoiding delays in returning children home. Long term foster care was seen as a viable option for children who could not return home. Adoption was in most cases the last resort as a permanency goal for children who could not return home because of the emphasis on parental rights and reunification. Due to these definitions of permanency, children continued to remain in foster care for long periods of time. Nationally the number of foster children rose dramatically as a result.

Beginning in 1974, a plethora of national laws and policies were enacted which either directly or indirectly helped shape today's definition of permanency for children. Some of these are briefly described here.

Child Abuse, Prevention and Treatment Act (CAPTA) of 1974

In 1974, The Child Abuse, Prevention and Treatment Act (P.L. 93-247) required states to (a) develop laws mandating the reporting of child abuse, and to (b) develop systems, either public or private to investigate these reports and provide services to the families. This act ultimately led to an influx of children into the foster care system due to the increase of reports without an increase in services to these families. 


\section{Indian Child Welfare Act of 1976}

The Indian Child Welfare Act (P.L. 95-608) sought to improve permanency for Native American children by requiring states to place these children with family or tribal members whenever possible. Placements were to be made in the child's community or within close proximity to the child's home. This law has had an enormous impact and today less than $1 \%$ of Kentucky's children in foster care are listed as Native American/Alaskan Indian (USDHHS, 2003c).

\section{Youakim vs. Miller (1979)}

This United States Supreme Court decision stated that relatives who provide care for children in foster care must be compensated and treated similarly to foster parents. This decision is cited as being one of the direct reasons foster care has grown so dramatically as relative placements have been one of the fastest growing, and children who are in these placements, generally leave the system at a slower rate than children who are not in relative foster care placements (Bland, 2000; Glisson, Bailey, \& Post, 2000; Pecora, Whittaker, Maluccio, \& Barth, 2000).

\section{Adoption Assistance and Child Welfare Act of 1980}

AACWA was enacted to reduce the growing number of children entering the foster care system and reduce the length of time these children remain in care. Courts were required to hold a permanency review when the child had been in care 18 months and every year thereafter. Case planning was required with the family with reasonable efforts being provided to ensure that children were not removed unnecessarily. The focus on permanency under this law 
continued to be on returning children home. While requiring these services be provided, no funds were provided to monitor states' compliance or financial incentives for meeting the required outcomes. However, for a short time after the passage of this act, the number of children entering the foster care system declined.

\section{Family Preservation and Support Initiative of 1993}

In order to provide stronger support for in home services to families, this act provided funds to preserve the family by preventing removals and reducing the length of time children spent in care. Intensive short-term services, case planning, coordination of services and community development of resources were supported and monitored through this legislation.

\section{Multiethnic Placement Act (MEPA) of 1994}

Even with the passage of the above cited laws, by 1994 the number of children in foster care had steadily increased since the mid 1980s. This was especially true for children of color. In 1980, minority children in care made up $50 \%$ of the overall number of children in foster care (USDHHS, 2003c). By 1990 , there were more minority children in care than any other racial group, including Caucasian children (USDHHS, 2003c). In order to address the negative outcomes that minority children were experiencing in foster care, President Clinton signed MEPA legislation. The intent of this legislation was to decrease the amount of time minority children spend waiting for foster or adoptive placements by requiring states to seek foster and adoptive homes to meet minority children's needs. 


\section{Adoption and Foster Care Analysis Reporting System}

In 1994 legislation was passed creating the Adoption and Foster Care Analysis Reporting System (Social Security Act, Title IV-E, 1994). AFCARS was the first electronic data collection system for child welfare outcomes. States were required to submit data yearly and financial incentives were provided for states to develop their own electronic systems.

\section{Interethnic Adoption Provisions Act of 1996}

By 1996, the disproportionate number of minority children in the foster care system had risen to $66 \%$ of all children in foster care (CWLA, 2002). Due to this, President Clinton repealed language in previous legislation, MEPA, that had allowed permissible consideration of race, ethnicity or culture in making foster and/or adoptive placements for children in care. The Interethnic Adoption Provisions Act outlawed racial matching of families and children or preference selection for foster/adoptive families in regards to the children they foster or adopt and provided significant federal penalties for states who were found to delay foster care or adoptive placements based on race.

\section{Adoption and Safe Families Act of 1997}

ASFA legislation established today's three primary goals of child welfare for children: safety, permanency, and well-being. This law set timelines for permanency to be obtained for all children in foster care. These timelines state that if a child has been in care 15 out of the last 22 months, states are required to pursue termination of parental rights or provide compelling reasons why this is not in the child's best interest. ASFA allows states to determine that reasonable 
efforts for family preservation do not have to be made in some cases in which aggravated circumstances exist, such as (a) the child has been in foster care for abuse previously, (b) the parent has had parental rights terminated on other children, (c) the parent is incarcerated for a period of one year or more, or (d) the parent has been convicted of harming another child.

ASFA does not view long term foster care or emancipation as preferable goals for children in foster care. Instead, return to parent and adoption are considered as providing better outcomes for these children. ASFA also sets standards for quality foster care by requiring two or fewer placements for children in care, safety measures for out of home placements and that children be placed in the least restrictive placement within the closest proximity to the child's home. ASFA requires connections to family and community to be maintained through visitation and maintenance of cultural needs. States' compliance with ASFA are monitored through AFCARS data and Child and Family Services Reviews. ASFA's definition of permanency is primarily a legal one based on the legal status of the child. Under ASFA, foster care is to be a temporary service until the child is either adopted, returns home or is placed in the permanent custody of relatives.

\section{Rationale for Study}

Children who remain in foster care for lengthy periods of time are often considered as legacies of an inadequate child welfare system. It is important to better understand the specific legacy these children have in order to determine (a) if trends exist that have been overlooked in service delivery, (b) if the current 
definition of permanency best meets all children's needs, (c) if outcomes of safety and well being outcomes correlate with permanency outcomes, and (d) how ASFA philosophy has affected practice for the child protection social worker and their families. By addressing these questions, information gained in this study will bridge information from CFSR reviews, past studies related to duration of care, and current child welfare data to provide a greater understanding of present permanency predictors. Specific variables related to family, child, social worker and macro outcomes need to be studied in the context of the recent CFSR findings. Many of these variables have been studied prior to ASFA and CFSR on site reviews. This study included only those children who have entered care since January 1, 1999. An additional two years were added to ASFA's passage date to account for training and other needs associated with implementing a new policy into practice. By 1999, differences related to permanency associated with ASFA should be discernible.

\section{Study Design}

It is apparent that many children are still unable to obtain permanency in the child welfare system. This study sought to compare children who have obtained positive permanency outcomes under ASFA with those who have not. Through these comparisons, this project has attempted to identify groups of children ASFA has benefited and which variables influence today's definition of permanency. With increased technology available through electronic data files, variables previously not incorporated into studies of duration of foster care have been included, i.e., (a) the amount spent on the child's specific care, (b) proximity 
of placement, (c) child well being ratings as they relate to permanency, (d) child's level of attachment, and (e) worker attitudes toward attachment. An increased number of social worker and macro variables than previously considered in past research were examined to obtain greater understanding of their influence on duration of foster care. Two research designs were utilized to obtain both quantitative and qualitative data:

1. A static-group comparison (Rubin \& Babbie, 1997) study of children who have found permanency compared to those who have not and

2. An ethnographic study (Rubin \& Babbie, 1997) of children in foster care over four years.

\section{Study One: Quantitative Data Collection}

In study one, a static group comparison design (Rubin \& Babbie, 1997) was utilized to compare quantitative data regarding groups of children who have and have not achieved permanency since ASFA's conception. The static group comparison design is a posttest only pre-experimental design that compares two nonequivalent groups after the introduction of a stimulus or intervention to one of those groups. In this study, the stimulus introduced was permanency. Data were collected from electronic state child welfare data systems, hardcopy files, and directly from child welfare social workers to compare children who receive permanency with those who remain in foster care. Secondary data from previous research studies and electronic child welfare management reports were also included. Cohort and longitudinal data were included to control for the effects of 
population dynamics (Wulczyn, 2001) and to assess the solidification of ASFA philosophy in practice.

\section{Study One: Sample}

The population for the first study consisted of all children who entered care for the first time on or since January 1999 in Kentucky. From this population two groups were sampled for comparison. The first group included all children who entered care on or since January 1, 1999 who had experienced 48 consecutive months or more in foster care and who were still in foster care as of March 30 , 2004. The second group was a random sample of children who entered foster care on or since January 1, 1999 and had experienced permanency either through return to parent, adoption, or permanent relative placement, and had not reentered the foster care system. It was expected that the sample size of each group would be approximately 200 . Numerous variables associated with family, child, system and social worker were assessed to determine what contribution they provide to obtaining timely permanency for children post ASFA (Table 1).

\section{Table 1}

\section{Study One-Variables}

\section{Family Yariablos Subset}

\begin{tabular}{|c|l|}
\hline 1 & $\begin{array}{l}\text { Median number of family visits with child per month for each year child has } \\
\text { been in foster care }\end{array}$ \\
\hline 2 & Parent's attendance at case planning conferences \\
\hline 3 & Parent's signature on case plan \\
\hline 4 & $\begin{array}{l}\text { Level of extended family and community support as assessed by social } \\
\text { worker }\end{array}$ \\
\hline 5 & Parental level of functioning as assessed by social worker \\
\hline 6 & Title IV-E eligibility of child, determined by parents income at time of removal \\
\hline 7 & Risk factors present at time of removal and most recently \\
\hline 8 & $\begin{array}{l}\text { Recidivism, operationalized as number of child protection and adult } \\
\text { protection referrals received on family prior to removal }\end{array}$ \\
\hline
\end{tabular}




\begin{tabular}{|r|l|}
\hline 9 & Number of parents in the home at the time of removal and most recently \\
\hline 10 & Severity of abuse as assessed by social worker \\
\hline 11 & Type of abuse \\
\hline 12 & Number of children \\
\hline 1 & Age \\
\hline 2 & Race \\
\hline 3 & Gender \\
\hline 4 & $\begin{array}{l}\text { Children's Behavior Checklist (CBCL) level for child both at time of removal } \\
\text { and most recently }\end{array}$ \\
\hline 5 & $\begin{array}{l}\text { Well being ratings obtained from child's providers during recent foster care } \\
\text { census }\end{array}$ \\
\hline 6 & Child's level of attachment \\
\hline 7 & Child/Youth level of development \\
\hline 1 & \\
\hline 1 & Number of moves child experienced \\
\hline 2 & Regularity of case planning conferences \\
\hline 3 & Permanency goal of child \\
\hline 4 & Worker attitude towards attachment \\
\hline 5 & Worker's educational degree \\
\hline 6 & $\begin{array}{l}\text { Number of years of experience with Department of Community Based } \\
\text { Services }\end{array}$ \\
\hline 7 & Median number of visits to parents monthly for each year since child's \\
& removal \\
\hline 8 & Median number of visits to child monthly for each year since child's removal \\
\hline & \\
\hline 1 & Proximity of child's placement to parent at time of removal and most recently \\
\hline 2 & Placement with siblings \\
\hline 3 & $\begin{array}{l}\text { Number of workers who had ongoing case manager responsibilities since } \\
\text { child was removed }\end{array}$ \\
\hline 4 & Degree of supervisor \\
\hline 5 & Amount spent on child's placement since time of removal \\
\hline 6 & Type of foster care placement \\
\hline 7 & Type of court system (family or separate) \\
\hline 8 & Number of continuances in court case \\
\hline & \\
\hline 1
\end{tabular}

\section{Study Two - Ethnographic Study of Legacy Children}

Interviews were conducted with children who had not received permanency and were still in the foster care system to acquire a better 
understanding of how they assessed their own permanency outcomes. Twenty current foster children who entered foster care on or after January 1, 1999 and who had spent at least 48 consecutive months in foster care were electronically randomly selected for ethnographic interviews. The interviewer sought to determine if the child's view of permanency and the outcomes they are receiving were consistent with the information gleaned from case files and aggregated data of children who spend lengthy periods of time in foster care. Of primary focus were barriers to permanency. If asked, what would these children report affected their length of stay in foster care?

During previous CFSR qualitative data collection, reviewers who interviewed children and collected other qualitative data did not find consistency with aggregated quantitative data outcomes. Overall, a lower percentage of compliance with permanency outcomes was found in cases where qualitative reviews were held as compared to cases where only quantitative data collection were utilized (USDHHS, 2003d). This finding supports the use of both qualitative and quantitative data to obtain an accurate picture of how the absence of having a permanent family has affected these children's lives. Bush and Gordon (1982) reported that "there is an untapped potential for improving social services and contributing to family stability by seeking out and paying attention to children's views" (p.314). When children in foster care are given the chance to express their opinions, their perceptions are often both insightful and crucial to effective social work practice (Curran \& Pecora, 1999). Researchers have rarely drawn on the opinions of foster children. Previously, most studies on children in foster care 
have not incorporated qualitative data from children, using, instead, case records, electronic data and interviews with those who provided services in contrast to those being served.

Several studies have lamented the absence of feedback from children in foster care (Festinger, 1983; Gil \& Bogart, 1982; Jacobson \& Cockerum, 1976). In Festinger's (1983) study "No one ever Asked Us", 277 former foster children were interviewed regarding their satisfaction with their foster care experiences. Among the many concerns raised by this study were that children wanted to be asked their opinions about decisions affecting them. Barth and Berry's (1987) studies reported the following observations regarding preferred permanency outcomes: (a) most children preferred their current setting compared to their previous family or out of home setting, with satisfaction highly associated with the child's sense of permanency, (b) children who had multiple placements and who sought a sense of belonging preferred adoption, and (c) children who had some choice in their foster care placements were significantly more satisfied in their placements than were children with no choices (Barth \& Berry, 1987).

Today's standards of practice related to permanency expect engagement of all parties including children and their families. Such expectations have evolved along with a higher standard of accountability for positive outcomes and more positive legacies for these children and those who serve them. Requirements for client participation and assessment of client satisfaction represent the ever-changing practices and philosophies regarding outcomes for children in foster care. 


\section{Research Questions}

These two studies will seek to answer the following research questions:

1. Study One: What, if any, differences exist in child, family, social worker and macro variables for Permanency Children compared to Legacy Children?, and which of these variables are predictors of long term foster care?

2. Study Two: What are Legacy Children's perspectives regarding permanency? 


\section{CHAPTER 2}

\section{LITERATURE REVIEW}

Beginning in the 1950s with Maas and Engler's (1959) landmark study, Children in Need of Parents, various aspects of the foster care system have been studied to determine contributing factors to length of time in foster care. Many of these studies considered variables associated with the family, child, social worker and macro systems. Differing conceptualizations and multiple research designs have created difficulties in understanding the overall effect that these variables have on permanency outcomes. These studies also reflect differing permanency philosophies of the time period under study. The current definition, measurement, and outcomes of permanency are set by Children and Family Services Reviews (CFSR) which are mandated by the Adoption and Safe Families Act (ASFA, 1997). Determining influences on length of time in care has taken on new importance due to laws such as ASFA that base funding for child welfare on compliance with variables that are thought to decrease length of time in care and increase child safety and well being. A state can lose $1 \%$ of its yearly child welfare federal budget on each of the 30 outcomes if found in noncompliance. In order to comply with CFSR, states are spending large amounts of 
money on training, developing resources, and tracking CFSR permanency indicators. With this investment, evidence based data is needed to support the most effective use of limited child welfare resources.

This chapter will provide an overview of the literature pertaining to factors that affect length of time in care. Four sections are provided to address family, child, social worker and macro variables. Each section will include findings pertaining to variables associated with these systems' influences on permanency for children. Possible explanations for the cited findings will also be provided. If the variable is one monitored by the CFSR, information will be given regarding federal measurement of the variable and states' compliance with its related outcomes. Data specific to Kentucky's CFSR will also be discussed to provide information pertaining to the sample being studied.

\section{Family Variables}

Numerous studies have considered the effects of family variables on length of stay in foster care. This project considered those reported most influential by previous studies and those that serve as indicators for the Child and Family Services Review. Visitation, parent's level of cooperation, degree of extended family support, risk factors present related to adult members of the family, poverty/Title IV-E eligibility, recidivism, number of children, and type of child abuse or neglect experienced within the family are all factors that were assessed to determine their effect on permanency. As can be seen from the literature review some of these variables have been considered more than others and appear to exert differing levels of influence on children's length of time in 
foster care. Table 2 provides a condensed view of findings related to families' influence on length of time in care. A similar table is included in each of the four sections of this chapter. Table 2 includes all research-based studies that could be located by the author involving studies specifically focused on predicting indicators of length of time in care. Only studies that found relationships between family variables and duration of care are included in the table. If the study included variables related to children, social worker or macro systems it will also be found in those sections. Detailed findings from these studies and other scholarly citations are provided following the table. This information has been categorized by family permanency indicator to provide focus on similarities and differences of findings in the context of CFSR measurements and recent state CFSR outcomes. Table 2 identifies 32 previous studies that included family variables as predictors of length of time in care. Overall, 14 of these studies reported positive results on visitation, 9 on removal reason of neglect, 10 on poverty issues, 5 on having more than one child in care, and 3 on removal from a single parent household. 


\title{
Table 2
}

\section{Families' Influence on Duration of Foster Care / Significant Findings}

\section{Included in the Study}

\begin{tabular}{|c|c|c|c|}
\hline Study & Type of study/Analysis & Data Source & $\begin{array}{l}\text { Sample } \\
\text { Size } \\
\text { /Power }\end{array}$ \\
\hline $\begin{array}{l}\text { Albers, Rittner, } \\
\text { \& Reilly, } 1993\end{array}$ & $\begin{array}{l}\text { Static-group comparison } \\
\text { group / Multiple regression }\end{array}$ & State electronic child welfare data & 40 \\
\hline
\end{tabular}

$\begin{array}{lll}\text { Avery, } 1999 & \begin{array}{l}\text { Longitudinal } \\ \text { Descriptive statistics }\end{array} & \begin{array}{l}\text { Hardcopy and electronic child } \\ \text { welfare data and questionnaires } \\ \text { completed by social workers }\end{array}\end{array}$
$\begin{aligned} & 1 \text { Siblings in the system / Siblings in the system }\end{aligned}$

\begin{tabular}{|c|c|c|}
\hline $\begin{array}{l}\text { Barth, } \\
\text { Snowden, } \\
\text { Broeck, Clancy. } \\
\text { Jordan, \& } \\
\text { Barusch, } 1986\end{array}$ & $\begin{array}{l}\text { Cohort studies, Stepwise } \\
\text { discriminate analysis }\end{array}$ & Child Welfare case records \\
\hline
\end{tabular}

1 Socioeconomic status, abuse severity, social isolation, client contract /

Severity of abuse and socioeconomic status

\begin{abstract}
Benedict \& Longitudinal / Multivariate Child Welfare case records 689 White, 1991 analysis

${ }^{1}$ Parent's age, marital status, Title IV-E eligibility, parental risk factors: physical health, alcohol and drugs and mental health, parental cooperation with case plan, recidivism, visitation, parents want child back / Recidivism, uncooperative, health problems and regular visitation
\end{abstract}

Courtney, 1994 Longitudinall

Event history analysis
Electronic Child Welfare case records

1 Number of parents in the home, AFDC eligibility, recidivism, and reason for removal / Poverty, sexual abuse, and removal from single parent home

\section{$\begin{array}{lll}\text { Courtney \& } & \text { Cohort groups/Cox } \\ \text { Wong, } 1996 & \text { Proportional Hazards Model }\end{array}$}

${ }^{1}$ Number of parents in the home, AFDC eligibility, recidivism, and reason for removal / Poverty and sexual or physical abuse 


\section{Table 2 (Continued)}

\begin{tabular}{|c|c|c|c|}
\hline Study & Type of study/Analysis & Data Source & $\begin{array}{l}\text { Sample } \\
\text { Size } \\
\text { /Power }\end{array}$ \\
\hline Davis, 1979 & $\begin{array}{l}\text { Static group comparison } \\
\text { design / Prediction by } \\
\text { classification }\end{array}$ & $\begin{array}{l}\text { Hardcopy child welfare case } \\
\text { files }\end{array}$ & $=193$ \\
\hline
\end{tabular}
Fanshel, 1975
Longitudinal
Hardcopy child welfare case
Multiple regression records
${ }^{1}$ Reason for removal, visitation, parental evaluations by caseworker / Visitation, removal reason of neglect, abuse or abandonment and positive parental evaluations by caseworker

$\begin{aligned} & \text { Fanshel \& Shinn, } \\ & 1978\end{aligned} \begin{aligned} & \text { Longitudinal I Child welfare hardcopy data files } \\ & \text { Contingencies, } \\ & \text { correlations }\end{aligned}$
$\begin{aligned} & \text { 1 Number of parents in the home, parental mental health problems, reason for placement, } \\ & \text { parental contacts / Neglect as reason for placement and parental mental health problems }\end{aligned}$
Finch, Fanshel \&
Cross Sectionall
Electronic child welfare data files
$20,000+$
Grundy, 1986 Regression Analysis
Number of children, recidivism, reason for removal / Placement reason of neglect and prior child protective services to family
Gibson, Tracy \&
Longitudinall
Child Welfare case records
DeBord, 1984
Regression
${ }^{1}$ Four types of contact: family-agency, family initiated-agency, social worker -initiated, and family-child contacts / Family initiated agency contacts and Family-child contacts

\begin{tabular}{|c|c|c|c|}
\hline $\begin{array}{l}\text { Glisson, Bailey \& } \\
\text { Post, } 2000\end{array}$ & Event History Analysis & $\begin{array}{l}\text { Child Welfare case records and } \\
\text { interviews with social workers, } \\
\text { parents and providers }\end{array}$ & 700 \\
\hline \multicolumn{4}{|c|}{$\begin{array}{l}\text { Tubstance abuse, number of siblings in care reason for placement, socioeconomic } \\
\text { status, and number of parents in home / Sexual abuse and having a sibling in care }\end{array}$} \\
\hline Goerge, 1990 & $\begin{array}{l}\text { Longitudinal/ } \\
\text { Event history analysis }\end{array}$ & $\begin{array}{l}\text { Computerized child welfare } \\
\text { records }\end{array}$ & $3,000+$ \\
\hline
\end{tabular}




\section{Table 2 (Continued)}

\begin{tabular}{|c|c|c|c|}
\hline Study & $\begin{array}{c}\text { Type of } \\
\text { study/Analysis }\end{array}$ & Data Source & $\begin{array}{l}\text { Sample } \\
\text { Size } \\
\text { /Power }\end{array}$ \\
\hline $\begin{array}{l}\text { Hess \& Folaron. } \\
1991\end{array}$ & $\begin{array}{l}\text { Static comparison } \\
\text { groupl } \\
\text { Regression analysis }\end{array}$ & $\begin{array}{l}\text { Qualitative interviews and } \\
\text { hardcopy case reviews }\end{array}$ & 40 \\
\hline
\end{tabular}

Jenkins, $1967 \quad$ Longitudinall Child welfare case records
Contingency Table 891
'Main source of support, housing circumstances, household composition, reason for
placement, religion, number of siblings, parental participation in decision to place child /
Religion, placement reason of mental illness, severe neglect and abuse or
overwhelming family problems
Jones, $1998 \quad$ Cohort groups/Logistic Electronic and hardcopy child regression welfare case records

${ }^{1}$ Family composition, employment status of caretakers, AFDC status, type of abuse, stressful family life events, characteristics of the caretaker; physical or mental health, substance abuse, disabilities, criminal involvement and maltreatment as a child and environmental characteristics /Poverty and housing

$\begin{aligned} & \text { Landy \& Munro, } \\ & 1998 \\ & 1 \text { Rre and post test }\end{aligned} \begin{aligned} & \text { Parental, child and social worker } \\ & \text { surveys }\end{aligned}$
Recidivism, physical illness, major losses in childhood/adolescents, dysfunctional
family of origin, poor education and/or employment record, intellectual functioning,
single teenage motherhood, criminal record or activities, failure to attach to the child,
mental illness, substance abuse, and developmental delays / Removal reason of abuse
or neglect, Socioeconomic status, parental health problems, number of family moves
and number of risk factors

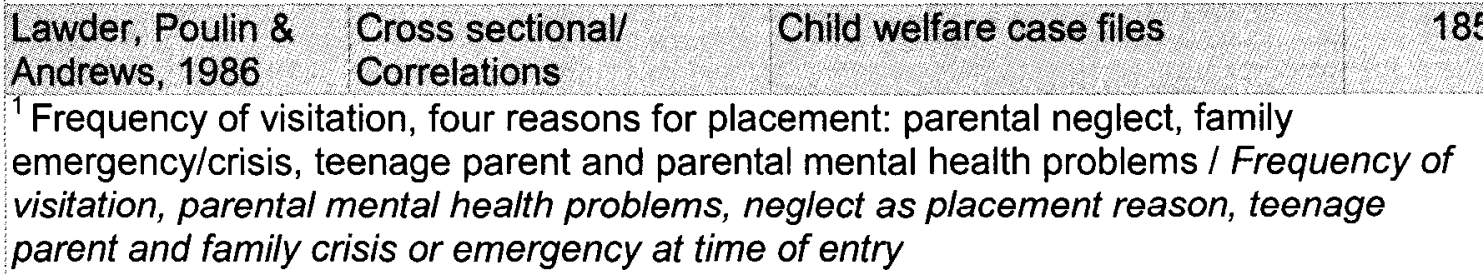

Leathers, 2002

Longitudinal

Electronic child welfare data files

/hierarchical regression analysis and interviews with social workers and foster parents

\footnotetext{
${ }^{1}$ Amount and location of visitation, maternal substance abuse and mental illness, parental involvement, and attendance at administrative reviews / Frequency of visitation, visitation in parent's home, participation in administrative reviews, and substance abuse
}

$1 \quad$ Family Variables included in Study / Significant Independent Family Variables 


\begin{tabular}{|c|c|c|c|}
\hline Study & $\begin{array}{c}\text { Type of } \\
\text { study/Analysis }\end{array}$ & Data Source & $\begin{array}{c}\text { Sample } \\
\text { Size } \\
\text { /Power }\end{array}$ \\
\hline $\begin{array}{l}\text { McMurty \& Lie, } \\
1992\end{array}$ & $\begin{array}{l}\text { Cross-sectional } \\
\text { IRelative risk }\end{array}$ & $\begin{array}{l}\text { Hardcopy and electronic child } \\
\text { welfare data case files }\end{array}$ & 775 \\
\hline
\end{tabular}

\begin{tabular}{ll} 
Mech, 1985 & $\begin{array}{l}\text { Longitudinal } \\
\text { IMeasures of central } \\
\text { tendencies }\end{array}$ \\
\hline 'Visitation / Visitation & National sample survey
\end{tabular}
Milner, 1987 Exit cohorts/Multiple Case records and interviews with 75 regression analysis social workers and supervisors
Biological family characteristics, biological family stressors, support system available to biological family, reason for removal, and visitation / Frequency and quality of visitation, family stressors, level of support available to family

\begin{tabular}{|c|c|c|c|}
\hline Olsen, 1982 & $\begin{array}{l}\text { Longitudinal/ } \\
\text { Multiple regression } \\
\text { analysis }\end{array}$ & $\begin{array}{l}\text { Data collected directly from child } \\
\text { welfare social workers }\end{array}$ & 1,900 \\
\hline
\end{tabular}
Oyserman \& Cross-sectional Data collected directly from child 590 Benbenishty, 1992 welfare social workers/5 point Likert-scale of visitation
Frequency and stability of visitation, ambivalence, biological/foster family relations, number of parents in the home, global evaluation, evaluated as enabling / Visitation and biological and foster family relations

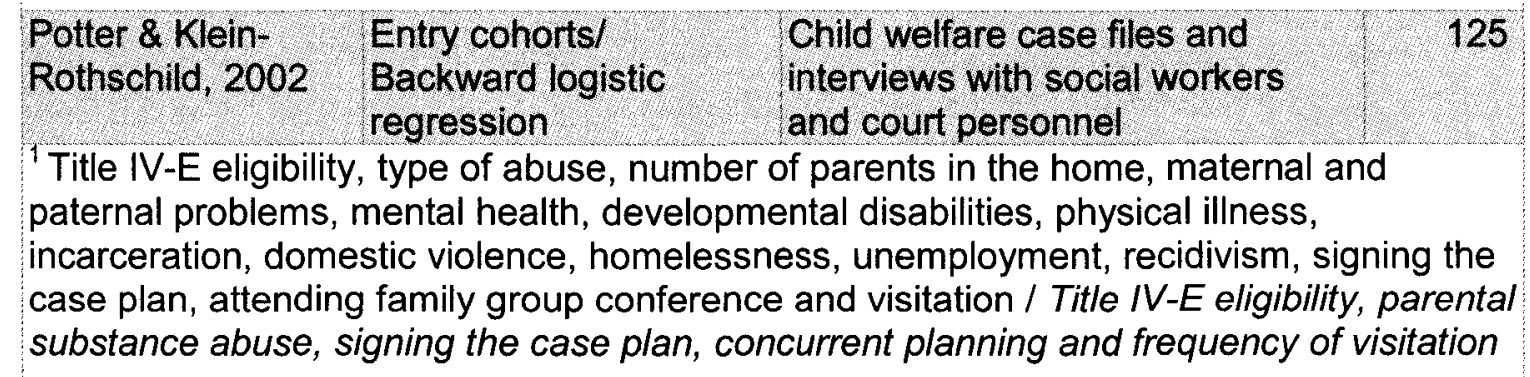
Proch \& Howard, Longitudinal Hardcopy child welfare case files 256 1986 IMeasures of central tendencies
'Frequency and location of visitation and reason for removal / Frequency and location of visitation, use of visitation plan

1 Family Variables included in Study / Significant Independent Family Variables 
Table 2 (Continued)

\begin{tabular}{|c|c|c|c|}
\hline Study & $\begin{array}{c}\text { Type of } \\
\text { study/Analysis }\end{array}$ & Data Source & $\begin{array}{l}\text { Sample } \\
\text { Size } \\
\text { /Power }\end{array}$ \\
\hline $\begin{array}{l}\text { Schmidt-Tieszen } \\
\& \text { McDonald, } \\
1998\end{array}$ & $\begin{array}{l}\text { Cross-sectional/ } \\
\text { Logistic regression }\end{array}$ & Child welfare case files & 147 \\
\hline
\end{tabular}

\begin{tabular}{|c|c|c|c|}
\hline $\begin{array}{l}\text { Seaberg \& Tolley, } \\
1986\end{array}$ & $\begin{array}{l}\text { Cohort group/Multiple } \\
\text { Regression }\end{array}$ & $\begin{array}{l}\text { Data set from national } \\
\text { probability sample }\end{array}$ & 3,950 \\
\hline
\end{tabular}

$\begin{array}{lll}\text { Stein \& Gambrill, } & \begin{array}{l}\text { Experimental and } \\ \text { control groups }\end{array} & \begin{array}{l}\text { Hardcopy child welfare files } \\ \text { and interviews with social } \\ \text { workers }\end{array}\end{array}$

${ }^{1}$ Reason for placement, parental drug abuse, parental psychiatric hospitalization, parent in prison, condition of household, abandonment, mental illness, visitation, parental problems with service delivery, and involvement in decision making for child's future / Signature on case plan, parental problems with service delivery
Wells \& Guo,
Cohort groups/Event history analysis
Electronic child welfare case 1999
1 Number of parents in the home, removal reason / Removal from a one parent files household, neglect or dependency as placement reason
White, Albers, \&
Longitudinal
Bitonti, 1996
It-test
Electronic child welfare case
'Frequency and setting of visitation, parent's age, family income, parent's marital status and parental problems identified at placement / Frequency and location of visitation

$\begin{aligned} & \text { Wulczyn, } \\ & \text { Orlebeke, }\end{aligned}$ Model
\& Melamid, 2000
Title IV-E eligibility / Title IV-E eligibility

$\&$ Melamid, 2000

Title IV-E eligibility / Title IV-E eligibility 


\section{Visitation}

Parental visitation has been defined as the heart of family reunification (Warsh, Maluccio, \& Pine, 1994).The rationale for establishing visitation as a crucial determinant for permanency outcomes is well supported in the literature (Hess \& Proch, 1988). Frequency of parental visitation has been shown to be a strong predictor of a child's being reunified (Benedict \& White, 1991; Davis, 1979; Fanshel, 1975; Fanshel, 1982; Fanshel et al., 1990; Fanshel \& Shinn, 1978; Lawder et al.,1986; Leathers, 2002; Milner, 1987; Oyserman \& Benbenishty, 1992; Proch \& Howard, 1986; Seaberg \& Tolley 1986; White, Albers, \& Bitonti, 1996). Visitation is the only factor on which there is consistent agreement across studies that supports a significant relationship with shorter stays in foster care (Benedict \& White, 1991).

Parental visitation is considered the primary child welfare intervention for maintaining the parent child relationship which is necessary for successful reunification (Downs, Costin \& McFadden, 1996; Hess \& Proch, 1993). The more children are visited by their parents the greater the attachment the parents have for their children (Milner, 1987). High correlations have been found between frequent, positively oriented visiting, and short-term placement (Milner, 1987). Likewise, infrequent or negatively oriented visiting correlated with increasingly longer stays in foster care (Fanshel \& Shinn, 1978; Mech, 1985; Milner, 1987). Parental visitation can also have a stabilizing effect upon the outcomes beyond permanency such as the child's safety and well-being (Cantos, Gries \& Slies, 1997; Colon, 1978; Fanshel \& Shinn, 1978; Hess, 1988; Littner, 1975; Tiddy, 
1986). Child welfare experts have found that positive or negative parental involvement affects the behavior of children in substitute care as well as the effectiveness of service providers (Schatz \& Bane, 1991).

Carefully planned parent-child contacts, in the context of the overall permanent plan can strengthen existing attachments or facilitate a shift in primary attachment when the plan is other than return to parent (Hess, 1982). This is especially true for children in long term care. For these children visitation may have both positive and negative effects. Some researchers (Fanshel, Finch, \& Grundy, 1990; Fanshel \& Shinn, 1978) have suggested that children who spend more time in care may have more difficulty with parental visiting than children who spend less time in care. The proportion of parents who visit their children in foster care declines rapidly over time. However, children whose parents continue to visit may be affected by the lack of resolution of their relationships with their biological parents. Biological parents who are visiting are not able to consistently care for their children, but they remain in the children's lives, leading to questions about their role in nurturing and providing as a parent.

Children may experience psychological disturbances and behavior problems due to boundary ambiguity (Boss, 1993) because their biological parents continue to be psychologically present although they are not physically present (Weinstein, 1960). Given the uncertainties of their relationships with each type of parent, these children may be unable to establish a secure relationship with either their biological or foster/adoptive parents without ambivalence and emotional distress. If children develop a close relationship with their foster 
families, they may feel that they have betrayed the psychologically present biological parent. If they retain a strong attachment to their biological parents, they may feel that they are betraying their foster parents, who provide daily care (Leathers, 2002; Poulin, 1985).

CFSR monitors visitation between parents and children as a permanency related indicator. Of the 52 states reviews, only 16 have been found in compliance on this indicator (USDHHS, 2003c). States were considered in compliance with this indicator if reviewers determined that the frequency of the visitation met children's needs, or that, when visitation was less frequent than needed, diligent efforts to promote more frequent visitation had occurred. Kentucky received an Area in Need of Improvement rating for this indicator due to only $60 \%$ of the applicable cases meeting the required standards (USDHHS, 2003e). The majority of cases reviewed were receiving less than monthly visits with either parent. Visitation with fathers was found to occur less frequently than visitation with mothers.

\section{Parent's Participation in Case Planning}

The concept of permanency planning requires formalized written case plans with specific permanency goals and objectives for parents and their children in foster care. Failing to establish such plans has been shown to contribute to the drift of children into long term foster care (Maas \& Engler, 1959). Specific permanency plans guide children to permanency goals such as reunification, adoption, permanent relative placement or, for some children, long term foster care. These plans disclose to all parties involved the objectives and 
tasks needed to obtain permanency, identify who is responsible for each objective and task, and set specific timelines for completion. Engagement of all parties is necessary to ensure that the plan will be successfully completed.

Many states now incorporate primary and secondary permanency goals through concurrent planning (Katz, Spoonemore, \& Robinson, 1994). Concurrent planning allows for one goal but requires preparation for alternative goals should the primary goal not be obtained. Potter and Klein-Rothschild (2002) found that families for whom concurrent planning was clearly identified in the written family service plan were more likely to achieve timely permanence. Tasks associated with concurrent planning include (a) placing children in foster/adoptive homes where the child's return to a parent will be supported and adoption can occur if the child does not return home, (b) early identification of risk factors associated with long term care, (c) goal setting and time limitations for completing tasks, and (d) full disclosure to parents regarding alternative plans if the child does not return home (Katz, Spoonemore, \& Robinson, 1994).

As with visitation, parent participation in case planning has been found to have significant effects on children's length of stay in foster care. Benedict and White (1991) reported that where parents were assessed as being cooperative with and agreeable to the agency plan, there were shorter stays in foster care. Leathers (2002) reported that maternal participation in administrative case reviews predict reunification, even after controlling for frequency of visiting. This suggests that parents who attend meetings in which permanency decisions are made may have a better chance at having their children returned than parents 
who do not. Attendance at administrative reviews may also increase a parent's chances for reunification because attendance may be reported to judges and others who ultimately decide whether a child is returned (Leathers, 2002).

The parent's signature on case plans is often considered symbolic of the parent's agreement with agency stated goals and objectives. Potter and KleinRothschild (2002) found that parents who signed the family service plan were more likely to achieve timely permanency. In Stein and Gambrill's (1977) study, $70 \%$ of the children whose parents signed contracts were reunified; $84 \%$ of those whose parents did not were categorized as long term placement. Gambrill and Wiltse (1974) posited that such goal oriented worker parent contacts and working agreements between work and parents facilitated early return home. For many parents in the child welfare system a potential barrier to such agreements is ambivalent parental attitudes about the parental role, reunification, and working with the child welfare agency (Maluccio, Fein \& Olmstead, 1988; Pike, Downs, Emlen, Downs, \& Case, 1977; Wald, Carlsmith, \& Leiderman, 1988). In many cases where children are not returned home, ambivalence about reunification has been noted in the primary caregiver (Fein \& Staff, 1991). Wald et al. (1988) found that a combination of parent ratings regarding their attitudes toward return, their visiting patterns, and their behavioral changes during their children's placement indicated whether return home was likely to take place. Ambivalence can be more easily identified by case planning with parents and obtaining commitment to fulfill required tasks. Evaluation of parental inability or 
unwillingness to complete case plan goals and objectives may be monitored and documented in order to determine the appropriateness of permanency goals.

Children and Family Service Reviews monitor parental participation in case planning as a permanency related indicator. Reviewers determine whether the parents had actively participated in identifying services and goals included in the case plan. If the parents were not involved, the reviewer determined if their involvement was contrary to the best interest of the child. Of the 52 states reviewed between 2001 and 2004 , only 5 or $9.6 \%$ were determined as meeting substantial compliance in this area (USDHHS, 2003c). States that did meet substantial compliance in this area had higher percentages of cases rated substantially achieved for permanency outcomes related to foster care reentries, stability of foster care placements and development and achievement of permanency plans.

Ninety-two percent of Kentucky's reviewed foster care cases were in compliance with this outcome and thus received a Strength rating on this issue (USDHHS, 2003e). However, concerns were noted by stakeholders who were interviewed (USDHHS, 2003e). Several parents noted that they had been shown the case plan and told what was in it, but did not have input into the content of the plan. Stakeholders expressed the opinion that foster and adoptive parents had a higher degree of involvement in case planning than biological parents and that the involvement of fathers in case planning is a rare occurrence (USDHHS, 2003e). 


\section{Risk Factors Present Specific to Adult Family Members}

A number of studies beginning in the 1950s to the present have identified factors that present substantial risk of long term foster care. Faller (1984) and Katz and Robinson (1991) developed risk matrices that include these factors as classifications of child welfare cases based on their probability for successful intervention (a) parent's physical health, (b) mental illness, (c) substance abuse, (d) domestic violence, (e) a lack of appropriate support systems, and (f) impaired intellectual functioning. These risk factors have now been incorporated into federal laws such as ASFA and many state laws that reduce the length of time required to work with families who exhibit these risk factors prior to seeking termination of parental rights.

Families in the child welfare system may have multiple risk factors occurring at once. For instance, a family may be experiencing domestic violence, substance abuse, a teenage parent, and children who previously spent time in foster care. With so many families in child welfare experiencing at least one of these risk factors, social workers may be having a difficult time determining which children are at the greatest risk of long term foster care. Social workers may also be struggling to meet the complex needs of these clients which often require a multidisciplinary and/or community approach. While the CFSR does not assess states' use of risk factors as a means to obtain permanency, states are held accountable for their available service array to meet the needs of each of its families. More information will be provided regarding service array in the System Variables section of this chapter. 


\section{Parental Physical Health}

Studies which considered the impact of a parent's physical health problems have produced inconsistent results. Benedict and White (1991) and Landy and Munro (1998) found that a parent's health problems negatively affected timely reunification. However, Jones (1998), Potter and Klein-Rothschild (2002), and Seaberg and Tolley (1986) did not find that parent's physical illnesses were related to length of stay in foster care. These findings may reflect social events that were occurring during each of these times. For instance, the AIDS epidemic may not have been widespread into these populations at the time of Seaberg and Tolley's (1986). More recent studies may also reflect the effect of reduced medical services due to fewer families receiving Medicaid and other welfare benefits, or improved economic conditions that increased families' abilities to maintain health insurance and receive medical services.

\section{Parental Mental IIIness and Emotional Problems}

Parental mental illness and emotional problems greatly reduce the likelihood of reunification, especially for those mental ailments that have been unresponsive to prior mental health services. For parents within the child welfare system a diagnosis of chronic and debilitating mental illness, psychosis, schizophrenia, borderline personality disorder, sociopathy, or other illnesses that respond slowly or not at all to treatment greatly increase a child's length of time in care (Faller, 1984; Fanshel \& Shinn, 1978; Jellinek, Murphy, Poitrast, Quinn, Bishop, \& Goshko, 1992; Jenkins, 1967; Katz \& Robinson, 1991; Lawder et al., 1986; Rzepnicki, Schuerman, \& Johnson, 1997; Schety, Angell, Morrison, \& 
Sack, 1979; Wattenberg, 2001). Incompetent parenting as a result of mental illness is one of the most common grounds on which courts terminate parental rights (Sackett, 1991). These outcomes may be due to the complexity of these ailments, the lack of availability of services to the families, and the limited probability of successful treatment.

Mentally ill parents typically are viewed from a pathology perspective that fails to address their desire to be competent parents (Ackerson, 2003). Parents who have serious and persistent mental illnesses are often overlooked in social work and mental health journals and mental health literature reflects little research on assessment of parental competence and what constitutes competent parenting by people with serious mental illnesses (Ackerson, 2003). Before deinstitutionalization many of these individuals resided in state hospitals and may have been less likely to marry or have children. An unforeseen consequence of the community mental illness revolution has been an increase in women with severe mental illnesses bearing and rearing children (Bachrach, 1984; Burr, Falek, Strauss, \& Brown, 1979; Nicholson, Geller, \& Fisher, 1996). Another reason these parents may have been overlooked is that they are caught in the gap between the child welfare and mental health systems. Their mental illness is viewed as an individual problem that is the responsibility of the local mental health system, whereas the safety and welfare of their children is the responsibility of the child welfare system. There may not be a clear understanding of who is responsible for the assessment and development of competent parenting. In a study of rural child welfare workers in Illinois, child 
welfare workers perceived themselves to be ill equipped to deal with assessment and treatment of the mentally ill parents they served (Raske, 1997). Community mental health providers while providing treatment for mental illness, are reported to not focus on the influence of parenting on the needs of their clients (Nicholson \& Branch, 1994; Nicholson, Geller, Fisher, \& Dion, 1993; Oyserman, Mowbray \& Zemencuk, 1994; Test \& Berlin, 1981).

\section{Chronic Substance Abuse}

Studies by Leathers (2002), Potter and Klein-Rothschild (2002), and Seaberg and Tolley (1986) reported that negative permanency outcomes are associated with chronic substance abuse. Not only does substance abuse contribute to duration of foster care, the lifestyle that often accompanies it affects permanency for children. Particular noted concerns include (a) parental support systems that consists solely of drug dealers and users, (b) involvement in prostitution or other criminal activity, (c) risk of incarceration, and (d) abuse of drugs or alcohol during pregnancy (Benedict \& White, 1991; Faller 1984; Jellinek et al., 1992; Katz \& Robinson, 1991; Potter \& Klein-Rothschild 2002; Rzepnicki et al., 1997; Schetky et al., 1979; Wattenberg, 2001).

Caseworkers have reported that substance abuse cases are among the most difficult and frustrating cases to manage (Semedei, Radel, \& Nolan, 2001). The multiple, complex problems faced by parents who abuse alcohol and other drugs are likely to require intervention beyond that which the child welfare agency has to offer. Few child welfare caseworkers have the clinical background to diagnose or treat substance abuse and treatment services from other sources 
may not meet the needs of child welfare clients (Semedei et al., 2001). Especially important for child welfare agencies, treatment programs rarely have a family and child focus. For instance, most substance abuse services are based on models designed for men and may not be culturally or linguistically appropriate for all clients, and may not address the alcohol and drug use patterns typical of child welfare clients. These services (a) may not be accessible through public transportation, (b) may be offered during limited daytime hours that may conflict with welfare system requirements for participation in work related activities, or (c) may not have child care available in conjunction with the program (Semedei et al., 2001).

National studies have shown that the availability of family services in conjunction with treatment actually declined in the 1980s. From 1991 to 1993 , only $8 \%$ of clients in outpatient drug treatment facilities, $37 \%$ of clients in short term inpatient programs, and $20 \%$ of patients in long term residential treatment programs received family related services (Etheridge, Craddock, Dunteman, \& Hubbard, 1995). Semedie et al. (2001) reported that these practices are changing. Several new promising strategies are being developed and implemented to improve services to clients with these needs and longitudinal studies are needed to determine the effects of these new programs.

\section{Domestic Violence}

Katz and Robinson (1991), Rzepnicki et al. (1997), and Wattenberg (2001) have identified long term domestic violence as a factor which decreases timely permanency for children in foster care. The impact of long term violence on 
children includes putting them at risk of physical harm, neglect or emotional abuse by observing and possibly being injured during the physical and emotional conflict between the involved adults. The time needed to break the cycle of domestic violence is often a long one. Refusal to leave the abusive partner, economic dependence on the batterer, parental low self esteem and the coexistence of child physical and emotional abuse may all contribute to long term foster care for children.

Children and parental responses to domestic violence varies according to the extent and frequency of the violence, repeated separations and moves, the child's age, sex, stage of development, and their role in the family. The abused parent of a child may have difficulty in providing the basic needs of attachment. Children who have lived in environments where domestic violence occurred, quickly learn that violence is an appropriate way to resolve conflict. These children may learn that victimization is inevitable or may exhibit externalizing behaviors that disrupt school adjustment and the development of trust based relationships. Older children who witness domestic violence may enter and remain in the child welfare system as a result of their efforts to escape their home environments. These children may run away, become involved in delinquent behavior, marry early, or demonstrate abusive behaviors to parental figures or peers.

\section{Lack of or Inappropriate Extended Family Support}

Permanency outcomes can also be negatively affected by the parent's childhood experiences such as growing up in foster care or group care or in a 
family of intergenerational abuse (Jellinek et al., 1992; Katz \& Robinson, 1991; Rzepnicki et al., 1997; Schetky et al., 1979; Wattenberg, 2001). Such experiences may leave the parent without basic nurturing and protective parental skills. Often these parents do not have a positive support system or appropriate relatives to share parenting. Hess and Folaron (1991) found that a lack of extended family support influenced increased parental ambivalence regarding their own parenting ability and likelihood of reunification.

\section{Parental Intellectual Functioning}

Parental intellectual functioning can affect a parent's ability to protect and provide for their children and, if their children are removed, to modify their understanding and behaviors to satisfy court and agency requirements for the return of their children. Parents who are intellectually impaired, mentally retarded, have developmental disabilities, or have shown significant self care deficits are less likely to have children who received timely permanency (Faller, 1984; Jellinek et al., 1992; Katz \& Robinson, 1991; Potter \& Klein-Rothschild, 2002, Rzepnicki et al., 1997; Schetky et al., 1979; Wattenberg, 2001). Parents with such deficits are often unable to properly parent without a high level of community and extended family support.

\section{Title IV-E Eligibility}

Under Title IV-E of the Social Security Act (P. L. 96-272) states are eligible for reimbursement of foster care cost for each child who was AFDC eligible prior to placement in foster care. About half of all children who enter foster care are IVE eligible (Courtney et al., 1999). These children have been found in various 
studies to be less likely to achieve timely permanency (Courtney \& Wong, 1996; Jones, 1998; Landy \& Munro, 1998; Potter \& Klein-Rothschild, 2002; Wulczyn et al., 2000). Poverty and AFDC eligibility is especially indicative of longer lengths of stay for children who exit to reunification and adoption (Albers et al., 1993; Courtney \& Wong, 1996; Jones, 1998; Wattenberg, 2001). Albers et al. (1993) found that children whose families received AFDC were more likely to be in foster care three years or longer. Other studies such as Barth et al. (1986), and Landy and Munro (1998) considered the effects of socioeconomic status on length of time in care. These studies found that parents with higher income and parental employment were associated with shorter lengths of stay in care.

\section{Recidivism}

Recidivism is recognized as a major barrier to ensuring permanency for children. Under the Adoption and Safe Families Act, recidivism may be used as an aggravated circumstance to not provide reasonable efforts for reunification to some children in foster care. Studies have shown that the probability of reunification is greatly reduced in the following specific instances of recidivism: (a) presence of serious prior harm to another child (including death), (b) prior foster care stays for other children, (c) termination of parental rights on another child, (d) repeated or premeditated harm or torture of the child in question, (e) three or more child protective service interventions for separate incidents, indicating a chronic pattern of abuse or severe neglect (Benedict \& White, 1991; Faller, 1984; Jellinek et al., 1992; Murphy, 1968; Schetky et al., 1979; Wattenberg, 2001), and (f) where families have received prior child protective 
service preventive measures that failed to keep the child with the parent (Katz \& Robinson, 1991).

Recidivism suggests a pattern of behavior that may be difficult to overcome and is difficult to measure due to the differing definitions of abuse and neglect from state to state. The Child Welfare Outcome 2000 Annual Report (United States Department for Health and Human Services, 2000a) identified three differences in state practices and procedures regarding recidivism (a) investigating new allegations of child maltreatment on open cases, (b) definitions and findings of maltreatment, and (c) availability and assignment to alternative services.

\section{Differences Investigating Abuse Reports on Open Cases}

In some states, new allegations of child maltreatment are not assigned for an investigation if an open case already exists on the family. Also, some states do not investigate past maltreatment that is reported after a child protective investigation case has already been opened.

\section{Differences in Definitions of an Indicated Report of Abuse}

Only 10 states in 2000 included the finding indicated maltreatment, but many states have dispositions such as services recommended, or unconfirmed that fall somewhere between a substantiated finding and a finding of unsubstantiated.

\section{Differences in the Availability of Alternatives Response System}

In some states, a report assigned to an alternative response is screened out of the child protection system. In these states, such reports are not included 
in the maltreatment reoccurrence, but in other states these reports may be investigated and included in the computation of recidivism. Kentucky's child abuse administrative regulations allow acceptance of Family in Need of Services (Finsa) referrals, where families may be offered services when maltreatment cannot be determined but risk of maltreatment exists (Kentucky Administrative Regulation, 922, 1:330, 2001).

Many children experience abuse or neglect prior to, during and after foster care. Each of these periods is considered in the CFSR by reviewing the overall recidivism rate, the percentage of children who are abused in foster care, and the number of children who reenter foster care due to abuse and neglect. For CFSR purposes, a state's performance on reducing the recurrence of child maltreatment is measured by safety outcome measure 1.1: Of all children who were victims of substantiated or indicated child abuse and/or neglect during the first six months of the reporting period, what percentage had another substantiated or indicated report within a six month period? Data for this factor come from the National Child Abuse and Neglect Data System (NCANDS). The CFSR national standard for recidivism requires that no more than $6.1 \%$ of cases will have repeat maltreatment within a six-month period of time (USDHHS, 2003c), including the percentage of children maltreated while in foster care. Kentucky's rating in this area was $8.1 \%$ (USDHHS, 2003e). Seventeen states or $32.7 \%$ of states received a rating of strength on this indicator (USDHHS, 2003c). Reviewers noted concerns with initiating a response, and lack of consistency 
between policy and practice regarding maltreatment in open child protection cases.

\section{Number of Children}

Studies have found that having more children in the family affects all types of permanency outcomes (Wattenberg, 2001). Children who have been waiting the longest for permanency are more likely than other children to have siblings in care (Avery, 1999). Children with a sibling in custody are $39 \%$ less likely to leave custody than children without siblings in care, even when controlling for other factors (Glisson et al., 2000). Children with siblings in care are less likely to exit to adoption (McMurty \& Lie, 1992) and less likely to exit to reunification (GroganKaylor, 2000; Potter \& Klein-Rothschild 2002). Findings that children from larger families experience longer length of stays may suggest that biological and foster/adoptive families are facing difficulties in caring for large numbers of children both financially and emotionally (Murphy, 1968).

Some studies have shown that children who remain in care the longest may have their chances for permanency improved by having siblings in foster care. For children with a goal of adoption, Avery's (1999) findings suggested that children who have experienced substantial delays and have siblings in the system might have an increased chance of adoptive placement if they were jointly listed with one or more of their siblings. Avery (1999) found that children who are placed with siblings were more likely to be adopted compared to those who were not placed with their siblings. This may particularly be true for older or 
disabled children who may be less adoptable than their younger and healthier siblings.

\section{Number of Parents in the Home}

Most children in foster care do not come from families where both parents live in the home. Foster children are predominantly removed from single mother headed households (Albert, 1988). There are conflicting findings regarding the effects of two parent families on length of stay in foster care. In a recent study, the probability of returning home was greatest for children living in two-parent families (Glisson et al., 2000). Wells and Guo (1999) found that children who lived with their mothers were reunified at a rate of $32.9 \%$ slower than a child who lived with both parents. Other studies have found limited or no relationship between permanency and number of parents in the home (Courtney, 1994; Courtney \& Wong, 1996; Jones, 1998; Seaberg \& Tolley 1986). Further study into this variable is needed to determine why such differences were found in these studies. Other factors such as the level of involvement of the non-custodial parent, degree of other forms of family and community support, and child related variables may interact to produce different conclusions.

\section{Type of Abuse Child Suffered}

Currently no common federal definitions exist for child physical abuse, neglect or sexual abuse. As previously discussed, standards for identifying and substantiating abuse and neglect differ from state to state making it difficult to determine levels of recidivism. This lack of standards has also made it difficult to assess how each type of abuse affects length of time in foster care. Several 
studies have considered how the type of abuse that occurred within the family affects length of time in care by reviewing the case files or legal documents which categorize each type of abuse. These studies have produced contradictory findings. In the 1999 Child Welfare Outcomes Annual Report (United States Department for Health and Human Services, 1999) states varied with respect to the percentages of child victims experiencing each type of maltreatment (physical abuse, neglect, medical neglect, sexual abuse, and psychological maltreatment/emotional abuse). These findings suggest the need for a greater understanding of not only what constitutes abuse, but how that abuse may affect permanency.

\section{Neglect}

Neglect is a form of maltreatment that is at times considered more benign than other forms of maltreatment, however, the often chronic nature of neglect may lead to longer lengths of stay (Albers et al., 1993; Berrick, Needell, Barth \& Jonson-Reid, 1998; Jones, 1998; Lawder et al., 1986; Olsen, 1982; Rzepnicki et al., 1997; Seaberg \& Tolley 1986; Wells \& Guo 1999). While physical or sexual abuse often involves the commission of a specific behavior by a parent, neglect involves the omission of behaviors that are seen as necessary to effective parenting. Parents who grew up in neglectful households may have behavior patterns that create difficulty in conforming to normalized parenting standards. These standards may be associated with economic expectations for families that they cannot or will not meet. Neglect may be a catch-all categorization for behaviors that do not fall into the physical or sexual abuse categories, but which 
are considered outside of normalized parenting behavior. Zuravin (1989)

reported 12 different subtypes of neglect: refusal to provide physical health care, abandonment/desertion, delay in providing physical health care, failure to provide a permanent home, refusal to provide mental health, housing hazards, housing sanitation, supervisory neglect, custody refusal, nutritional neglect, custodyrelated neglect, and educational neglect.

\section{Physical Abuse}

The relationship between physical abuse and length of stay in foster care is not clear. Some studies have found that when the primary placement reason was physical abuse, median length of stay was shorter than the median stays for other placement reasons such as neglect or sexual abuse (Benedict \& White, 1991). These findings may reflect a difficulty in substantiating physical abuse or cultural norms related to spanking and corporal punishment. The length of time a child who has suffered physical abuse spends in care may be directly related to the extent of the abuse suffered. Goerge (1990), and Barth et al. (1986) found that children who were more severely abused went home at a slower rate. For children who are more severely abuse, a greater length of stay may be expected in order to address prevention of further abuse. Intentional acts of severe physical abuse may be related to parental emotional or psychological functioning, loss of control difficulties or the accumulated effects of substance abuse, domestic violence or other high-risk behaviors. These behaviors may also be associated with other forms of abuse that contribute to more complex issues needing lengthy treatment. 


\section{Sexual Abuse}

Sexual abuse of children is difficult for many to understand. Cultural norms, criminal prosecution, and complexity of treatment often influence the length of time children who are sexually abused spend in care (Davis, Landsverk, \& Newton, 1997). Some studies have found that children who are victims of sexual abuse may not receive timely permanency, especially for exits to reunification and adoption (Courtney, 1994; Courtney \& Wong, 1996; Glisson et al., 2000). In Glisson and his colleagues' (2000) study, sexually abused children had a $33 \%$ lower probability of exiting care than children who were not sexually abused. Children who have been sexually abused may exhibit behaviors that require extensive treatment and/or more restrictive placements. Social workers may also have difficulties with services for reunification due to no contact orders between the offending parent and the child or other legal restrictions. Such orders as well as other concerns related to the child's safety may extend the child's length of time in care due to the need to address treatment issues prior to visitation or other reunification efforts.

\section{Summary of Family Variables}

While numerous family variables appear to affect length of time in care, not all have received the same attention as permanency indicators. Some variables such as visitation, Title IV-E eligibility, and recidivism have been studied extensively. Other variables, including parental risk factors, have not received as much attention from researchers. Studies that included visitation as a predictor of permanency overwhelmingly demonstrated a strong relationship 
between shorter lengths of stay in foster care and visitation. Other variables have produced inconsistent or weak relationships from one study to another. As previously stated, this may be attributed to several factors including type of study, time period, and statistical tools. A review of the literature suggested that some variables, such as visitation and number of children in the family may, over time, produce less significant or different findings for children who spend long periods of time in care, compared to those who exit care earlier. CFSR findings suggest that states are struggling with family related variables and CFSR reviewers found particular difficulties in the area of case planning with families.

\section{Child Variables}

One aspect of this project will be to consider how individual characteristics of children placed in foster care affect different types of permanency. It is important to understand how children may affect their own permanency outcomes to address deficits in providing for these children's needs. CFSR encourages the engagement of children in planning for their future. In order to development appropriate permanency plans for children in foster care, there must be an understanding of the relationship between specific child variables and permanency outcomes. Variables such as age, ethnicity, and medical, psychological, and behavior problems are thought to greatly influence permanency for children. By better understanding these variables this project hopes to profile the types of children who are not receiving permanency post ASFA. To facilitate this goal, some of the stronger predictive child variables from the literature will be examined, i.e. age, race, gender, Auchenbach scores 
(behavioral functioning), child's level of well being, and the child's ability to attach (Table 3). Of these variables, only child well being is evaluated during CFSR onsite reviews. While CFSR does not assess delays to permanency due to child demographics, specific groups of children, including children with disabilities, minority children, infants, and older children are monitored through AFCARS data to ensure that their permanency needs are met.

\section{Table 3}

Significant Findings: Child's Influence on Duration of Foster Care

\begin{tabular}{|c|c|c|c|}
\hline Study & Type of study/Analysis & Data Source & $\begin{array}{l}\text { Sample } \\
\text { Size } \\
\text { /Power }\end{array}$ \\
\hline $\begin{array}{l}\text { Albers, } \\
\text { Rittner, \& } \\
\text { Reilly, } 1993\end{array}$ & $\begin{array}{l}\text { Static-group comparison } \\
\text { group / Multiple } \\
\text { regression }\end{array}$ & $\begin{array}{l}\text { State electronic child welfare } \\
\text { data }\end{array}$ & 404 \\
\hline
\end{tabular}

$\begin{array}{lll}\text { Barth, } 1997 & \text { Longitudinal Cohort Electronic child welfare data } \\ \text { entries, multinomial logit files } \\ \text { model }\end{array}$

${ }^{2} \mathrm{Age}$ and ethnicity/Age at entry and ethnicity

$\begin{aligned} & \text { Barth, } \\ & \text { Snowden, }\end{aligned}$
Broeck,
Clancy,
Jordan, \&
discriminate analysis

$2 \quad$ Child Variables included in Study / Significant Independent Child Variables 


\section{Table 3 (Continued)}

\begin{tabular}{|c|c|c|c|}
\hline Study & Type of study/Analysis & Data Source & $\begin{array}{l}\text { Sample } \\
\text { Size } \\
\text { /Power }\end{array}$ \\
\hline Courtney, 1994 & $\begin{array}{l}\text { Longitudinall } \\
\text { Event history analysis }\end{array}$ & $\begin{array}{l}\text { Electronic Child Welfare case } \\
\text { records }\end{array}$ & 8,748 \\
\hline
\end{tabular}
Courtney \& Cohort groups/Cox Child Welfare case records 8,625 Wong, 1996 Proportional Hazards Model
${ }^{2}$ Age, gender, ethnicity, health problems/Age at entry, ethnicity, health problems

Finch, Fanshel \& Cross Sectionall Electronic child welfare data 20,000+ Grundy, 1986 Regression Analysis files

${ }^{2}$ Age and ethnicity/Age at entry

\begin{tabular}{|c|c|c|}
\hline $\begin{array}{l}\text { Frazer, Walton, } \\
\text { Lewis, Pecora, \& } \\
\text { Walton, } 1996\end{array}$ & $\begin{array}{l}\text { Experimental and } \\
\text { Control Group }\end{array}$ & $\begin{array}{l}\text { Public Child welfare data and } \\
\text { interviews with social workers } \\
\text { and caregivers }\end{array}$ \\
\hline
\end{tabular}

$\begin{aligned} & \text { Glisson, Bailey \& } \\ & \text { Post, } 2000 \\ & \text { history analysis }\end{aligned}$
$\begin{aligned} & \text { Age, gender, ethnicity, and disabilities/Child mental health problems, ethnicity } \\ & \text { interviews with social workers, } \\ & \text { and disabiliites }\end{aligned}$

Goerge, $1990 \quad \begin{aligned} & \text { Longitudinal/Event } \\ & \text { history analysis }\end{aligned} \quad \begin{aligned} & \text { Electronic child welfare case } \\ & \text { files }\end{aligned}$

2 Ethnicity, age, gender and behavior problems/Age and race

Goerge, Wulczyn Longitudinal/Hazard Hardcopy child welfare data \& Harden, 1994 Rate Analysis files

2 Age and ethnicity/Age and ethnicity

Horwitz, Simms, Longitudinal/Logistic Child welfare case records ?272 \& Farrington, Regression 1994

Age at entry, disabilities, health problems, ethnicity and gender/Age at entry, developmental delays and ethnicity 
Table 3 (Continued)

\begin{tabular}{|c|c|c|c|}
\hline Study & Type of study/Analysis & Data Source & $\begin{array}{l}\text { Sample } \\
\text { Size } \\
\text { /Power }\end{array}$ \\
\hline Jenkins, 1967 & $\begin{array}{l}\text { Longitudinal/ } \\
\text { Contingency Table }\end{array}$ & Child welfare case records & 891 \\
\hline
\end{tabular}

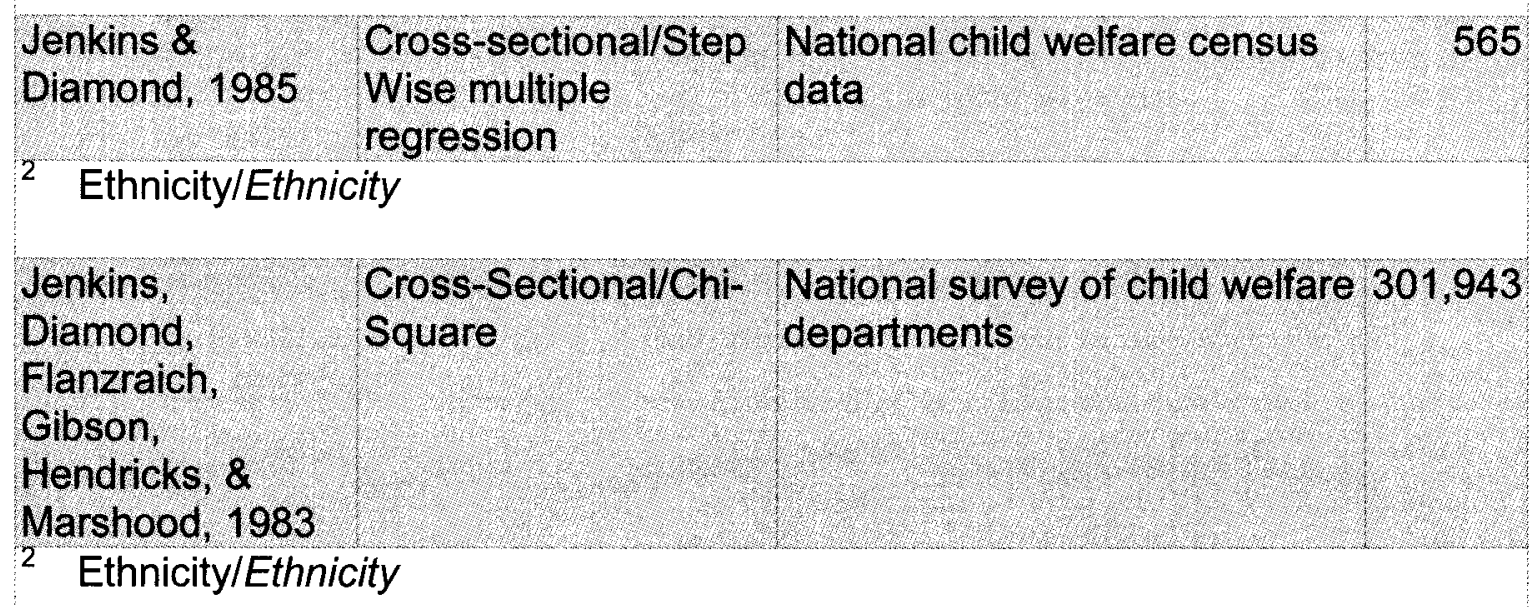

\begin{tabular}{|c|c|c|}
\hline Jones, 1998 & $\begin{array}{l}\text { Cohort } \\
\text { groups/Logistic } \\
\text { regression }\end{array}$ & $\begin{array}{l}\text { Electronic and hardcopy child } \\
\text { welfare case records }\end{array}$ \\
\hline $\begin{array}{l}\text { problems, sut } \\
\text { sleeping prob } \\
\text { problems }\end{array}$ & $\begin{array}{l}\text { ties, school diffici } \\
\text { ice and alcohol a } \\
\text {, age, ethnicity al }\end{array}$ & $\begin{array}{l}\text { learning disabilities, or mental } \\
\text { other psychological problems, } \\
\text { nder/Ethnicity and medical or b }\end{array}$ \\
\hline
\end{tabular}
Kemp \& Bodonyi, Cohort groups/Cox Hardcopy and electronic case 458 2000 Proportional Hazards Model files, interviews with social workers and supervisors 2 Age, ethnicity and gender/Gender (male) and ethnicity (African American and Hispanic)

\begin{tabular}{|c|c|c|}
\hline $\begin{array}{l}\text { Kemp \& Bodonyi, } \\
2002\end{array}$ & $\begin{array}{l}\text { One shot case } \\
\text { study/Cox } \\
\text { Proportional Hazards } \\
\text { Model }\end{array}$ & $\begin{array}{l}\text { Hardcopy and electronic case } \\
\text { files, interviews with social } \\
\text { workers and supervisors }\end{array}$ \\
\hline
\end{tabular}

2 Age, ethnicity and gender/Gender (male), ethnicity and age at placement 
Table 3 (Continued)

\begin{tabular}{|c|c|c|c|}
\hline Study & $\begin{array}{c}\text { Type of } \\
\text { study/Analysis }\end{array}$ & Data Source & $\begin{array}{l}\text { Sample } \\
\text { Size } \\
\text { /Power }\end{array}$ \\
\hline $\begin{array}{l}\text { Lawder, et al., } \\
1986\end{array}$ & $\begin{array}{l}\text { Longtudinal/Multiple } \\
\text { regression }\end{array}$ & Child welfare case files & 185 \\
\hline
\end{tabular}

2 Behavior problems, disabilities, ethnicity and gender/Number of behavior problems exhibited by the child

Magura, 1979 Cross sectional/Trend Electronic child welfare data 48,727 Analysis

2 Age at placement/Age at placement

$\begin{array}{lll}\text { McMurty \& Lie, } & \begin{array}{l}\text { Cross-sectional } \\ \text { IRelative risk }\end{array} & \begin{array}{l}\text { Hardcopy and electronic child } \\ \text { welfare data case files }\end{array}\end{array}$

2 Age, behavior problems, disabilities, ethnicity and gender/Ethnicity, age at placement, and disabiliites

Olsen, 1982 Cross-sectional/ Path Child welfare case records and Analysis surveys of social workers

${ }^{2}$ Ethnicity, social-emotional handicap, mental handicap, physical handicap and age/Age, physical handicap and ethnicity (being Caucasian)

Potter \& Klein- Entry cohorts/ Child welfare case files and

Rothschild, 2002 Backward logistic interviews with social workers 125 regression and court personnel

2 Ethnicity and emotional or behavioral problems, age and medical condition/Ethnicity and emotional or behavioral problems

Schmidt-Tieszen Cross-sectionall Child welfare case files

\& McDonald, Logistic regression 1998

2 Age, ethnicity, gender, physical, medical, emotional, developmental disabilities, and learning disabilities/Ethnicity, age at entry, emotional problems, and developmental delays

\begin{tabular}{|c|c|c|c|}
\hline $\begin{array}{l}\text { Schwartz, Ortega, } \\
\text { Guo \& Fishman, } \\
1994\end{array}$ & $\begin{array}{l}\text { Longitudinal/Multiple } \\
\text { regression }\end{array}$ & $\begin{array}{l}\text { Electronic child welfare case } \\
\text { files }\end{array}$ & 4,085 \\
\hline \multicolumn{4}{|c|}{2 Gender, age and ethnicity/Age and ethnicity } \\
\hline $\begin{array}{l}\text { Seaberg \& Tolley, } \\
1986\end{array}$ & $\begin{array}{l}\text { Cohort group/Multiple } \\
\text { Regression }\end{array}$ & $\begin{array}{l}\text { Data set from national } \\
\text { probability sample }\end{array}$ & 3,950 \\
\hline
\end{tabular}


Table 3 (Continued)

\begin{tabular}{|c|c|c|}
\hline Study & $\begin{array}{c}\text { Type of } \\
\text { study/Analysis }\end{array}$ & Data Source \\
\hline $\begin{array}{l}\text { Sherman, } \\
\text { Newman \& } \\
\text { Shyne, } 1973\end{array}$ & $\begin{array}{l}\text { Longitudinal/ Chi- } \\
\text { Square }\end{array}$ & $\begin{array}{l}\text { Hardcopy child welfare data } \\
\text { files }\end{array}$ \\
\hline
\end{tabular}

${ }_{2}^{2} \mathrm{Age}$, behavior problems, ethnicity and gender/Age and gender

Wells \& Guo, Cohort groups/Event Electronic child welfare case 2,616 1999 history analysis files

2 Age, gender, ethnicity, health status at entry/Ethnicity and presence of health problems

White, Albers, \& Longitudinal

Bitonti, 1996

${ }^{2}$ Ethnicity/Ethnicity
Electronic child welfare case files

\begin{tabular}{|c|c|c|c|}
\hline Wulczyn, 1994 & $\begin{array}{l}\text { Longtudinal/Event } \\
\text { History analysis }\end{array}$ & $\begin{array}{l}\text { Electronic child welfare data } \\
\text { files and vital statistics data }\end{array}$ & 8,137 \\
\hline
\end{tabular}

2 Ethnicity, age and disabilities/Ethnicity, age and disabilities

$\begin{aligned} & \text { Wulczyn, } \\ & \text { Orlebeke, } \\ & \& \text { Melamid, } 2000\end{aligned}$
2 Gender, age and ethnicity/Gender (female), being an infant at time of placement
and ethnicity

Summarized findings of the above table are as follows: 25 of the 33

studies found that ethnicity was related to length of time in care, 22 found age to be a significant finding, and 16 identified child characteristics related to child well being as predictor variables for permanency. Gender had weak or inconsistent links to time in foster care. No studies were found that specifically addressed a child's level of attachment. 


\section{Age}

Age has been found to be a powerful predictor of permanency outcomes Albers et al., 1993; Barth, 1997; Barth et al., 1986; Courtney, 1994; Courtney \& Wong, 1996; Fanshel \& Shinn, 1978; Fernandez, 1999; Finch et al., 1986; Frazer et al., 1996; Goerge, 1990; Goerge et al., 1994; Horawitz et al., 1994; Jenkins, 1967; Kemp \& Bodonyi, 2002; Magura, 1979; McMurty \& Lie, 1992; Olsen, 1982; Schmidt-Tieszen \& McDonald, 1998; Schwartz et al., 1994; Sherman et al., 1973; Wulczyn, 1994; Wulczyn et al., 2000). Significant findings related to age include:

1. Each additional year in care reduced the probability of being adopted by one sixth (Finch et al.,1986),

2. Each additional year of age at initial placement was associated with a $12 \%$ decrease in the hazard rate of a permanent outcome (Kemp \& Bodinyi, 2002),

3. The change of one year in a child's age increases the odds that long term foster care will be the goal by a factor of 1.39 and the variable of age is the most significant variable in case planning (Schmidt-Tieszan \& McDonald, 1998),

4. McMurty and Lie (1992) estimated that each year of increase in age reduces the odds of adoption by $22 \%$. Similarly, each year of increase in age for children who do exit to adoption increases the odds of adoption disruption by $32 \%$ (Barth et al., 1988), and

5. Children adopted from foster care and those who are waiting are similar 
when examined by gender and race: the major difference between the two groups is in age (Casey Family Programs, 2003).

Specific paths to permanency may be especially affected by a child's age at entry into foster care. Children who fall into the youngest and oldest age groups of children in foster care are those less likely to find timely permanency due to the permanency goals most commonly chosen for them (Courtney \& Wong, 1996). Researchers have reported that historically infants have been especially prone to long lengths of time in care due to being less likely to be reunified with their parents (Westat, 2001). Depending on the study, infant's time in foster care has been found to be anywhere from $22 \%$ (Goerge et al., 1994) to 41\% (Barth, 1997) longer than older children. Wulczyn (1994) found that 1 in 2 infants remain in care over two years. Even after lengthy stays in foster care, infants may not find permanency. Somewhere between a quarter and a third of infants entering care experience long stays that do not result in a legalized permanent placement (Berrick et al., 1998). In a study of over 4,000 infants in Michigan, Schwartz et al. (1994) found that $28 \%$ of these children had still not achieved a permanent outcome four years after their initial placement.

These studies may reflect some of the primary concerns ASFA has proposed to resolve by freeing more children for adoption. Recent studies and AFCARS data have found that ASFA may indeed be working for younger children who are more likely to leave foster care via adoption than reunification (Westat, 2001). Significantly more of the children who entered care in fiscal year 2001 as infants were adopted than remained in foster care (32\% adopted vs. $19 \%$ 
remained in foster care). The most recent AFCARS data reported that nationally $4 \%$, or 22,957 children, who entered care during fiscal year 2001 , were one year old or younger. Infants also made up approximately $4 \%$, or 10,923 , of the children who exited care during fiscal year 2001 (USDHHS, 2003a).

Adolescents are similar to infants in that they are also likely to experience longer lengths of stay in foster care. Ụnlike infants, however, adolescents are less likely to exit to adoption. Age has been reported to be the most significant factor distinguishing between children who are adopted and those who remain in long term foster care (Avery, 1998; Barth \& Berry, 1987; Kossoudji, in press; Rosenthal, 1993; Schmidt-Tieszen \& McDonald 1998; Triseliotis, 2002). Eightytwo percent of children adopted from foster care in fiscal year 2000 were under 11 (United States Department for Health and Human Services, 2000b). By contrast, children ages 11 to 15 accounted for $22 \%$ of the adoption eligible children but only $14 \%$ of actual adoptions, and those ages 16 to 18 accounted for $4 \%$ of the adoption eligible children, but only $2 \%$ of the actual adoptions (United States Department for Health and Human Services, 2003c). The low number of available adolescents for adoption suggests that not only are older children and youth less likely to be adopted than younger children (Barth \& Courtney, 1994) they are also less likely to have adoption as a case plan goal (Schmidt-Tieszen \& McDonald, 1998).

In 2000 , more than 19,000 children aged out of foster care (Wertheimer, 2002). Children who are at the highest risk of aging out of foster care are those who entered as teenagers (USDHHS, 2003c). Explanations for why older 
children linger in care suggest that discrimination may exist against older children in the adoption system on the part of both social workers and foster parents. Older children's permanency plans are more likely to be long term foster care (Olsen, 1982), and it is much harder to find adoptive families willing to adopt older children (Barth \& Berry, 1988). Social worker beliefs regarding adolescents' suitability for adoption or the lack of an appropriate family may also affect the choice of permanency goal. Older children are considerably more attached to family of origin even following termination of parental rights and therefore may not favor adoption for themselves. A'study by Bush and Gordon (1982) found that half of 111 foster children judged unlikely to return home did not want to be adopted because it would signal an end to ties with their families of origin. Social workers of these children may be supporting the desires of youth who choose long term foster care over adoption, affirming their right to self-determination (Westat, 2001).

\section{Race}

Numerous studies have shown that minority children, particularly African American children, experience negative permanency outcomes (Albers et al., 1983; Barth, 1997; Barth et al., 1986; Courtney, 1994; Courtney \& Wong, 1996; Glisson, Bailey, \& Post, 2000; Goerge, 1990; Goerge et al., 1994; Horawitz et al., 1994; Jenkins, 1967; Jenkins \& Diamond, 1985; Jenkins et al., 1983; Jones, 1998; Kemp \& Bodonyi, 2000; Kemp \& Bodinyi, 2002; McMurty \& Lie, 1992; Olsen, 1082; Potter \& Klein-Rothschild, 2002; Schmidt-Tieszen \& McDonald, 1998; Schwartz et al.,1994; Seaberg \& Tolley, 1986, Wells \& Guo, 1999; White et 
al., 1996; Wulczyn, 1994; Wulczyn et al., 2000). Most of these studies were conducted prior to the implementation of permanency planning or mandated shortened time frames for obtaining permanency for children in foster care.

Laws such at MEPA and ASFA specifically address the permanency needs of minority children by requiring states to recruit foster/adopt families for minority children, provide training in the areas of cultural competency and by levying financial penalties in states where discrimination in placement procedures are found. The intent of these practices is to overcome the permanency gap between minority and non-minority children. This gap is especially evident in the area of adoption. Minority children are adopted at half, and in some cases, onethird, the rate of non-minority children and when they are adopted they take twice as long to do so (Barth 1997; Kossoudji, in press; McMurty \& Lie, 1992). Barth and Courtney (1994) found that African American children were significantly less likely to be adopted, even after four years in foster care. AFCARS data for 2001 (USDHHS, 2003c) reported that African American children were disproportionately represented within the group of children waiting to be adopted (45\%). Hispanics made up $12 \%$ and other minorities groups were $8 \%$ of this population.

African American children historically are over-represented among children who do not find permanency. In 1999, only $33 \%$ of black foster children left care, compared with $53 \%$ of whites and $39 \%$ of Hispanics (USDHHS, 1999). More than $35 \%$ of youth aging out of foster care in 1999 were black, even though black children account for only $15 \%$ of children under 18 . Courtney and Wong 
(1996) reported that lower hazards of favorable discharge for African American children indicate that, once in care, many of these children are likely to remain indefinitely. In a recent study, being African American decreased the odds of permanency by $89.6 \%$ (Potter \& Klein-Rothschild, 2002). Being a minority does not affect all children in the foster care system in the same manner. In Kemp and Bodinyi's (2002) study, being African American reduced odds of permanency by $40 \%$ but being Latino enhanced odds of permanency by $86 \%$. Interestingly, CFSR reviewers did not find race to be a factor that delayed permanency, especially in the area of adoption. It may be that some minority groups are experiencing more positive permanency outcomes than others and are thereby affecting overall findings for minorities as a group.

\section{Gender}

The relationship between gender and the type of exit from foster care appears to very weak or at best inconsistent (Schwartz et al.,1994; Westat, 2001). Several researchers have found that gender was not significantly related to length of stay in foster care (Albers et al., 1993; Benedict \& White, 1991; Frame, Berrick, \& Brodowski, 2000; Lawder et al., 1986; Murphy, 1968). Other studies have reported binary findings regarding gender's relationship to permanency, with some reporting that males have greater chances at permanency (Fernandez, 1999; Seaberg \& Tolley,1986; Sherman et al, 1973) and others reporting that females are more likely to achieve permanency outcomes than males (Kemp \& Bodinyi, 2002). Each of these studies may be 
correct depending on type of permanency outcome being studied (reunification or adoption) and the desires of adopting families during each time period.

\section{Children's Behavior Checklist Level}

The Child Behavior Checklist $(\mathrm{CBCL})$ is a widely used standardized behavioral checklist that identifies children who display behavior problems and excessive aggression. Kentucky utilizes the $\mathrm{CBCL}$ for a variety of reasons, including monitoring the levels of behavioral and psychological dysfunction of children in foster care as a method to determine restrictiveness of placement, and as a tool to assist in assigning lévels of payment to match levels of service need.

Children who enter Kentucky's foster care system have CBCL scores completed within 90 days of entry and every six months thereafter while in care. Some studies have found that children who enter care with higher CBCL scores were less likely to exit care (Glisson et al., 2000). As many as $70 \%$ of the children in foster care enter with clinical levels of psychosocial functioning (Glisson, 1994). Children with more severe psychosocial functioning have been found to have their possibilities of exiting care reduced by as much as $1.3 \%$ lower for every 1 point increase in their CBCL externalizing scores (Glisson et al., 2000). In a study conducted with children in long term foster care, externalizing behaviors and attention problems were among the most frequently occurring problem behaviors (Armden et al., 2000). Of the problem behaviors, children in long term care scored very true or often true on the following subscale indicators: acts young for age, clings, can't concentrate, acts without thinking, can't sit still, 
argues, demands attention, easily jealous, lies, cheats and lacks guilt. Children's percentages of problems in these areas were 2 to 7 times that of other children (Armden et al., 2000).

\section{Well Being Rating}

For children placed in the child welfare system, the need for permanency may exacerbate already existing well peing deficits or may create new ones. Children in foster care experience the trauma of separation from their families, multiple moves and other anxiety producing events that may increase their vulnerability and compound their edúcational, physical and mental health problems. Samples of children currently entering foster care find 30 to $60 \%$ exhibiting clinical levels of emotional and behavioral disorders (Hochstadt, Jaudes, Zimo, \& Schachater, 1987; Mclntyre \& Keesler, 1986; Thompson \& Fuhr, 1992; Urquiza, Wirtz, Peterson, \& Singer, 1994). In a review of literature on psychopathology among children in foster care, Pilowsky (1985) found "a prevalence of psychopathology among children in family foster care that is higher than would be expected from normative data, even when this population is compared with children who have backgrounds of similar deprivation" (p.609). Halfon et al. (1995) applied a multi-disciplinary assessment protocol to 213 children in foster care and found that $80 \%$ had developmental, emotional, or behavioral problems.

Monitoring assessment and provision of services to children in foster care that meet educational, medical and mental health needs is a part of the CFSR review. Child well being outcomes are evaluated by examining indicators to 
families' capacities to provide for their children's needs. This includes biological, foster and adoptive families. Child well being is intrinsically tied to safety and permanency outcomes. Several studies have found that children who have greater needs for educational, medical and mental health services are at greater risk of long term foster care (Avery, 1999; Barth et al., 1986; Benedict \& White, 1991; Courtney, 1994; Courtney \& Wqng, 1996; Glisson et al., 2000; Horwitz et al., 1994; Jenkins, 1967; Jones, 1998; Lawder et al., 1986; McMurty \& Lie, 1992; Olsen, 1982; Potter \& Klein-Rothschild, 2002; Schmidt-Tieszen \& McDonald, 1998; Seaberg \& Tolley, 1986; Wells' \& Guo, 1999; Wulczyn, 1994; Wulczyn, Orlebeke, \& Melamid, 2000). Schmidt-Tierszen and McDonald (1998) found that children with developmental disabilities were more than four times as likely to be assigned the goal of long term foster care as those without these disabilities.

Potter and Klein-Rothschild (2002) found that children with emotional or behavioral conditions were less likely to achieve timely permanency (decreased the odds by $92.5 \%$ ). Landsverk et al. (1996) found similar results. Children with behavioral or emotional difficulties were half as likely to be reunified with their families as children without problems, regardless of their type of maltreatment, family circumstances, and other background characteristics. Children with health problems have been found to experience a reunification rate that is $39.8 \%$ slower than a child without such problems (Wells \& Guo, 1999).

Results of the CFSR indicate that most states, including Kentucky, do not have adequate services for children in foster care. Sixteen states have received strength ratings for their educational services. Twenty states received strength 
ratings for physical health services (USDHHS, 2003c). Only four states received a strength rating in the area of mental health services. Of these three, Kentucky received a strength rating in educational services only. Particular challenge areas appear to be in (a) fragmentation of responsibility and funding, (b) gaps in service, (c) unmet need and disparities in access, (d) lack of family partnerships and support, (e) lack of workers' understanding of mental health problems of children and adolescents in the child welfare system, and (f) a lack of focus on screening, prevention, and early intervention (National Child Welfare Resource Center for Family-Centered Practice'[NCWRCFCP], 2003a).

\section{Child's Level of Attachment}

Attachment has been described as the base upon which the emotional health, social relationships, and one's world view are built (NCWRCFCP, 2003b). The ability to trust and form relationships will affect the emotional health and security of the child, as well as the child's development and future relationships (NCWRCFCP, 2003b). Normal attachment occurs within the first two years of life. Problems with the parent-child relationship during this time, or breaks in the consistent caregiver-child relationship at any time, prevent attachment from developing normally (NCWRCFCP, 2003b). A wide range of attachment problems may result in varying degrees of emotional disturbances in children. Katz, Spoonemore, and Robinson (1994) described how secure and insecure attachment develops and the different types of behavior seen in children related to their type of attachment. 


\section{Secure Attachment}

Secure attachment occurs when the child is seen as comfortable and calm in the parent's presence and wary or anxious when the parent departs. The parent is consistently responsive and there is reciprocity in the interaction between the parent and the child. The parent is seen by the child as a source of safety and security.

\section{Insecure Attachment}

Insecure attachments involves three types of behavioral patterns by the parent and child (a) Avoidant behavior includes a high level of motor activity by the child. The child is unaffected when the parent leaves and non-reactive when the parent returns. The parent is insensitive and avoids bodily contact. The child sees the parent as likely to rebuff any interaction initiated by the child (b) anxious behavior occurs when the child is fearful or agitated when the parent leaves and cannot be soothed when the parent returns. The parent is seen as insensitive, minimally responsive, and giving of delayed, inconsistent, and/or inappropriate responses. The child sees the parent as not available or unresponsive (c) the last type of behaviors seen in insecure attachment are disorganized behaviors. When this occurs the child's behavior is bizarre or extreme. The child overtly rejects, punishes, or disciplines the parent. Role reversal may occur between the parent and child with the child assuming the caretaker role. The parent is seen by the child as ineffective, inconsistent, helpless, and punitive (Katz et al., 1994).

By having a greater understanding of attachment and separation, social workers and care providers may be able to anticipate some of the challenges that 
children may present when reunified with parents or placed into an adoptive home. Avery (1999) found that in approximately $28 \%$ of the cases, the social workers noted that strong emotional ties to a significant other in the child's life were an obstacle to permanent placement. Almost $43 \%$ of these children had a strong emotional tie to either a foster parent or a significant other who was not considered an adoption resource for the child. CFSR monitors states' compliance with promoting attachment by assessing the degree of efforts agencies make to support or maintain the bond between the child in foster care and their mothers and fathers. This item is rated a strength when (a) there is strong bond between the parent and child that the agency supported, or (b) there was not a strong bond between the parent and the child, but the agency made concerted efforts to promote bonding (USDHHS, 2003d). CFSR considers the need for attachment even in cases where termination of parental rights has occurred if it is assessed as being in the child's best interest. Twenty-one states received a strength rating in this area (USDHHS, 2003c). Kentucky received an Area in Need of Improvement rating on this indicator. Reviewers determined that in $75 \%$ of the applicable cases sufficient efforts had not been made to search for the father or promote the father-child relationship (USDHHS, 2003d).

\section{Summary of Child Variables}

Of all child permanency indicators, race, age and well being characteristics appear to exert the most influence on length of time in care. ASFA, MEPA and other laws were developed because of the lag these children have in finding permanency compared to young, healthy, non-minority children. 
Several of the studies cited were conducted prior to ASFA and almost all were completed prior to the start of CFSR site reviews. Interestingly CFSR site reviews did not produce the same findings as those found in the previously cited studies. This could signify that these laws have been helpful in finding permanency for children who have historically lingered in foster care. Increased attention to child well being, including educational, phyșical and mental health issues could also be influencing these children's outcomes.

\section{Social Worker Variables}

Social workers are directly reśponsible for implementing statutes and policies into daily practice. Their conceptions of and attitudes toward permanency may directly affect their practices in a number of ways. Research has shown that social worker attitudes: (a) favor the maintenance of children in foster care (Emlen, 1976), (b) limit the likelihood of adoption (Board of Social Welfare, 1975), and (c) have a greater influence on exits from foster care than family or macro variables (Shapiro, 1976). The actions of the social worker may be more important in determining permanency related outcomes than the problems that brought the child into placement, the child's psychological characteristics, or the characteristics of the child's foster parents (Stone \& Stone, 1983).

Social workers' conceptions and attitudes about permanency are related to their understanding of what permanency is and what consequences it will have for the families and children to whom they provide services. Gambrill and Stein (1985) identified a number of beliefs that social workers may have regarding permanency that could prevent delays in exiting children from foster care: (a) 
permanency planning can be achieved only under ideal circumstances, i.e., low caseloads and for children only recently entering foster care, (b) permanency planning is synonymous with adoption, (c) permanency is just good casework, which they are already doing (d) permanency planning is pointless since nothing is permanent, and (e) permanency planning is unfair to clients. Many of these beliefs are directly associated with soçial workers' ability to evaluate their own practices. The evaluation of effectiveness of social work practice in child welfare has become a requirement of most federally funded programs. Social workers must now be able to assess their own practices as they relate to fulfillment of client goals in order to obtain funding. CFSR's evaluation of service delivery includes a review of social worker activities that are thought to influence permanency: (a) number of moves a child experienced while in foster care, (b) permanency goal given to the child by the social worker, (c) median number of monthly visits to the child and both parents, (d) regularity of case planning conferences, and lastly (e) services or activities that facilitate the parent child attachment.

Table 4 demonstrates that less attention has been given to social workers' influence on length of time in care compared to child and family characteristics. Nineteen research studies reported significant findings of social worker variables on length of time in foster care. Other studies that included social worker variables but did not produce significant findings are discussed later in this chapter. Few studies have addressed education and experience of the social worker as they relate to permanency outcomes. Seven of the 19 studies included 
in this table found that social worker contacts with parents and family/agency relations reduced length of time in care. Placement history or number of placements was found to increase length of time in care in 7 studies.

\section{Table 4}

\section{Significant findings:- Worker's Influence on Duration of Foster Care}

\begin{tabular}{|c|c|c|c|}
\hline Study & Type of study/Analysis & Data Source & $\begin{array}{l}\text { Sample } \\
\text { Size } \\
\text { /Power }\end{array}$ \\
\hline $\begin{array}{l}\text { Albers, Rittner, } \\
\text { \& Reilly, } 1993\end{array}$ & $\begin{array}{l}\text { Static-group comparison } \\
\text { group / Multiple regression }\end{array}$ & State electronic child welfare data & 404 \\
\hline
\end{tabular}

Barth \& Longitudinal/Event history Courtney, 1994 analysis Surveys of adoptive parents and

${ }^{3}$ Placement history/Placement history

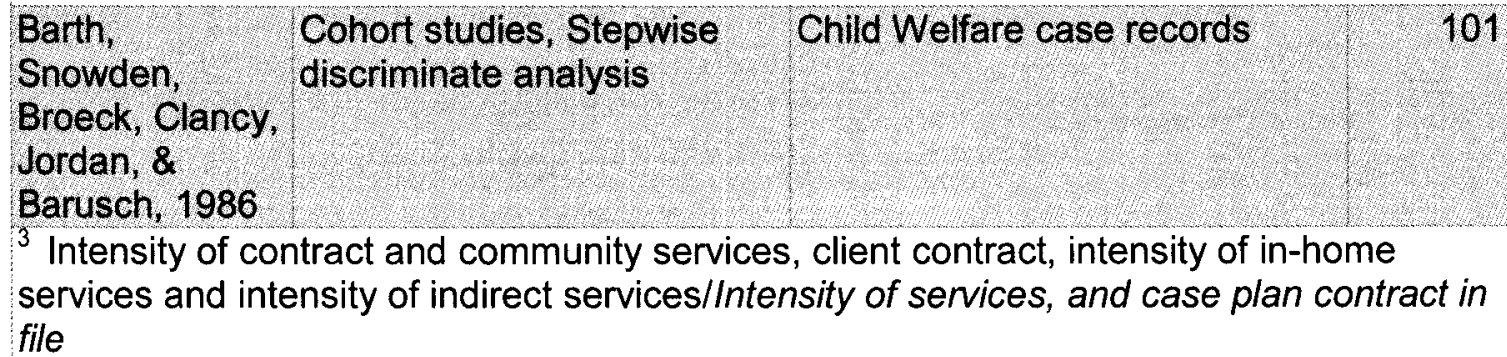

Benedict \& Longitudinal / Multivariate

Child Welfare case records

White, 1991 analysis

${ }^{3}$ Permanency goal, services to implement plan and caseworker contact with mother/Permanency goal, caseworker-parent contact and worker actions and family/agency relations

Boyd, 1979 LongitudinalT - Test Hardcopy child welfare data files

${ }^{3}$ Case planning and family-social worker contact/Case planning and client-family contact

\begin{tabular}{|c|c|c|}
\hline $\begin{array}{l}\text { Courtney \& } \\
\text { Wong, } 1996\end{array}$ & $\begin{array}{l}\text { Cohort groups/Cox } \\
\text { Proportional Hazards Model }\end{array}$ & Child Welfare case records \\
\hline
\end{tabular}

3 Social Worker Variables included in Study / Significant Independent Social Worker Variables 
Table 4 (Continued)

\begin{tabular}{|c|c|c|c|}
\hline Study & Type of study/Analysis & Data Source & $\begin{array}{l}\text { Sample } \\
\text { Size } \\
\text { /Powe }\end{array}$ \\
\hline $\begin{array}{l}\text { Fanshel \& Shinn, } \\
1978\end{array}$ & $\begin{array}{l}\text { Static group } \\
\text { comparison design I } \\
\text { Prediction by } \\
\text { classification }\end{array}$ & $\begin{array}{l}\text { Hardcopy child welfare case } \\
\text { files }\end{array}$ & 19 \\
\hline
\end{tabular}

$\begin{array}{lll}\text { Fernandez, } 1999 & \begin{array}{l}\text { Longitudinal/Event } \\ \text { history analysis }\end{array} & \begin{array}{l}\text { Interviews with child welfare } \\ \text { workers }\end{array}\end{array}$

3 Number of moves/Number of moves

\begin{tabular}{|c|c|c|c|}
\hline $\begin{array}{l}\text { Gibson, Tracy \& } \\
\text { DeBord, } 1984\end{array}$ & $\begin{array}{l}\text { Longitudinal } / \\
\text { Contingencies, } \\
\text { correlations }\end{array}$ & $\begin{array}{l}\text { Child welfare hardcopy data } \\
\text { files }\end{array}$ & $\begin{array}{l}\text { Gibson, } \\
\text { Tracy \& } \\
\text { DeBord, } \\
1984\end{array}$ \\
\hline
\end{tabular}

Goerge, 1990 Longitudinall $\quad$ Child Welfare case records 48

${ }^{3}$ Number of moves/Number of moves

Goerge, 1994 Longitudinal/Hazard Hardcopy child welfare data Rate Analysis files

3 Social worker experience, education, number of placements, caseworker activities/Number of moves

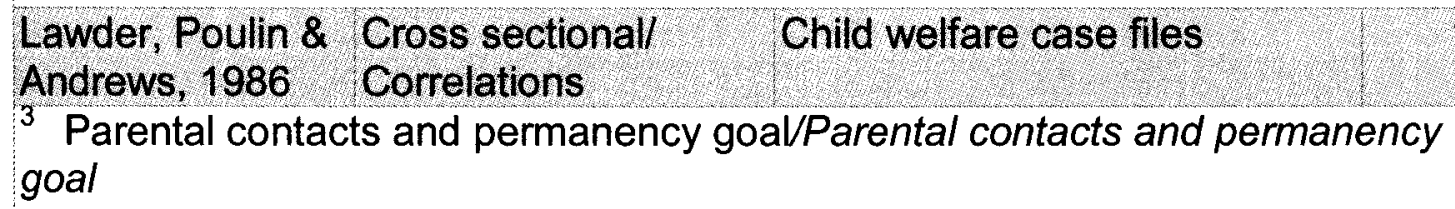

$\begin{array}{llll}\text { Milner, } 1987 & \begin{array}{l}\text { Exit cohorts/Multiple } \\ \text { regression analysis }\end{array} & \begin{array}{l}\text { Case records and interviews } \\ \text { with social workers and } \\ \text { supervisors }\end{array}\end{array}$

${ }^{3}$ Parent-social worker contacts, family-agency relations, worker actions, worker education and experience/Intensity of service delivery and responsiveness to parents

3 Social Worker Variables included in Study / Significant Independent Social Worker Variables 
Table 4 (Continued)

\begin{tabular}{|c|c|c|c|}
\hline Study & Type of study/Analysis & Data Source & $\begin{array}{l}\text { Sample } \\
\text { Size } \\
\text { /Power }\end{array}$ \\
\hline Olsen, 1982 & $\begin{array}{l}\text { Longitudinal/ } \\
\text { Multiple regression } \\
\text { analysis }\end{array}$ & $\begin{array}{l}\text { Data collected directly from } \\
\text { child welfare social workers }\end{array}$ & 1,900 \\
\hline \multicolumn{4}{|c|}{${ }^{3}$ Permanency plan and placement history/Permanency plan } \\
\hline $\begin{array}{l}\text { Potter \& Klein- } \\
\text { Rothschild, } 2002\end{array}$ & $\begin{array}{l}\text { Entry cohorts/ } \\
\text { Backward logistic } \\
\text { regression }\end{array}$ & $\begin{array}{l}\text { Child welfare case files and } \\
\text { interviews with social workers } \\
\text { and court personnel }\end{array}$ & 125 \\
\hline
\end{tabular}
Seaberg \& Cohort group/Multiple Data set from national $\quad 3,950$ Tolley, 1986 Regression probability sample
3 Permanency plan, worker experience and education/Caseworker having increased years of experience and caseworker having degree other than social work

Stein \& Gambrill, Experimental and 1977
Hardcopy child welfare files and interviews with social workers

${ }^{3}$ Case planning and use of contracts with parents/Case planning and use of contracts

Turner, 1984 Longitudinal/Descriptive Hardcopy child welfare data statistics and correlations files and telephone interviews with social workers

${ }^{3}$ Caseworker activities, case planning, and parent-social worker contacts/Social worker-parent contacts

White, Albers, \& Longitudinal Bitonti, 1996 t-test
Electronic child welfare case files

${ }^{3}$ Social worker-parent contacts, family-agency relations, worker actions/Parental contacts and family agency relations

3 Social Worker Variables included in Study / Significant Independent Social Worker Variables 


\section{Number of Moves}

Multiple placements have been associated with failed reunification and subsequent reentry (Courtney, 1994; Fanshel \& Shinn, 1978; Goerge, 1990; Olsen, 1982; Pardeck 1984). As children experience more placements, the probability of permanency decreases and the vulnerability of foster care drift increases (Albers et al., 1993; Barth \& Courtney, 1994; Fernandez, 1999; Goerge, 1994; Potter \& Klein-Rothschild, 2002). With each change in placement, children may experience an increased sense of rejection and impermanence as well as a decrease in their willingnes's and ability to form emotional ties with their caregivers (Kadushin, 1980).

CFSR monitors stability in placement by the number of moves that children experience. Permanency Outcome 1 considers a number of indicators regarding stability in placement, one of which is the percentage of children in foster care for 12 months or more who experience no more than 2 placements. Forty-seven states reviewed were noted as needing improvement in this area (USDHHS, 2003c). Kentucky's statewide rating of $80.3 \%$ did not meet the national standard of $86.7 \%$ for this outcome (USDHHS, 2003e). Identified concerns of CFSR reviewers included information obtained from the statewide assessment and from stakeholder interviews indicating that children were not carefully matched with foster care providers at the time of placement into foster care or when a placement change was necessary (USDHHS, 2003e). Reviewers concluded that this was either because the appropriate assessments were not being conducted, or because there was an insufficient number of placement 
resources resulting in placement decisions being made on the basis of what was available rather than what was needed. The CFSR also noted that other sources which had conducted case reviews, such as Kentucky's Foster Care Review Board, had identified behavior problems as a contributing factor to placement instability for Kentucky's foster care population (USDHHS, 2003e).

\section{Regularity of Casę Planning Conferences}

Boyd (1979) revealed that with proper planning it is possible to move children out of placement more quickly. Case planning involves the identification of a permanency goal and regular mónitoring of progress made toward that goal. A lack of intensive, proactive, and well monitored case planning may contribute to foster care limbo (Barth et al., 1986; Fanshel, 1982; Stein \& Gambrill, 1977). CFSR assesses states compliance with providing a periodic regular case planning of each child in care, at least every six months, either by a court or by administrative review. Nationally, case planning was one of the weakest systemic indictors, with only five of the reviewed states being viewed as having a strength in this area (USDHHS, 2003c). This indicator was rated as a strength for Kentucky. Kentucky's Cabinet for Health and Family Services (CHFS) policy requires a six-month case plan review until a child reaches permanency (Kentucky Revised Statutes $620.180,2001$ ). The case plan conference must include biological parents, foster care providers, children age 8 and older, case workers, supervisors, and objective third parties. Stakeholders who were interviewed during Kentucky's CFSR commented that six month reviews occur regularly and in a timely manner (USDHHS, 2003e). 


\section{Permanency Goal of Child}

All children who enter foster care must have a permanency goal.

Permanency goals designated by ASFA include (a) return to parent, (b) adoption,

(c) guardianship, (d) permanent relative placement, and (e) long term foster care.

Kentucky's policy requires establishment of a permanency goal by the social

worker within five days of entry into foster care and a review of that goal every six months. These reviews are necessary to determine the appropriateness of the goal when considering the needs of the child and the progress made by the family toward reunification. Children, who have goals of reunification typically spend less time in foster care (Benedict \& White, 1991; Courtney \& Wong, 1996; Lawder et al., 1986). Reunification is the designated permanency goal for most children in foster care, followed closely by adoption. Of the CFSR reviewed cases during $2002,39 \%$ had a goal of reunification, $28 \%$ had goals for adoption, and $20 \%$ had goals of long term foster care (USDHHS, 2003c). According to 2001 AFCARS data, $57 \%$ of foster children nationally exited care through reunification (USDHHS, 2001a). CFSR assesses compliance with outcomes for permanency through reunification based on the national standard of $76.2 \%$ or more of children in foster care who exit to reunification due so within 12 months (USDHHS, 2003c). Children with a goal of adoption are expected to find permanency within 24 months through finalized adoptions. In $2001,18 \%$ of children nationally exited to adoption while $22 \%$ had goals of adoption (USDHHS, 2003a). Children who exit care through adoption may spend longer periods of time in care depending on age and time needed to obtain termination of parental 
rights (Courtney \& Wong, 1996). Children with permanency goals other than reunification and adoption may experience even longer lengths of stay in foster care. Approximately one-fourth of children in foster care have a goal other than adoption or reunification or have no designated permanency goal (Mallon, Aledort, \& Ferrara, 2002).

Four permanency indicators are used by CFSR reviewers to assess the timely establishment of appropriate permanency goals. The first indicator, permanency goal for child, is rated a strength if the reviewer found the goal to meet the needs of the child and the goal was established in the required time frame. Nationally, only states received a strength rating on this item (USDHHS, 2003c). Kentucky received an area in need of improvement rating based on the finding that in $50 \%$ of the applicable cases, reviewers determined that the agency had not established an appropriate goal for the child in a timely manner (USDHHS, 2003e). The case review found that the children in 28 foster care cases had the following permanency goals: 17 adoption, 7 long term foster care, 3 reunification and 1 had a goal of permanent placement with relatives (USDHHS, 2003e).

Of the other three permanency goal related indicators (a) permanency goal of reunification, guardianship, or permanent placement with relatives was found in strength in 12 states, (b) permanency goal of adoption was found a strength in 6 states, and (c) permanency goal of other planned permanent living arrangement was identified as a strength in 17 states (USDHHS, 2003c). Of these, Kentucky received an area in need of improvement rating in indicators a 
and $b$, and a strength rating on indicator $c$ (USDHHS, 2003e). These indicators were rated a strength if reviewers determined that the goal had been achieved in a timely manner or if the goal had not been achieved, the agency was making diligent efforts to achieve the goal.

\section{Worker Attitude Toward Attachment}

Social workers are often the primary individuals responsible for pursuing permanent placements for children in foster care. In order to do this, social workers must consider the effects of attachment on obtaining each type of permanency. CFSR developed a spécific permanency outcome to consider attachment by assessing the continuity of family relationships and connections of children in foster care. This outcome is measured by proximity of the foster care placement, if siblings are placed together, visitation, use of relative placements, and relationship of the child and parents. Social workers are expected to make diligent efforts to promote attachment and to comprehend the effects of attachment on permanency and well being for children. Objectives and tasks to accomplish attachment are a required part of out-of-home case planning for Kentucky's social workers (CHFS, 2003). Due to shortened time frames for permanency, social workers must have the ability to factor this information into timely decisions regarding permanency. Ambivalence regarding permanency on the part of the social worker may affect outcomes for children by leading to longer lengths of stay in foster care (Fein \& Staff, 1991). Such delays may be affected by social workers' (a) evaluation of the parents, (b) their own beliefs regarding the adoptability of the child, or (c) their own predictions regarding the 
children's likelihood of returning home (Avery 1999; Fanshel \& Shinn, 1978;

Leathers 2002). In a study of New York's children who had waited the longest for permanency through adoption, $74 \%$ of these children's workers identified them as unadoptable (Avery, 1999). Social worker ambivalence regarding permanency planning may also affect those children's relationships with their families. Research has suggested that as many as half of all foster children may be formally restricted from contact with their families for reasons other than concern for the safety of the child (Millham, Bullock, Hosie, \& Haak, 1986).

\section{Social Workers' Educational Degrees}

Social workers who hold degrees in the social work field are thought to possess skills specifically needed to provide quality services to families and children. Few studies have assessed what effect, if any, the type of degree held by the social worker actually affects service delivery. Those who have studied this dynamic have found that having staff with social work degrees more often produced positive permanency outcomes. Seaberg and Tolley (1986) found that a degree in social work (either bachelors and masters) was associated with a decrease in length of stay in foster care for children. Albers et al. (1993) reported that workers with degrees in social work were more likely to affect a permanent plan within three years than staff without social work degrees. The level of education child welfare social workers possess varies across states. Some states do not require social workers to hold post secondary degrees. As of 2000 , only four states required a bachelor's in social work (BSW) for caseworkers, and two specified a master's in social work (MSW) for supervisory positions (Steib \& 
Blome, 2003). Only about one-fourth of child welfare services are delivered by staff with BSWs or MSWs (Zlotnick, 1998). Kentucky is one of the few public or private child welfare agencies that are accredited through Council on Accreditation (COA, 2001). COA requires that at least $90 \%$ of social workers hold bachelor degrees in one of the following fields of study: social work, psychology, psychiatric nursing, psychiatry, menta| health counseling, rehabilitation counseling, pastoral counseling, marriage and family therapy and human services.

Some bachelors programs aré now offering social work degrees that specialize in public child welfare. In these programs, students receive the same training as public child welfare staff. In Kentucky, the evaluation of the Public Child Welfare Certification Program found that workers who come out of the program (BSW with child welfare concentration):

1. Were more likely than other workers to place children in a least restrictive environment,

2. Were more likely to have a permanency goal for children in care,

3. Were more likely to have a permanency goal of adoption at 13 months in theie cases,

4. Had only 1 child with a goal of return to parent at 30 months of a case, compared to 9 children with a goal of return to parent at 30 months of a case, and

5. Were more on top of their paperwork (Huebner, 2003). 
CFSR does not evaluate states' hiring requirements for child welfare social workers although these are system indicators for initial and ongoing child protection social workers. Thirty four states received a strength rating in the initial training indicator and 27 received a strength rating for ongoing training (USDHHS, 2003c). Kentucky received a strength rating in both of these areas (USDHHS, 2003e).

\section{Experience Level of Social Worker}

Child welfare agencies spend millions of dollars each year to retain staff. Training, educational stipends and financial incentives are some of the tools used to improve public child welfare's staff retention rate. Having experienced staff is considered necessary to provide timely permanency services to children in foster care. The literature suggests, however, that years of experience is not related to permanency outcomes. Having a more experienced social worker has not been found to improve the accuracy of clinical judgement (Garb, 1998). Seaberg and Tolley (1986) found that having a social worker with more experience increased length of time in care. Other studies reported that having a more experienced social worker increased odds of a successful reunification, but did not consider in what time period (Festinger, 1996), or found that caseworker tenure did not have a particularly strong effect on the likelihood of reunification (Goerge, 1994).

\section{Number of Visits to Parents}

Contact between the family and social worker is a tool utilized by child welfare to (a) develop the therapeutic relationship and (b) monitor progress on case planning goals and service delivery, such as providing individual social work 
counseling or parenting training. Jones, Neuman, and Shyne (1976) identified the relationship between the parent and the social worker as the most important predictor variable of reduced length of stay in care and achieving reunification. Frequency of visits between the family and social worker should be consistent with the needs of the family and be focused around case planning, service delivery and goal attainment. Timely permanency has been found to be a direct result of regular quality contact between the family and social worker (Benedict \& White, 1991; Boyd, 1979; Fanshel, 1975; Gibson et al., 1984; Turner, 1984; White et al., 1996). In tracking the fréquency of social work contacts, Shapiro (1976) noted that in $49 \%$ of the cases, children went home in the first year when social workers had monthly contact with either the parent or the child.

Nationally, seven states met standards for this indicator (USDHHS, 2003c). Kentucky's child welfare policy requires monthly in-home contact with parents until permanency is obtained. During Kentucky's on site CFSR case review, the typical pattern of visitation between social workers and parents shown in Table 5.

\section{Table 5}

Number of Parents and Social Worker Visits by Parent and Frequency $(n=$ 35 cases) (USDHHS, 2003e)

\begin{tabular}{|c|c|c|}
\hline Visits with Mothers & & Visits with Fathers \\
\hline 1 & Weekly & 2 \\
\hline 2 & Twice Monthly & 1 \\
\hline 23 & Monthly & 13 \\
\hline 9 & $<$ Monthly & 9 \\
\hline-- & No Visits & 7 \\
\hline
\end{tabular}


Kentucky received a rating of area needing improvement on this indicator due to reviewer's findings in $37 \%$ of the applicable cases that neither the frequency or quality of visitation met standards to sufficiently monitor child safety and well being or promote attainment of case goals (USDHHS, 2003e).

\section{Number of Visits to Children}

Contact between social worker and the child in foster care has not been found to have a direct relationship with length of time in care (Milner, 1987), but is a priority for child welfare administrators due to child welfare's responsibility for not only permanency but also the safety and well being of the child in foster care. News stories of foster children who have experienced abuse and neglect in the foster care system are regularly featured. These cases elucidate the system's accountability to properly monitor and provide for children in its foster care. Children in foster care have case planning goals involving the child's physical, mental health, educational, attachment and permanency needs. Visits between the child and social worker focus on monitoring these goals with both the children and their care providers. Kentucky's child welfare policy requires a minimum of one monthly visit with the foster child in the foster home. Some children with special needs, such as medically fragile foster children are required to be visited more often. During CFSR reviews held in 2002, significant relationships were found between caseworker visits with children and

1. providing services to protect children in the home,

2. preventing removals,

3. managing risk of harm to children, 
4. establishing and achieving permanency goals of reunification, guardianship and permanent placement with relatives,

5. placement children with sibling,

6. preserving children's connections while in foster care,

7. maintaining parent-child relationships,

8. assessing needs and providing services to children and families,

9. involving children and parents in case planning,

10. caseworker visits with parents and,

11. meeting educational, physical health, and mental health needs of children (USDHHS, 2003d).

A strength rating in this area was significantly associated with substantial achievement for both permanency related outcomes (USDHHS, 2003c). In 53\% of the cases where caseworker visits with children were rated as a strength, Permanency Outcome 1 was also rated as substantially achieved (USDHHS, $2003 c)$. In $78 \%$ of the cases where caseworker visits were rated as a strength, Permanency Outcome 2 was rated as substantially achieved (USDHHS, 2003c). During Kentucky's CFSR, 25 foster care cases received both qualitative and quantitative reviews. In these cases the following visitation pattern between social worker and foster child were found:

1. Weekly visitation -3 cases,

2. Visits occurring twice a month -4 cases,

3. Visits occurring once a month -18 cases and,

4. Visits occurring less than monthly - 3 cases (USDHHS, 2003e) 
Kentucky received an area in need of improvement rating on this indicator based on the finding that in $22 \%$ of the cases, reviewers determined that visits with children were not of sufficient frequency and/or quality.

\section{Summary of Social Worker Variables}

Permanency outcomes related to social workers are heavily utilized by CFSR reviews to assess permanency outcomes. Regularity of case planning, number of moves, services to facilitate attachment, permanency goals and social worker contact with families and children are all used as permanency indicators by the CFSR. Although few of these indicators have received extensive study, several were found to be significantly related to permanency outcomes during CFSR site visits. Number of moves and social worker/family contact appear to be particularly related to decreasing children's length of time in care. Inconsistent findings have been reported in the effect of social workers' educational degrees and levels of experience on duration of care. More work is needed to understand relationships between permanency and these indicators. States that have undergone CFSR on-site visits have found particular difficulties with regularity of case planning, social worker/parent contact and number of moves. Kentucky is also struggling with permanency indicators related to the identification and timely establishment of appropriate permanency goals.

\section{System Variables}

Numerous macro systems exist to which child welfare is accountable: (a) The Adoption and Foster Care Analysis Reporting System (AFCARS) (Social Security Act, of 1986), (b) Statewide Automated Child Welfare Information 
System (SACWIS) (The Omnibus Budget Reconciliation Act, 1993, P.L. 103-66),

(c) court systems, (d) federal, state and local child welfare agencies, (e)

placement systems, (f) accrediting agencies, such as Council on Accreditation

(2001), and (g) numerous others including the Child Welfare of League of

America that monitors and promotes quality foster care services in child welfare.

These macro systems influence child welfare in a number of ways. Data collection through systems such as AFCARS and SACWIS direct attention and resources to variables that each of these systems monitor. Courts, placement systems, and local child welfare agencies may contribute to child welfare services through their culture and value systems. The CFSR itself is a macro system through its current control of federally funded child welfare. Some express concerns that CFSR standards are unrealistic and possibly unrepresentative of the needs of children in the child welfare system. Others, including the CFSR, recognize the need for systemic change and macro directives to ensure accountability. CFSR systemic variables that will be considered in this section include service array, court systems, and placement systems (USDHHS, 2003c). Other macro variables, such as staff turnover, financial resources for children, and legal status of children will also be discussed.

Table 6 includes the following 19 studies that found significant relationships between macro variables and permanency outcomes, 10 studies in which the type of placement was found to increase length of time in care, 7 studies that reported delays in permanency in rural areas and 6 studies in which 
court related barriers to permanency and/or described service delivery issues

contributed to delays to permanency.

\section{Table 6}

\section{Significant findings: Macro Influences on Duration of Foster Care}

\begin{tabular}{|c|c|c|c|}
\hline Study & Type of study/Analysis & Data Source & $\begin{array}{l}\text { Sample } \\
\text { Size } \\
\text { /Power }\end{array}$ \\
\hline $\begin{array}{l}\text { Benedict \& } \\
\text { White, } 1991\end{array}$ & $\begin{array}{l}\text { Longitudinal / } \\
\text { Multivariate analysis }\end{array}$ & Child Welfare case records & 689 \\
\hline
\end{tabular}

Berrick et al., Longitudinal/Regression Electronic child welfare data 1997 files

4 Type of placement/Type of placement and region

$\begin{array}{lll}\text { Courtney, } & \text { Longitudinall } & \text { Electronic Child Welfare case } \\ 1994 & \text { Event history analysis } & \text { records }\end{array}$

4 Type of placement/Type of placement

\begin{tabular}{|c|c|c|}
\hline $\begin{array}{l}\text { Courtney \& } \\
\text { Wong, } 1996\end{array}$ & $\begin{array}{l}\text { Cohort groups/Cox } \\
\text { Proportional Hazards } \\
\text { Model }\end{array}$ & Child Welfare case records \\
\hline
\end{tabular}

${ }^{4}$ Region, type of placement/Type of placement, rural region and type of placement

Festinger \& Experimental and control Hardcopy child welfare case

Pratt, 2002 groups/Cox Proportional hazards analysis

files and interviews with social workers and stakeholders

${ }^{4}$ Placement type, time between tpr and adoption, court-judge and type of services/Type of placement, court continuances, not having the same judge, lack of continuity in court, and lack of options for location of adoption finalization Finch, Fanshel Longitudinal \& Grundy, IMultiple regression Hardcopy child welfare case 1986 records $20,000+$

${ }^{4}$ Placement type, legal status of child and type of services/Legal status of child 
Table 6 (Continued)

\begin{tabular}{|c|c|c|c|}
\hline Study & Type of study/Analysis & Data Source & $\begin{array}{l}\text { Sample } \\
\text { Size } \\
\text { /Power }\end{array}$ \\
\hline $\begin{array}{l}\text { Frazer et al., } \\
1996\end{array}$ & $\begin{array}{l}\text { Experimental and } \\
\text { Control Group }\end{array}$ & $\begin{array}{l}\text { Public child welfare data and } \\
\text { interviews with social } \\
\text { workers and caregivers }\end{array}$ & 110 \\
\hline
\end{tabular}

$\begin{array}{llll}\text { Glisson, Bailey \& } & \text { Cross Sectionall } & \text { Electronic child welfare data } & 700 \\ \text { Post, } 2000 & \text { Regression Analysis } & \text { files }\end{array}$

4 Type of placement, proximity of placement and region/Rural region

$\begin{array}{lll}\begin{array}{l}\text { Glisson \& } \\ \text { Hemmelgarn, }\end{array} & \begin{array}{l}\text { Longitudinal/Stepwise } \\ \text { Regression }\end{array} & \begin{array}{l}\text { Surveys of social workers and } \\ \text { stake holders and child } \\ \text { welfare data files }\end{array} \\ \begin{array}{ll}4 \text { Organization climate, inter-organizational service coordination/High conflict, } \\ \text { lack of cooperation, lack of role clarity, lack of personality and inter-organizational } \\ \text { coordination }\end{array}\end{array}$

\begin{tabular}{l|l|l|l|l|l} 
Goerge, 1990 & $\begin{array}{l}\text { Longitudinal/ } \\
\text { Regression }\end{array}$ & Child Welfare case records & 1,196 \\
& ${ }^{4}$ Type of placement and region / Type of placement and juridiction
\end{tabular}

$\begin{array}{lll}\text { Goerge, } 1994 & \begin{array}{l}\text { Longitudinal/Hazard } \\ \text { Rate Analysis }\end{array} & \begin{array}{l}\text { Hardcopy child welfare data } \\ \text { files }\end{array} \\ { }^{4} \text { Number of caseworkers/Having more social worker turnover }\end{array}$

\begin{tabular}{|c|c|c|c|}
\hline $\begin{array}{l}\text { Jenkins \& } \\
\text { Diamond, } 1985\end{array}$ & $\begin{array}{l}\text { Cross- } \\
\text { sectional/Stepwise } \\
\text { Multiple Regression }\end{array}$ & $\begin{array}{l}\text { National child welfare census } \\
\text { data }\end{array}$ & 565 \\
\hline \multicolumn{4}{|c|}{4 Region/Region } \\
\hline $\begin{array}{l}\text { Martin, et al., } \\
2002\end{array}$ & $\begin{array}{l}\text { Longitudinal/Descriptive } \\
\text { statistics/T Test of } \\
\text { Means }\end{array}$ & $\begin{array}{l}\text { Child welfare case files and } \\
\text { court records }\end{array}$ & 124 \\
\hline
\end{tabular}

4 System Variables included in Study / Significant Independent System Variables 
Table 6 (Continued)

\begin{tabular}{|c|c|c|c|c|}
\hline Study & $\begin{array}{c}\text { Type of } \\
\text { study/Analysis }\end{array}$ & \multicolumn{1}{c}{ Data Source } & $\begin{array}{c}\text { Sample } \\
\text { Size } \\
\text { /Power }\end{array}$ \\
Olsen, 1982 & $\begin{array}{l}\text { Longitudinal/ } \\
\text { Multiple regression } \\
\text { analysis }\end{array}$ & $\begin{array}{l}\text { Data collected directly from } \\
\text { child welfare social workers }\end{array}$ & 566 \\
\hline
\end{tabular}

${ }^{4}$ Type of placement and legal status of child/Type of placement and legal status of child

\begin{tabular}{|c|c|c|c|}
\hline $\begin{array}{l}\text { Potter \& Klein- } \\
\text { Rothschild, } 2002\end{array}$ & $\begin{array}{l}\text { Entry cohorts/ } \\
\text { Backward logistic } \\
\text { regression }\end{array}$ & $\begin{array}{l}\text { Child welfare case files and } \\
\text { interviews with social workers } \\
\text { and court personnel }\end{array}$ & 125 \\
\hline
\end{tabular}
Webster et al., Longitudinal/Multi- Electronic child welfare data 5,557 1998 variant analysis files
${ }^{4}$ Type of placement/Specialized foster care
Wells \& Guo, Cohort groups/Event Electronic child welfare case 2,616 1999 history analysis files
${ }^{4}$ Placement type/Hospitalization as first placement

Wulczyn, Proportional Hazards Electronic child welfare datal 4,171 Orlebeke,

\& Melamid, 2000

${ }^{4}$ Placement type and services to family/Placements in kinship home, move to more restrictive placement, and the agency providing services

4 System Variables included in Study / Significant Independent System Variables

\section{Proximity of Placement}

To ensure that children grow up in their own communities, child welfare agencies are expected to recruit and maintain placements within local communities. These placements are necessary to maintain children's connections to schools, neighbors, extended family members, religious groups, and others who represent the child's ethnic and cultural affiliations. Close 
proximity of placement to a child's family and community is necessary to promote regular sibling visitation and family participation in service delivery. In determining compliance with this standard, CFSR reviewers assess whether children are placed in the same county or community as parents or relatives. If placements are outside of the county or community the special needs of the children, such as placement with siblings, is considered. Kentucky, along with 48 other states, was seen as having proximity of placement as a strength. In Kentucky, $100 \%$ of the cases reviewed reflected that the cabinet had made diligent efforts to ensure that children' were placed in foster care placements that were in close proximity to parents or relatives, or necessary to meet their individual special needs (USDHHS, 2003e).

\section{Number of Social Workers Assigned to Cases}

Drift within the child welfare agencies implies lack of direction toward permanency for children in foster care, although due to the high turnover within child welfare, foster children are likely to have several social workers. Retention of staff is necessary not only to maintain continuity of services but also to prevent additional losses and further attachment issues for children. Potter and KleinRothschild (2002) found that families who had fewer caseworkers were more likely to achieve timely permanency (52.4\% less likely for each additional worker). However, Goerge (1994) found that having higher caseworker turnover increased children's likelihood of returning home. Explanations for these contradictory findings may pertain to differences in the therapeutic relationship 
between the family and the social worker or social worker attitudes toward attachment, as previously discussed.

\section{Amount Spent on Child's Placement}

In 1997, the year ASFA was implemented, it was projected that America would spend close to $\$ 17$ billion on public agency child welfare. The majority of these funds were designated to provide foster care (Lipner \& Goertz, 1996). Based on a survey of state child welfare agencies, federal funding accounts for less than half $(42 \%)$ of state child welfare expenditures with the remainder supported by state ( $49 \%$ ) and local ( $8 \%)$ funding (Lipner $\&$ Goertz, 1996).

Previous research indicates that the social and economic well being of a community directly affects services to children placed in state custody (Glisson \& Hemmelgarn, 1998). Characteristics such as the median income and the rural/urban nature of a community are important to children's services because they represent differences in resources, cultural norms and community structure that affect judicial decisions and service availability (Glisson et al., 2000). Several studies of duration of care reported that children in more rural counties, where there may be even fewer resources, were less likely to leave custody than similar children in more urban counties (Benedict \& White, 1991; Berrick et al., 1997; Courtney \& Wong, 1996; Glisson et al., 2000; Goerge, 1990; Jenkins \& Diamond, 1985; Martin et al., 2002; Potter \& Klein-Rothschild, 2002). Goerge (1990) reported that children in rural areas experienced decreasing probabilities of reunification while children in urban settings experienced more constant probability of reunification. 
Children who spend long periods of time in care may require additional resources beyond those needed by other children. Unfortunately, the average stipend provided to foster parents is approximately half the average cost of raising a child who has no special needs. In 2001, the United States Department of Agriculture estimated the average cost of raising a nine-year-old child, minus health care cost, at $\$ 8,470$ per year. Nationally, the average amount provided to foster parents to meet the needs of a nine-year-old, was $\$ 4,848$ per year (Lino, 2002). Kentucky is one of the few states to enact legislation to provide foster care payments consistent with USDA stańdards (Kentucky Revised Statutes, $605.120(3)$.

\section{Type of Foster Placement}

Children in foster care may reside in one of several different types of placements including foster care, group homes, relative or kinship placements, facility placements and detention or hospital settings. Of these, kinship and group home placements have been found to be negatively associated with permanency (Benedict \& White, 1991; Berrick et al., 1997; Courtney \& Wong, 1996). Children in group care may have a lowered hazard of timely permanency because of behavior problems that led to their placement in such settings. These behavior problems may make it more difficult for parents or parental surrogates to care for children who experience group care, and less likely for potential parents to adopt them (Courtney \& Wong, 1996).

Children in foster care are expected to be placed in the least restrictive placement available, that meets the child's needs. Relative placements, even 
though associated with longer foster care stays, are the preferred placements for children in foster care, along with family foster care. These placements are consistent with child welfare values and CFSR standards that promote attachment and connections to community, extended family and significant others involved with the child. These types of placements may provide timely permanency for children who exit to repnification or adoption. Under ASFA, relative placements are held to the same standards for permanency as foster care placements. Relatives are expected to assume permanent custody of the children in their care within one year if the child cannot return home.

Potter and Klein-Rothschild (2002) found that children whose first placement was foster care were more likely to achieve timely permanency. Placements in any setting other than a foster care home, including relative, group home or other more restrictive placements, has been associated with lowered hazard of both return to parent and adoption (Courtney \& Wong, 1996). Due to the expectations for more community-like settings for children, the number of children in community type placements is increasing. Child welfare may be considered as having its own de-institutionalization similar to the adult deinstitutional movement of the 1950s and 1960s. Specialized foster care agencies now exist instead of institutions to provide services to children who have a greater number of behavior problems than children previously placed in community settings. Research completed in California reported that children who were placed in specialized foster care agencies had lengths of stay that were twice as long as children in conventional foster care (Webster et al., 1998). 
These findings suggest that more information is needed to determine the relationship between type of placement and permanency.

\section{Court System}

For children in the state's custody, courts are the focal point for achieving placement in safe, nurturing, permanent homes. The timely movement of children out of foster care and into safe permanent family relationships has become the overriding principle for a court's entire child welfare caseload. ASFA addressed the role of the court by requiring judicial permanency hearings at designated points. Timetables for permanency héarings are governed by federal and state statutes. A case may move to a permanency hearing as soon as 30 days after adjudication, or as late as 14 months after the child's removal. Other court hearings related to permanency include termination of parental rights hearings, post-permanency hearing reviews, adoptions, and other hearings to formalize case closure.

Over the last 10 years, a number of efforts have been made to improve the court's role in obtaining permanency for children. Previously, court barriers were related to a lack of continuity in court processes, i.e., delays in court hearings, fragmentation of court cases because more than one judge and/or Guardian Ad Litems were involved, and lack of collaboration between the court and key players who have provided services to the family and child. Martin et al. (2002) found that numerous court continuances were the norm for most cases.

Festinger and Pratt (2002) found that (a) court continuances, (b) not having location options to finalize adoptions, (c) not remaining with the same judge or 
county and (d) lack of continuity after termination of parental rights all contributed to longer lengths of stay in foster care. Other studies have found that cases with less time between petition filing and adjudication, and between adjudication and the order for the treatment plan were more likely to achieve timely permanence (Potter \& Klein-Rothschild, 2002), and that lack of legal advocacy for parents, crowded court calendars, and the lack ; of adequate services to parents contributed to longer lengths of stay (Bryce \& Ehlert, 1971).

Four CFSR systemic indicators are used to monitor court related barriers to permanency: standards for a six-mionth periodic review, timeliness of permanency reviews, termination of parental rights process, and collaboration with caregivers in the court process. Forty two states met requirements for periodic case reviews, 26 met requirements for timely permanency hearings, 22 met standards for their termination process, and 26 were found in compliance with standards regarding collaboration with caregivers in the court process (USDHHS, 2003c). Of these four indicators, Kentucky received a rating of substantial conformity in six month periodic reviews only (USDHHS, 2003e). A lack of consistency was noted regarding compliance in the other three indicators.

Lengthy termination of parental rights appeals were found ( 9 states) to contribute to delays in permanency for children (USDHHS, 2003d). States who received ratings of substantial conformity on outcomes related to these factors also had higher ratings on (a) adoption, (b) proximity of placements, (c) preserving connections, (d) meeting the needs and services of children, parents 
and foster parent, (e) child/family involvement in case planning, and (f) worker visits with parents (USDHHS, 2003c).

\section{Legal Status of Children}

The Adoption and Safe Families Act (1997) proposes that as the number of children who are legally freed for adoption increases, so will the number of adoptions. Obviously, without termination of parental rights, adoption cannot occur, but what effect, if any, does termination of parental rights have on a child's chances of permanency? Avery (1999) suggested that delays in permanency were not related to delays in termination of parental rights but more likely occurred in the post termination period. Currently, nearly 1 in 10 children in care are without legal ties to a permanent family and very often remain in this interim state for relatively long periods (Craig \& Herbert, 1997; Sheldon, 1997). Craig and Herbert (1997) estimated that as many as 50,000 legally free children were in foster care. Guggenheim (1995) coined the phrase legal orphans to describe legally free children who experience long waits between termination and the legal permanency. The available evidence suggests that legally free children spend long periods in care even after termination. Tatara (1993) reported that $46 \%$ of the legally free children in their sample had been waiting two years or longer to be adopted. Each year a significant number of legally free children age out of foster care without having acquired permanent family connections (Craig \& Herbert, 1997; Guggenheim, 1995).

During CFSR reviews, concerns were noted in 10 states regarding a lack of efforts to free children for adoption (USDHHS, 2003d). In these states, 
reviewers found that reunification goals were maintained too long, and that agencies were not filing for termination of parental rights in a timely manner, or documenting reasons for not filing (6 states) (USDHHS, 2003d). There were also concerns that adoption was not adequately considered before a decision was made for long term foster care (11 states) (USDHHS, 2003d).

\section{Service Array}

CFSR expects each state to maintain a service array (available community services) that meets the needs of the children and families. To do this, states must perform needs asséssments with its stakeholders and staff, and states are held accountable for their development of a service array compatible with the needs of its children and families regardless of who provides the service or the funding. Service availability is considered important because the provision of intensive, time limited services has been found to match or increase reunification rates, and to decrease length of time in care, sometimes up to onethird (Boyd, 1979) compared to traditional child welfare services (Gibson et al., 1984; Jones et al., 1976; Lahti, 1982). In a large study of intensive services conducted in Illinois, Rzepnicki et al. (1997) found that type and amount of services provided to families increased the rate of successful reunification. Child welfare social workers are expected to work in collaboration with educational, mental and physical health, domestic violence and substance abuse providers to assess and provide services that match the needs of child welfare clients.

Martin, Barbee, Antle, and Sar (2002) reported that high risk foster care cases often linger due to systemic barriers related to assessment, case plans, 
service coordination, court process and role confusion. In some instances, services were not provided in a timely manner for the main issues that led to the removal of the child. Service providers were not clear about their roles or expected work products in the court process (Martin et al., 2002). Glisson and his colleagues posited that the strongest predictor of children lingering in care was the failure to adequately assess and respond to the complex needs of high risk families (Festinger, 1996; Glisson, 1994, 1996; Glisson, Bailey, \& Post, 2000; Martin, Peters, \& Glisson, 1998; Nugent \& Glisson, 1999).

CFSR encourages the development of community services through indicators relevant to provisions for quality services for those served by the child welfare system. Three indicators exist regarding states' service array: array of services, accessibility of services, and ability to individualize services. States are considered to be in compliance with this indicator if the state has in place an array of services that (a) assess the strengths and needs of children and families and determine other service needs, (b) address the needs of families in addition to individual children to create a safe home environment, (c) enable children to remain safely with their parents when reasonable, and (d) help children in foster and adoptive placements achieve permanency. These services must be accessible to families and children in all political jurisdictions and individualized to meet the unique needs of children and families served by the agency. Twenty three states received strength rating for service array, 25 received strength rating for availability of service, 9 received strength rating for accessibility to services and 30 received strength rating for their ability to individualize services 
(USDHHS, 2003c). Kentucky was not found to be in compliance with this indicator. A rating of area in need of improvement was given in both the service array and accessibility to services indicators.

CFSR reviewers noted that although Kentucky has a broad array of services that assess the strengths and needs of children and families, the Statewide Assessment and the on-site, review showed gaps in services, in addition to concerns regarding service accessibility in some areas of the state. Agency staff and community partners contacted during the statewide assessment identified gaps in mental health, doméstic violence, sexual offender, substance abuse, respite care services, transportation to access services, medical care, counseling services for indigent adults, child care services for parents who work evening and night shifts, and lastly, services for children 12 and older. Several stakeholders who were interviewed reported that although numerous providers for these services existed, barriers such as waiting lists prevented services from being accessed. Accessibility gaps were found particularly in rural areas due to limited resources and lack of transportation. One stakeholder who was interviewed commented that services were "a mile wide and an inch deep" (USDHHS, 2003e).

\section{Summary of Macro Variables}

Placements other than a foster care home have been shown to increase a child's length of time in care and some studies have reported that relative placements and institutions produce the longest stays in care for children. 
Children who live in more rural regions are reported to spend more time in care, which may be due to lack of resources available in these areas.

Location and type of placement may relate directly to another macro variable - the amount of money spent on the child during their time in care. Prior to development of electronic data collection tools such as SACWIST, AFCARS and state electronic child welfare data systems, macro variables including the amount spent on child's length of time in care may not have been accessible for study. Kentucky's TWIST data collection system is now able to capture macrorelated variables including payments for foster children's placements and services and court data. These improvements increase states' and researchers' abilities to assess the impact of macro variables on duration of foster care.

Kentucky continues to struggle with its service array. Gaps in services and lack of collaboration among service providers were found to exist during Kentucky's recent CFSR review. The legal status of children is another variable that needs more extensive study. Some have reported concerns regarding the number of legal orphans in the child welfare system. CFSR is requiring more children to have their legal ties to biological parents permanently severed. Some of these children will never again have a legal family.

\section{Conclusions}

Children who spend long periods of time in foster care have historically been influenced by multiple variables. Laws, such as ASFA are now relying on family, child, social worker, and macro variables to predict permanency for children in foster care. Compliance with indicators associated with these 
variables determines federal child welfare funding to states. Children and Family Service Reviews held between 2001 and 2004 have demonstrated that states are struggling with these variables and with obtaining the outcomes purposed to be products of them. CFSR findings that past variables which were seen as highly correlated with permanency (visitation, ethnicity, age of child and permanency goal) are now having littlę or no effect on permanency have raised new questions regarding predictor variables. Many children are still spending lengthy periods of time in care. Thousands of these children exit the child welfare system each year without having obtained permanency. Additional research is needed to determine what relationships exist between family, child, social worker and macro predictor variables and obtaining permanency for children. Why do Legacy Children still exist? What are the consequences of laws such as ASFA to Legacy Children? And can there be a common definition of permanency applied to the needs of all children in foster care? 


\section{CHAPTER 3 \\ METHODOLOGY}

This chapter will provide the research procedures, i.e., participants, research design, data collection, and data analysis. As discussed in the previous chapter, many variables affect length of time in care. Therefore, the overarching research question was proposed: What are the predictors of children in foster care placements becoming Legacy Children?

\section{Participants}

Participants were children who entered foster care in Kentucky for the first time on or since January 1, 1999. The sample was divided into two groups in terms of permanency achievement. The first group consisted of all current foster children who have spent 48 or more consecutive months in foster care, and have not reached the age of 18 (Legacy Group, $n=125$ ). A second group consisted of randomly selected children who have spent less than 24 months in foster care, did not reach the age of 18 while in care, and exited to adoption, reunification, or permanent relative placement (Permanency Group, $n=150$ ).

Social workers assigned to these foster children were included to examine social worker influence on duration of care $(n=100)$. Additionally, a random sample of 20 Legacy Group children was selected for qualitative interviews 
to obtain more insight into these children's perspectives of permanency.

\section{Research Designs}

Two research designs were used to include quantitative and qualitative measures. The first, a post-test only, static group comparison design, was selected to learn if myriad factors predict whether children will fall into the Legacy vs. Permanency groups. To control for, maturation, mortality and other internal validity concerns, comparisons were also made by yearly entry and exit cohort groups for the years 1999 through 2003.

The second design was an eth́nographic study a randomly sample of 20 children from the Legacy Children group. The project director conducted ethnographic interviews with these children at their placement sites. Ethical concerns involving informed consent, confidentiality and work with minors were addressed through Internal Review Board procedures involving both university and cabinet committees. Child Assent (Appendix A) and Guardian Consent Forms (Appendix B) were developed for the 20 children who were interviewed. Informed consents for social workers involved in the study were also developed (Appendix C)

\section{Variables Operationalized}

Table 7 operationalizes the independent variables under study. The primary dependent variable was group--whether children fall into the Permanency or Legacy Groups, as previously defined. Children who were over 18 were excluded from this study for several reasons (a) states are not required to meet CFSR standards for these children, (b) children over 18 are allowed to 
remain in the care of the state for educational purposes on a voluntary basis and (c) children volunteering to remain in care may affect sampling through a possibly biased positive view of foster care.

\section{Table 7}

\section{Variables Operationalized}

\begin{tabular}{|c|c|c|c|}
\hline $\begin{array}{l}\text { Variable } \\
\text { Subgroup }\end{array}$ & Predictor Variable & Typę of Data & Operationalization \\
\hline Family & $\begin{array}{l}\text { Number of } \\
\text { parent/child visits }\end{array}$ & Ratio Data & $\begin{array}{l}\text { Number of monthly face to face visits } \\
\text { between parent(s) and the child } \\
\text { documented in case file. }\end{array}$ \\
\hline Family & $\begin{array}{l}\text { Parent's attendance } \\
\text { at case planning } \\
\text { conference(s) }\end{array}$ & Ratio Data & $\begin{array}{l}\text { Number of case planning conference } \\
\text { attended by the parent documented in } \\
\text { case file }\end{array}$ \\
\hline Family & $\begin{array}{l}\text { Parent's signature on } \\
\text { case plan }\end{array}$ & Ratio Data & $\begin{array}{l}\text { Number of case plans where parent's } \\
\text { signature is observable on signature } \\
\text { page of DCBS case plan }\end{array}$ \\
\hline Family & $\begin{array}{l}\text { Family Support } \\
\text { Rating }\end{array}$ & $\begin{array}{l}\text { Ordinal data } \\
\text { ( } 0 \text { to } 4 \text { rating) }\end{array}$ & $\begin{array}{l}\text { CQA rating given at time of entry into } \\
\text { care and most current to describe } \\
\text { family level of support from } \\
\text { community and other resources }\end{array}$ \\
\hline Family & $\begin{array}{l}\text { Individual Adult } \\
\text { Patterns of Behavior } \\
\text { Rating }\end{array}$ & $\begin{array}{l}\text { Ordinal Data } \\
\text { ( } 0 \text { to } 4 \text { rating) }\end{array}$ & $\begin{array}{l}\text { CQA rating assigned by social worker } \\
\text { both at time of entry and most current } \\
\text { rating to describe adult's high-risk } \\
\text { behavior. }\end{array}$ \\
\hline Family & Title IV-E eligibility & $\begin{array}{l}\text { Ordinal data } \\
(0-\text { not eligible, } \\
1 \text { eligible })\end{array}$ & $\begin{array}{l}\text { Child's IV-E determination } \\
\text { documented on MO43 ASFA } \\
\text { Requirements, Twist Management } \\
\text { Report }\end{array}$ \\
\hline Family & Risk Factors & Ordinal Data & $\begin{array}{l}\text { Risk factors documented on CQA by } \\
\text { social worker at time of removal and } \\
\text { most current }\end{array}$ \\
\hline Family & Recidivism & Ratio data & $\begin{array}{l}\text { Number of documented substantiated } \\
\text { child abuse or neglect referrals in } \\
\text { case file }\end{array}$ \\
\hline Family & $\begin{array}{l}\text { Number of parents in } \\
\text { home }\end{array}$ & Ratio data & $\begin{array}{l}\text { Number of adults documented in } \\
\text { CQA living in the home the child was } \\
\text { removed from at time of removal and } \\
\text { most current }\end{array}$ \\
\hline
\end{tabular}


Table 7 (Continued)

\begin{tabular}{|c|c|c|c|}
\hline $\begin{array}{l}\text { Variable } \\
\text { Subgroup }\end{array}$ & Predictor Variable & Type of Data & Operationalization \\
\hline Family & Severity of abuse & $\begin{array}{l}\text { Ordinal data } \\
\text { ( } 0 \text { to } 4 \text { rating) }\end{array}$ & $\begin{array}{l}\text { CQA maltreatment rating documented } \\
\text { by social worker at time of child's } \\
\text { entry into care }\end{array}$ \\
\hline Child & Child's age & Ratio data & $\begin{array}{l}\text { Calculated from child's date of birth } \\
\text { on W029 Children in Placement } \\
\text { TWIST Management Report }\end{array}$ \\
\hline Child & $\begin{array}{l}\text { Child's race } \\
\text { Caucasian } \\
\text { African American } \\
\text { Hispanic } \\
\text { Native } \\
\text { American/Alaskan } \\
\text { Eskimo } \\
\text { Other }\end{array}$ & Nominal data & $\begin{array}{l}\text { Child's race documented on W029 } \\
\text { Children in Placement TWIST } \\
\text { Management Report }\end{array}$ \\
\hline Child & $\begin{array}{l}\text { Children's Behavior } \\
\text { Checklist Level }\end{array}$ & $\begin{array}{l}\text { Ordinal data } \\
\text { (1 to } 5 \text { rating) }\end{array}$ & $\begin{array}{l}\text { Child's CBCL level documented on } \\
\text { Children's Review Program monthly } \\
\text { report }\end{array}$ \\
\hline Child & Well Being Rating & $\begin{array}{l}\text { Nominal } \\
\text { and Interval }\end{array}$ & $\begin{array}{l}\text { Caregiver's responses to questions } \\
\text { related to child's well being completed } \\
\text { during foster care census }\end{array}$ \\
\hline Child & $\begin{array}{l}\text { Type of abuse child } \\
\text { suffered } \\
\text { Sexual abuse } \\
\text { Physical abuse } \\
\text { Neglect } \\
\text { Dependency }\end{array}$ & $\begin{array}{l}\text { Ordinal } \\
\text { Dichotomous } \\
\text { data }\end{array}$ & $\begin{array}{l}\text { Type of all substantiated child } \\
\text { protection referrals documented by } \\
\text { social worker in TWIST }\end{array}$ \\
\hline Child & $\begin{array}{l}\text { Child's level of } \\
\text { attachment }\end{array}$ & Ratio data & $\begin{array}{l}\text { Social worker responses to } \\
\text { behavioral indicators on Child } \\
\text { Behavior Checklist which make up } \\
\text { External and Internal Behavioral } \\
\text { Score. }\end{array}$ \\
\hline Child & $\begin{array}{l}\text { Child/Youth } \\
\text { Development }\end{array}$ & $\begin{array}{l}\text { Ordinal rating } \\
\text { ( } 0 \text { to } 4 \text { rating) }\end{array}$ & $\begin{array}{l}\text { Child/Youth Development CQA rating } \\
\text { documented by social worker at time } \\
\text { of removal and currently }\end{array}$ \\
\hline $\begin{array}{l}\text { Social } \\
\text { Worker }\end{array}$ & Number of moves & Ratio Data & $\begin{array}{l}\text { Number of placements documented } \\
\text { on child's placement log in TWIST } \\
\text { placement system }\end{array}$ \\
\hline
\end{tabular}


Table 7 (Continued)

\begin{tabular}{|c|c|c|c|c|}
\hline $\begin{array}{l}\text { Variable } \\
\text { Subgroup }\end{array}$ & Predictor Variable & Type of Data & \multicolumn{2}{|c|}{ Operationalization } \\
\hline $\begin{array}{l}\text { Social } \\
\text { Worker }\end{array}$ & $\begin{array}{l}\text { Regularity of case } \\
\text { planning }\end{array}$ & Ratio data & \multicolumn{2}{|c|}{$\begin{array}{l}\text { Number of days between case } \\
\text { planning conferences }\end{array}$} \\
\hline \multirow[t]{2}{*}{$\begin{array}{l}\text { Social } \\
\text { Worker }\end{array}$} & Permanency Goal & Nominal data & \multicolumn{2}{|c|}{$\begin{array}{l}\text { Documented permanency goal on } \\
\text { child's most recent Child/Youth Action } \\
\text { Plan portion of case plan }\end{array}$} \\
\hline & & * & $\begin{array}{l}\text { 1. Return to } \\
\text { parent } \\
\text { 2. Adoption } \\
\text { 3. Permanent } \\
\text { Relative } \\
\text { Placement }\end{array}$ & $\begin{array}{l}\text { 4. Emancipation } \\
\text { 5. Planned } \\
\text { Permanent Living } \\
\text { Arrangement }\end{array}$ \\
\hline $\begin{array}{l}\text { Social } \\
\text { Worker }\end{array}$ & $\begin{array}{l}\text { Worker's attitude } \\
\text { toward attachment }\end{array}$ & Ordinal Data & \multicolumn{2}{|c|}{$\begin{array}{l}\text { Social Worker's response on Macro } \\
\text { related survey }\end{array}$} \\
\hline $\begin{array}{l}\text { Social } \\
\text { Worker }\end{array}$ & $\begin{array}{l}\text { Most Recent } \\
\text { Worker's Degree }\end{array}$ & Ordinal Data & \multicolumn{2}{|c|}{$\begin{array}{l}\text { Most recent Social Worker's degree } \\
\text { documented as part of worker's title in } \\
\text { TWIST. } 0 \text { - Non COA degree } \\
1 \text { - COA degree }\end{array}$} \\
\hline $\begin{array}{l}\text { Social } \\
\text { Worker }\end{array}$ & $\begin{array}{l}\text { Most recent social } \\
\text { worker's experience } \\
\text { level }\end{array}$ & Ratio data & \multicolumn{2}{|c|}{$\begin{array}{l}\text { Number of months most recent social } \\
\text { worker has been employed as a } \\
\text { Kentucky public child welfare social } \\
\text { worker }\end{array}$} \\
\hline $\begin{array}{l}\text { Social } \\
\text { Worker }\end{array}$ & $\begin{array}{l}\text { Median Number of } \\
\text { Social Worker/Family } \\
\text { visits }\end{array}$ & Ratio data & \multicolumn{2}{|c|}{$\begin{array}{l}\text { Number of monthly face to face in } \\
\text { home social worker visits with family } \\
\text { documented in TWIST file }\end{array}$} \\
\hline $\begin{array}{l}\text { Social } \\
\text { Worker }\end{array}$ & $\begin{array}{l}\text { Median number of } \\
\text { social worker/child } \\
\text { visits }\end{array}$ & Ratio data & \multicolumn{2}{|c|}{$\begin{array}{l}\text { Number of monthly face to face social } \\
\text { worker visits with child documented in } \\
\text { TWIST file }\end{array}$} \\
\hline System & $\begin{array}{l}\text { Proximity of } \\
\text { placement }\end{array}$ & Ratio data & \multicolumn{2}{|c|}{$\begin{array}{l}\text { Number of miles between child's } \\
\text { current placement and parent's home }\end{array}$} \\
\hline System & $\begin{array}{l}\text { Placement with } \\
\text { siblings }\end{array}$ & $\begin{array}{l}\text { Ordinal } \\
\text { ( } 0 \text { no, } 1 \text { yes })\end{array}$ & \multicolumn{2}{|c|}{$\begin{array}{l}\text { Child is currently placed with siblings } \\
\text { who are in foster care }\end{array}$} \\
\hline System & $\begin{array}{l}\text { Number of social } \\
\text { workers }\end{array}$ & Ratio data & \multicolumn{2}{|c|}{$\begin{array}{l}\text { Number of DCBS social workers } \\
\text { documented in TWIST who have had } \\
\text { case manager responsibilities since } \\
\text { child's removal }\end{array}$} \\
\hline
\end{tabular}


Table 7 (Continued)

\begin{tabular}{|c|c|c|c|}
\hline $\begin{array}{l}\text { Variable } \\
\text { Subqroup }\end{array}$ & Predictor Variable & Type of Data & Operationalization \\
\hline System & Degree of supervisor & Ordinal data & $\begin{array}{l}\text { Degree of supervisor documented in } \\
\text { TWIST. } 0-\text { Non social work degree } \\
1-\text { BSW } 2-\text { MSW }\end{array}$ \\
\hline System & $\begin{array}{l}\text { Amount spent on } \\
\text { child's placement } \\
\text { since time of removal }\end{array}$ & Ratio data & $\begin{array}{l}\text { Total amount paid for child's care } \\
\text { since entering foster care } \\
\text { documented on TWIST data report. }\end{array}$ \\
\hline \multirow[t]{2}{*}{ System } & \multirow[t]{2}{*}{$\begin{array}{l}\text { Type of foster care } \\
\text { placement }\end{array}$} & Ordinal data & $\begin{array}{l}\text { Current placement Type documented } \\
\text { on W029 Children in Placement } \\
\text { TWIST Management Report }\end{array}$ \\
\hline & & - & $\begin{array}{l}\text { 4. Group home } \\
\text { 5. Facility } \\
\text { 6. Detention } \\
\text { 7. Hospital }\end{array}$ \\
\hline System & Type of court system & Nominal data & $\begin{array}{l}\text { Type of court system documented on } \\
\text { court reports found in child's } \\
\text { hardcopy child welfare case file } \\
\text { Family court } \\
\text { District court/Circuit court }\end{array}$ \\
\hline System & $\begin{array}{l}\text { Length of time until } \\
\text { termination of } \\
\text { parental rights }\end{array}$ & Ratio data & $\begin{array}{l}\text { Number of months from time child } \\
\text { enters foster care until the time } \\
\text { documented in the hardcopy case file } \\
\text { as the date of termination of parental } \\
\text { rights }\end{array}$ \\
\hline
\end{tabular}

\section{Procedure for Data Collection}

Data were collected from electronic child welfare case files, hardcopy case records, surveys of DCBS social workers and interviews with Legacy Group children. Data from Kentucky's electronic child welfare data system, The Worker's Information System (TWIST) were acquired through an electronic data report created for this project. Data that could not be collected electronically from TWIST, i.e., parents' signature on case plan, were recorded on the Hardcopy Data Sheet (Appendix D) during hardcopy case file reviews. Because of the 
multiple forms and sources of data under study in this project, a data source outline illustrates the origin of each predictor variable (Table 8)

\section{Table 8}

\section{Data Source Outline}

\begin{tabular}{|c|c|}
\hline Predictor Variable & Data Source \\
\hline \multicolumn{2}{|c|}{ Family Variables } \\
\hline Number of Monthly Parent/Child & Electronic and Hardcopy Child Welfare Case \\
\hline Visit & Files \\
\hline Parent's attendance at case & Electronic and Hardcopy Child Welfare Case \\
\hline planning & Files \\
\hline Parent's signature on case plan & Hardcopy Case Files \\
\hline Family S & TWIST Electronic Data Report \\
\hline Individual Adult Rating on CQA & TWIST Electronic Data Report \\
\hline Title IV-E eligibility & $\begin{array}{l}\text { TWIST Management Report MO43. } \\
\text { Secondary data. }\end{array}$ \\
\hline Risk Factors & TWIST Electronic Data Report \\
\hline Recidivism & TWIST Electronic Data Report \\
\hline Number of parents in home & Electronic and Hardcopy Case Files \\
\hline $\mathrm{Se}$ & TWIST Electronic Data Report \\
\hline \multicolumn{2}{|c|}{ Child Variables } \\
\hline Child's age & TWIST Electronic Data Report \\
\hline Child's race & TWIST Electronic Data Report \\
\hline Child's gender & TWIST Electronic Data Report \\
\hline Children Behavior Checklist level & Children's Review Program Report \\
\hline rating & Foster Care Census Data \\
\hline Type of abuse suffered & TWIST Electronic Data Report \\
\hline Child's level of Appendix & Children's Review Program Secondary Data \\
\hline $\begin{array}{l}\text { Child Development Rating on } \\
\text { CQA }\end{array}$ & Electronic Data Report \\
\hline \multicolumn{2}{|c|}{ Social Worker Variables } \\
\hline Number of moves & $\begin{array}{l}\text { TWIST Electronic Data Report and } \\
\text { Hardcopy Child Welfare Case Files }\end{array}$ \\
\hline $\begin{array}{l}\text { Regularity of case planning } \\
\text { conferences }\end{array}$ & $\begin{array}{l}\text { Electronic and Hardcopy Child Welfare Case } \\
\text { Files }\end{array}$ \\
\hline Permanency goal of child & TWIST Electronic Data Report \\
\hline Worker's attitude towards & Social Worker Empathy and Appendix? \\
\hline Appe & $\begin{array}{l}\text { Survey Section of Macro Variable related } \\
\text { Survey }\end{array}$ \\
\hline $\begin{array}{l}\text { Most recent social worker's } \\
\text { degree }\end{array}$ & TWIST Electronic Data Report \\
\hline $\begin{array}{l}\text { Number of years of experience of } \\
\text { most recent social worker }\end{array}$ & $\begin{array}{l}\text { Social Worker Empathy and Appendix? } \\
\text { Survey Section related to Macro Variables }\end{array}$ \\
\hline
\end{tabular}


Table 8 (Continued)

\begin{tabular}{|c|c|}
\hline $\begin{array}{l}\text { Predictor Variable } \\
\text { Number of monthly social } \\
\text { worker/parent visits } \\
\text { Number of monthly social } \\
\text { worker/child visits }\end{array}$ & $\begin{array}{l}\text { Data Source } \\
\text { Electronic and Hardcopy Child Welfare Case } \\
\text { Files } \\
\text { Electronic and Hardcopy Child Welfare Case } \\
\text { Files }\end{array}$ \\
\hline \multicolumn{2}{|c|}{ System Variables } \\
\hline $\begin{array}{l}\text { Proximity of child's placement } \\
\text { Placement with siblings } \\
\text { Number of social workers } \\
\text { Degree of supervisor } \\
\text { Amount spent on child's } \\
\text { placement }\end{array}$ & $\begin{array}{l}\text { TWIST Electronic Data Report } \\
\text { TWIST Electronic Data Report } \\
\text { TWIST Electronic Data Report } \\
\text { TWIST Electronic Data Report } \\
\text { TWIST Electronic Data Report }\end{array}$ \\
\hline $\begin{array}{l}\text { Type of foster home placement } \\
\text { Type of court system } \\
\text { Length of time until termination of } \\
\text { parental rights }\end{array}$ & $\begin{array}{l}\text { TWIST Electronic Data Report } \\
\text { Hardcopy Child Welfare Case File } \\
\text { Hardcopy Child Welfare Case File }\end{array}$ \\
\hline
\end{tabular}

Qualitative data collection occurred through interviews with 20 randomly selected Legacy Children. Qualitative research does not always follow the conventional rules of data collection. This type of research is needed in circumstances where the population being studied may be especially vulnerable or where special problems exist in collecting data, such as through children. Children from 8 to 18 were interviewed because Kentucky's Cabinet for Health and Family Services' policy requires children of these ages participate in case planning. A series of questions were asked of these children to determine their understanding of permanency (Appendix E). A portion of these questions were multiple choice to compare children's answers with data entered into the TWIST system regarding barriers to permanency for the child. Other questions were open-ended and analyzed through content analysis (Singleton \& Straits, 1999). Common themes were identified regarding children's responses related to their 
perceptions of the quality of care received, involvement in case decision making, attachment, permanency, and suggestions for improving service delivery.

\section{Instruments}

\section{Child Behavior Checklist}

The Child Behavior Checklist (CBCL, Auchenbach- 1992) (Appendix F) consists of 118 items describing behayioral and emotional problems as reported by social workers, parents, teachers and/or others working with children (Landy \& Munro, 1998). Researchers have frequently used the CBCL as a tool to determine the extent and effect of externalizing and internalizing behaviors in foster children. Most of the CBCL problem behavior items are grouped into empirically derived subscales of related items (Armsden, Pecora, Payne, \& Szatkiewicz, 2000): Withdrawn, Somatic Complaints, Anxious/Depressed, Social Problems, Thought Problems, Attention Problems, Delinquent Problems, and Aggressive Problems. Another sub-scale, Sex Problems, was derived for children

under 12 . There are three problem behavior summary scores: (a) Internalizing (sum of Withdrawn, Somatic Complaints, and Anxious/Depressed), (b)

Externalizing (sum of Delinquent Behavior and Aggressive Behavior), and (c) Total Problems (sum of all problem behavior items).

CBCL competence items assess the child's involvement in play and work activities, social relationships, and school performance. The CBCL has three competence sub-scales: Activities, Social, and School. As discussed in chapter two, the CBCL is completed by Kentucky child welfare social workers within 90 days of the child entering foster care and at least every six months thereafter as 
long as the child remains in care. CBCL scores are reported to Kentucky's Children's Review Program who track these data for service delivery trends. The $\mathrm{CBCL}$ has been shown to have high levels of reliability. Individual item intra-class correlation (ICC) of greater than .90 were obtained between item scores obtained from mothers filling out the $\mathrm{CBCL}$ at 1-week intervals, mothers and fathers filling out the $\mathrm{CBCL}$ on their clinically-referręd children, and three different interviewers obtaining CBCLs from parents of demographically matched triads of children (Armsden, Pecora, Payne, \& Szatkiewicz, 2000). For this project, CBCL scores were obtained from secondary data reports and/or hardcopy case files.

\section{Survey of Macro Related Influence on Permanency}

This survey is a compilation of various measurement tools used to assess macro contributors to permanency. This survey has previously been utilized with Kentucky child welfare social workers to evaluate the effectiveness of child welfare training through pre and post training testing (Antle, 2003). Five measures were used to evaluate the influence of permanency related training, social worker's attitude toward attachment, social worker personality traits, and macro factors such as supervisor support.

1. The Learning Benefit Inventory (Appendix G), developed and validated by van $\mathrm{Zyl}$ and van $\mathrm{Zyl}(2000)$, was used to assess permanency related training. This measure contains 70 items measured on a five-point Likert scale, ranging from none of the time to all of the time. Internal consistency reliability of the scale has been determined to be satisfactory, with the Cronbach alpha scores of factors or sub-scales 
ranging from 0.75 to 0.89 . Construct validity of the scale has been established in previous studies.

2. The short version of The Big Five Questionnaire (Appendix H) was used to evaluate five social worker personality traits: extraversion, conscientiousness, openness to experience, agreeableness, and neuroticism (Caprara, Barbaranelli, Borgogni, \& Perugini, 1993). This short version contains 40 adjectives, and respondents use five-point Likert scales to rate the degree to which that adjective accurately describes them. The reliability and validity of this scale were established through large-scale studies. The average weighted mean coefficient for the five sub-scales is 0.75 (Viswesvaran \& Oanes, 2000). Construct validity of this scale was supported through high correlations with the similar NEO-PI scale (Barbaranelli, Caprara, Maslach, 1997).

3. Supervisor support of permanency related training were measured using the Supervisor Sub-Scale of the Training Transfer Inventory (Appendix I). (Coetsee, 1998). This sub-scale measures the degree to which supervisors support new learning, such as that needed to change practices related to permanency. This sub-scale contains 14 items. Respondents rate their degree of agreement for each of the 14 items on five-point Likert scales. The internal consistency of this scale has been found to be acceptable, with a Cronbach alpha score of 0.884 
4. The Abridged Version of Fraley, Waller and Brennan's (2000) Experiences in Close Relationships Questionnaire (15 items reduced from 36) (Appendix J) was used to assess social workers' attachment styles. Questions that relate to avoidant and anxious behaviors are included in this instrument. High validity and reliability of this inventory has been found in previous ștudies (Bartholew \& Horowitz, 1990; Fraley, Waller, \& Brennan, 2000; Hazan \& Shaver, 1987).

5. The last section of the macro related survey is The Abridged Version of the Empathy and Distress Measure (Empathy Section only) (Bateson, O'Quin, Fultz, Vanderplas \& Isen, 1983) (Appendix K). This measure asks social workers to evaluate their perceptions of mothers, fathers and children they work with on 15 different personality characteristics. The chronbach alphas for the empathy measure ranges from .79 to .90 (Barbee, 2000; Bateson, O'Quin, Fultz, Vanderplas, \& Isen, 1983; Mikulincer \& Florian, 1999; Mikulincer, Gillath, Halevy, Avihou, Avidan, \& Eshkoli, 2001).

\section{Procedures for Data Analysis}

Predictive analyses were conducted with variables from cohort groups of Legacy Children and the control group, Permanency Children, to identify children most at risk of long term foster care. Data analysis focused on appraisal of the research question of this project to determine which children are benefiting most from ASFA and CFSR requirements through identification of variables associated with duration of foster care. Frequencies and descriptive measures were used to 
become familiar with the data and to identify possible trends. The use of multiple linear regression analysis and path modeling were selected to identify variables from each of the four subgroups which were predictive of long term foster care and to illustrate the strength of each variable's predictive relationship with placement in the Legacy Group.

Multiple linear regression is a statistical technique designed to predict values of a dependent variable with knowledge of the values of one or more independent (or predictor) variables (George \& Mallery, 2003). For this study, the dependent variable was the dichotomous variable Legacy Group (Legacy Group -1 , Permanency Group $=0$ ). Regression analysis allows researchers to quantify the relationship between independent variables and Legacy Group through regression or Beta weights assigned to each independent variable. Path modeling (Schumacker \& Lomax, 1996) was used in this project to diagram the independent variables influence on placement in the Legacy Group and to demonstrate relationships with other variables which are indirect predictors of Legacy Group.

To contain our data collection and perform statistical analysis, a data file was created with the Statistical Package for the Social Sciences (SPSS). This data file displays model information, goodness of fit statistics related to project variables and allows for additional analysis of findings. Through SPSS, measures of central tendencies were also performed to identify issues with missing data, randomness of our sample, outliers, scaling issues and collinearity. Findings from the statistical analysis were formatted into text and graphic forms for completion 
of this dissertation as well as presentation to child welfare staff for consideration of service delivery trends.

The next chapter will present results from the completed statistical analyses. Finally, the last chapter will summarize findings and discuss implications for social work practice, policy and research for the Kentucky DCBS and the field of social work in general., 


\section{CHAPTER 4}

\section{RESULTS}

Results are presented in two șections. The first reports findings related to the comparison of children who have experienced long term foster care (Legacy Group) with those children who exited care within 24 months (Permanency Group). Findings specific to child, family, social worker and macro variables and their effects on permanency for foster children are discussed in detail. The second section reports the results of ethnographic interviews with 20 current foster children who have lived in foster care for at least 48 continuous months.

\section{Static Group Comparison Design}

The total sample size for the static group comparison design was 275 children. The sample included Kentucky's entire population of previously defined Legacy Group (125 children) and 150 Permanency Group members selected through a stratified random sample. The stratified random sample was utilized due to the low number of the Permanency Group who had exited to adoption in the initial random sample. A large number of the Legacy Group had adoption as a permanency goal. In order to ensure the groups were as similar as possible, 
the initial random sample of Permanency Group was modified to include children who exited to a goal of adoption. The Permanency Group was also stratified to account for children who left foster care at different times during the period under study. Thirty children per year for the years 1999 through 2003 were included in the stratified random sample.

\section{Data Analysis}

Goals of data analysis included identifying (a) differences in the Legacy and Permanency Groups and (b) which variables either directly or indirectly predicted placement in the Legacy Group. To accomplish these goals, data analysis began by performing descriptive and frequency statistical analyses with SPSS.

Independent Samples T test and Chi-Square analysis were conducted with each of the independent variables to identify statistically significant differences in the Legacy and Permanency Groups. Bonferroni test were conducted to ensure results did not change. Due to the large number of variables contained in this project, a number of statistical procedures were then performed to build the best model for predicting Legacy Group membership by ensuring inclusion of significant direct and indirect predictive variables. A correlation matrix was completed to discover correlations and intercorrelations among all variables (Appendix L).

Four Multiple Linear Regression models were calculated, one for each of the four variable subgroups, to determine the relationship between predictor subgroup variables and the dependent variable Legacy Group. Variables which did not produce significant coefficient $t$ scores within the .000 to .050 significance 
levels were then excluded from each subgroup model. To determine the best overall model for predicting placement in the Legacy Group, significant predictors from each of the four subgroups were included in an integrated regression model. Variables in this final model whose coefficient $t$ scores fell within the .000 to .050 significant levels were identified as direct predictors of Legacy Group. Regression analyses were then completed with each of the direct predictors as dependent variables to determine their relationship with other variables that indirectly predicted Legacy Group. Path modeling has been utilized to illustrate the relationship of these variables with Legằcy Group membership.

Following are findings for each of the four subgroups and the integrated model. Information regarding the completed statistical analysis is followed by more specific detail of findings related to each individual independent variable. Findings pertaining to both significant and non-significant predictors from each subgroup are provided. Predictor variables will be presented first, followed by variables that were significantly different between the groups and then variables which were not significantly different or predictive of Legacy Group. It is important to review findings from all variables to be able to fully understand the successes and failures of ASFA.

\section{Family Variable Findings}

Table 9 includes descriptive statistics related to all family variables. Findings from the independent samples $t$ test and chi square analyses and their significance levels are also included in this table. 
The Legacy and Permanency Groups were found to be statistically different in five areas of family variables (a) poverty/resources, (b) type and severity of abuse, (c) adult risk indicators, (4) visitation and (5) sibling group.

Table 9

Family Variable Descriptive Statistics

\begin{tabular}{|c|c|c|c|}
\hline Family Variable & Legacy Group & $\begin{array}{c}\text { Permanency } \\
\text { Group }\end{array}$ & $\boldsymbol{p}$ \\
\hline $\begin{array}{l}\text { Mean number of } \\
\text { monthly parent and } \\
\text { child visits }\end{array}$ & $\begin{array}{l}N=125, M=.59 \\
S D=.93\end{array}$ & $\begin{array}{l}N=150, M= \\
2.21 \\
S D=4.87\end{array}$ & $\begin{array}{l}p<.0001 \\
t=3.65\end{array}$ \\
\hline $\begin{array}{l}\text { Mean number of case } \\
\text { plans attended } \\
\text { by parent(s) }\end{array}$ & $\begin{array}{l}N=125 \\
M=.38 \\
S D=.33\end{array}$ & $\begin{array}{l}N=150, M= \\
.34 \\
S D=.33\end{array}$ & $\begin{array}{l}p<n s \\
t=.74\end{array}$ \\
\hline $\begin{array}{l}\text { Mean number of case } \\
\text { plans signed } \\
\text { by parent(s) }\end{array}$ & $\begin{array}{l}N=125, M=.37 \\
S D=.33\end{array}$ & $\begin{array}{l}N=150, M= \\
.34 \\
S D=.42 \\
\end{array}$ & $\begin{array}{l}p<n s \\
t=.66\end{array}$ \\
\hline $\begin{array}{l}\text { Mean number of adult } \\
\text { risk factors identified by } \\
\text { social worker }\end{array}$ & $\begin{array}{l}N=125, M=5.14 \\
S D=5.53\end{array}$ & $\begin{array}{l}N=150, M= \\
3.68, S D= \\
3.66\end{array}$ & $\begin{array}{l}p<.009 \\
t=2.62\end{array}$ \\
\hline Title IV-E eligibility & $\begin{array}{l}n=88 \text { eligible, } \\
(56.8 \%)\end{array}$ & $\begin{array}{l}n=78 \\
\text { eligible, } \\
(40.7 \%)\end{array}$ & $\begin{array}{l}p<.001 \\
X^{2}=9.64\end{array}$ \\
\hline $\begin{array}{l}\text { Mean number of child } \\
\text { abuse referrals }\end{array}$ & $\begin{array}{l}N=125, M=3.42 \\
S D 2.14\end{array}$ & $\begin{array}{l}N=150, M= \\
3.27 \\
S D=3.14\end{array}$ & $\begin{array}{l}p<n s \\
t=.45\end{array}$ \\
\hline Sibling group & $88 \%$ had siblings & $\begin{array}{l}65.3 \% \text { had } \\
\text { siblings }\end{array}$ & $\begin{array}{l}p<.0001 \\
X^{2}= \\
19.01\end{array}$ \\
\hline $\begin{array}{l}\text { Initial severity of abuse } \\
\text { mean rating }\end{array}$ & $\begin{array}{l}N=125, M=2.26 \\
S D=1.63\end{array}$ & $\begin{array}{l}N=150, M \\
=1.51 \\
S D=1.59\end{array}$ & $\begin{array}{l}p<.0001 \\
t=3.84\end{array}$ \\
\hline $\begin{array}{l}\text { Initial family and } \\
\text { community support } \\
\text { mean rating }\end{array}$ & $\begin{array}{l}N=125, M=1.68 \\
S D=1.52\end{array}$ & $\begin{array}{l}N=150, M= \\
.99 \\
S D=1.12\end{array}$ & $\begin{array}{l}p<.0001 \\
t=4.34\end{array}$ \\
\hline $\begin{array}{l}\text { Initial adult patterns of } \\
\text { behavior mean rating }\end{array}$ & $\begin{array}{l}N=125, M=2.77 \\
S D=1.59\end{array}$ & $\begin{array}{l}N=150, M= \\
2.08, S D= \\
1.68\end{array}$ & $\begin{array}{l}p<.001 \\
t=3.46\end{array}$ \\
\hline
\end{tabular}


Table 9 (Continued)

\begin{tabular}{|c|c|c|c|c|c|c|}
\hline \multicolumn{2}{|c|}{ Family Variable } & \multicolumn{2}{|c|}{ Legacy Group } & \multicolumn{2}{|c|}{$\begin{array}{c}\text { Permanency } \\
\text { Group }\end{array}$} & $P$ \\
\hline \multicolumn{2}{|c|}{$\begin{array}{l}\text { Mean number of } \\
\text { parents in the home at } \\
\text { Time of removal }\end{array}$} & \multicolumn{2}{|c|}{$\begin{array}{l}N=125, M=1.22 \\
S D=.62\end{array}$} & \multicolumn{2}{|c|}{$\begin{array}{l}N=150, M= \\
1.21 \\
S D=.61\end{array}$} & $\begin{array}{l}p<n s \\
t=.14\end{array}$ \\
\hline \multicolumn{7}{|c|}{ Type of Abuse } \\
\hline \multicolumn{2}{|c|}{ Legacy Children } & \multicolumn{2}{|c|}{$\begin{array}{c}\text { Permanency } \\
\text { Children }\end{array}$} & $x^{2}$ & df & $p$ \\
\hline $\begin{array}{l}\text { Sexual } \\
\text { Physical } \\
\text { Neglect } \\
\text { Dependency } \\
\text { Emotional }\end{array}$ & \begin{tabular}{r|}
$18.4 \%$ \\
$38.4 \%$ \\
$48.8 \%$ \\
$17.2 \%$ \\
$7.2 \%$
\end{tabular} & $\begin{array}{l}\text { Sexual } \\
\text { Physical } \\
\text { Neglect } \\
\text { Dependency } \\
\text { Emotional }\end{array}$ & $\begin{array}{c}11.3 \% \\
41.3 \% \\
73.3 \% \\
22.0 \% \\
9.3 \% \\
\end{array}$ & $\begin{array}{c}x^{2}= \\
6.03 \\
x^{2}= \\
2.36 \\
x^{2}= \\
6.78 \\
x^{2}= \\
1.28 \\
x^{2}= \\
0.40\end{array}$ & $\begin{array}{l}d f 1 \\
d f 1 \\
d f 1 \\
d f 1 \\
d f 1\end{array}$ & $\begin{array}{l}p<.014 \\
p<n s \\
p<.007 \\
p<n s \\
p<n s\end{array}$ \\
\hline
\end{tabular}

With 1 being Legacy Group and 0 being Permanency Group, a Pearson Correlation Coefficient was calculated for the relationship between the family variables and placement in the Legacy Group (Table 10). Seven family variables were found to have strong positive correlations $(p<.000$ to .050$)$ with being in the Legacy Group. In order of significance these included: (a) having more than one child in care, (b) higher risk associated to family support rating at time of entry, (c) higher maltreatment rating at time of entry, (d) higher mean number of adult risk factors present, (e) sexual abuse has occurred, (f) higher risk due to adult functioning rating at time of entry and (g) Title IV-E eligibility. Two family variables were found to have a strong negative correlation with Legacy Group:

(a) having a finding of neglect, and (b) number of monthly face to face parent child contacts. 
Table 10

Family Variables and Legacy Group Correlations $(N=275)$

\begin{tabular}{|l|c|c|}
\hline \multicolumn{1}{|c|}{ Family Variable } & Pearson $\boldsymbol{r}$ & $\boldsymbol{p}$ \\
\hline Mean number of monthly parent and child visits & -.21 & .000 \\
\hline Sibling group & .26 & .000 \\
\hline Initial family use of resources mean rating & .25 & .000 \\
\hline Initial severity of abuse mean rating & .22 & .000 \\
\hline Initial adult patterns of behavior mean rating & .20 & .001 \\
\hline Title IV-E eligibility & .18 & .002 \\
\hline $\begin{array}{l}\text { Mean number of adult risk factors identified by social } \\
\text { worker }\end{array}$ & .15 & .009 \\
\hline Type of abuse: Sexual & & \\
$\quad$ Physical & .14 & .014 \\
Emotional & .09 & .134 \\
Deglect & -.03 & .526 \\
$\quad-.15$ & .009 \\
\hline Mean number of case plans attended by parent(s) & -.06 & .258 \\
\hline Mean number of case plans signed by parent(s) & .04 & .457 \\
\hline Mean number of child abuse referrals & .04 & .507 \\
\hline Mean number of parents in the home at time of removal & .02 & .650 \\
\hline
\end{tabular}

(Legacy Group $=1$, Permanency Group = 0; Variables of Title IV-E eligibility, Sibling Group and Type of abuse are all coded as 1 if the variable was present in the case and 0 if the variable was not present)

All family variables were entered into the Family Predictor Regression Model (Model 1) to assess their predictability in determining placement in the Legacy Group. A number of family variables were identified through this analyses that needed to be excluded from the final family model due to their nonsignificant coefficient $t$ scores: maltreatment rating at point of entry $\beta=.05, n s$; number of adult risk factors $\beta=.06, n s ;$ case plans attended by parents $\beta=1.80$, $n s$; case plans signed $\beta=-1.70, n s ;$ Title IV-E eligibility $\beta=.09, n s ;$ number of referrals $\beta=.03, n s ;$ adult functioning rating at time of entry $\beta=.09, n s ;$ number of parents in the home at time of removal $\beta=-.02, n s$; presence of 
physical abuse $\beta=.03, n s$; presence of emotional abuse $\beta=.02$, ns; and presence of dependency $\beta=-.06, n s$.

A significant regression equation was found for the final family model ( $F$ $\left.(5,269)=13.85, p<.0001, R^{2}=.25\right)($ Tables 11 and 12$)$ with five family variables being identified in this model as significant predictors of being in the Legacy Group: (a) lower level of family suppoirt $\beta=.20, p<.0001$, (b) less monthly parent/child face to face visitation $\beta=-.20, p<.0001$, (c) entering care as part of a sibling group $\beta=.24, p<.0001$, (d) presence of sexual abuse $\beta=$ $.12, p=.01$, and (e) presence of neglect $\beta=-16, p<.002$ (Table 13). Of these, entering care as part of a sibling group demonstrated the greatest predictive ability by having the highest Beta weight of .24 . This was also the family variable with the strongest Pearson Correlation Coefficient. In total, the Family Predictor Regression Model accounted for approximately $25.5 \%$ of the variance in the Legacy Group when considering only family variables.

\section{Table 11}

Family Variables and DV Legacy Group Model Summary

\begin{tabular}{|r|r|r|r|r|r|}
\hline Model & $\mathbf{R}$ & $\mathbf{R}$ Square & $\begin{array}{c}\text { Adjusted R } \\
\text { Square }\end{array}$ & $\begin{array}{r}\text { Std. Error of the } \\
\text { Estimate }\end{array}$ & $\begin{array}{r}\text { Durbin } \\
\text { Watson }\end{array}$ \\
\hline 1 & .50 & .25 & .20 & .44 & .47 \\
\hline
\end{tabular}

Table 12

Family Variables and DV Legacy Group ANOVA table

\begin{tabular}{|l|r|r|r|r|r|}
\hline \multicolumn{1}{|c|}{ Model } & $\begin{array}{r}\text { Sum of } \\
\text { Squares }\end{array}$ & df & Mean Squares & F & Sig. \\
\hline Regression & 17.36 & 16 & 1.08 & 5.50 & .000 \\
Residual & 50.82 & 258 & .19 & & \\
Total & 68.18 & 274 & & & \\
\hline
\end{tabular}




\section{Table 13}

Family Variable and DV Legacy Group Coefficients

\begin{tabular}{|c|c|c|c|c|c|c|}
\hline \multirow[t]{2}{*}{ Model } & \multicolumn{2}{|c|}{$\begin{array}{l}\text { Unstandardized } \\
\text { Coefficients }\end{array}$} & \multirow{2}{*}{$\begin{array}{c}\begin{array}{c}\text { Standardized } \\
\text { Coefficients }\end{array} \\
\text { Beta }\end{array}$} & \multirow[t]{2}{*}{$r$} & \multirow[t]{2}{*}{$p$} & \multirow[t]{2}{*}{$\begin{array}{l}\text { Correlations } \\
\text { Zero Order }\end{array}$} \\
\hline & B & $\begin{array}{l}\text { Std. } \\
\text { Error }\end{array}$ & & & & \\
\hline (Constant) & 1.72 & .07 & & 23.27 & .000 & \\
\hline $\begin{array}{l}\text { Sibling } \\
\text { Group }\end{array}$ & .28 & .05 & .243 & 4.45 & .000 & .26 \\
\hline $\begin{array}{l}\text { Family } \\
\text { Support } \\
\text { Rating }\end{array}$ & 7.30 & .02 & .200 & 3.62 & .000 & .25 \\
\hline $\begin{array}{l}\text { Average } \\
\text { monthly } \\
\text { visitation }\end{array}$ & -2.74 & .00 & $=-206$ & -3.73 & .000 & -.21 \\
\hline Neglect & -.17 & .05 & -.169 & -3.08 & .002 & -.15 \\
\hline $\begin{array}{l}\text { Sexual } \\
\text { Abuse }\end{array}$ & .17 & .07 & .129 & 2.37 & .018 & .14 \\
\hline
\end{tabular}

(Legacy Group = 1, Permanency Group = 0; Variables of Sibling Group, neglect and sexual abuse coded as 1 if variable was present in case, 0 if not present)

The Family Predictor Path Model (Figure 2) elucidates the predictive relationship between the dependent variable Legacy Group and the five significant predictor family variables. The most significant direct predictor in this model was child entering care as part of a sibling group $(\beta=.24)$. Other direct predictors are presence of sexual abuse, fewer monthly parent/child face to face visits, no finding of neglect and lower family and community support system rating. The family and community support system rating variable is based on indicators selected by the social worker relating to the level of risk associated with the family's support system. A multiple linear regression was calculated to predict family and community support rating based on the social worker's 
selection of each of the available family support indicators. Two indicators were significant predictors of family support rating: (a) family does not have basic resources/support system to meet basic needs and (b) living arrangements seriously endanger the physical health of children $\left(R^{2}=.175\right)$. Beta weights are included for each of the direct and indirect predictors and indicators associated with these variables.

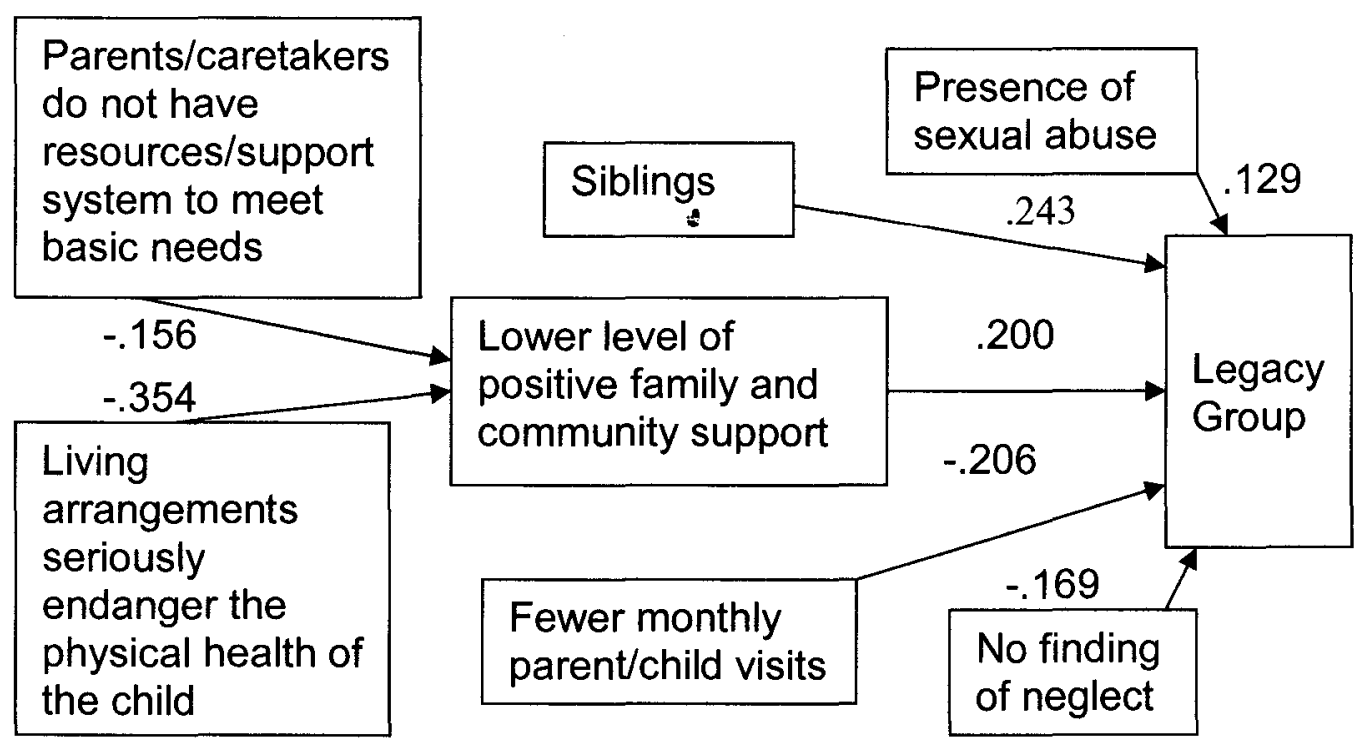

Figure 2 Family Predictor Path Model

Family Variables Predictive of Legacy Group

Further data analyses were conducted with the five family variables that were found to be strong predictors of Legacy Group in the Family Predictor Regression Model in order to identify trends or possible relationships with other variables. Detailed information regarding these variables follows, along with information pertaining to predictors of the one family variable that occurred after the child entered care, parent/child visitation. Another family variable, family and 
community support rating, was based on indicators selected by the social worker. Information regarding these indicators is provided as predictors of that variable.

\section{Legacy Group Predictor: Sibling Group}

When considering only family variables this study found that the most significant predictor of Legacy Group was the child entering foster care as a member of a sibling group. The effects of family size on permanency was assessed for this project by collecting data pertaining to the number of parents in the home at the time of removal and if the child was a part of a sibling group. No significant differences were found in the nuntber of parents who were in the home at time of removal $(M=1.21, S D=.61)$. Both the Legacy and Permanency Groups were removed from predominantly single parent households. Legacy Children were significantly more likely to be a part of a sibling group. Eighty-eight percent of Legacy Children had at least one sibling in foster care compared to $65.3 \%$ of Permanency Children who had at least one sibling in care $\left(x^{2}(d f 1)=\right.$ $19.01, p<.0001)$. Legacy Children were also more likely to be placed apart from their siblings. $48.2 \%$ of the Legacy Group were placed apart from their siblings compared to $30.6 \%$ of the Permanency Group $x^{2}(d f 2)=49.87, p<.000$.

\section{Legacy Group Predictor: Lack of Positive Family and Community Support}

Findings from data collected pertaining to family variables suggest families of Legacy Children are different in the support they receive from their families and within their communities. At point of entry, these families were rated as having fewer positive familial and community supports than families of children who returned home within the Adoption and Safe Families Act's prescribed time 
frames. Having a higher level of risk associated with family and community support system rating was found to be a significant predictor belonging in the Legacy Group. Families of Legacy Children had a mean family support score of 1.68 compared to .99 for Permanency Children's families (SD Legacy Group $=$ 1.52; $S D$ Permanency Group $=1.12, t=4.34, p<.0001)$. A multiple linear regression analysis conducted with the dependent variable of family support ratings and number of parents in the home as a predictor variable was not significant $(\beta=.05, p<.33)$ with an $R^{2}$ of .003. Affects of poverty on permanency were assessed by identifying children who were Title IV-E eligible. Title IV-E eligibility requires the family's income be below the poverty line at point of entry into foster care. $58.6 \%$ of Legacy families were Title-IV-E eligible compared to $40.7 \%$ of Permanency families $x^{2}(d f 1)=9.64, p<.001$.

\section{Predictors of Family and Community Support Rating}

Social workers assigned the family and community support rating based on standardized anchors which include specific indicators related to the family's use of family and/or community supports. Higher ratings are indicative of a higher level of risk. Twenty percent of Legacy families were identified by their social workers as having the indicator: parents do not have resources/support system to meet the basic needs of their children. This was compared to $9.3 \%$ of Permanency families, $\left(x^{2}(d f 1)=6.37, p<.01\right)$. Chi-Square analyses did not find a significant relationship existed between the indicator living arrangements endangers the physical health of the child and placement in the Legacy Group $\left(x^{2}(d f 1)=.54, p=.33\right)$. Regression analyses were calculated to predict family 
support rating based on these indicators. Both of these indicators were found to be significant predictors of the family and community support system rating.

\section{Legacy Group Predictor: Parent/Child Visitation}

This project reviewed visitation at several different points in time. Number of visits during the following time frames were calculated; first 30 days, first 90 days, first 6 months, first year and each year thereafter that the child remained in foster care. Total number of parent/child face to face visits prior to and post termination of parental rights were also obtained. Calculations were completed to determine the average number of monthly face to face contacts, average number of pre termination visits and average number of post termination visits. This data gave a number of insights into parent/child visitation patterns for these two groups of families. For the Legacy Group, visitation with their families gradually decreased after six months compared to visitation between the Permanency Group and their children, which gradually increased throughout the time the child was in foster care. Families of the Legacy Group whose parent's rights had not been terminated experienced 16.40 mean visitations after one year, 9.86 mean visits during the second year, 4.10 mean visits during the third year, 2.80 mean visits during the fourth year and 1.14 mean visits during the fifth year. The Permanency Group experienced 7.30 mean visits with their families after six months, 18.61 mean visits during the first year and 24.5 mean visits during the second year the child was in foster care.

Overall, Legacy Children had a lower mean number of visitations for their entire time in care with .59 mean visits per month compared to 2.21 mean visits 
per month for Permanency Children (SD Legacy Group $=.93 ; S D$ Permanency Group $=4.87, t=-3.65, p<.0001)$. Independent samples t-test were completed through SPSS computations using the expected number of visits for each child minus the actual number of visitations. Expected number of visitations was computed by multiplying the number of months in foster care by two. Two monthly parent/child face to face visits are required per DCBS policy unless restrictions for visitations exist such as the court has ordered no visits. The Legacy Group had a mean difference in their number of expected and number of actual visits of -47.88 compared to -.17 visits for Permanency children ( $S D$ Legacy Group $=56.29 ; S D$ Permanency Group $=36.20, t=-8.48, p<.0001$ ) Number of visitations after termination of parental rights was also collected. Legacy Children whose parental rights were terminated had a higher mean number of post termination parent child visits $(M$ Legacy group $=4.84 ; M$ Permanency Group $=.26 ; t=.80, p<.42$ ).

A number of reasons for limited visitation were documented for both the Legacy and Permanency Group: (a) agency did not allow visits for reasons other than safety, i.e., parents not in compliance with case plan (4.8\%), (b) court ordered no contact $(6.5 \%)$, (c) parental ambivalence (.6\%), (d) parents requested placement/voluntary termination $(9.5 \%)$, (e) parents did not maintain contact with the agency $(35.7 \%)$, (f) parents are incarcerated $(14.9 \%)$, (g) court ordered no contacts due to safety concerns $(2.4 \%)$, (h) distance between parent and child (3\%), (i) parents did not show up for visits (16.1\%), (j) children requested not to 
visit (4.2\%), and (k) parents deceased (.6\%). Overall 162 children had clearly documented reasons for lack of appropriate number of visitations.

Chi-Square analyses were completed to determine the effect that maltreatment indicators and child specific risk indicators, which are discussed in more detail later in this chapter, may have on parent/child visitation. The only maltreatment indicator that had a significant relationship with a lack of appropriate number of parent/visit was the indicator: maltreating adult exhibits no remorse or guilt $\left(x^{2}(d f 1)=8.26, p<.002\right)$. None of the child specific indicators were found to have a relationship with the number of parent/child visitations being appropriate.

\section{Predictors of Parent/Child Visitation}

Regression analysis completed with the dependent variable mean number of monthly parent/child visitation identified four strong predictors of this variable including: (a) monthly social worker/child face to face contacts, (b) child's age at entry, (c) number of days between case plans and (d) finding of neglect. ( $R^{2}=$ $.17, p<.000)$. The strongest predictor of increased monthly face to face parent/child visitation was increased number of social worker/child monthly visits $(\beta=.26, p<.000)$. Children in this study who averaged at least two monthly parent/child visitations had a mean of $1.89 \mathrm{child} / \mathrm{social}$ worker face to face monthly visitations. Children who did not have appropriate monthly parent/child visitations averaged .93 child/social worker monthly visitations $(t=8.42, p<$ $.000)$. The second predictor of increased parent/child visitation was decreased number of days between case plans $(\beta=-.22, p<.000)$. Children with 
appropriate face to face monthly parent/child visitations had a mean of 79.94 days between case plans compared to a mean of 116.28 days between case plans for children who did not have appropriate monthly parent/child visitations ( $t$ $=-3.86, p<.000)$.

A finding of neglect was also a strong predictor of parent/child visitations $(\beta=-.139, p<.01)$. Of the 185 children with a finding of neglect in this study, 142 did not have appropriate number of parent/child monthly visitations. The last predictor of increased parent/child visitations was increased age at entry $(\beta=.12$, $p<.02$ ). Children in the oldest and youngešt groups had the highest mean number of monthly parent/child visitations. Children between the ages of 15 to 18 years at entry into foster care had the highest mean number of parent visitations at $5.66(n=18)$, followed by children 0 to 5 years of age with a mean 1.20 mean parent visitations $(n=106)$.

\section{Legacy Group Predictor: Sexual Abuse and Neglect}

Legacy children in this study had a statistically significant relationship with being sexually abused: $23.2 \%$ of Legacy children compared to $12 \%$ of Permanency children had been sexually abused $x^{2}(d f 1)=6.03, p<.01$. Physical and emotional abuse and dependency were not found to have a relationship with being in the Legacy or Permanency Groups; physical $\left(x^{2}(d f 1)=2.26, p<.08\right)$; emotional $\left(x^{2}(d f 1)=.40, p<.34\right)$; dependency $\left(x^{2}(d f 1)=1.28, p=.16\right)$. Members of the Permanency Group however, were found to have a statistically significant relationship with having been neglected: $59.2 \%$ of the Legacy Group compared to $74 \%$ of permanency children had been neglected $\left(x^{2}(d f 1)=6.783, p=.007\right)$. A 
multiple linear regression was calculated to predict placement in Legacy Group based on occurrence of sexual abuse and neglect. The finding of sexual abuse and no finding of neglect were found to be significant predictors of Legacy Group.

\section{Family Variables That Were Not Predictive of Legacy Group}

Family variables related to extent and severity of abuse or neglect and adult risk factors were not found to be predictors of Legacy Group when considering only family variables. Data analyses did find the Legacy and Permanency Groups differed significantly in a number of these variables. In addition, strong correlations were found befween these variables and the dependent variable Legacy Group. Family variables related to participation in case planning were not predictive of Legacy Group or significantly different between the two groups.

\section{Extent and Severity of Abuse}

Legacy families were found to have perpetrated more severe maltreatment than Permanency families $(M$, Legacy Group $=2.26 ; M$, Permanency Group $=1.51, S D$, Legacy Group $=1.63 ; S D$, Permanency Group $=$ $1.59, t=3.84, p<.0001)$. The maltreatment rating was based on standardized anchors utilized to assess location, type and extent of maltreatment suffered by the child. These anchors included a number of indicators for risk of maltreatment. A multiple linear regression was completed with the dependent variable being the maltreatment rating and maltreatment indicators as predictor variables. With 0 being absence of indicator and 1 being indicator selected by social worker as 
present in case, the following four indicators were identified as significant predictors of maltreatment rating:

1. Maltreating adult was seen as exhibiting no remorse or guilt for the maltreatment $(\beta=.15, p<.01)$,

2. Having a perpetrator who refused to vacate the residence for the protection of others in the home. $(\beta=.17, p<.003)$,

3. Cannot explain injuries or conditions $(\beta=.14, p<.02)$, and

4. Current investigative findings suggest pattern of escalating maltreatment $(\beta=.151, p=.01)$.

Although Legacy families were found to have a higher mean number of child protection referrals than permanency families, they were not identified as often as Permanency families as having recidivism as a risk factor $\left(x^{2}(d f 1)=.01\right.$, $p<n s)$. Legacy families were also not significantly different than Permanency families in relation to adults in the household having criminal charges related to harming a child $\left(x^{2}(d f 1)=.00, p<n s\right)$.

\section{Adult Risk Issues}

Families of the Legacy Group were found to be rated by their social workers as having significantly higher risk in their individual adult patterns of behavioral functioning at point of entry into foster care for their child ( $M$ Legacy Group $=2.77 ; M$ Permanency Group $=2.08, S D$ Legacy Group $=1.59 ; S D$ Permanency Group $=1.68, t=3.46, p<.001$ ). Behavioral indicators of risk were assessed by social workers using standardized anchors. Ten behavioral indicators were available for selection by the social worker. Legacy families were 
found to have a mean number of 5.14 behavioral risk indicators selected by their social workers compared to 3.68 indicators for Permanency families, (SD Legacy Group $=5.53 ; S D$ Permanency Group $=3.66, t=2.62, p<.009)$.

Of particular interest were the effects of domestic violence, mental health, chemical dependency and other factors used by courts and social workers to decide the family's likelihood of positive change. Legacy families were identified slightly less often than Permanency families as having a documented history, or observable indicators of alcohol or drug usage in the family $\left(x^{2}(d f 1)=1.17, p<\right.$ .11), and as having one or both adults' drug'/alcohol use as endangering the well being of their self or other family members $\left(x^{2}(d f 1)=.00, p<n s\right)$. There was also a trend indicating that Legacy families had more domestic violence $\left(x^{2}(d f 1)=\right.$ $2.34, p<.08)$, but no relationship with serial relationships $\left(x^{2}(d f 1)=.01, p<n s\right)$, parents/caretakers being disabled $\left(x^{2}(d f 1)=.002, p<n s\right)$, and/or parents having health related problems $\left(x^{2}(d f 1)=.40, p<n s\right)$. Legacy families were different, however, in the area of mental health issues. While Legacy families did not differ in regard to the number of families with mental illness, they were significantly more likely to have family members who exhibited bizarre behaviors that could pose a risk to the safety of self or others $\left(x^{2}(d f 1)=7.70, p<.005\right)$ and to have behavior that had not changed as a result of mental health intervention $\left(x^{2}(d f 1)=\right.$ $13.88, p<.0001)$

\section{Participation in Case Planning}

Participation in case planning was not a predictor of Legacy Group or significantly different between the Legacy and Permanency Groups. 
Comparisons of case planning participation were also made based on child's permanency goal. When both groups were combined, children with a permanency goal of return to parent had the highest mean for case plan attendance $(M=.44, S D=.42)$, followed by emancipation $(M=.33, S D=.47)$, adoption $(M=.32, S D=.34)$, placement with relatives $(M=.32, S D=.44)$, and planned permanent living arrangement $(M=.29, S D=.32)$. These findings were then assessed separately for each of the two groups. For the Legacy Group having a permanency goal of return to parent produced a higher mean number of case plans attended by parents $(M=.45, S B=.31)$, followed by adoption $(M=$ $.39, S D=.33)$, emancipation $(M=.33, S D=.47)$, planned permanent living arrangement $(M=.29, S D=.32)$ and placement with relatives $(M=.20, S D=$ $.34)$.

The Permanency Group had the highest number of case plans attended if the permanency goal was return to parent $(M=.44, S D=.43)$ followed by placement with relatives $(M=.34, S D=.46)$. Permanency children with a goal of adoption had the lowest average number of case plans attended $(M=.19, S D=$ .34). Number of case plans attended and signed by the parent was also reviewed by year of entry for Permanency children. The Legacy Group was excluded from this analysis due to entering foster care in the years 1999 and 2000 only. Gradual increases were found in parental involvement. Families of children who entered care in 1999 attended a mean of $.36(S D=.35)$ case plans compared to families of children who entered care in 2003 who attended a mean of .39 case plans $(S D=.49)$. 


\section{Summary Findings of Family Variables}

Permanency for children in this project was influenced by a number of family variables. At entry into foster care, the Legacy Group had been more severely abused and had been exposed to parents/caretakers who had mental health problems that had not been successfully treated and/or who were exhibiting bizarre behavior. Members of the Legacy Group came from families with fewer positive familial and community support systems who were exposed to poverty and multiple risk factors. Five family variables were identified in the family regression model as direct predictórs of placement in the Legacy Group. Path modeling utilizing only family variables identified a family influenced path to the Legacy Group as being one where the child enters care with siblings, with a higher probability of being a victim of or exposed to sexual abuse, having fewer positive family and community support systems but where neglect is not present. While in care the family averages fewer monthly face to face visits than other children. The family not having resources or a support system to meet basic needs and having living arrangements that seriously endanger the physical health of the child were found to be significant predictors of the level of family and community supports rating assigned by the social worker.

\section{Child Variable Findings}

This project had originally purposed the use of Foster Care Census data to assess the effects of child well being on permanency. After a review of data, it was determined that valid and reliable comparisons could not be made for the Permanency and Legacy Groups utilizing census data due to the low number of 
Permanency Group children included in the census. Census data were available for only two children in the Permanency Group. Instead of using foster care census data, the variables related to child development rating, Auchenbach level and Child Behavior Checklist data were assessed to identify the effects of the child's behavioral, physical and emotional well being on permanency. Table 14 includes descriptive data related to all six child variables. The Legacy Group was significantly different or was found to have a relationship with three of the child variables: (a) race of the child, (b) child's developmental rating as assessed by their social worker at time of entry, and (c) child's most recent or exiting Auchenbach Level

Table 14

Child Variable Descriptive Statistics

\begin{tabular}{|c|c|c|c|}
\hline Child Variable & Legacy Group & $\begin{array}{c}\text { Permanency } \\
\text { Group }\end{array}$ & $p$ \\
\hline Gender & $\begin{array}{l}\text { Female } n=67 \\
(53.6 \%) \\
\text { Male } n=58 \\
(46.4 \%)\end{array}$ & $\begin{array}{l}\text { Female } n=83 \\
(55.3 \%), \\
\text { Male } n=67 \\
(44.7 \%)\end{array}$ & $\begin{array}{l}p<n s \\
x^{2}=.08\end{array}$ \\
\hline Race & $\begin{array}{l}\text { African American } \\
10.4 \% \\
\text { Caucasian } 86.4 \% \\
\text { Unable to } \\
\text { determine } 3.2 \%\end{array}$ & $\begin{array}{l}\text { African American } \\
22.7 \% \\
\text { Caucasian } 75.3 \% \\
\text { Unable to } \\
\text { determine } 2.0 \%\end{array}$ & $\begin{array}{l}X^{2}=7.42, \\
d f=2 \\
p<.02\end{array}$ \\
\hline Mean age at entry & $\begin{array}{l}N=125, M=7.48 \\
S D=3.91\end{array}$ & $\begin{array}{l}N=150, M=6.93 \\
S D=5.84\end{array}$ & $\begin{array}{l}P<n s \\
t=.89\end{array}$ \\
\hline $\begin{array}{l}\text { Initial Auchenbach } \\
\text { level }\end{array}$ & $\begin{array}{l}n=115, M=2.54 \\
S D=1.53\end{array}$ & $\begin{array}{l}n=39, M=2.51 \\
S D=1.52\end{array}$ & $\begin{array}{l}p<n s \\
t=.07\end{array}$ \\
\hline $\begin{array}{l}\text { Last Auchenbach } \\
\text { level }\end{array}$ & $\begin{array}{l}n=115, M=3.02 \\
S D=1.48\end{array}$ & $\begin{array}{l}n=39, M=.2 .28 \\
S D=1.37\end{array}$ & $\begin{array}{l}p<.007 \\
t .=2.75\end{array}$ \\
\hline $\begin{array}{l}\text { Mean initial child } \\
\text { development } \\
\text { rating }\end{array}$ & $\begin{array}{l}N=125, M=2.07 \\
S D=1.43\end{array}$ & $\begin{array}{l}N=150, M=1.12 \\
S D=1.24\end{array}$ & $\begin{array}{l}p<.0001 \\
t=5.84\end{array}$ \\
\hline
\end{tabular}


Table 15 includes Pearson correlations coefficients completed in SPSS that identified two child variables with strong positive correlations to being in the Legacy Group. In order of significance these included: (a) having a higher child development rating and (b) higher last Auchenbach level. One variable, race, with Caucasian being 0 and minority being 1 , was found to have a strong negative correlation with being in the Legacy Group.

Table 15 Child Variable and Legacy Group Correlation Table

\begin{tabular}{|l|r|r|}
\hline \multicolumn{1}{|c|}{ Child Variable } & Pearson r & P \\
\hline Child development rating at entry & & \\
\hline Race & .33 & .000 \\
\hline Last Auchenbach level & -.16 & .007 \\
\hline Age at entry & .21 & .007 \\
\hline Gender & .05 & .371 \\
\hline Initial Auchenbach level & .01 & .775 \\
\hline
\end{tabular}

(Legacy Group = 1, Permanency Group = 0; Gender: Male = 1, Female =0; Race: Minority = 1, Caucasian =0).

The Child Predictor Regression Model (Model 2) demonstrated a significantly strong predictive relationship with placement in the Legacy Group ( $F$ $\left.(2,27)=21.40, p<.0001, R^{2}=.13\right)($ Tables 16 and 17$)$. This regression model was not as strong, however, as the family model. Model two accounted for $13.6 \%$ of the variance in Legacy Group when only considering child variables. Two child variables were excluded from the child model due to having non-significant coefficient $t$ scores. These included (a) age at entry $(\beta=-.13, p<n s)$, and (b) gender $(\beta=.05, p<n s)$. Variables related to the child's Auchenbach level and Child Behavior Checklist data were excluded from the regression analysis due to only 154 of the 275 children in this study having Auchenbach levels and Child Behavior Checklist data. More information regarding findings related to 
Auchenbach levels and Child Behavior Checklist data are discussed later in this chapter.

Table 16

Child Variable and DV Legacy Group Model Summary

\begin{tabular}{|r|r|r|r|r|r|}
\hline Model & R & R Square & $\begin{array}{r}\text { Adjusted } \\
\text { R Square }\end{array}$ & $\begin{array}{c}\text { Std. Error } \\
\text { of the } \\
\text { Estimate }\end{array}$ & $\begin{array}{r}\text { Durbin } \\
\text { Watson }\end{array}$ \\
\hline 2 & .36 & .13 & .13 & .46 & .25 \\
\hline
\end{tabular}

Table 17

Child Variable and DV Legacy Group ANOVA Table

\begin{tabular}{|l|r|r|r|r|r|}
\hline \multicolumn{1}{|c|}{ Model } & $\begin{array}{c}\text { Sum of } \\
\text { Squares }\end{array}$ & Df & $\begin{array}{c}\text { Mean } \\
\text { Squares }\end{array}$ & F & Sig. \\
\hline Regression & 9.27 & 2 & 4.63 & 21.40 & .000 \\
Residual & 58.91 & 272 & .21 & & \\
Total & 68.18 & 274 & & & \\
\hline
\end{tabular}

Two child variables were identified as significant predictors of placement in the Legacy Group. These included: (a) higher child development rating ( $\beta=$ $.33, p<.0001)$, and (b) child is Caucasian $(\beta=-.15, p<.0001)$ (Table 18). 
Table 18

Child Variable and DV Legacy Group Coefficient Table

\begin{tabular}{|c|c|c|c|c|c|c|}
\hline \multirow[t]{2}{*}{ Model } & \multicolumn{2}{|c|}{$\begin{array}{l}\text { Unstandardized } \\
\text { Coefficients }\end{array}$} & \multirow{2}{*}{$\begin{array}{c}\text { Standardized } \\
\text { Coefficients } \\
\text { Beta }\end{array}$} & \multirow[t]{2}{*}{$r$} & \multirow[t]{2}{*}{$p$} & \multirow{2}{*}{$\begin{array}{l}\text { Correlation } \\
\text { s } \\
\text { Zero Order }\end{array}$} \\
\hline & B & $\begin{array}{l}\text { Std. } \\
\text { Error }\end{array}$ & & & & \\
\hline $\begin{array}{l}\text { (Constant) } \\
\text { Initial child } \\
\text { development } \\
\text { rating }\end{array}$ & $\begin{array}{r}1.69 \\
.11\end{array}$ & $\begin{array}{l}.04 \\
.02\end{array}$ & .331 & $\begin{array}{r}38.61 \\
5.87\end{array}$ & $\begin{array}{l}.000 \\
.000\end{array}$ & .33 \\
\hline Race & -.20 & .07 & -.157 & -2.79 & .006 & -.16 \\
\hline
\end{tabular}

(Legacy Group $=1$, Permanency Group $=0$; Vąriable race coded minority $=1$, Caucasian $=0$ )

The Child Predictor Path Model includes regression Beta weights for both the direct and indirect child predictors of Legacy Group (Figure 3). In this model child development rating was the most significant predictor of Legacy Group ( $\beta$ $=.331$ ). Social workers assign this rating based on indicators of risk due to the child's specific needs. Regression analyses were completed for all child development indictors and the dependent variable child development rating. Of the seven child risk indicators, five were significant predictors of the assigned rating for child development. These included in order of significance: (a) child has serious physical, emotional and behavioral symptoms, (b) child is disabled, (c) the child is 0 to 5 years of age and/or cannot protect self, (d) child is medically fragile, and (e) child has exceptional needs that the parents cannot or will not meet. Indicators child is 0 to 5 years of age and/or cannot protect self and child being medically fragile had negative Beta weights demonstrating that Legacy children are older and are seen as being able to protect themselves and were not 
identified as medically fragile. The second child predictor of Legacy Group was race. With minority children being coded 1 and Caucasian being 0 , this variable also had a negative Beta weight, indicating that being a minority was not predictive of long term foster care.

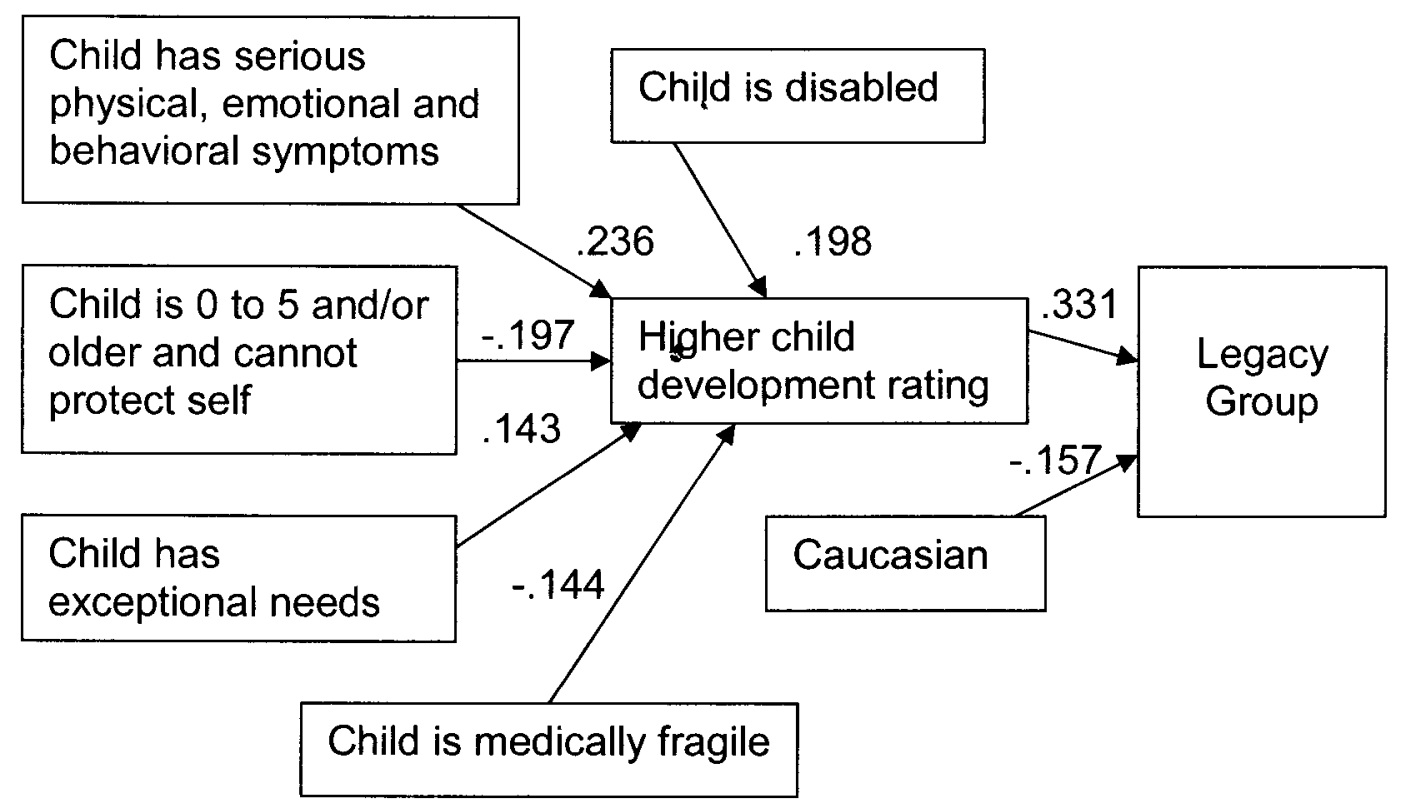

Figure 3 Child Predictor Path Model

\section{Child Predictors of Legacy Group}

Both of the child variables identified as strong predictors of Legacy Group in the Child Predictor Regression Model occurred prior to or upon entry into care: race of the child (Caucasian) and higher initial child development rating. Further analysis of these variables was completed to determine their relationship with other variables that occurred while the child was in foster care. The child predictor variable, child development rating, was based on risk indicators selected by the social worker pertaining to the child's educational, physical and 
behavioral needs. Information related to these indicators is being provided as predictors of the child development rating variable.

\section{Legacy Group Predictor: Child Development Rating}

All of the children in this project were rated on their well being at point of entry by their social workers. The child development rating is based on social workers assessment of children's levels of risk to due to their educational, physical, emotional, and behavioral needs. Legacy Group members were found to have a statistically significantly higher mean initial child development rating than the Permanency Group ( $M$ Legåcy Group= 2.07, $S D=1.43 ; M$ Permanency Group $=1.12, S D=1.24, t=5.8, p<.0001)$. Comparisons of the most recent child development rating for the Legacy Group and exiting child development rating for the Permanency Group demonstrated that the Legacy Group current rating was significantly higher than the Permanency Group's exiting level ( $M$ Legacy Group $=1.49 ; M$ Permanency Group $=.81 ; t=4.32, p<.0001)$.

\section{Predictors of Child Development Rating}

To obtain the child development rating social workers identify seven specific child risk indicators. A multiple linear regression was calculated to predict child development rating based on child risk indicators. Five indicators were found to be predictors of child development rating: (a) child is disabled $\beta=.19$, (b) child has serious physical, emotional and behavioral symptoms $\beta=.23$, (c) child is zero to five years old and/or cannot protect self $\beta=-.19$, (d) child has exceptional needs $\beta=.14$ and (e) child is medically fragile $\beta=-.14$. Two of these 
indicators, child is medically fragile, and child is 0 to 5 and/or cannot protect self had negative Beta weights.

\section{Legacy Group Predictor: Race of Child}

Race of the child was found to have a significant relationship with, and to be a significant predictor of membership in the Legacy Group. Legacy children were predominantly Caucasian (86.4\%), $10.4 \%$ were African American, and the remainder's race was listed as unable to determine. This compared to the Permanency Group which was made up of $75.3 \%$ Caucasian, $22.7 \%$ African Americans, and $2 \%$ whose race was $\hat{l}_{\text {isted }}$ as unable to determine. A chi-square indicated a significant relationship between race and permanency with Caucasian children being much more likely to be in the Legacy Group $\left(x^{2}(d f 2)=\right.$ $7.42, p<.02)$.

A significant difference was also found in social workers' rating of race, cultural or ethnic issues being present as a risk factor. Twenty-three percent of the Legacy Group were identified by their social workers as having race, cultural or ethnicity being a risk factor that needed to be addressed, compared to $13.3 \%$ of the Permanency Group $\left(x^{2}(d f 1)=4.53, p<.02\right)$. This included 39 Caucasian children (17.6\% of Caucasians) and 10 African Americans children (21.3\% of African Americans) for both groups combined. Chi-Square analyses were performed to determine if a relationship existed between race of child and permanency goal. A significant relationship was found with being an African American child and having the permanency goal of adoption $(p<.04)$. All of the 
African American Legacy members and $50 \%$ of the African American

Permanency members had the goal of adoption.

\section{Child Variables That Were Not Predictive of Legacy Group}

Auchenbach and Child Behavior Checklist data were excluded from the Child Predictor Regression Model due to the low number of children on whom these data were available. Descriptive information regarding these data is provided in an effort to understand how permanency may be affected by a child's behavioral needs. Two other child variables, gender and age at entry were not predictive of Legacy Group or significantly different between the two groups. Analyses were completed with age at entry and other variables to determine the effect of age on permanency in combination with other variables.

\section{Auchenbach/Children's Behavior Checklist}

Auchenbach and Children Behavior Checklist data were not available for all participants of this project. Auchenbach levels were available for 125 Legacy Children and 29 Permanency Group. Fewer children had Internal, External and Total Behavior scores available. The inclusion of more Permanency Group members with Auchenbach/Children's Behavior Checklist data was not obtainable through random sampling because it was impossible to identify these children electronically. Because these data were not available for all children in this study, these variables were excluded from the Child Regression Model. Auchenbach level and Children Behavior Checklist scores for the Legacy and Permanency Groups were compared through independent samples t-test. Data from both of these measures (completed within 60 days of the child entering 
foster care and at least every six months thereafter that the child was in foster care) were analyzed to determine the level of behavioral improvement for the child while in foster care. This data included an overall Auchenbach level of 1 to 5 assigned to the child based on the Child Behavior Checklist scores and a social history completed by the social worker, parent, or caretaker. Internal and External scores derived from specific ițems on the Children's Behavior Checklist and Total Behavior (T scores) based on overall number of problem behaviors identified on the Children's behavior checklist were also collected and analyzed. Higher levels and scores are indicative of the child having greater behavioral needs.

As discussed in chapter two, these scores relate to three problem behavior summary scores: (a) Internalizing (sum of Withdrawn, Somatic Complaints, and Anxious/Depressed), (b) Externalizing (sum of Delinquent Behavior and Aggressive Behavior), and (c) Total Problems (sum of all problem behavior items). Initial Internal, External, and T scores for the Legacy Group were all significantly lower than the Permanency Group, (Internal M Legacy Group $=54.08, M=$ Permanency Group $=60.25, t=-2.18, p<.04) ;($ External $M$ Legacy Group $=58.14 ; M$ Permanency Group $=68.71, t=-3.4, p<.001) ;(T$ Total $M$ Legacy Group $=57.69 ; M$ Permanency Group $=66.00, t=-2.79, p<$ .006). Initial scores at time of entry and most recent scores for Legacy Children or scores at exit for Permanency Children were compared to determine what effect, if any, foster care may had produced on the child's behavior. 
Although the Permanency Group continued to have a higher average in each of the three behavioral areas, Legacy Group members were found to have an increase in all three of their mean scores, while Permanency Children were found to have decreases in their mean scores; (Internal $M$ Legacy Group = 54.26; $M$ Permanency Group $=59.60, t=-1.96, p<.05) ;($ External $M$ Legacy Group $=59.98, M$ Permanency Group $=67.50, t=-2.64, p<.009) ;($ Total Behavior $M$ Legacy Group $=59.64 ; M$ Permanency Group $=65.44, t=-2.06, p<$ .04). Overall, Legacy children's Auchenbach levels were found to have increased while the Permanency Group's Auchênbach levels decreased ( $M$ Legacy Group $=3.02 ; M$ Permanency Group $=2.28, t=2.755, p=.007$ ). Comparisons were also made using Legacy children's Auchenbach levels completed at the time they had been in foster care for 2 years compared to the Permanency Group's exiting levels completed when the child had been in care for 2 years. In this comparison, Legacy Group members were found to have a higher mean level at 3.11 compared to the Permanency Group's mean level of 2.28.

These scores were also considered by permanency goal to determine how obtaining specific types of permanency may affect a child's behavioral functioning. Children who exited to a goal of adoption had the most improvement in their behavioral functioning as determined by their Internal and External scores. These children had a mean decrease of two points in their Internal scores and a decrease of over three points (3.7) in their External scores. Children who exited to adoption also had a decrease in their Total Behavior score $(-1.77)$ and their Auchenbach level (-.21). Children who exited care by 
obtaining permanency goals of return to parent and placement with relatives had a zero mean difference in their Internal, External and Total Behavior scores and a decrease in their Auchenbach level (Placement with relatives $M=-.66$; Return to parent $M=-.18$ ). Independent samples $t$ tests were completed to determine the effect of parent/child visitation on child behavior. Overall children with a decrease on their Internal and Externąl scores were more likely to have an appropriate number of monthly parent/child visitations. Children who had an appropriate mean number of monthly parent/child visitations had a mean decrease of -1.34 in their External scores and -.26 in their Internal scores. Children who did not have an appropriate mean number of monthly parent/child visitations had a mean increase of 1.21 in their External scores and .64 in their Internal scores. Appropriate number of visitations was defined by child having two or more monthly face to face visitations with parents as required by DCBS policy.

\section{Gender and Age at Entry}

Data pertaining to each child's gender and age were collected and analyzed for this project. Legacy and Permanency Groups were not found to be significantly different in regards to age at entry or gender; gender $\left(x^{2}(d f 1)=.08, p\right.$ $<n s) ;$ entry age ( $M$ Legacy Group $=7.58, S D=3.91 ; M$ Permanency Group $=$ $6.93, S D=5.84, t=.89, p<n s)$. Legacy children's entry ages ranged from one month to 13.84 years, and Permanency children's ages ranged from less than one month to 17.11 years. Age at entry was calculated by permanency goal for the Legacy Group and/or type of permanency obtained by the Permanency 
children at time of exit from foster care. Children who exited the system to adoption were found to be much younger at time of entry $(M=3.77$ years, $S D=$ 5.13) than children who are currently waiting to be adopted $(M=6.78, S D=$ 3.63).

\section{Summary of Findings Related to Child Variables}

The most significant child prediçtors of Legacy Group were found to be child development rating at time of entry and the race of the child. For children in this group, being Caucasian and having higher risk based on the child's emotional, physical and educational ñeeds were predictive of placement in the Legacy Group. Child risk indicators of being disabled, having serious physical, emotional and behavioral symptoms, and exceptional needs were predictive of the higher child development rating. Child being 0 to 5 and/or older and cannot protect self and child being medically fragile were identified as significant negative predictors of Legacy Group. Auchenbach level and Child Behavior Checklist data findings identified the Legacy Group as entering care with fewer behavioral needs but more behavioral needs while in care in comparison to the Permanency Group whose behavioral needs either remained the same or decreased. Behavioral needs of both groups were found to have a relationship with permanency goal and parent/child visitation.

\section{Social Worker Findings}

Table 19 contains findings related to the 7 social worker variables in this study, 6 of which were found to be significantly different between the Legacy and 
Permanency groups: (a) permanency goal, (b) length of time between case planning conferences, (c) number of face to face social worker/parent contacts, (d) number of face to face social worker/child contacts, (e) number of foster care placements, and (f) experience level of social worker.

This study had hoped to assess variables related to social worker's attachment and empathy via survey dạta. Due to the extremely low response rate (less than $5 \%$ ), these data were not included in this study. More information regarding possible explanations for the low response rate are provided in the next chapter.

Table 19

Social Worker Variable Descriptive Statistics

\begin{tabular}{|c|c|c|c|}
\hline Variables & Legacy Group & $\begin{array}{c}\text { Permanency } \\
\text { Group }\end{array}$ & $p$ \\
\hline $\begin{array}{l}\text { Mean number of } \\
\text { foster care } \\
\text { placements child has } \\
\text { experienced }\end{array}$ & $\begin{array}{l}N=125, M= \\
5.09, S D=3.68 \\
\text { Range }=1-24\end{array}$ & $\begin{array}{l}N=150, M=1.99 \\
S D=1.73\end{array}$ & $\begin{array}{l}p<.000 \\
t=9.14\end{array}$ \\
\hline $\begin{array}{l}\text { Mean number of days } \\
\text { between case } \\
\text { planning }\end{array}$ & $\begin{array}{l}N=125, M=173 \\
S D=33.66\end{array}$ & $\begin{array}{l}N=150 \\
M=52.31 \\
S D=57.66\end{array}$ & $\begin{array}{l}p<.000 \\
t=20.59\end{array}$ \\
\hline Permanency goal & $\begin{array}{l}\text { Adoption } \mathrm{n}=97, \\
\text { Emancipation } \mathrm{n}= \\
2, \\
\text { Return to Parent } \\
\mathrm{n}=8, \\
\text { Relative } \\
\text { Placement } \mathrm{n}=3 \text {, } \\
\text { Planned } \\
\text { Permanent Living } \\
\text { Arrangement } \mathrm{n}= \\
15\end{array}$ & $\begin{array}{l}\text { Adoption } n=50, \\
\text { Return to Parent } n \\
=80, \\
\text { Relative } \\
\text { Placement } \mathrm{n}=20,\end{array}$ & $\begin{array}{l}p<.000 \\
x^{2}= \\
95.80\end{array}$ \\
\hline $\begin{array}{l}\text { Educational degree of } \\
\text { social worker }\end{array}$ & $\begin{array}{l}\text { COA degree } \\
N=88\end{array}$ & $\begin{array}{l}\text { COA degree } \\
n=108\end{array}$ & $\begin{array}{l}p<.43 \\
x^{2}=.06\end{array}$ \\
\hline
\end{tabular}




\begin{tabular}{|c|c|c|c|}
\hline Variables & Legacy Group & $\begin{array}{c}\text { Permanency } \\
\text { Group }\end{array}$ & $p$ \\
\hline $\begin{array}{l}\text { Experience of social } \\
\text { worker }\end{array}$ & $\begin{array}{l}N=125 \\
M=6.19 \text { years } \\
S D=4.42\end{array}$ & $\begin{array}{l}N=150 \\
M=7.96 \text { years, } \\
S D=6.72\end{array}$ & $\begin{array}{l}p<.02 \\
t=-2.30\end{array}$ \\
\hline $\begin{array}{l}\text { Mean number of } \\
\text { monthly social worker } \\
\text { face to face contacts } \\
\text { with family }\end{array}$ & $\begin{array}{l}N=125 \\
M=.96 \\
S D=.90\end{array}$ & $\begin{array}{l}N=150, M=1.46 \\
S D=1.46\end{array}$ & $\begin{array}{l}p<.001 \\
t=-3.31\end{array}$ \\
\hline $\begin{array}{l}\text { Mean number of } \\
\text { monthly social worker } \\
\text { face to face contacts } \\
\text { with child }\end{array}$ & $\begin{array}{l}N=125 \\
M=.93 \\
S D=.53\end{array}$ & $\begin{array}{l}N=150, M=1.33 \\
S D=1.04\end{array}$ & $\begin{array}{l}p<.0001 \\
t=-3.31\end{array}$ \\
\hline
\end{tabular}

With Permanency Group being 0 and,Legacy Group being 1, two social worker variables were identified as having strong positive correlations with being in the Legacy group. In order of significance these were: (a) number of days between case plans, and (b) number of foster care placements. Four social worker variables had strong negative correlations with Legacy Group membership: (a) number of monthly face to face contacts between social worker and child, (b) number of monthly face to face contacts between social worker and family, (c) permanency goal and (d) experience level of social worker (Table 20).

\section{Table 20}

Social Worker Variables and Legacy Group Correlations

\begin{tabular}{|l|r|r|}
\hline \multicolumn{1}{|c|}{ Social Worker Variable } & Pearson $\boldsymbol{r}$ & $\boldsymbol{p}$ \\
\hline Mean number of days between case planning & .78 & .000 \\
\hline $\begin{array}{l}\text { Mean number of foster care placements child } \\
\text { has experienced }\end{array}$ & .48 & .000 \\
\hline $\begin{array}{l}\text { Mean number of monthly social worker face } \\
\text { to face contacts with child }\end{array}$ & -.22 & .000 \\
\hline $\begin{array}{l}\text { Mean number of monthly social worker face } \\
\text { to face contacts with family }\end{array}$ & -.19 & .001 \\
\hline Permanency goal & -.14 & .015 \\
\hline Experience of social worker & -.15 & .022 \\
\hline
\end{tabular}


Table 20 (Continued)

\begin{tabular}{|c|r|r|}
\hline Social Worker Variable & Pearson $\boldsymbol{r}$ & $\boldsymbol{p}$ \\
\hline Educational degree of social worker & -.01 & .771 \\
\hline
\end{tabular}

(Legacy Group = 1, Permanency Group =0; Educational Degree of Social Worker - COA Degree = 1, Degree not recognized by COA =0)

The third regression model included all social worker variables and the dependent variable, Legacy Group. Of,the 7 social worker predictor variables, 5 were excluded from the final model due to non-significant $t$ coefficient scores (permanency goal $\beta=-.04$, ns ; educational degree of social worker $\beta=-.001$, $n s$; experience level of social worker $\hat{\beta}=.05, n s$; mean number of monthly face to face contacts with the family $\beta=-.02, n s$; and mean number of face to face social worker contacts with the child $\beta=.03, n s)$. A significant regression equation was found with the final social worker model $(F(2,272)=237.25)$ with an $R^{2}$ of .636 (Tables 21 and 22). The Social Worker Predictor Regression Model accounted for more variance than the child and family models combined. $63.6 \%$ of the variance in the Legacy Group was accounted for by the two significant predictor social worker variables (a) number of days between case planning conferences $(\beta=.70, p<.0001)$, and $(b)$ number of placements child has experienced $(\beta=$ $.18, p<.0001$, Table 23). As both of these variables increased so did likelihood of placement in the Legacy Group.

Both variables also had the strongest correlations of the social worker variables with Legacy Group. The Social Worker Predictor Path Model (Figure 4) includes the significant social worker predictors of Legacy Group. Regression analyses were completed with both of these predictors as dependent variables to 
identify indirect predictors of Legacy Group. Four predictors of the variable more days between case plans were identified. In order of significance these variables were (a) having fewer social workers, (b) more restrictive placement, (c) parental rights being terminated, and (d) having fewer monthly face to face parent/child visits. Three variables were identified as predictors of increased number of placements: (a) higher child development rating, (b) more restrictive placement, and (c) higher average monthly cost of child's care. The 2 direct predictors and 7 indirect predictors and their Beta weights are demonstrated in the Social Worker Predictor Path Model (Figure 4).

Table 21

Social Worker Variable and DV Legacy Group Model Summary

\begin{tabular}{|c|c|c|c|c|c|}
\hline Model & $\mathbf{R}$ & R Square & $\begin{array}{c}\text { Adjusted } \\
\mathbf{R} \\
\text { Square }\end{array}$ & $\begin{array}{l}\text { Std. Error } \\
\text { of the } \\
\text { Estimate }\end{array}$ & $\begin{array}{l}\text { Durbin } \\
\text { Watson }\end{array}$ \\
\hline 3 & .79 & .63 & .63 & .30 & .1 .06 \\
\hline
\end{tabular}

Table 22

Social Worker Variable and DV Legacy Group ANOVA Table

\begin{tabular}{|l|r|r|r|r|r|}
\hline \multicolumn{1}{|c|}{ Model } & $\begin{array}{c}\text { Sum of } \\
\text { Squares }\end{array}$ & \multicolumn{1}{|c|}{ Df } & $\begin{array}{c}\text { Mean } \\
\text { Squares }\end{array}$ & \multicolumn{1}{|c|}{ F } & Sig. \\
\hline Regression & 43.33 & 2 & 21.66 & 237.25 & .000 \\
Residual & 24.84 & 272 & .09 & & \\
Total & 68.18 & 274 & & & \\
\hline
\end{tabular}


Table 23

Social Worker Variables and DV Legacy Group Coefficients Table

\begin{tabular}{|c|c|c|c|c|c|c|}
\hline \multirow[t]{2}{*}{ Model } & \multicolumn{2}{|c|}{$\begin{array}{c}\text { Unstandardized } \\
\text { Coefficients }\end{array}$} & \multirow{2}{*}{$\begin{array}{c}\begin{array}{c}\text { Standardized } \\
\text { Coefficients }\end{array} \\
\text { Beta }\end{array}$} & \multirow[t]{2}{*}{$\bar{t}$} & \multirow[t]{2}{*}{$p$} & \multirow[t]{2}{*}{$\begin{array}{l}\text { Correlations } \\
\text { Zero Order }\end{array}$} \\
\hline & B & $\begin{array}{l}\text { Std. } \\
\text { Error }\end{array}$ & & & & \\
\hline (Constant) & 2.12 & .03 & & 65.20 & .000 & \\
\hline $\begin{array}{l}\text { Days } \\
\text { between } \\
\text { case plans }\end{array}$ & 4.54 & .00 & .702 & 17.30 & .000 & .78 \\
\hline $\begin{array}{l}\text { Number of } \\
\text { placements }\end{array}$ & 2.85 & .00 & .183 & 4.50 & .000 & .48 \\
\hline
\end{tabular}

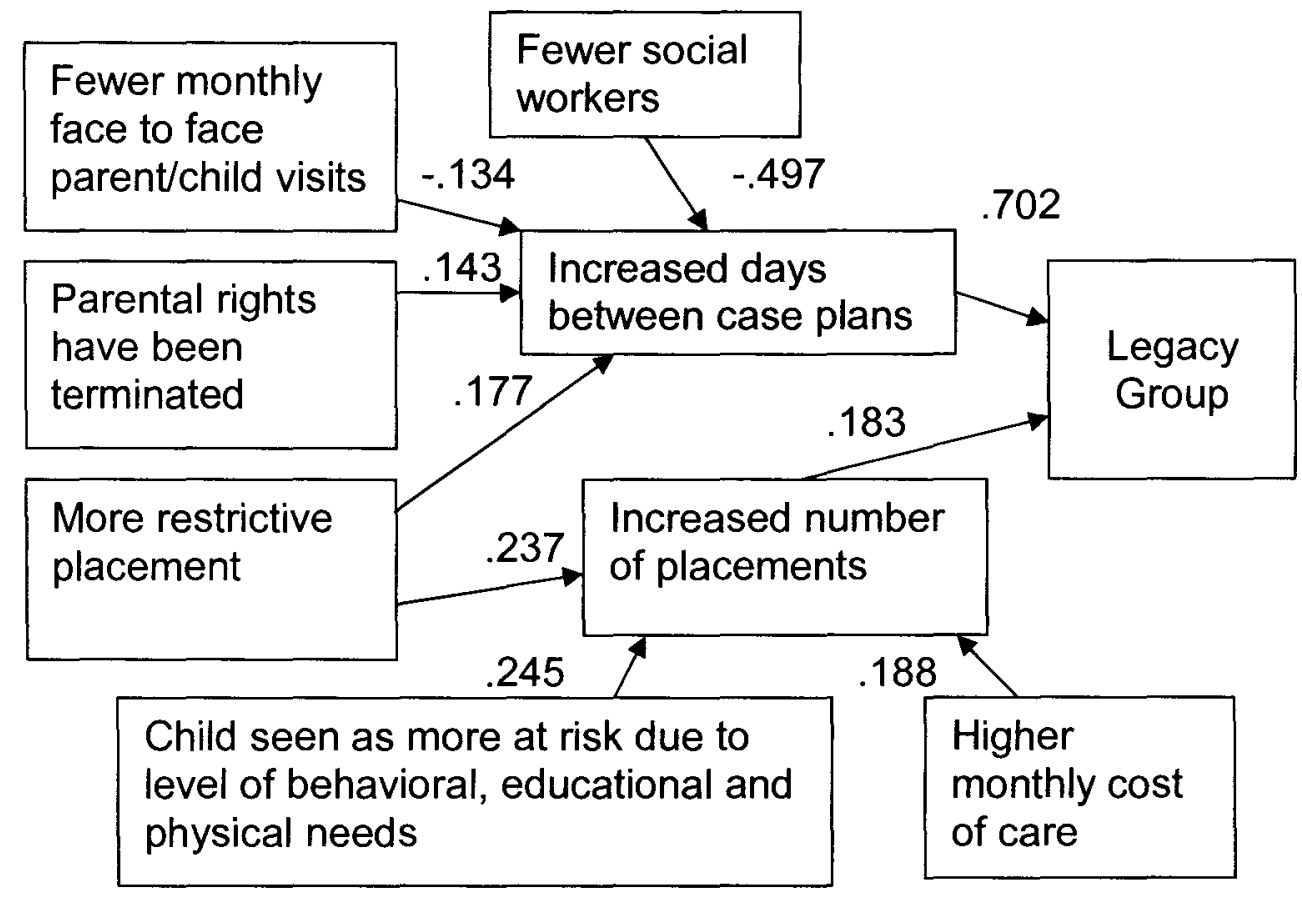

Figure 4 Social Worker Predictor Path Model

Social Worker Variables Predictive of Legacy Group

Further statistical analyses were completed with the two social worker 
variables identified as strong predictors of Legacy Group membership and their predictors to gain a better understanding of how social worker variables affected permanency for children. These direct and indirect predictors of permanency were found to have a number of statistically significant relationships with other variables in this study.

\section{Legacy Group Predictor - Days Between Case Plans}

Independent samples $t$ test identified a number of differences in the number of case plans completed and the length of time between case plans for the Legacy and Permanency Groups. Social workers of Legacy children completed a greater number of case plans both prior to termination of parental rights and for the lifetime of the case than social workers for Permanency Children (pre termination $M$ Legacy Group $=6.05 ; M$ Permanency Group $=1.75$; $S D$ Legacy Group = 2.63; $S D$ Permanency Group $=1.02, t=18.43, p<.0001$; lifetime of case $M$ Legacy Group $=8.45 ; M$ Permanency Group 2.01, SD Legacy Group $=1.48, S D$ Permanency Group $=1.26, t=38.80, p<.0001)$. In order to determine if differences existed for these two groups between length of time between each case plan, dates for each case planning conference was entered into SPSS and the number of days between case plans calculated. The mean number of days between case planning conferences for the Legacy Group was 172.71 days compared to 52.31 days for the Permanency Group (SD Legacy Group $=33.66 ; S D$ Permanency Group $=57.66, t=20.59 ; p<.0001)$.

Length of time between case plans was also examined by permanency 
goal. Children with a goal of planned permanent living arrangement had the highest mean length of time between case plans at 156 days $(S D=21.56)$. This was followed by adoption $(M=142, S D=60.86)$, placement with relatives $(M=$ 58.7, $S D=68.48)$, return to parent $(M=56, S D=71.90)$, and emancipation $(M=$ $38.5, S D=66.55)$.

Time between case plans was then analyzed by permanency goal and year entered care. For children with goals of emancipation and placement with relatives, gradual decreases were found for each year. For children with a goal of adoption, mean lengths of time betwêen case plans were less for each entry year with the exception of 2001, but adoption continued to be the goal with the greatest length of time between case plans. Children who entered care in 2003 and had a permanency goal of adoption experienced a mean of 70.5 days between case plans compared to 32.63 days for children with the goal of return to parent and 22.30 days between case plans for children with a goal of placement with relatives. Children with a goal of return to parent had the most turbulent changes in length of time between case plans compared by entry year ( $M 1999=88$ days, $M 2000=20$ days, $M 2001=43$ days, $M 2002=30$ days, and $M 2003=33$ days). Although the Legacy Group had significantly longer periods of time between case planning conferences, decreases were seen in the days between their case planning conferences when reviewed by time frames. The mean number of days between Legacy Group's first and second case plan was 211.13 days compared to a mean of 180 days between their 8 th and 9 th 
case plans $(S D$ Legacy Group $=152.10, S D$ Permanency Group $=103.67, t=$ $8.31, p<.000)$.

\section{Predictors of Number of Days Between Case Plans}

Four predictors of increased days between case plans were identified:

(a) fewer social workers, (b) more restrictive placement, (c) fewer monthly face to face parent/child visitations, and (d) parental rights had been terminated. For the first predictor, fewer social workers, means were compared for number of days between case plans by number of social workers assigned to the case. Children who had one social worker during theîr entire time in foster care had the lowest mean number of days between case plans at $56.24(n=95, S D 75.09)$ with the two groups combined. For Legacy Children only however, having one social worker produced one of the highest lengths of time between case plans at 181.56 days $(n=17, S D=40.97)$. Legacy children who had three social workers during their entire time in care had the lowest mean number of days between case plans $(M=162.96, n=31, S D=30.31)$.

The second predictor of having more time between case plans was type of placement. Children who were in the most restrictive placements had the highest mean number of days between case plans. Mean number of days between case plans were the lowest for children in relative placements $(M=55.70, n=40, S D$ $=71.61)$. Children in psychiatric settings, family treatment homes and private child care agencies had the highest mean number of days between case plans $(M$ Psychiatric settings $=137.00, n=8, S D=70.29 ; M$ Family treatment homes $=$ 
133.77, $n=8, S D=67.58 ; M$ Private child care agencies $=128.02, n=50, S D=$ 84.08).

The third predictor of increased number of days between case plans was having fewer monthly face to face parent/child visitations. Independent samples $\mathrm{t}$ tests were calculated to determine if significant differences in number of days between case plans existed for children who had 2 or more monthly parent/child visitations compared to children who did not have an appropriate number of parent/child visits. Mean number of days between case plans with appropriate number of monthly parent/child visits was $73.92(n=60, S D=75.49)$ days compared to $116.28(n=215, S D=75.00)$ days for children who did not have appropriated number of visits $(t=-3.86, p<.0001)$.

Lengths of time between case plans were also computed for the last predictor variable, termination of parental rights. Overall, mean length of time between case plans for children whose parental rights were terminated was $137.29(n=136, S D=60.47)$ compared to 77.44 days, $(n=139, S D=80.05)$ for children whose rights were not terminated $(t=-6.98, p<.0001)$. For Legacy Children whose parental rights were terminated mean length of time between case plans was 170.60 days compared to other Legacy Children whose rights were not terminated at 177.36 . Permanency Children whose rights were terminated had much lower mean number of days between case plans at 79.93 , compared to the Legacy Group but a higher mean when compared to other Permanency children whose rights were not terminated at 38.47. Number of days between the first and second case plans for children whose parental rights were 
terminated was highest when considering all case plans at 179.22 days $(S D=$ 139.72) compared to 103.39 days for children whose rights were not terminated $(S D=136.47)$. Mean length of time between first and second case plans for Legacy Group members whose rights were terminated was 220.50 days, compared to 108.22 days for Permanency Group members whose rights were terminated.

\section{Legacy Group Predictor: Number of Foster Care Placements}

Range of number of placements for children in this study was 1 to 24 placements. Legacy Children experiehced an average of 5.09 placements compared to 1.99 mean placements for the Permanency Group (SD Legacy Group = 3.68; $S D$ Permanency Group $=1.73, t=9.14, p<.0001)$. The number of foster care placements a child had experienced was analyzed by permanency goal and year of entry into foster care. For both groups combined, children with a goal of planned permanent living arrangement had a higher mean number of placements $(M=4.47, S D=3.13)$, followed by children with a goal of adoption $(M=4.18, S D=3.35)$, emancipation $(M=2.55, S D=3.47)$, return to parent $(M=$ $2.47, S D=2.74)$ and placement with relatives $(M=1.35, S D=.93)$. When the two groups were reviewed separately, Legacy Group members with the goal of emancipation had the highest number of placements $(M=9)$. Legacy children with a goal or return to parent had a mean of 5.88 placements and a mean of 5.12 for Legacy Group children with a goal of adoption. Legacy children with a goal of placement with relatives had the lowest mean number of placements $(M=$ 2.33). 
Mean number of placements were computed by year of entry into foster care. For each entry year since 1999 , the mean number of foster care placements has declined. Children entering care in 1999 experienced a mean of 4.38 placements $(S D=3.47)$. This compared to 1.73 for children entering in 2000 $(S D=.77), 1.55$ for children entering in $2001(S D=1.05), 1.23$ for children entering in $2002(S D=.65)$, and 1.09 for children entering foster care in 2003 $(S D=.30)$.

\section{Predictors of Number of Placements}

Three variables were found to be strong predictors of increased number of placements: (a) more restrictive placements, (b) increased cost of care, and (c) higher child development ratings. Number of placements compared by type of placement for the Permanency and Legacy groups found some consistency between the two groups for the groups combined, children whose last placement type was in psychiatric hospitals had the highest mean number of placements at 19. This was also the placement type with the highest mean placements for each group separately. In addition, both groups had higher mean placements for children being cared for by private foster care agencies compared to children being cared for by state foster parents. Placement with relatives was found in both groups to have the lowest mean number of placements compared to either private or public foster care $(M$ Relative Placements $=1.70, S D=2.42 ; M$ Private Foster Care $=4.60, S D=3.41 ; M$ Public Foster Care $=3.32, S D=2.64)$.

Number of placements increased not only with type of placement, but also 
cost of placement. CFSR standards expect children to have $<2$ placements during their time in foster care. To determine the effects on cost of having $>2$ placements, number of placements was recoded into a dichotomous variable of 0 being children with $<2$ placements and 1 respectively those children with $>2$ placements. Children with $<2$ placements had an average cost of care of $\$ 1,259.16(n=153, S D=\$ 1,827.57)$ compared to $\$ 2,435.94(n=122, S D=$ $\$ 2435.94)$ for children with more than two placements $(t-3.68, p<.0001)$.

Children with only one placement had the lowest average monthly cost of care at $\$ 684.57(n=89, S D=\$ 914.42)$.

The last variable that was predictive of number of placements was higher initial child development rating. Means were computed for each of the 0 to 5 child development ratings. Children with 0 ratings had the lowest mean number of placements $(M=2.58, n=93, S D=3.03)$. Children with higher ratings had higher mean number of placements, rating of $1=M 2.90(n=49, S D=2.44)$; rating of $2=3.30(n=54, S D=2.86)$; rating of $3=4.73(n=45, S D=3.67)$; rating of $4=4.76(n=34, S D=3.51)$.

\section{Social Worker Variables That Were Not Predictive of Legacy Group}

Social worker variables related to selection of permanency goals, amount of social worker contact with the parents and the child, and experience level of the most recent social worker were not predictive of Legacy Group, but were significantly different between the Permanency and Legacy Groups. Educational degree of the most recent social worker was also not a predictor of Legacy Group, nor was it significantly different between the two groups. 


\section{Permanency Goal}

The two most common permanency goals social workers of Legacy Children were Adoption (77.6\%) and Planned Permanent Living Arrangement $(11.2 \%)$. Social workers were still working toward permanency goals of return to parent for more than $5 \%$ of the Legacy Group and goals of relative placements for $3.2 \%$ of the Legacy Group. The least common goal that social workers had assigned to Legacy Children was emancipation (1.6\%). Due to the stratified random sample approximately one third of the Permanency Group had a permanency goal of adoption. The remaining Permanency Group had the following permanency goals: return to parent (53.3\%) and placement with relatives $(13.3 \%)$.

\section{Social Worker Contacts with Child and Family}

The Legacy Group and their families averaged fewer monthly face to face contacts with their social workers than the Permanency Group. Social workers were found to have made a mean of less than one monthly face to face contact with families of the Legacy Group $(M=.96, S D=.53, t=-3.31, p<.001)$ and less than one mean monthly face to face contact with the Legacy Children. $(M=.933, S D=.90, t=-3.79, p<.0001)$. The Permanency Group had a mean of 1.33 monthly face to face contacts with their social workers $(S D=1.04, t=-3.99$, $p<.0001)$, and a mean of 1.46 social worker face to face contacts with their families $(S D=1.46, t=-3.45, p<.001)$. These contacts were while the child was in foster care and included all locations where face to face contact occurred. For the lifetime of the case, including both the time the child was in care and the time 
prior to and after the child returned home, the average total number of face to face visits documented as having taken place in the parent/caretaker's home were 13.26 for the Legacy Group and 23.17 for the Permanency Group ( $S D$ Legacy Children = 12.55; $S D$ Permanency Group $=50.75, t=-1.88, p<.06$ ) . Social workers had a much higher mean number of face to face contacts with families of the Legacy Group prior to termination of parental rights compared to Permanency families ( $M$ Legacy Group 33.72; $M$ Permanency Group 7.78, $S D$ Legacy Group $=27.92 ; S D$ Permanency Group $=9.22, t=10.70, p<.000$ ).

Number of contacts between social worker and the child and the variables of placement type and year of entry were examined to determine their influence on permanency. For the two groups combined, social worker contact was highest for children in medically fragile placements. Children who were placed with relatives or were placed with private child care agencies had the lowest number of monthly contacts with their social workers. When reviewed by year of entry, gradual increases were observed for social worker face to face contacts with both children and parents. The mean number of monthly social worker/child face to face contacts for each entry year were $M 1999=1.02, M 2000=1.23, M 2001$ $=1.27, M 2002=1.61$ and $M 2003=1.52$. Mean numbers of monthly social worker face to face contacts with families for each entry year were: $M 1999=$ $1.06, M 2000=1.42, M 2001=1.73, M 2002=1.39$, and $M 2003=1.85$.

Social workers for $130(47.3 \%)$ of the children in this project documented reasons for their limited contact families: (a) family had numerous moves while child was in care (2.3\%), (b) parents incarcerated (14.6\%), (c) parents moved out 
of state $(13.1 \%)$, (d) parents did not maintain contact with agency $(50.8 \%)$, (e) parents refused face to face contact with agency (18.5\%) and (f) parents deceased $(.8 \%)$.

\section{Experience Level of Social Worker}

Total number of months of employment with DCBS for the most recent social worker assigned to Legacy and Permanency child were collected for this study. Twenty-eight of the Permanency children's social workers were no longer employed by DCBS and therefore their experience level was not available. The length of time the most current sociaf worker had been assigned to the case was also not available. Independent samples t test suggested that social workers of the Legacy Group had significantly less experience than social workers of the Permanency Group ( $M$ Legacy Group $=6.19, S D=4.42 ; M$ Permanency Group $=$ 7.96, $S D=4.42 ; t=-2.30, p<.02)$.

\section{Educational Degree of Social Worker}

Educational degree of most recent social worker was not found to be have a relationship with or to be predictive of Legacy Group. These data were then recoded into a dichotomous variable with 0 being degree not recognized by Council on Accreditation (COA), and 1 being COA approved degree. COA is the accrediting body for public child welfare agencies, including Kentucky's

Department for Community Based Services. Most of the children in this study had social workers with a COA approved degree $(n=196)$. This included 88 of the Legacy Group and 108 Permanency Group $\left(x^{2}=.08\right.$, df $\left.1, p<.43\right)$. To determine the effects of educational degree on retention, independent samples $t$ 
test found no significant differences in the experience level of staff without COA approved degrees $(N=227, t=1.01, p<.31)$.

\section{Summary of Social Worker Variable Findings}

Two social worker variables were found to be significant predictors of membership in the Legacy Group. The social worker influenced path model to Legacy Group illustrates the predictive relationship between having more days between case planning conferences and a higher number of placements for the Legacy Group. Number of days between case plans was the strongest social worker predictor, accounting for morê than $70 \%$ of the variance in the Legacy Group. Regression analyses completed with increased number of days as the dependent variable identified four strong predictors of being a Legacy Child: (a)

fewer social workers, (b) more restrictive placement, (c) child's parental rights being terminated, and (d) fewer monthly face to face parent/child visitations. Regression analyses were also conducted with the second direct child predictor of Legacy Group, increased number of placements. Three variables were predictive of the number of placements for Legacy Children: (a) more restrictive placement, (b) higher child development rating, and (c) higher average monthly cost of care for the child. Individual attributes of social workers, including experience level and variables related to amount of contact with the parent and child, and assignment of permanency goal, were not found to be predictors of Legacy Group but were significantly different between the two groups. 


\section{System Variables Findings}

Descriptive data are provided for the eight system variables to demonstrate comparisons between the Legacy and Permanency Groups (Table 26). Variables found to be significantly different between the Legacy and Permanency children groups were: (a) number of social workers, (b) type of placements, (c) parental rights are terminated, and (d) cost of care.

\section{Table 24}

System Variables Descriptive Statistics

\begin{tabular}{|c|c|c|c|}
\hline System Variable & Legacy Group & $\begin{array}{c}\text { Permanency } \\
\text { Group }\end{array}$ & $p$ \\
\hline $\begin{array}{l}\text { Proximity of } \\
\text { placement }\end{array}$ & $\begin{array}{l}N=125, M=45.26 \\
S D=80.50\end{array}$ & $\begin{array}{l}N=150, M=38.45 \\
S D=56.27\end{array}$ & $\begin{array}{l}p<n s \\
t=.76\end{array}$ \\
\hline $\begin{array}{l}\text { Degree of } \\
\text { supervisor }\end{array}$ & $\begin{array}{l}n=65 \text { non social } \\
\text { work degree, } n=18 \\
\text { BSW, } n=42 \mathrm{MSW}\end{array}$ & $\begin{array}{l}n=102 \text { non social } \\
\text { work degree, } \\
n=14 \mathrm{BSW} \\
n=34 \mathrm{MSW}\end{array}$ & $\begin{array}{l}p<.02 \\
x^{2}=7.32\end{array}$ \\
\hline $\begin{array}{l}\text { Mean number of } \\
\text { social workers } \\
\text { based on number } \\
\text { of months in foster } \\
\text { care }\end{array}$ & $\begin{array}{l}N=125 \\
M=.06 \\
S D=.03\end{array}$ & $\begin{array}{l}N=150 \\
M=.37 \\
S D=.38\end{array}$ & $\begin{array}{l}p<.0001 \\
t=-9.00\end{array}$ \\
\hline $\begin{array}{l}\text { Mean monthly cost } \\
\text { of child's care }\end{array}$ & $\begin{array}{l}N=125 \\
M=\$ 1399.67 \\
S D=938.86\end{array}$ & $\begin{array}{l}N=150 \\
M=\$ 2874.75 \\
S D=\$ 3508.87\end{array}$ & $\begin{array}{l}p<.01 \\
t=-2.35\end{array}$ \\
\hline $\begin{array}{l}\text { Most current mean } \\
\text { daily amount paid } \\
\text { for child's care }\end{array}$ & $\begin{array}{l}N=125 \\
M=\$ 86.42 \\
S D=\$ 68.25\end{array}$ & $\begin{array}{l}N=150 \\
M=\$ 41.32 \\
S D=\$ 41.34\end{array}$ & $\begin{array}{l}p<.0001 \\
t=-2.35\end{array}$ \\
\hline Type of placement & $\begin{array}{l}\text { State foster care } \\
62.4 \% \\
\text { Private foster care } \\
\text { and residential } \\
\text { settings } 20.8 \% \\
\text { Relative } 5.6 \% \\
\text { Psychiatric hospital } \\
4 \% \\
\text { Adoptive placement } \\
1.6 \%\end{array}$ & $\begin{array}{l}\text { State foster care } \\
62.4 \% \\
\text { Private foster care } \\
\text { and residential } \\
\text { settings } 16.7 \% \\
\text { Relative } 21.3 \% \\
\text { Psychiatric hospital } \\
2 \% \\
\text { Adoptive placement } \\
3.3 \%\end{array}$ & $\begin{array}{l}x^{2}= \\
19.15 \\
d f=8 \\
p<.014\end{array}$ \\
\hline
\end{tabular}


Table 24 (Continued)

\begin{tabular}{|c|c|c|c|}
\hline System Variable & Legacy Group & $\begin{array}{c}\text { Permanency } \\
\text { Group }\end{array}$ & $p$ \\
\hline Court system & $\begin{array}{l}n=88(70.4 \%) \\
\text { District/Circuit court, } \\
n=37(29.6 \%) \\
\text { Family court }\end{array}$ & $\begin{array}{l}n=95(63.3 \%) \\
\text { District/Circuit court } \\
n=55(36.7 \%) \\
\text { Family court }\end{array}$ & $\begin{array}{l}p<n s \\
x^{2}=1.52\end{array}$ \\
\hline $\begin{array}{l}\text { Termination of } \\
\text { parental rights }\end{array}$ & $\begin{array}{l}n=86(68.8 \%) \\
\text { Legally free for } \\
\text { adoption }\end{array}$ & $\begin{array}{l}n=50(33.3 \%) \\
\text { Legally free for } \\
\text { adoption }\end{array}$ & $\begin{array}{l}p<.0001 \\
x^{2}=34.31\end{array}$ \\
\hline
\end{tabular}

Three system variables demonstrated strong positive correlations with

Legacy Group: (a) degree of supervișor, (b) type of placement, and (c) legal status of child. Two system variables had strong negative correlations with Legacy Group: (a) mean number of social workers assigned to the case, and (b) mean monthly cost of child's care. Table 25 identifies all system variables and their strength of correlations with Legacy Group.

\section{Table 25}

System Variables and Legacy Group Correlations $(n=275)$

\begin{tabular}{|l|r|r|}
\hline \multicolumn{1}{|c|}{ System Variable } & Pearson $\mathbf{r}$ & \multicolumn{1}{c|}{$\mathbf{P}$} \\
\hline $\begin{array}{l}\text { Mean number of social workers based on } \\
\text { number of months in foster care }\end{array}$ & -.47 & .000 \\
\hline Legal status of child & & \\
\hline Type of placement & .35 & .000 \\
\hline Degree of supervisor & .16 & .005 \\
\hline Mean monthly cost of child's care & -.14 & .011 \\
\hline Court system & -.07 & .019 \\
\hline Proximity of Placement & .04 & .218 \\
\hline
\end{tabular}

(Legacy Group $=1$, Permanency Group $=0$; Degree of Supervisor $-M S W=1$, Other degree $=0$; Type of Placement Coded 1 to 7 from least to most restrictive placement; Court system: Family Court $=1$, District/Circuit Court $=0$ ).

The last variable subgroup regression model completed for this project was the System Predictor Regression Model (Model Four). Three system 
variables were excluded from the final system model due to their inability to predict Legacy Group (type of court system, degree of supervisor, and proximity of placement). The final system model produced a significant regression equation $\left(F(4,27)=5.44, R^{2}\right.$ of .31$) .31 \%$ of the variance in the Legacy Group were accounted for by these variables when considering only system variables.

Table 26

System Variables and DV Legacy Group Model Summary

\begin{tabular}{|r|r|r|r|r|r|}
\hline Model & R & R Square & $\begin{array}{c}\text { Adjusted } \\
\mathbf{R} \\
\text { Square }\end{array}$ & $\begin{array}{c}\text { Std. Error } \\
\text { of the } \\
\text { Estimate }\end{array}$ & $\begin{array}{c}\text { Durbin } \\
\text { Watson }\end{array}$ \\
\hline 4 & .56 & .31 & .30 & .41 & .40 \\
\hline
\end{tabular}

Table 27

System Variables and DV Legacy Group ANOVA Table

\begin{tabular}{|l|r|r|r|r|r|}
\hline \multicolumn{1}{|c|}{ Model } & \multicolumn{1}{|c|}{$\begin{array}{c}\text { Sum of } \\
\text { Squares }\end{array}$} & \multicolumn{1}{|c|}{ df } & $\begin{array}{c}\text { Mean } \\
\text { Squares }\end{array}$ & \multicolumn{1}{|c|}{ F } & Sig. \\
\hline Regression & 46.25 & 4 & 11.56 & 142.36 & .000 \\
Residual & 21.02 & 270 & .08 & & \\
Total & 68.18 & 274 & & & \\
\hline
\end{tabular}

In Model 4, four system variables were found to be significant predictors of Legacy Group: (a) living in a more restrictive placement, (b) having fewer social worker changes in the case, (c) a lower monthly cost of child's care, and (d) child's parental rights had been terminated. The most significant system predictor variable was average number of social workers assigned to the case. This variable had a Beta weight of -.400 indicating that the Legacy Group had significantly fewer social workers. Regression analyses were completed with this 
variable and the other three strong system predictor variables as dependent variables.

Five variables were identified as strong predictors of increased number of social workers $\left(R^{2}=.447, p<.0001\right)$. In order of significance these were (a) decreased number of days between case plans $\beta=-.433$, (b) increased social worker/parent face to face contact $\beta=.248$, (c) child's rights have not been terminated $\beta=-.156$, (d) nonoccurrence of physical abuse $\beta-.104$ and (e) lower child development rating $\beta=-.096$. Variables identified as strong predictors of the second system predictor, more restrictive placements were (a) higher last per $\operatorname{diem} \beta=.423$, (b) child's permanency goal $\beta=-.203$, (c) higher entry age $\beta=$ .160 , and (d) not having siblings $\beta=.112$. The third strong system predictor, higher average cost of care, had three strong predictors: (a) more restrictive placement $\beta=.198$, (b) number of placements $\beta=.188$, and (c) higher age at entry $\beta=.127$. The last system predictor, child's parental rights are terminated, had eight strong predictors: (a) child's permanency goal is adoption, $\beta=-.368$, (b) increased number of days between case plans $\beta=.179$, (c) increased number of social workers assigned to the case $\beta=.147$, (d) fewer average monthly face to face parent/child visits $\beta=-.141$, (e) lack of occurrence of neglect $\beta=-.138$, (f) higher maltreatment rating $\beta=.121$, (g) child is a minority, $\beta=.119$ and $(h)$ child is younger at entry into foster care $\beta=-.100$. The System Predictor Path Model (Figure 5) identifies the four direct strong system predictors and the indirect predictor associated with each along with their corresponding Beta weights. 
Table 28

System Variable and DV Legacy Group Coefficients Table

\begin{tabular}{|c|c|c|c|c|c|c|c|}
\hline \multirow[t]{2}{*}{ Model 4} & \multicolumn{2}{|c|}{$\begin{array}{c}\text { Unstandardized } \\
\text { Coefficients }\end{array}$} & \multirow{2}{*}{\multicolumn{2}{|c|}{$\begin{array}{c}\text { Standardized } \\
\text { Coefficients }\end{array}$}} & \multirow[t]{2}{*}{$t$} & \multirow[t]{2}{*}{$p$} & \multirow[t]{2}{*}{$\begin{array}{l}\text { Correlations } \\
\text { Zero Order }\end{array}$} \\
\hline & $B$ & $\begin{array}{l}\text { Std. } \\
\text { Error }\end{array}$ & & & & & \\
\hline (Constant) & 1.78 & .10 & & & 17.65 & .000 & \\
\hline $\begin{array}{l}\text { Termination } \\
\text { of parental } \\
\text { rights }\end{array}$ & .19 & .05 & . & .194 & 3.56 & .000 & .35 \\
\hline $\begin{array}{l}\text { Average } \\
\text { cost of care }\end{array}$ & -3.97 & .00 & : & -.216 & -4.09 & .000 & -.14 \\
\hline $\begin{array}{l}\text { Type of } \\
\text { placement }\end{array}$ & 4.63 & .01 & & .171 & 3.23 & .001 & .16 \\
\hline $\begin{array}{l}\text { Average } \\
\text { number of } \\
\text { social } \\
\text { workers }\end{array}$ & -.61 & .08 & & -.400 & -7.40 & .000 & -.47 \\
\hline
\end{tabular}




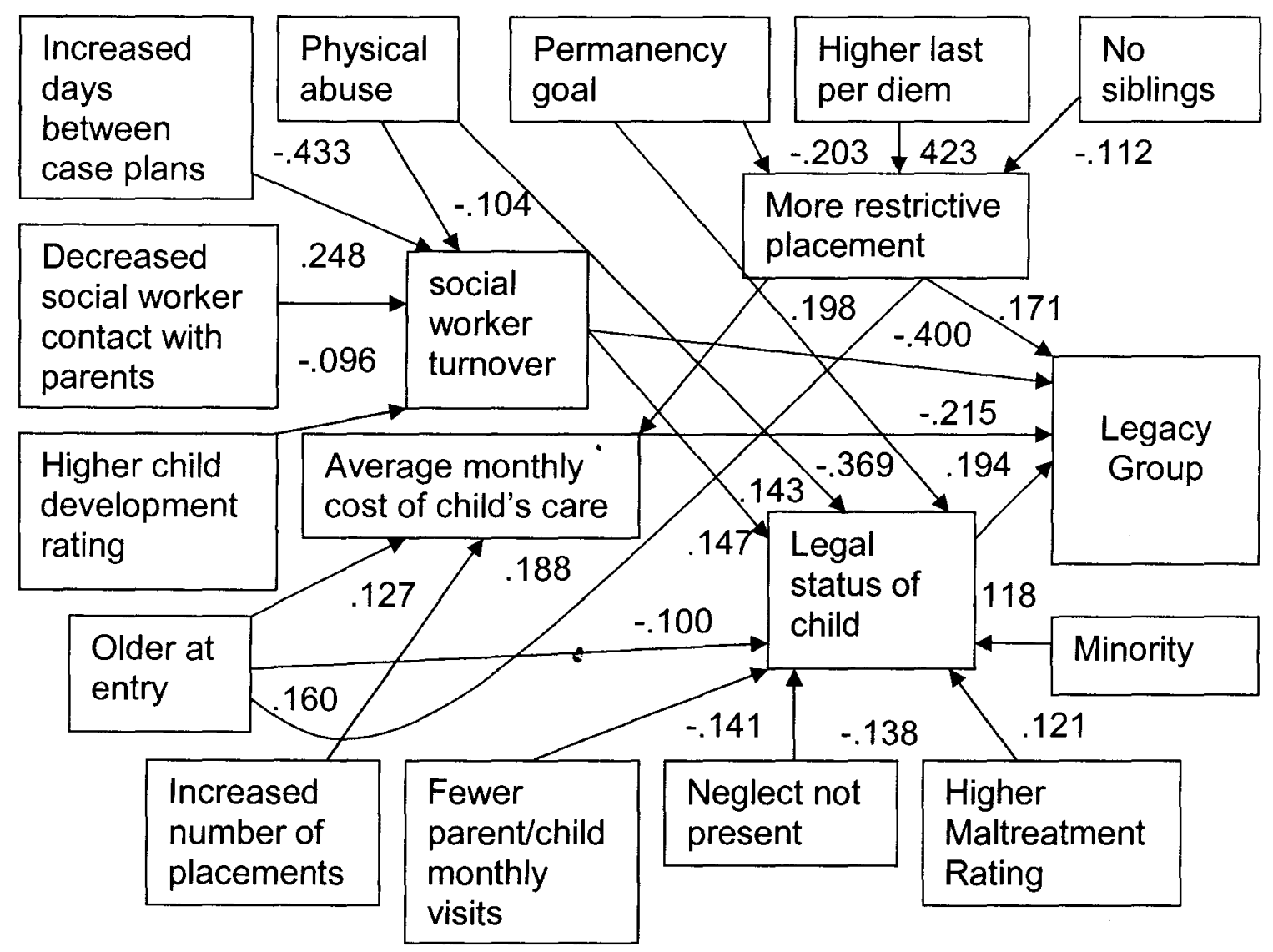

Figure 5 System Predictor Path Model

\section{System Variables Predictive of Legacy Group}

Following is more information pertaining to the four predictive system variables identified in the System Predictor Regression Model. Detailed descriptive data are provided related to these variables and their predictors.

\section{Legacy Group Predictor: Number of Social Workers Assigned to Case}

Children in the Legacy Group experienced significantly fewer social worker changes than the Permanency Group. To allow for the differences in time in foster care, the number of social workers assigned to the case was divided by the number of months the child was in care. Legacy children averaged .0685 
social workers compared to .37 for Permanency children (SD Legacy Group $=$ $.03 ; S D$ Permanency Group $=.37 t=-9.0, p<.0001)$. Mean number of social workers were analyzed by permanency goal of the child. Children with a goal of planned permanent living arrangement had the lowest mean number of social worker changes at $.04(S D=.02)$, followed by children with a goal of adoption (M $=.11(S D=.09)$, return to parent $(M=.45, S D=.41)$, and goal of emancipation $(M=.50, S D=.40)$.

\section{Predictors of Number of Social Workers Assigned to the Case}

Five variables were strong predictors of number of social workers assigned to the case: (a) number of days between case plans, (b) physical abuse, (c) amount of parent/social worker face to face contact, (d) initial child development rating, and (e) child's parental rights being terminated. Regression analyses completed with the dependent variable being average number of social workers, and the predictor of days between case plans accounted for $34.4 \%$ of the variance in average number of social workers. Children with a finding of physical abuse had significantly fewer social workers than children with no finding of physical abuse. These children had a mean of $.19(S D=.23)$ social workers compared to $.27(S D=.37) t=2.07, p<.03$. Children with parental rights terminated had a mean of $.11(S D=.006)$ social workers compared to .35 $(S D=.03)$ social workers for children whose rights were not terminated $(t=6.58$, $p<.0001)$. Independent samples $t$ test were completed to determine if children's whose parental rights are terminated had significantly different child development 
ratings. No significant differences were found $(M$ Parental rights terminated $=$

1.66, $S D=.147 ; M$ Parental rights not terminated $=1.46, t=-1.22, p<.22$ ).

\section{Legacy Group Predictor: Type of Placement}

Type of placement for the Legacy and Permanency Groups were collected as nominal data that also included a numerical rating. Type of placement was rated by level of restrictiveness with relative and adoptive placements being the least restrictive placements, followed by DCBS foster care, private agency foster care and facilities, shelters, and psychiatric hospitalization. Legacy Children were more likely to be in more restrictive placements than children in the Permanency Group. Both the Permanency and Legacy Groups had comparable numbers being cared for by state foster parents. The Legacy Group had a greater number of children being care for by private child care agencies in private foster homes or residential facilities $(20.8 \%$ for Legacy Group vs. $16.7 \%$ for Permanency Group). The Legacy Group also had a greater number of children in psychiatric facilities. Four percent of Legacy Group members compared to $2 \%$ of the Permanency Group's last placement were listed as a psychiatric hospital. Legacy Children were less likely to experience less restrictive placements such as placement with relatives and adoptive placements. Slightly over $5 \%$ of Legacy children compared to $21.3 \%$ of the Permanency Group were placed with relatives and only $1.6 \%$ of Legacy Group compared to $3.3 \%$ of the Permanency Group were in adoptive placements. 


\section{Predictors of Type of Placement}

Four variables were identified as predictors of being in more restrictive placements: being older at entry, not having siblings, permanency goal, and higher last per diem. Mean entry age for children in the least restrictive placement, relative placement, was 7.27 years $(S D=4.00)$. Mean entry age for children in the most restrictive placement, psychiatric hospitals, had a mean entry age of 12.05 years $(S D=5.05)$. Sixty-seven of the 275 children in this study had no siblings. The majority of these children were placed in DCBS foster homes ( $n$ $=37$ ). Three of these children were placed in adoptive homes and 6 were placed with relatives. The remaining children with no siblings were placed in the most restrictive placements including psychiatric settings $(n=6)$, private child care agencies $(n=11)$ family treatment homes $(n=2)$, and medically fragile placements $(n=2)$.

Children with goals of emancipation were in the most restrictive placements $(M=6.00, S D=4.24)$, followed by children with goals of adoption (M $=3.80, S D=1.55)$, return to parent $(M=3.51, S D=2.07)$, planned permanent living arrangement $(M=3.40, S D=1.72)$ and placement with relatives $(M=1.65$, $S D=1.26)$. More restrictive placements were also more costly. Private child care agencies had the highest average per diem at $\$ 119.82(S D=\$ 71.09)$, followed by family treatment homes $(M=\$ 103.42, S D=\$ 76.89)$, Psychiatric settings $(M=$ $\$ 103.42, S D=\$ 120.15)$, and medically fragile setting $(M=\$ 60.13, S D=\$ 34.26)$.

Placements with the lowest per diem were adoptive placements $(M=\$ 17.85, S D$ 
$=\$ 3.43)$, relative placements $(M=\$ 22.38, S D=\$ 38.36)$, and DCBS foster homes $(M=\$ 45.51, S D=\$ 45.03)$.

\section{Legacy Group Predictor: Average Monthly Cost of Care}

Total cost of care for the children in this project ranged from 0 to $\$ 481,273$. For total time in foster care, the monthly cost of caring for a member of the Legacy Group averaged $\$ 1,366.07,(S D=938.86)$ compared to $\$ 2,127.17$ $(S D=3508.87)$ for the Permanency Group. However, the last daily amount paid for the Permanency Group's, care compared to the most recent daily amount paid for the Legacy Group's care, was̊ lower $(M$ Legacy Group $=\$ 86.42 ; M$ Permanency Group $=\$ 41.32)$. Children with a goal of return to parent had the highest mean monthly cost of care for both groups combined $(M=\$ 2127.64)$. Legacy children with this goal had a mean monthly cost of $\$ 1,186.09$ compared to Permanency children whose monthly mean cost for care was $\$ 2,233.73$. Children with a goal of adoption had the second highest mean cost of care for both groups combined at a mean of $\$ 1,907.86$ per month. When the two groups were reviewed separately Permanency children whose goal was adoption had a much higher mean monthly cost of care at $\$ 2,735.43$ compared to $\$ 1,481.28$ for the Legacy Group. Children with a goal of placement with relatives had the lowest mean total cost of care at $\$ 761.88$ for both groups combined.

\section{Predictors of Average Monthly Cost of Care}

Three variables were strong predictors of cost of care: type of placement, number of placements, and age at entry. Children in relative placements had the lowest average monthly cost of care when reviewed by type of placement. 
Average monthly cost of care for children placed with relatives was $\$ 504.18$. This compared to a mean monthly cost of $\$ 1,453.87$ for children placed in DCBS foster care and $\$ 3,779.77$ for children placed with private child care agencies. As previously discussed children who are in more restrictive placements also have a greater number of placements. Information regarding cost of care in relation to number of placements has already beęn provided and will not be repeated here.

The last predictor of monthly cost of care was being older at entry.

Children who were between the ages of 0 to 5 years had an average monthly cost of care of $\$ 1,449.99(n=106, S \delta=\$ 1,600.74)$, followed by children between the ages of 6 to 10 years $(M=\$ 1,492.70, n=65, S D=\$ 1,923.09), 11$ to 15 years $(M=\$ 2,124.52, n=57, S D=\$ 2,277.23)$, and 16 to 18 years $(M=$ $\$ 4,683.67, n=8, S D=\$ 9,575.07)$.

\section{Legacy Group Predictor: Termination of Parental Rights}

Termination of parental rights must occur to legally make the child available for adoption, $68.8 \%$ of the Legacy Group was legally free for adoption. Due to the stratified random sample discussed at the beginning of this chapter, one-third of the Permanency Group was also legally free for adoption.

The difference in the amount of time it took for termination of parental rights (tpr) so that these children could become legally free for adoption for these two groups was statistically significant $(N=136, t 11.91, d f 134, p<.0001)$. The Legacy Group averaged being in foster care 34.41 months prior to a legal judgment freeing them for adoption compared with 9.48 months for the Permanency Group. Kentucky has Family Court in several of its larger judicial 
court circuits and more traditional district and circuit court systems in many of the smaller counties of Kentucky. For this project, $29.6 \%$ of Legacy children and $36.7 \%$ of the Permanency Group's cases were overseen by Family Courts. Chi Square and Independent Samples T Test analyses were conducted to determine if type of court system affected whether parental rights were terminated and if rights were terminated the amount of time prior to termination. Chi-square analysis did not find a relationship between type of court system and child being legally free for adoption $x^{2}(d f 1)=.03, p<.50$. Independent Samples $t$ test did not find a statistically significant difference in the amount of time prior to tpr for children in the family court versus traditional circuit/district court systems. The mean length of time to termination of parental rights in circuit/district court for these children was 23.95 months compared to 20.84 months for children in the family court system.

\section{Predictors of Termination of Parental Rights}

Eight variables were identified as predictors of termination of parental rights: (a) permanency goal of adoption, (b) being younger at entry, (c) being a minority, (d) no finding of neglect, (e) higher maltreatment rating, (e) increased number of social workers, $(\mathrm{g})$ fewer parent/child face to face visitations, and $(\mathrm{h}$ ) increased number of days between case plans. Of these permanency goal was the strongest predictor. Of the 136 children in this study whose parental rights had been terminated, 127 had goals of adoption $\left(x^{2}(d f 4)=187.51, p<.0001\right)$. The remaining children whose parental rights had been terminated had the following goals: 1 return to parent, 2 emancipation and 6 had goals of planned 
permanent living arrangement. Mean age at entry for children whose parental rights were terminated was 6 years $(S D=4.60)$, compared to 8.34 years $(S D=$ 5.23) years for children whose rights were not terminated $(t=3.92, p<.0001)$.

Minority children were also more likely to have parental rights terminated. Of the 47 minority children in this study, 30 had parental rights terminated ( $x^{2}$ ( $d f$ $1)=4.68, p<.03)$. Length of time until,termination for minority children was much shorter at 19.26 months $(S D=17.11)$ compared to 26.94 months $(S D=14.46)$ for Caucasian children $(t=2.23, p<.02)$. Severity and type of abuse were also predictors of termination of parental rights. Children whose parental rights were terminated had a mean initial maltreatment rating of 2.27 compared to 1.44 for children whose rights were not terminated $(t=-4.27, p<.0001)$. These children were also significantly less likely to have a finding of neglect. Eighty-three of the 185 children with a finding of neglect had parental rights terminated $\left(x^{2}(d f 1)=\right.$ $4.76, p<.03)$.

Number of days between case plans for children whose rights were terminated were 137.29 compared to 77.44 days for children whose rights were not terminated $(t=-6.98, p<.0001)$. Children who had fewer parent/child visits were more likely to have parental rights terminated. Mean number of monthly face to face parent/child pre termination visits were .45 for children whose rights were eventually terminated. Children whose rights were not terminated had 2.49 monthly pre-termination visits with their parents $(t=4.68, p<.0001)$. 


\section{System Variables That Were Not Predictive of Legacy Group}

Two system variables were not predictive of Legacy Group, educational degree of supervisor and proximity of placement. As discussed in the section on termination of parental rights, type of court system was also not a predictor of Legacy Group. Educational degree of the supervisors in the Legacy and Permanency Groups did differ significantly.

\section{Educational Degree of Supervisor}

Although educational degree was not found to be a predictor of Legacy Group, it was found to have a significånt relationship with Legacy Group. Educational degree of supervisor was coded as a dichotomous variable of $0=$ does not have Masters in Social Work, and 1 = supervisor has Masters of Social Work. Supervisors for 76 of the children in this study had Masters of Social Work degrees. This included 42 of the Legacy Group and 34 of the Permanency Group. Chi Square analyses conducted for the relationship between supervisor's degree and Legacy Group was significant $\left(x^{2}=4.07, d f 1, p<.03\right)$.

\section{Proximity of Placement}

Statistically significant differences were not found in the distance Legacy and Permanency Groups were placed from their homes. The Legacy Group had a slightly higher mean number of miles between their home and their most recent placement $(M$ Legacy Group $=45.26 ; S D=80.50 ; M$ Permanency Group $=$ $38.45, S D=56.27 t=.76, n s)$. These data were also compared by race of child, type of placement and year of entry. African American children were placed significantly closer to their homes than Caucasian children ( $M$ African American $=$ 
17.52 miles; $M$ Caucasian $=46.82$ miles, $S D$ African American $=28.08, S D$ Caucasian $=76.58)$. Regarding effects of placement type on proximity, children who were placed in psychiatric hospitals or with private child care agencies were placed further from their homes $(M=63.19, S D=60.81)$. Children in adoptive placements or with relatives were placed closest to their homes of removal ( $M$ adoptive placements $=12.95, S D=12.74 ; M$ relative placements $=34.48 ; S D=$ 64.61). By year of entry, children were placed the following mean number of miles from their homes; $M 1999=46.14$ miles; $M 2000=30.48$ miles; $M 2001=$ 28.55 miles; $M 2002=29.68$ miles and, M $2003=53.81$ miles.

\section{Summary of System Variable Findings}

Eight system variables were included in this study. Four of these variables were significantly different between the Legacy and Permanency Groups including average number of social workers assigned to the case, type of placement, legal status and cost of care. Legacy Children were found to have fewer social worker changes, more restrictive placements, were more likely to be legally free for adoption and had a lower mean monthly cost of care. These four variables were also strongly correlated with Legacy Group, along with a fifth variable, degree of supervisor. The average cost of care and number of social workers were negatively correlated, while restrictiveness of placement, being legally free for adoption and the supervisor having a Masters of Social Work were positively correlated. The System Regression Model was completed with all system variables to determine their relationship with predicting Legacy Group. The four variables identified in this model as significant predictors were the same 
variables found to be significantly different between the two groups and to have strong correlations with Legacy Group with the exception of degree of supervisor. These variables produced a strong regression equation by accounting for approximately $31.9 \%$ of the variance in the Legacy Group when only considering system variables.

\section{Integrated Regression Model}

Variables found to be strong direct predictors from each of the four subgroups regression models were included in the Integrated Regression Model to determine the best overall model for predicting Legacy Groups. Thirteen variables were included in this model with the following coming from each model; 1. Family Model - having more than one child, occurrence of neglect, occurrence of sexual abuse, mean number of monthly parent/child visits, and family and community support rating; 2 . Child Model - initial child development rating, and race; 3. Social Worker Model - number of days between case plans and number of moves child experiences; and 4. System Model - average cost of child's care, legal status of child, type of placement and average number of social workers assigned to the case. After initial analysis, 6 variables were excluded from the model due to their inability to predict Legacy Group: including average number of social workers $\beta=-.00, n s ;$ type of placement $\beta=.02, n s$; initial child development rating $\beta=-.04, n s ;$ occurrence of neglect $\beta=-.02 ; n s ;$ presence of sexual abuse $\beta=.04, n s ;$ and mean number of monthly parent/child visitation $\beta=$ $-.001, n s$. Tables 29,30 and 31 include the regression equation, significance levels and predictive variables for this model. With the inclusion of all significant 
predictor variables identified in the four subgroup models, the final model accounted for approximately $69.7 \%$ of the variance in the Legacy Group. Number of days between case plans was the most significant predictor with a Beta weight of .58 and zero order correlation of .78 .

Table 29

Integrated Model Summary (Dependent Variable Legacy Group)

\begin{tabular}{|l|r|r|r|r|r|}
\hline $\begin{array}{c}\text { Model 5 } \\
\text { Integrated }\end{array}$ & $\mathbf{R}$ & R Square & $\begin{array}{c}\text { Adjusted } \\
\mathbf{R} \\
\text { Square }\end{array}$ & $\begin{array}{c}\text { Std. Error } \\
\text { of the } \\
\text { Estimate }\end{array}$ & $\begin{array}{c}\text { Durbin } \\
\text { Watson }\end{array}$ \\
\hline Integrated & .83 & .69 & .68 & .27 & 1.18 \\
\hline
\end{tabular}

Table 30

Integrated Model ANOVA Table (Dependent Variable Legacy Group)

\begin{tabular}{|l|r|r|r|r|r|}
\hline \multicolumn{1}{|c|}{ Model 5 } & $\begin{array}{c}\text { Sum of } \\
\text { Squares }\end{array}$ & \multicolumn{1}{|c|}{ df } & $\begin{array}{c}\text { Mean } \\
\text { Squares }\end{array}$ & \multicolumn{1}{|c|}{ F } & Sig. \\
\hline Regression & 47.52 & 7 & 6.79 & 87.78 & .000 \\
Residual & 20.65 & 267 & .07 & & \\
Total & 68.18 & 274 & & & \\
\hline
\end{tabular}


Table 31

Integrated Model Coefficients Table

\begin{tabular}{|c|c|c|c|c|c|c|}
\hline \multirow[t]{2}{*}{ Model 5} & \multicolumn{2}{|c|}{$\begin{array}{l}\text { Unstandardized } \\
\text { Coefficients }\end{array}$} & \multirow{2}{*}{$\begin{array}{c}\begin{array}{c}\text { Standardized } \\
\text { Coefficients }\end{array} \\
\text { Beta }\end{array}$} & \multirow[t]{2}{*}{$t$} & \multirow[t]{2}{*}{$\mathbf{p}$} & \multirow[t]{2}{*}{$\begin{array}{l}\text { Correlations } \\
\text { Zero Order }\end{array}$} \\
\hline & B & $\begin{array}{l}\text { Std. } \\
\text { Error }\end{array}$ & & & & \\
\hline (Constant) & 2.25 & .06 & & 35.91 & .000 & \\
\hline $\begin{array}{l}\text { Termination } \\
\text { of parental } \\
\text { rights }\end{array}$ & 8.19 & .03 & .082 & 2.14 & .033 & .35 \\
\hline $\begin{array}{l}\text { Average } \\
\text { cost of care }\end{array}$ & -3.51 & .00 & -.190 & -5.29 & .000 & -.14 \\
\hline $\begin{array}{l}\text { Days } \\
\text { between } \\
\text { case plans }\end{array}$ & 3.81 & .00 & .588 & 13.92 & .000 & .78 \\
\hline $\begin{array}{l}\text { Number of } \\
\text { placements }\end{array}$ & 3.83 & .00 & .245 & 6.23 & .000 & .48 \\
\hline $\begin{array}{l}\text { Race of } \\
\text { child }\end{array}$ & -.12 & .04 & .091 & -2.60 & .010 & -.16 \\
\hline Siblings & .10 & .04 & .092 & 2.61 & .009 & .26 \\
\hline $\begin{array}{l}\text { Family } \\
\text { support } \\
\text { rating }\end{array}$ & 3.56 & .01 & .097 & 2.76 & .006 & .25 \\
\hline
\end{tabular}

\section{Integrated Legacy Predictor Path Model}

Direct and indirect paths to Legacy Group are included in the Legacy

Predictor Path Model. The seven variables identified in the Integrated Regression

Model included as direct predictors of Legacy Group were (a) entering care with siblings, (b) child being Caucasian, (c) lower rating of family and community support rating, (d) lower average cost of child's care, (e) higher number of days 
between case plans, (f) child being available for adoption, and (g) child having a higher number of placements.

To determine indirect relationships with Legacy Group, regression analysis were completed with each of the four direct predictors that occurred after the child entered foster care as dependent variables. The integrated Legacy Predictor Path Model demonstrates the se relationships and includes the Beta weights for each of the indirect predictors. These four variables and their predictor variables in order of significance were:

1. Number of days between case plans predictor variables; average number of social workers assigned to the case, more restrictive placement, the child is legally free for adoption and lower number of monthly parent/child visits

2. Average cost of child's care predictor variables: More restrictive placement, increased number of placements, and older entry age,

3. Child is legally available for adoption predictor variables: Permanency goal of adoption, return to parent or relative placement, increased number of days between case plans, increased number of social workers assigned to the case, fewer monthly parent/child visits, no finding of neglect, higher maltreatment rating at point of entry into foster care, child is Caucasian, and child is younger at entry into foster care, and

4. Number of placements predictor variables: Initial child development rating, average cost of child's care and type of placement. 
One direct predictor and two indirect predictor variables of Legacy Group were ratings assigned by the social worker at point of entry into foster care. These ratings were based on indicators of risk. Regression analyses were completed with each of the three ratings as dependent variables and the indicators as predictor variables. Indicators predictive of each rating and their Beta weights are included in the Integrated Legacy Predictor Path Model. 


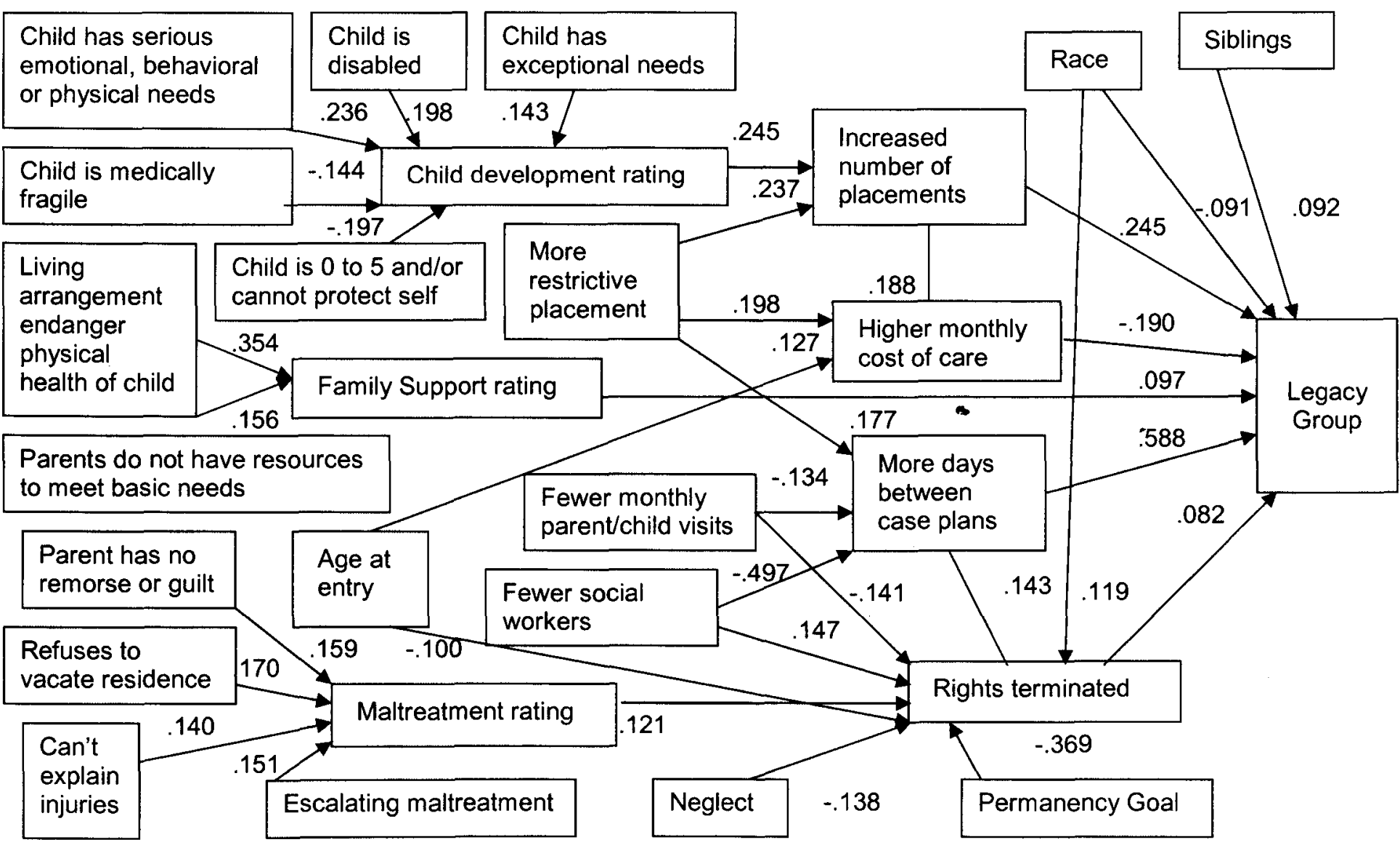

Figure 6 Integrated Legacy Predictor Path Model 


\section{Ethnographic Interviews}

Information gathered directly from a random sample of Legacy Children in ethnographic interviews was included to increase knowledge regarding children's perceptions of permanency. Twenty current foster care children who had spent four years or more in care were interviewed for this project. Four children from each of the following age groups were randomly selected, 8 to 9 years, 10 to 11 years, 12 to 13 years, 14 to 15 years and 16 to 17 years old. Interviews with 13 females and 7 males were conducted at each child's current residence. Ten of these children were Caucasian and terf were African American. Their median length of time in care was 55 months. Although they had long periods of time in foster care, $20 \%$ ( 4 children) had only had 1 placement during their entire stay in foster care. Over $50 \%$ ( 11 children) were in foster/adoptive placements and were in some stage of the adoption process.

\section{Perceptions of Permanency}

During these interviews children were asked questions related to their perceptions of permanency. Children were asked specific questions about their length of stay in foster care and their permanency goal. Almost every child reported their stay in foster care to be longer than reported in both their electronic and hardcopy file. Thirteen children accurately reported their permanency goal. Of these 13, 12 children had goals of adoption. Only 1 child reported not knowing her permanency goal. Five of the 7 children who inaccurately reported their permanency goal, reported to having goals of relative placement or return to parent but actually had goals of adoption or planned permanent living with their 
current foster families. One child reported her goal was adoption but it was actually permanent planned living with her current foster family. Fifteen of the foster children agreed with their permanency goals. Of the 12 children who had goals of adoption, 9 agreed that this was the correct goal for them.

The children who did not agree with their permanency goal being adoption said that this was due to their age or their own desires about being adopted. These children made statements such as "Feel I am too old to be adopted, no one would adopt a 17 year old, and I don't want to be adopted". Two children stated they did not want to be adopted, but could not articulate why. Children who agreed with their permanency goal gave responses consistent with a need for a permanent family including: "I want a new start and my own family", "I want to be apart of something" and "I have been waiting on this since I was 2 years old".

All children were asked if they understood what the word permanency meant and if anyone had spoke to them about what permanency meant for them. Four of the 20 children interviewed stated they understood what permanency meant and could describe accurately how permanency related to them. Other children's perceptions of permanency seemed to be closely related to past definitions of permanency, such as permanency means "long term care" or "you stay where you are until you have somewhere else to go". When asked to rate their own ability to influence the length of time until permanency was achieved, children rated themselves as having the least amount of power to influence how long they stay in foster care compared to social workers, judges, foster parents, 
birth parents and therapist. All children, even those in adoptive placements who reported understanding that permanency meant being adopted and having a "forever family", reported concerns about the possibility of being moved.

\section{Placement Stability}

Regardless if the child had 1 or 20 different placements, instability of placement was a recurrent theme for the 20 legacy children interviewed. Although 14 of the 20 children interviewed stated that they participated in case planning and were involved in making decisions for their future, these children appeared to lack confidence in their placement future. Children spoke openly about their feelings of helplessness and insecurity regarding placement decisions: "social workers move you anytime they feel like it", "I might be moved away from someone before they can adopt me" and "I don't want to keep moving to different homes".

All children interviewed reported a higher number of placements than they had actually experienced. On average, children reported having 5 more placements than documented by the Children's Review Program, the agency which is responsible for tracking children's moves in foster care. Although these children had concerns related to stability in placement, they also appeared hopeful that permanency could be achieved for them. When asked "How long do you expect to stay where you are currently?" 15 of the 20 children interviewed stated they expected their current placement to be their last. Children responded they would be staying in their current placement: until the age of 18 , they were adopted, as long as they were a child, or for their entire life. Nineteen of the 20 
children interviewed reported liking their current placement more than past placements. Reasons for this varied from feeling more respected and loved to having a greater amount of freedom than previously experienced.

While most of the children interviewed seemed to be expressing their feelings regarding a need for permanency, they also appeared to maintain emotional connections to their birth families. Children were asked questions related to their entry into foster care to assess their understanding of their history. Most of these children were unable or unwilling to inform the interviewer why they were placed in foster care. Some children would state nonspecific answers such as "My mom was unable to take care of us". Older children were more likely to doubt reasons they had been told of why they could not live with their parents and also to hold out hope that they may intend return to their parent's or a relative's care again.

All of the children interviewed stated they had little to no contact with their birth families. When asked if they would like to have more, less or about the same about of contact with their birth families, approximately $25 \%$ responded that they would like to have more contact with their birth family, with the majority of these children being in the oldest two categories of children interviewed.

\section{Suggestions for Improvement of Foster Care}

The final questions asked of Legacy Children during the ethnographic interviews were: What are the best and worst things about foster care and how would you change foster care? Children's responses focused on their need for permanency, safety, and well being. Foster care was noted as being positive by finding families and keeping children safe. Some children reported they were 
being provided for in ways their families could or would not. Children reported being healthy, being treated good, being happy, excited about living with a parent that is nice, and knowing that they are cared about. They also reported the need to be treated similar to other children who are not in foster care. Legacy children wanted to ability to drive a car, hunt, have more contact with siblings, not be moved from place to place, have more freedom and have a greater voice in decisions being made for them.

Legacy children had several suggestions for changing the foster care system. When asked this question, chilidren appeared to give much thought prior to answering: I don't understand a lot of what is on my paperwork, I would like to know what some of this means, they need to watch who they hire as foster parents, some foster parents just want a check, foster kids need more allowance, talk to kids more, treat everyone the same, don't take so long to be adopted, need to have better relationships with parents and relatives, don't send kids to respite as much - unless they really need it, work more toward getting the kids back with their families and with the courts, let kids be adopted by the first home they are in, make them feel good in their homes, see my social worker more, help kids when they first come into foster care - it is scary first coming into care. 


\section{CHAPTER 5}

\section{DISCUSSION}

The purpose of this final chapter is to summarize the findings from data analysis and to integrate this data with previous literature and other findings pertaining to permanency for children in foster care. The findings will be discussed by variable area. There will also be a discussion of the limitations of this research and data analysis. Implications for social work practice, policy and research will be provided. Lastly, recommendations for future research based on the results of this study will be outlined.

The Adoption and Safe Families Act (ASFA) of 1997, P.L., 105-89, created new outcomes for children in foster care and expectations for those who are responsible for the foster care system. With ASFA's implementation, states are required to ensure that children have permanent families either through return to parent and/or relatives, or through adoption within a two year time frame. Although seven years have passed since ASFA's passage, many children continue to remain in foster care indefinitely. All 50 states, along with the District of Columbia and Puerto Rico, have undergone initial reviews to determine their compliance with obtaining ASFA goals for safety, permanency and well being of 
children. None have passed ASFA's Permanency Outcome 1 related to achieving permanency and stability in placement. Seven states have passed Permanency Outcome 2 which evaluates children's continuity and preservation of family relationships and connections. After each review, states were allowed to submit Program Improvement Plans to demonstrate how improvements will be made in any outcomes that were not achieved. If states do not show an increase in their compliance with outcomes during subsequent reviews held every two years, federal funding may be decreased by $1 \%$ for each of the outcomes still not in compliance. States have now begứn their second round of Child and Family Service Reviews. Kentucky's next review will begin in 2006. To prepare, states must address barriers to permanency. This dissertation examined variables used as indicators of permanency by Child and Family Service reviewers. These variables were considered by subgroups of family, child, social worker and system variables to determine the overall impact of each on permanency and to provide direction for service delivery. An integrated regression model which included variables from all of the four subgroups identified seven variables that were strongly predictive of long term foster care for the children in this study. Understanding the influence of these variables on permanency may provide Kentucky's DCBS and other child welfare agencies opportunities to guide service delivery toward meeting the needs of these populations.

\section{Summary of Findings by Predictor Variable}

Seven variables were found to be significant predictors of placement in the Legacy Group. Three of these variables were present at point of entry into foster 
care: (a) entering foster care with siblings, (b) being Caucasian, and (c) lower level of positive support from extended family and community. The remaining four variables occurred after the child entered care: (a) longer periods of time between case planning conferences, (b) lower average cost of care, (c) number of moves the child experienced, and (d) termination of parental rights. The following discussion focuses on underștanding how these variables and their predictors affected permanency for the children in this study.

\section{Level of Family and Community Support}

Families of children in long term care were found to be more likely to have incomes below the poverty line $\left(x^{2}(d f 1)=9.64, p=.001\right)$ and to be assessed by their social workers as having fewer positive resources to support their families $(M$ Legacy Group $=1.68, S D=1.52 ; M$ Permanency Group $.99, S D=1.12, p<$ $.000)$. Indicators associated with the family's living arrangements and not having basic resources to meet the needs of the child were predictive of level of family support as rated by the social worker at entry into foster care. Previous studies have reported similar results with this project including findings that about half of all children who enter out of home care are IV-E eligible (Courtney, et al., 1999) and that children whose families received AFDC were more likely to be in care three years or longer (Albers et al, 1993).

The level of risk associated with lack of positive support may have been exacerbated by the greater needs of these families, especially in the area of mental health. Parents/caretakers of Legacy Children in this project statistically had more adult risk indicators $(M$ Legacy Group $=5.14, S D=5.53 ; M$ 
Permanency Group $=3.68, S D=3.66), t=2.62, p<.0001$ and a higher risk rating for their individual adult patterns of behavior ( $M$ Legacy Group $=2.77, S D$ $=1.59 ; M$ Permanency Group $=2.08, S D=1.68), p<.001$. The only adult risk indicators found to have a statistically significant relationship with permanency were those associated with the parent/caretaker having a mental health problem that either was not being treated or was not improving with treatment. Prior studies have shown that a diagnosis of chronic and debilitating mental illness, psychosis, schizophrenia, borderline personality disorder, sociopathy, or other illnesses that respond slowly or not af all to current treatment, greatly increase a child's length of time in foster care (Faller, 1984; Fanshel \& Shinn, 1978; Jellinek, Murphy, Poitrast, Quinn, Bishop, Goshko, 1992; Jenkins, 1967; Katz and Robinson, 1991; Lawder et al., 1986; Rzepnicki, Schuerman \& Johnson, 1997; Schety, Angell, Morrison, \& Sack, 1979; Wattenberg, 2001). Mental illness has also been documented as the most common reason to terminate parental rights (Sackett, 1991).

Parents/caretakers in these families may have themselves come from abusive environments or have been raised in foster care. If this is true extended family may not be considered as positive or safe connections for the family and the child. Relatives may be less likely to be approved as caretakers for the child because of prior involvement with child protection agencies. Families of the Legacy Group may also have a reluctance to seek community supports because of fear of the child protection system or others becoming involved in their lives. Some have expressed concerns regarding child protection social workers' 
inability to effectively treat clients with mental illness and the lack of clear objectives for improving parenting and role definition for mental health providers whose clients are also in the child protection system (Ackerson, 2003; Raske, 1997). Due to many more mentally ill persons living in the community instead of mental health institutions, child protection social workers and mental health providers may be dealing with many more individuals who are mentally ill and parents. While DCBS appears to be have trained social workers to identify and assess the extent to which mental illness contributes to risk of harm to children, more work appears to still be needed in the areas of developing support systems and providing services to these families. One issue that would potentially be helpful to staff is recognizing reasons that mentally ill parents may not seek treatment.

During Kentucky's last CFSR, an Area in need of improvement rating was received in both its service array and accessibility to services indicators. Significant gaps were found in several services including, but not limited to, childcare, transportation, medical, and mental health service. Such gaps could definitely impact these families' abilities to improve their behavioral functioning.

\section{Siblings in Foster Care}

For this study, the children who entered foster care as part of a sibling group were more likely to experience extended stays in foster care. Although Legacy Children were statistically more likely to be a part of a sibling group ( $x^{2}$ $(\mathrm{df1})=19.01, p<.000$ ), they were also more likely to be placed separately from all or some of their siblings. Previous studies have produced similar findings. 
Glisson et al., (2000) found that children with a sibling in foster care were 39\% less likely to leave custody than children without siblings in care, even when controlling for other factors. In other studies, children who were apart of a sibling group were less likely to exit to adoption and reunification. Over $70 \%$ of the Legacy Group's permanency goals were adoption. Less than $7 \%$ had goals of reunification. Avery (1999) found that children placed with their siblings were more likely to be placed for adoption than those not placed with their siblings. Due to Legacy Children's increasing behavioral needs, they may be considered less adoptable than their younger or healthier siblings or these needs may be viewed as too great to be met if other children are placed in the home. However, this project's findings along with the previous literature suggest that greater success may be found in obtaining permanency for these children if sibling groups can be placed together.

CFSR recognized children's needs of attachment with siblings. Agencies are to place siblings together if at all possible. As part of Kentucky's Program Improvement Plan, $90 \%$ of DCBS social workers and foster parents must complete training related to understanding the attachment needs of children by December 2005. One of the primary goals of this training is to increase recognition of sibling attachment.

\section{Race of the Child}

Numerous statutes and policies have been developed to address the overrepresentation of minority children in America's foster care population. Some of these include MEPA (P.L. 103-382), IEPA (P.L. 104-88) and ASFA (P.L. 105- 
89). Findings from this dissertation suggest that these measures may be working.

Race was found to be a significant predictor of Legacy Group in this study, however, not in the same manner discerned in other studies. Approximately $86.4 \%$ of the children in this study who experienced long term care were Caucasian. CFSR aggregated state data from initial reviews and concluded that race was not a barrier to permanency especially for children with a goal of adoption. Significant relationships were found in this study with African American children being more likely to be freed for adoption and to have adoption as a permanency goal. African American children were also significantly more likely to be placed closer to their own communities than Caucasian children (M African American $=17.52, S D=28.08 ; M$ Caucasian $=46.82, S D=76.58)$ suggesting that greater opportunities for these children to find permanency may be found in their own communities. Improvements may also be due to Kentucky's increased efforts to remove barriers to permanency for minority children through by recruiting of foster and adoptive parents for minority children.

\section{Number of Foster Care Placements}

Ethnographic interviews completed with current foster children who are experiencing long term foster care, suggest that foster children's number one concern is being moved from place to place. Regardless of the number or type of placements these children had experienced, they voiced concerns about suddenly being moved. These children also had great hopes that they would find permanency, feeling that their most recent or next placement would be their last. Stability of placement is thought to greatly impact children's emotional, 
behavioral and physical well being. This study found that number of moves is closely associated with permanency. CFSR standards for placements are $<2$ placements during the child's entire time in care. Members of the Legacy group had a mean of $5.09(S D=3.68)$ number of placements compared to the Permanency Group who had a mean of $1.99(S D=1.73)$ different placements. Predictors of having more foster care placements were respectively: child development rating at time child entered foster care $(\beta=245)$, more restrictive placement $(\beta=.237)$, and higher average monthly cost of care $(\beta=.188)$.

Legacy children were found to have sígnificantly higher child development risk ratings at entry into foster care $(M$ Legacy Group $=1.49, S D=1.43 ; M$ Permanency Group $=1.12, S D=1.24, t=5.8, p<.0001)$. These ratings are assigned by the social worker as an indication of the abuse/neglect risk to the child based upon their physical, behavioral and emotional needs. Factors such as age, medical needs, educational level, and intellectual functioning are included as anchors in this rating. Within this development rating specific indicators of risk were identified as being predictors of child development rating: child has serious physical, emotional or behavioral symptoms $(\beta=.236)$, child is disabled $(\beta=.198)$, child has exceptional needs that the parent would not/could not meet $(\beta=.143)$, child is older than 0 to 5 and is seen as being able to protect self $(\beta=-.197)$, and child is not medically fragile $(\beta=-. .144)$. 
The second predictor of number of moves was type of placement. Legacy children were found to be in more restrictive placements than the permanency children group. Children who were placed in psychiatric hospital settings and private child care had a higher mean number of placements than children who were placed in less restrictive placements such as with relatives and in DCBS foster homes ( $M$ Psychiatric Hospitals = 19; $M$ Private Child Care $=4.60 ; M$ DCBS foster care $=3.32 ; M$ Relative Placements $=1.70)$. Increased number of moves may have occurred as children were moved from less to more restrictive placements in response to increasing behavioral needs. Permanency may be more difficult to obtain for children who live in the most restrictive placements, including detention, group homes and institutions. These children may not know how to live in family like settings or to interact in a community settings, such as school. Knowing a child is currently living in an institution may also be a concern for potential adoptive parents. Social workers, who are handling cases such as these, where children may have severe behavior problems but also need permanency, may be uncertain how to accomplish both goals of meeting the child's mental health and permanency needs. One of the concerns that children who were interviewed expressed was the being placed in respite too often. Children with more severe needs may be placed in respite homes, thus giving children the perceptions of having more placements. The use of respite services for these children may also contribute to attachment difficulties if numerous respite providers are used. Respite placements can be used for up to two weeks in some cases. These issues need further consideration as some children's 
needs may necessitate longer periods of treatment prior to placement into an adoptive home or returning them home.

Lastly, having a higher cost of care was predictive of number of moves. Obviously, the most restrictive placements are also the most costly. Higher average costs suggest that children may have started out in more restrictive placements and remained in these placements for most of their stay in foster care. Results suggest something different, Legacy Group were found to have a lower average monthly cost of care suggesting they were placed in less restrictive and less costly placements during at least a part of their stay in foster care. During Kentucky's last CFSR, concerns were noted by reviewers that children were not matched with placements that met their needs, but instead, placements were made based on what was available.

Portions of data pertaining to stability of placement from this study were promising. For each year of entry considered in this study the mean number of placements decreased $(M 1999=4.32, S D=.3 .47 ; M 2000=1.73, S D=.77 ; M$ $2001=1.55, S D=1.05 ; M 2002=1.23, S D=.65 ; M 2003=1.09, S D=.30)$.

\section{Cost of Care}

Variables associated with cost of foster care were collected included the last per diem paid to the care provider for the child's care and total cost of care for the child's entire stay in foster care. To obtain an average mean monthly cost of care for each child, total cost of care was divided by the total number of months the child was placed in foster care. Legacy children had a significantly higher most recent daily cost of care than the Permanency Group ( $M$ Legacy 
Group $=\$ 86.42, S D=\$ 68.25 ; M$ Permanency Group $=\$ 41.32, S D=\$ 41.32, t=$ $-2.35, p<.000$ ), but a significantly lower average monthly cost of care for total time in foster care $(M$ Legacy Group $=\$ 1,399.67, S D=\$ 938.86 ; M$ Permanency Group $=\$ 2,874.75, S D=\$ 3,508.87, t=-2.35, p<.01)$.

Three variables were found to predict cost of care (in order of significance): more restrictive type of placement $(\beta=.198)$, increased number of placements $(\beta=.188)$, and being older at entry $(\beta=.127)$. Cost of care for Kentucky's foster children may increase as number of moves increase due to this being a determining factor in assigning the child's Auchenbach level on which payment is based. More restrictive placements are also often more costly due to the provision of intensive services including individual and family counseling, psychiatric services, educational, medical and behavioral services. Placements for younger children into these types of settings are discouraged due to concerns regarding institutionalization. CFSR monitors the number of children 12 or under, who are placed in institutions or group homes. States are expected to have fewer than $5 \%$ of their total foster care population under the age of 12 in such placements. Older children may be more likely to be placed in institutional settings and not be placed in foster/adoptive placements due to concerns about attachment to the family of origin and beliefs that older children are not adoptable (Barth \& Berry, 1988; Bush \& Gordon, 1982; Westat, 2001)

\section{Number of Days between Case Plans}

Regularity of case planning was the strongest predictor of Legacy Group. Legacy children were found to have a significantly longer length of time between 
case planning conferences with a mean of 173 days $(S D=33.66)$ between conferences compared to 52.31 mean days $(S D=57.66)$ for the Permanency Group. Kentucky's DCBS requires that case planning conferences occur at least every six months (Kentucky Revised Statutes 620.180, 2001). For children who found permanency in this study, case planning was occurring closer to every three months than the six month requirement. Regression analyses conducted with days between case plans as a dependent variable assisted in identifying four predictors of increased number of days between case plans: having fewer social worker changes while child was in foster care $(\beta=-.497)$, living in a more restrictive type of placement $(\beta=.177)$, child being legally free for adoption $(\beta=$ $.143)$, and lower number of monthly parent/child visits $(\beta=-.134)$.

The strongest predictor of increased days between case plans was fewer social worker changes. Continuity of care is an issue considered as extremely important because of concerns related to grief and loss that children in long term care may experience and fears of children being lost in the foster care system. Having fewer social workers is thought to be preferable in order to ensure that the social worker is fully aware of the child's need and can serve as an advocate for those needs. In this study, the need for permanency was the primary consideration. For children in this project having fewer social workers did not ensure the need for permanency was met. One possible explanation is the increased use of specialized teams who are responsible for time limited tasks. In some regions of Kentucky's DCBS, the use of specialized teams means a different social worker may be assigned at the following points of the case: (a) at 
the time adoption becomes the goal, (b) when termination of parent rights are obtained, (c) when recruitment activities are needed to identify an adoptive parent for the child, and (d) when a decision is made to change the goal from adoption to an alternative goal.

Changing workers may also increase the number of reviews and guidance for the case, and may reduce stagnation by addressing the possibility of permanency being delayed because of social worker ambivalence or particular attitudes about permanency. There has not been consistency with findings from previous studies regarding how social worker turnover influences permanency. Potter and Klein-Rothschild (2002) reported that children were $52.4 \%$ less likely to achieve permanency for each additional social worker assigned to their cases. Goerge (1994) found that having more caseworker turnover increased children's likelihood of finding permanency, especially to reunification. This dissertation had hoped to consider social workers' beliefs related to attachment and empathy as predictors of permanency. Unfortunately, information was not available due to the low response rate of surveys sent to staff to assess these issues.

The second predictor of increased days between case plans was more restrictive placement. Days between case plans may be greater for children in these placements for a number of reasons. Children in these placements were placed significantly further away from the home $(M=63.19, S D=60.81)$. DCBS policy requires less face to face social worker contact with these children than children in other types of placements. Children in these placements are to have one face to face social worker visit every three months. All other placements, 
such as with relatives and DCBS foster homes, require a monthly face to face visit. Having more contact with the child may increase the social worker's ability to prepare the child for permanency and to recruit adoptive homes for the child. Due to termination of parental rights these children would in most cases not be having contact with family members or have a community support system and therefore may lose connections to their communities without some type of work to maintain those ties through face to face contact. Children who are in more restrictive placements are also thought to have more behavioral needs which require longer periods of time to stabilize or treat. Discussions of permanency may create even more behavioral problems. Scheduling of case planning conferences may be based on the child's behavioral progress prior to attempts to facilitate permanency.

Being legally free for adoption was also a strong predictor of longer lengths of time between case plans. During each case planning conference completed by the social worker a permanency goal is selected for the child. This is the anticipated goal that the child will exit foster care and ultimately that will determine the child's legal status if the child's goal is adoption. Permanency goals are selected by the social worker, but must be approved by both the social worker's supervisor, the court system and in some areas by other staff, who oversee permanency issues on both regional and state levels. These goals may also be reviewed by community partners and/or independent bodies such as Kentucky's Foster Care Review Board that is made up of private citizens. Legacy Children predominantly had been given a permanency goal of adoption 
( $77 \%)$. The original random sample of Permanency children was modified to include a sufficient number of children with a goal of adoption for comparisons. In order for this goal to be accomplished termination of parental rights must occur making the child legally free for adoption.

Case planning is extremely important for parents whose children's permanency goal is adoption. Case plans are often used in termination of parental rights proceedings to demonstrate whether parents have made progress on goals and objectives given to them by the social worker, court or others. Participation in case planning was significantly different for families of the Permanency and Legacy Groups who had goals of adoption in this project. Permanency children with the goal of adoption had the lowest parental attendance at case planning conferences with less than $20 \%$ attendance. For Legacy children, parental attendance at case planning conferences when the goal was adoption had the second highest attendance at approximately $40 \%$ followed only by the goal of return to parent. These findings suggest that the families of Legacy children are remaining more involved in case planning than Permanency families. Families with increased involvement may be seen as having more interest in having their children returned to them. These families may have been given more time between case plans to make improvements before their progress was evaluated in order to make decisions regarding changing the child's permanency goal from return to parent to adoption or other alternate goals. This project also found that families of Legacy children had greater involvement than permanency families in case planning even after 
termination of their parental rights. Since case planning conferences are also attended by the child, such involvement may give conflicting messages to the child regarding their future and need to be accepted into a permanent family.

The last variable that was predictive of days between case plans was average number of monthly face to face parent/child visitations. Parent/child visitation has historically been viewed as one of the primary indicators of permanency for children. Legacy and Permanency children appeared to travel in different directions on their parent/child visits. While Legacy children began with more mean face-to-face visitations affer the first 30 days up to the first six months, their number of visitations gradually decreased after this time.

Permanency children had lower mean number of visits during the first 30 days, 90 days and first six months, than Legacy Children. However, after the first six months their face to face visitations gradually increased. Permanency children families had a statistically significant higher mean number of monthly visitations than the Legacy Children families overall at 2.2187 visits per month. Legacy children families had a mean of .5988 monthly face to face visitations. A minimum of two visits per month between children in out of home care and their families is a DCBS requirement for all families, unless other restrictions have been put into place, such as a court ordered no contact between the parent and child. Visitation for this project was not documented by number of parents who attended each visit. However this would be useful data. If both parents are not visiting simultaneously, as was the case for most children in this project, the required number of monthly face to face parent/child visitations would be four, 
two visitations per parent per month. CFSR reviewers noted that in most cases reviewed, visitation with both parent, especially fathers was occurring less frequently than required.

More work is needed to thoroughly assess issues pertaining to visitation. In a recent study completed with a large sample of Kentucky's foster children, foster/adoptive parents were asked to rate the importance of the child visiting with their biological parents and the results were as follows; $31 \%$ said this did not apply to the children in their care (due to reasons such as getting ready to adopt the child or an absent parent), $18 \%$ ratted the visitation as very important, $18 \%$ were neutral on this question, $9 \%$ rated it as very unimportant, and $8 \%$ of the foster/adoptive parents said that the visitation was unimportant (Sullivan, 2002). Overcoming barriers to maintaining parent/child attachment is monitored through CFSR reviews. A chi-square analysis did not find that visitation was affected by the child's needs, or by the level of maltreatment experienced by the child. However, the child's well being was influenced by parent/child visitation. Children who had an appropriate number of visitations were found to have improved behavioral functioning as evident by their improved Internal, External and Total Behavior Scores on the Children's Behavior Checklist. Previous studies have found that parent/child visitation can have a stabilizing effect for children in foster care and that positive parental involvement can impact the effectiveness of service providers (Cantos, Gries \& Stiles, 1997; Colon, 1978; Fanshel \& Shinn, 1978; Hess, 1988; Littner, 1975; Schatz \& Bane, 1991; Tiddy, 1986). More work 
is needed to understand how attitudes regarding visitation may impact parent/child contact and to understand the impact of visitation on child well being.

\section{Termination of Parental Rights}

Previous studies have expressed concerns that while ASFA increases the number of children available for adoption by easing termination or parental rights laws, the end results will not be more children adopted, just more children who have had their legal ties with their biological parents severed (Avery, 1999; Craig \& Hebert, 1997; Guggenheim, 1995; Sheldon; 1997). Aggregated state data support these concerns. Of the 523,000 children in foster care in $2003,118,000$ or $22.5 \%$ were waiting to be adopted (USDHHS, 2004). In 2003, approximately 49,000 children were legally adopted through the public child welfare agency, a $7.5 \%$ decrease from 53,000 in 2002 (USDHHS, 2004). $68.8 \%$ of the Legacy Group and $33.3 \%$ of the Permanency Group were legally free for adoption. To determine at what point termination of parental rights may have affected permanency for these children, the number of months in care until termination was calculated. Statistically significant differences were found between the two groups in the number of months they remained in foster care prior to termination of parental rights occurring. Mean length of time until termination of parental rights for the Permanency Group was 9.48 months compared to 34.41 months for the Legacy Group. CFSR reviewers had documented concerns in several states that reunification goals were maintained for too long, termination of parental rights were not being filed in a timely manner, and that adoption was not considered prior to making decisions for long term foster care (USDHHS, 2003d). 
Some studies have found however, that delays in permanency most often occurred in the post termination period (Avery, 1999; Craig \& Hebert, 1997; Sheldon, 1997; Tatara, 1993). ASFA mandates that agencies file to terminate parental rights after the child has been in foster care 15 of the last 22 months. For the Legacy Group in this project, this did not occur.

To determine which children were more likely to have parental rights terminated a regression analysis was completed with legal status as the dependent variable. Eight predictors of being legally free for adoption were identified: (a) no finding of neglect, (b) increased days between case plans, (c) child being older at entry, (d) increased number of social workers, (e) less parent/child visitation, (f) child being African American, (g) permanency goal of adoption and $(\mathrm{h})$ higher maltreatment rating at entry. Variables that were present at entry will be discussed first. From these findings children who enter care with a higher maltreatment rating, being younger, African American and having no finding of neglect were more likely to have parental rights terminated. Findings related to race have previously been discussed. The fact that more African American children are available for adoption may be due to increased recruitment and encouragement for transracial adoptions. Social workers may be more willing to terminate rights on children when they know there is a greater likelihood of them being adopted. They may also be more willing to terminate parental rights, if no appropriate family exists for relative placements. Children in this study had significantly lower levels of family support. African American children are thought to have greater familial support in regards to relative 
placements due to cultural norms and/or extended familial obligations. The decision to terminate parental rights on African American children may be clearer in cases where children have no familial ties exist or those ties are inappropriate.

Being younger at point of entry prior to ASFA was a predictor of long term foster care. It was proposed this was due to families of these children being given extensive periods of time to overcome the issues related to abuse or neglect. Furthermore, younger children are consider more vulnerable due to their inability to protect themselves, courts may be more cautious about returning them home, but also more ambivalent about terminfating rights on younger children. The longer children remain in foster care the less likely they are to exit to adoption.

Members of the Legacy Group who had goals of adoption were significantly older at entry than Permanency Children who had exited to a goal of adoption. The only Kentucky court decision published which specifically discussed ASFA, addresses the issue of age in terms of terminating parental rights. In this ruling, the Court of Appeals of Kentucky overruled a lower court's decision which cited the children's ages as a reason to deny termination of parental rights - specifically, that the children knew who their families were and that adoption was unlikely for them due to their ages. Judge J. Combs, writing for the Court of Appeals of Kentucky stated "although the children are teenagers, their rights to a safe and stable home should be afforded no less consideration than that afforded to a child of tender age. The statute (ASFA) does not place any age limit on the right of a child to have his best interest weighted in the balance" (p. 5). This very recent ruling (May 28, 2004) may assist social workers 
in making decisions regarding termination of parental rights on other older Kentucky foster children.

Other indicators of termination of parental rights that were present at point of entry were (a) having no finding of neglect, and (b) a higher maltreatment rating. Children in the Legacy Group had more child protection referrals, higher maltreatment rating at entry and a number of indictors that were predictive of more severe maltreatment. Courts may be more willing to terminate parental rights on children who are more severely abused and where poverty or lack of resources are problematic.

ASFA allows for the expedited permanency of children whose families have histories of severe abuse and neglect. These cases are deemed to have "aggravated circumstances" existing that do not require the social worker to make reasonable efforts to reunify the child and family. Some of these aggravated circumstances involve maltreatment, specifically if a parent has been criminally convicted or was involved in harming a child. Reunification is greatly reduced in the presence of serious prior harm, which includes repeated or premeditated harm to the child in question and where three or more child protective service interventions have occurred. Many members of the Legacy Group had experienced severe maltreatment as evidenced by the maltreatment rating given at the time the child entered foster care: however, these families were less likely to have received criminal charges related to harming a child. The lack of legal interventions with these families may have prevented the use of "aggravated circumstances" to expedite permanency for some children. 
Aggravated circumstances as a whole should be reviewed to determine the extent of its use to obtain permanency in cases where it is allowed.

After entering foster care, children becoming legally free for adoption was influenced by having a greater number of days between case plans, increased number of social workers assigned to the case, fewer monthly parent/child visitations, and the child having a permanency goal of adoption. The process to terminate parental rights previously discussed identified the role of case planning and permanency goal in this practice. Termination cannot occur without recognition by the court that the family has not made progress to alleviate risk of abuse and neglect. Agencies must also demonstrate that the parents were fully aware of the consequences. Full disclosure of permanency goals and time frames are required by ASFA. Having an increased number of days between case plans for children with a goal of adoption may be due to delays in making decisions to change the child's permanency goal to adoption, or in court delays.

Reasons for court system delays were not clearly documented in the DCBS electronic or hardcopy files. DCBS has recently begun an initiative to document court dates for each child in care in their electronic files. This practice should improve the ability to track reasons for delays in termination of parental rights cases. In response to lack of compliance with establishing appropriate permanency goals within mandated time frames, Kentucky now requires a review of each foster child's permanency needs by a DCBS attorney when the child has been in care for nine months. This process may help to ensure that permanency goals are appropriate, and result in changing goals to adoption if needed. 
Findings that children who have a goal of adoption is predictive of being legally free for adoption is a good sign. Courts play an integral role in permanency for children. Rulings in these matters suggest that courts are aware of the need to pursue permanency through termination of parental rights. Prior to ASFA, substantially fewer terminations of parental rights and adoptions were occurring.

The last two variables that were predictive of the child being legally free for adoption were (a) having more social workers, and (b) fewer parent/child visitations. The use of specialized teams as previously discussed as being predictive of more frequent case planś may have helped facilitate the termination process in a timely manner. Staff who are familiar with the termination process may be more capable of completing tasks such as working with court officials - a task with which that less inexperienced staff may not be as familiar or competent. Having staff who are better trained in ASFA may also help recognize cases which should move quickly to termination such as in cases where there is little to no contact between the parent and child. Parents who do not regularly visit their children or who are restricted from visitation by the court may be more likely to have permanency expedited due to parents not fighting termination or ongoing risk issues which prevent visitation. These children may also be seen as more capable of attaching to new families due to lack of visitation.

\section{Limitations of the Research}

Limitations of this research are those associated with the collection of data from secondary sources. Much of the data were acquired from hardcopy DCBS files, electronic reports acquired from DCBS' TWIST computer files, and from 
other sources, i.e., Auchenbach and Children's Behavior Checklist data obtained from the Children's Review Program. These data were originally collected for other reasons. There is always the possibility that pertinent information was not properly documented. Because hardcopy and electronic DCBS files were used as documentation for CFSR outcomes, which this study measures, data findings should be consistent.

A number of internal validity weaknesses are associated with the static group comparison design used in this study, i.e., selection and mortality. The entire population of Kentucky's Legacy children was compared to a stratified random sample of children who obtained permanency within ASFA's required time frames. This project could not control for the possibility that these groups differed in some manner that influenced the permanency outcomes they experienced. Legacy Group members had been in foster care for at least 48 continuous months, meaning that they entered foster care primarily in 1999 and 2000. The Permanency Group entered foster care anywhere from 1999 through 2003. As time passed, it is possible that practices and policies related to ASFA have become more progressive, affecting children who enter the system more recently in a more substantial manner than children who have been in foster care longer.

Mortality is another limitation of this study. Because many children leave the foster care system within very short periods of time, data may not be collected for them to the extent it is collected for children who remain in the system for longer periods of time. One example of this is Auchenbach/Child 
Behavior Checklist data. Social workers have 90 days to complete these instruments after the child enters care. These data would not be available for most children who exited the foster care system prior to 90 days, making it extremely difficult to understand the behavioral effects of short term foster care.

\section{Implications for Social Work Practice}

Social work has historically attempted to advocate for individual needs and rights of clients within standards set by professional organizations and government agencies. Child welfare has undergone a number of changes to improve the lives of children in foster care by setting standards to guide national child welfare practice. Funding for child welfare is now directly tied to accomplishing goals set by the Adoption and Safe Families Act. Research such as this, can assist individual social workers and agencies in evaluating their practices related to permanency. Outcome driven social work is still considerably new for child welfare and other forms of social work. Agencies must find ways to marry the concepts of research outcomes with direct field practices that accomplish goals and standards set by governmental agencies and recognized social work values associated with direct micro practice.

The qualitative research component herein supports the concepts related to direct micro practice, including client centered services. Foster children who were interviewed during this dissertation expressed concerns regarding several of the variables measured by CFSR reviewers, including stability of placement and connections with parents or others. The integrated model suggests that paying attention to the symptoms of the children as they enter care is important 
and can be used to match children with appropriate placements and services. Some children entering foster care may need to be placed in more restrictive placements at the onset. Legacy children appeared to have more severe needs but to be placed in least restrictive placements. These children eventually graduated to more restrictive placements. The use of thorough assessments and more restrictive placement for intensively treatment may be needed for some children at entry into foster care to address behavioral issues that be barriers to permanency.

\section{Usefulnéss for DCBS}

Each state, including Kentucky, must submit quarterly progress reports on meeting CFSR outcomes to the United States Department of Health and Human Services. This study found that Kentucky is improving in many of the permanency indicators that CFSR monitors, including number of placements, number of social worker contacts with parents and children, and regularity of case planning. Studies such as this may assist DCBS in developing strategies to address areas which continue to be deficiencies related to permanency.

With the limited resources of child welfare, focus could be placed on variables that are predictive of membership in the Legacy Group. Three of the seven variables, including the strongest predictor of Legacy Group, related to social worker or system variables that occurred after the child entered care. Understanding the influence these variables have on increasing the length of time children spend in foster care may improve the chances of permanency for some Kentucky children. This may be accomplished by using variables predictive 
of long term care to proactively plan. For example, children who entered foster care one child in part a sibling group, are Caucasian, or with a low level of positive family and community support, were more likely to be in long term care in this study. Knowing this may assist social workers in developing strategies directly associated with these barriers, such as development of more support services to care for sibling groups, identifying and strengthening family and community support systems, and recruitmenting of foster/adoptive parents who are willing to offer permanency to these children.

\section{Implications for Policy}

Variables that were found to either directly or indirectly predict permanency in this study can also be used to understand how effective current policies, are and to make suggestions for revising policies as needed. One policy that may need further review is ASFA legislation relating to aggravated circumstances. In many of the Legacy Children's cases, aggravated circumstances appeared to exist, especially in the areas of repeat maltreatment and parents' continued incapacitation due to mental illness even after treatment. For these children however, permanency was not expedited according to the purpose of aggravated circumstances. Review of this policy is needed to determine the barriers to its use. The use of assessment centers such as the CATS clinic in Lexington and the FORECAST clinic in Louisville may help give useful information to workers to determine early in the case the severity of the problem and the likelihood that the situation will change enough to warrant a 
return to parent. The usefulness of this type of intervention for this purpose needs to be explored further.

Findings from this study suggest that cases which received more attention through case reviews and increased case planning may be more likely to achieve permanency. CFSR does not specify how often case reviews should occur with the exception of administrative court reviews that must occur annually.

Kentucky's accrediting agency, Council on Accreditation recommends that case planning occur every three months; however, COA only requires agencies to follow their own policies mandates regarding case planning time frames. Children who found permanency in this study had a mean of 52 days between case plans. Kentucky requires that case plans be completed as least every six months. Length of time between case plans was found to be less for case plans held more recently. Case planning was noted as a strength for Kentucky during its last CFSR review. Kentucky may want to consider changing its policy regarding regularity of case plans to continue the positive trends being seen in this area.

\section{Directions for Future Research}

This study included only a small portion of Kentucky's foster care population. With Kentucky's advanced data collection system, great opportunities exist to obtain an increased understanding of barriers to permanency. A number of areas were identified that are encouraging for Kentucky's child welfare system. Long term analysis is needed to determine whether these trends will continue and if so, whether they truly affect permanency as proposed by CFSR. One area where positive trends were identified is case planning. Decreasing the length of 
time between case planning conferences was the strongest predictor of finding permanency for children. More comparison studies are needed to support these findings.

These data also suggest that the special needs of some children in foster care are determining factors for establishing timeframes for permanency. Legacy Children entered foster care being seen as more at risk for abuse and neglect due to their levels of behavioral, educational and medical needs. They were more likely to be placed in settings associated with having more intensive behavioral needs such as group homes and privăte child care agencies. This study raised questions regarding the influence of behavioral needs and permanency on one another. Legacy Children in this study were found to have behavioral needs which increased during their time in care compared to members of the permanency group whose behavioral needs decreased. Further clarification is needed to determine whether behavioral needs affected permanency or lack of permanency affected behavioral needs. This study would suggest both. Social workers may be attempting to balance the child's needs for permanency with behavioral functioning. These children may need more time to stabilize behaviors and to adjust to new family and community settings. Taking the needed time to meet these children's needs may decrease chances of permanency due to children becoming older and more accustomed to living in facilities and group homes instead of family settings. 


\section{Conclusions}

The Adoption and Safe Families Act created specific safety, child well being and permanency outcomes for foster children. ASFA legally mandates states to find permanent families for the majority of foster children within a two year time frame. States are monitored through Child and Family Service Reviews to determine their compliance with indicators thought to be specifically tied to achieving permanency. While several states have shown improvement in the safety and well being for children, very few states, including Kentucky, have been able to meet the national standards related to permanency for children in foster care. The purpose of this project was to determine which children are most at risk for long term foster care after implementation of ASFA legislation. Federal indicators of ASFA compliance were assessed including variables associated with children, their families, the social workers and macro system factors.

Quantitative and qualitative data collection focused on increasing knowledge of variables that predict permanency and characteristics of children in long term foster care. Each of the four variable subgroups contained variables that were predictive of and/or significantly different between the Legacy and Permanency Groups. The family variables subgroup contained five variable areas that were significantly different: poverty/resources, type and severity of abuse, adult risk indicators, parent/child visitation, and being a part of a sibling group. Of these, having a sibling group, lower level of positive family and community support, fewer parent/child monthly visitations, presence of sexual 
abuse, and nonoccurrence of neglect were predictors of placement in the Legacy Group when only considering family variables.

The child variable subgroup demonstrated that the Legacy Group was predominantly Caucasian and that most were entering care with behavioral problems that increased during their stays in foster care. This compared to Permanency Group whose behavioral problems were seen as either remaining the same or decreasing while in foster care. Legacy Children at point of entry into foster care were rated by their social workers as being more at risk of abuse and neglect due to their behavioral, physićal and emotional needs. Indicators related to child having exceptional needs, or severe behavioral, physical and emotional symptoms, or being older and able to protect themselves, were predictors of how the social worker rated their developmental needs. Child variables which were strong predictors of Legacy Group were race of the child (Caucasian) and higher child development ratings.

Social worker subgroup variables identified a number of differences between the two groups: Legacy Group were more likely to have goals of adoption, increased number of days between case planning, fewer social worker contacts with the family and the child, increased number of foster care placements for the children, and social workers with less experience. The social worker variables, increased number of days between case plans and increased number of foster care placements were strong predictors of long term foster care when only considering social worker variables. 
Four variables from the system variable subgroup were significantly different with the Legacy Group having fewer social worker changes, more restrictive placements, more likely to have parental rights terminated, lower average monthly cost of care, and supervisors with Masters of Social Work degrees. All of the system variables with the exception of supervisor's degree were predictive of long term foster care when only considering system variables.

Predictors of Legacy Group from each of the four variable subgroups were entered into a regression analyses, the following were strongly predictive of long term foster care and accounted for $70^{\circ} \%$ of the variance (a) Caucasian, (b) increased number of placements, (c) lower levels of positive family support present at the time of removal, (d) parental rights are terminated, (e) increased number of days between case plans, and (f) lower average monthly cost of the child's care. The most significant predictor of Legacy Group was days between case planning conferences. This variable accounted for $58.8 \%$ of the variance in Legacy Group when all predictor variables were considered. Regression analyses completed with predictor variables that occurred after the child entered foster care as dependent variables identified a number of variables which indirectly predicted placement in Legacy Group.

Qualitative data found that children in long term foster care have concerns and hopes for their futures. The most common area of concern for foster care pertained to their stability of placement. Children were especially concerned about the number of moves they had experienced or may experience in the future. All children interviewed expressed a desire for permanency although 
some could not specifically articulate what permanency meant for them. Although the time these children had spent in care was considerably long (at least 48 continuous months), to these children it was even longer, with almost every child reporting a longer period of time in care than they actually experienced. Children interviewed offered a number of suggestions for improvements in the foster care system.

This project found that although some children are still experiencing long term foster care, Kentucky has already made a number of policy and practice changes to meet CFSR standards. Improvements are being shown in several indicators of permanency including number of moves, regularity of case planning and amount of social worker contact between the parent and the child. 


\section{REFERENCES}

Ackerson, B. (2003). Parents with serious and persistent mental illness: Issues in assessment and services. Social Work, 48(2), 187-195.

Adoption Assistance and Child Welfare Act, 1980, P. L. 96-272, 94 Stat. 500.

Adoption and Safe Families Act (1997). P.L. 105-90, H. R. 867. Section 103.

Albert, V. (1988). Welfare Dependency and Welfare Policy: A statistical study.

Westport, CT: Greenwood Press.

Albers, E., Rittner, B., \& Reilly, T. (1993). Children in foster care: Possible factors affecting permanency planning. Child and Adolescent Social Work Journal, 10(4), 329-341.

Antle, B. (2002). Training Evaluation for Supervisor Best Practice in Child Welfare. Dissertation Abstracts International, 44, p. 1468-1623, UMI Number: 3078061. 
Armsden, G., Pecora, P., Payne, V., \& Szatkiewicz, J. (2000).Children placed in long-term foster care: An intake profile using the child behavior checklist/4-18. Journal of Emotional \& Behavioral Disorders, 8(1), 49-66.

Areen, J. (1975). Intervention between parent and child: A reappraisal of the state's role in child neglect and abuse cases. The Georgetown Law Journal, 63(4), 887-937.

Avery, R. J. (1998). Foster care histories of children freed for adoption in New York State: 1980-1993. Phase I Grant Report, Grant Number: 5 R01 HD 27529-05. Washington, DC: National Institute for Health and Human Development, U.S. Department of Health and Human Services.

Avery, R. J. (1999). Identifying obstacles to adoption in New York State's out-ofhome care system. Child Welfare, 78(5), 653-172.

Bachrach, L.L. (1984). Deinstutionalization and women: Assessing the consequences of public policy. American Psychologist, 39, 1171-1177.

Barbaranelli, C., Caprara, G.V., \& Maslach, C. (1997). Individuation and the Five Factor Model of Personality Traits. European Journal of Psychological Assessment, 13(2), 75-84.

Barbee, A.P. (2000). Empathy. In D. Levinson, J. Ponzetti, P. Jorgensen (Eds.), Encyclopedia of human emotions. New York: MacMillen Publishing.

Barth, R.P. (1997). Effects of age and race on the odds of adoption versus remaining in long-term out-of-home care. Child Wefare, 76, 285-308.

Barth, R.P., \& Berry, M. (1987). Outcomes of child welfare services since permanency planning. Social Services Review, 61, 71-90. 
Barth, R.P., \& Berry, M. (1988). Adoption and disruption: Risks, rates and responses. New York: Aldine.

Barth, R.P.; Berry, M., Yoshikami, R., Goodfield, R.K., \& Carson, M.L. (1988).

Predicting adoption disruption. Social Work, 33(3), 227-235.

Barth, R.P., \& Courtney, M. E. (1994). Timing is everything: An analysis of the time to adoption and legalization. Social Work Research, 18(3), 139-149.

Barth, R.P., Snowden, L.R., Broeck, E.T., Clancy, T., Jordan, C., \& Barusch, A.S. (1986). Contributors to reunification or permanent out-of-home care for physically abused children. Joúrnal of Social Service Research, 9(2/3), 3145.

Bartholomew, K. \& Horowitz , L. M. (1990). Attachment styles among young adults: A test of a four-category model. Journal of Personality and Social Psychology, 61, 226-244.

Bateson, C.D., O'Quin, K., Fultz, J., Vanderplas, M., \& Isen, A. (1983). Influence of self reported distress and empathy on egoistic versus altruistic motivation to help. Journal of Personality and Social Psychology, 45, 706718.

Benedict, M., \& White, R. (1991). Factors associated with foster care length of stay. Child Welfare, 70(1), 45-48.

Berrick, J., Barth, R.P., Needell, B., \& Jonson-Reid, M. (1997). Group care and young children. Social Services Review, 71, 257-274. 
Berrick, J., Needell, B., Barth, R.P., \& Jonson-Reid, M. (1998). The tender yearsToward developmentally sensitive child welfare services for very young children. New York: Oxford University Press.

Bland, K. (2000). Waiting for too long. The Arizona Republic, September 18.

Board of Social Welfare. (1975). Foster care needs and alternatives to placement: A plan for action. New York: New York State Board of Welfare. Boss, P. (1993). Boundary ambiguity: A block to cognitive coping. In A. Tumbull, J.M. Patterson, \& S.K. Behr (Eds.). Cognitive coping, families and disabilities (pp. 257-270). Baltimore, Brookes.

Boyd, P.E. (1979). They can go home again! Child Welfare, 9, 609-615.

Brace, C.L. (1872). The Dangerous Classes of New York. New York: Wynkoop \& Hallenback.

Bremner, R. (Ed.), (1970). Children and youth in America, A documented history, 1600-1865, (Vol. 1). Cambridge, MA: Harvard University Press.

Bremner, R. (Ed.). (1971). Children and Youth in America: A documented history, 1865-1965 (Vol. 2). Cambridge, MA: Harvard University Press.

Bryce, M.E., \& Ehlert, R.C. (1971). 144 Foster children. Child Welfare, 50, 499503.

Burr, W.A., Falek, A., Strauss, L.T., \& Brown, S.B. (1979). Fertility in psychiatric outpatients. Hospital and Community Psychiatry, 30, 527-531.

Bush, M., \& Gordon, A.C. (1982). The case for involving children in child welfare decisions. Social Work, 27(4), 309-314. 
Cabinet for Health and Family Services. (2003). Standard of Practice, 7C, 4-12, Section 1-8.

Campbell, Donald T., \& Stanley, Julian C. (1983). Experiemntal and quasiexperimental designs for research. Chicago: Rand McNally.

Cantos, A.L., Gries, L.T., \& Slis, V. (1997). Behavioral correlates of parental visiting during family foster care, Child Welfare, 76, 309-329.

Caprara, G.V., Barbaranelli, C., Borgogni, L., \& Perugini, M. (1993). The "Big Five Questionnaire": A new questionnaire to assess the five factor model. Personality and Individual Différences, 15(3), 281-288.

Casey Family Programs (2003). Indvidualized and Targeted Recruitment for Adoption. Retreived from www.casey.org/cnc on April, 1, 2003.

Child Abuse Treatment and Prevention Act. (1974). Public Law 93-247. Coatsee, W.J. (1998). An evaluation model for human services interventions. Unpublished dissertation. Rand Afrikaans University, Johannesburg. Colon, F. (1978). Family ties and child placement. Family Process, 17, 289-312. Council on Accreditation Standards and Self-Study Manual. $7^{\text {th }}$ Edition, 2001. Courtney, M. E. (1994). Factors associated with the reunification of foster children and their families. Social Service Review, 68, 81-108.

Courtney, M. E., Barth, R. P., Berrick, J., Brooks, D., Needell, B. \& Park, Linda, (1999). Race and child welfare services: Past research and future directions. Child Welfare 125(2), 100-137.

Courtney, M.E., \& Wong, Y.L.I. (1996). Comparing the timing of exits from substitute care. Children and Youth Services Review, 18, 307-334. 
Craig, C., \& Herbert, D. (1997). The state of the children: An examination of government-run foster care. Dallas, TX: National Center for Policy Analysis.

Curan, M.C., \& Pecora, P.J. (1999). Incorporating the perspectives of youth placed in family foster care: Selected research findings and methodological challenges.

Davis, E.W. (1979). Long term versus short term placement of children in foster care: The development of a predictive instrument. Dissertation Abstracts International, 39(A-8), p. $4147^{\circ}$

Davis, I.P., Landsverk, J., \& Newton, R. (1997). Duration of foster care for children reunified within the first year of care. Child Welfare Research Review, 2, 272-293.

Downs, S.W., Costin, L.B., \& McFadden, E.J. (1996). Child welfare and family services: Policies and practice $\left(5^{\text {th }}\right.$ ed.). White Plains, NY: Longman.

Emlen, A. (1976). Barriers to planning for children in foster care. Portland, OR: Portland State University, Regional Research Institute for Human Services.

Ethridge, R., Craddock, S., Dunteman, G., \& Hubbard, R. (1995). Treatment services in two national studies of community-based drug abuse treatment programs. Journal of Substance Abuse, 7, 9-25.

Faller, K. (1984). Permanency planning with scarce resources. Children Today, 13(2), 25-36. 
Family Preservation and Support Services Program. Enacted as part of the Omnibus Budget Reconciliation Act of 1993 (P.L. 103-66) Title XIII, Chapter 2, Subchapter C, Part 1.

Family Welfare Research Group (1992). Pathways through child welfare services: Executive summary. Child welfare research center: Berkley, California.

Fanshel, D. (1975). Parental visiting of children in foster care: Key to discharge? Social Services Review, 4, 493-514.

Fanshel, D. (1982). On the road to permanency: An expanded database for children in foster care. New York: Child Welfare League of America.

Fanshel, D., Finch, S. J., \& Grundy, J. F. (1990). Foster children in a life course perspective. New York: Columbia University Press.

Fanshel, D., \& Shinn, E. (1978). Children in foster care: A longitudinal study. New York: Columbia University Press.

Fein, E., \& Staff, I. (1991). Implementing reunification services. Families in Society: The Journal of Contemporary Human Services, 72(6), 335-343.

Fenster, J. (1997). The case for permanent foster care. Journal of Sociology and Social Welfare, 24, 117-126.

Fernandez, E. (1999). Pathways in substitute care: Representation of placement careers of children using event history analysis. Children and Youth Services Review, 21, 177-216.

Festinger, T. (1983). No one ever asked us... A postscript to foster care. New York: Columbia University Press. 
Festinger, T. (1996). Going home and returning to foster care. Children and Youth Services Review, 18, 383-402.

Festinger, T., \& Pratt, R. (2002). Speeding adoptions: An evaluation of the effects of judicial continuity. Social Work Research, 26(4), 217-224.

Finch, S.J., Fanshel, D., \& Grundy, J.F. (1986). Factors associated with the discharge of children from foster care. Social Work Research and Abstracts, 22, 10-18.

Fraley, R. C., Waller, N. G., \& Brennan, K. A. (2000). An item response theory analysis of self-report measures of adult attachment. Journal of Personality and Social Psychology, 78, 350-365.

Frame, L., Berrick, J., \& Brodowski, M.L. (2000). Understanding reentry to out-ofhome care for reunified infants. Child Welfare, 79(4), 339-370.

Frazer, M.W., Walton, E., Lewis, R., Pecora, P.J., \& Walton, W.K. (1996). An experiment in family reunification: Correlates of outcomes at one-year follow-up. Children and Youth Services Review, 18(4/5), 335-61.

Gambrill, E.D., \& Stein, T.J. (1985). Working with biological parents: Important procedural ingredients. Children and Youth Services Review, 7, 173-189.

Gambrill, E.D., \& Wiltse, K.T. (1974). Foster care: Prescriptions for change. Public Welfare, 15, 39-47.

Garb, H.N. (1998). Studying the clinician: Judgement research and psychological assessment. Washington, DC: American Psychological Association.

George, D. \& Mallery, P. (2003). SPSS for Windows. Boston, Pearson Education Inc.. 
Gibson, T.L., Tracy, G.S., \& DeBord, M.S. (1984). An analysis of variables affecting length of stay in foster care. Children and Youth Services Review, 6(2), 135-145.

Gil, E., \& Bogart, K. (1982). Foster children speak out: A study of children's perspectives of foster care. Children Today, 11(1), 7-9.

Glisson, C. (1994). The effect of services coordination teams on outcomes for children in state custody. Administration in Social Work, 18, 1-23.

Glisson, C. (1996). Judicial and service decisions for children entering state custody: The limited role of mental health. Social Services Review, 70, 257-281.

Glisson, C.; Bailey, J., W.; \& Post, J. A. (2000). Predicting the time children spend in state custody. The Social Service Review, 74(2), 253-280.

Glisson, C., \& Hemmelgarn, A. (1998). The effects of organization climate and interorganizational coordination on the quality and outcomes of children's service systems. Child Abuse and Neglect, 22(5), 401-421.

Goerge, R. (1990). The reunification process in substitute care. The Social Service Review, 64(3), 422-457.

Goerge, R. (1994). The effect of public child welfare worker characteritics and turnover on discharge from foster care. In: Child Welfare Research Review, Vol. 1, pp. 205-217. Columbia University Press, New York. Goerge, R., Wulczyn, F., \& Harden, A. (1994). Foster care dynamics, 1983-1992: A report from the multistate foster care data archive, Chicago: Chapin Hall Center for Children. 
Grogan-Kaylan, A.C. (2000). The effect of population level characteristics of the foster care caseload on reunification from foster care. Unpublished dissertation, University of Wisconsin-Madison.

Guggenheim, M. (1995). The effects of recent trends to accelerate the termination of parental rights of children in foster care - An empirical analysis in two states. Family Law Quarterly, 29, 121-140.

Halfon, N., Mendoca, A., \& Berkowitz, G. (1995). Heatlh status of children in foster care. Archives of Pediatric and Adolescent Medicine, 149, 386-392.

Hazan, C. \& Shaver, P.R. (1987). Romantic love conceptualized as an attachment process. Journal of Personality and Social Psychology, 59, 511-524.

Hess, P.M. (1982). Parent-Child attachment concept: Crucial for permanency planning. Social Casework: The Journal of Contemporary Social Work, 63, 46-53.

Hess, P.M. (1988). Case and contact: Determinates of planned visit frequency $n$ foster family care. Child Welfare, $67,311-326$.

Hess, P.M., \& Folaron, G. (1991). Ambivalence: A challenge to permanency for children. Child Welfare, 70(4), 403-426.

Hess, P.M. \& Proch, K. O. (1988). Family visiting in foster care: A guide to practice. Washington, DC: Child Welfare League of America. 
Hess, P.M. \& Proch, K.O. (1993). Visiting: The heart of family reunification. In B.A. Pine, R. Warsh, \& A.N. Maluccio (Eds.). Together again: Family reunification in foster care (pp.119-139). Washington, DC: Child Welfare League of America.

Hochstadt, N., Jaudes, P., Zimo, D., \& Schachter, J. (1987). The Medical and Psychosocial Needs of Children entering foster care. Child Abuse and Neglect, 11, 53-62.

Horwitz, S.A., Simms, M.D., \& Farrington, R.C. (1994). Impact of developmental problems on young children's éxits from foster care. Journal of Developmental and Behavioral Pediatrics, 15(2): 105-110.

Huebner, Ruth, (2003). Public Child Welfare Certification Program Outcomes Evaluation. Paper prepared for the Cabinet for Health and Human Services, January 27, 2003.

Indian Child Welfare Act, P.L. 95-608, 25 U.S.C. Chapter 21, Subchapter I, Section 1911 (1978).

Interethnic Adoption Provisions Act of the Small Business Job Protection Act of 1996 (P.L. 104-88). Title I, Subtitle H, Section 1808, Removal of Barriers to Interethnic Adoption.

Jacobson, E., \& Cockerum, J. (1976, November/December). As foster children see it: Former foster children talk about foster family care. Children Today, $5(6), 32-36$ 
Jellinek, M.S., Murphy, J.M., Poitrast, E., Quinn, D., Bishop, S., \& Goshko, M. (1992). Serious child mistreatment in Massachusetts: The course of 206 children through the courts. Child Abuse \& Neglect, 16, 179-185.

Jenkins, S. (1967). Duration of foster care; Some relevant antecedent variables. Child Welfare, 46, 450-455.

Jenkins, S., \& Diamond, B. (1985). Ethnicity and foster care: Census data as predictors of placement variables. American Journal of Orthopsychiatric, 55(2), 267-276.

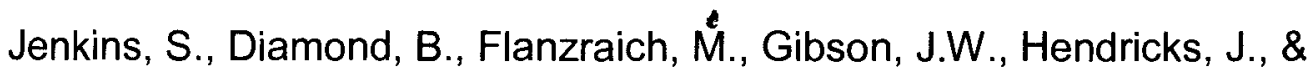
Marshood, N. (1983). Ethnic differentials in foster care placements. Social Work Research and Abstracts, 19(4), 41-45.

Jones, L. (1998). The social and family correlates of successful reunification of children in foster care. Children and Youth Services Review, 20, 305-323. Jones, M.A., Neuman, R., \& Shyne, A.W. (1976). A second chance for families: Evaluation of a program to reduce foster care. New York: Child Welfare League of America.

Kadushin, A. (1980). Child welfare services ( $3^{\text {rd }}$ ed.). New York: Macmillian Press.

Kadushin, A., \& Martin, J.K. (1988). Child Welfare Services (4 ${ }^{\text {th }}$ ed.). New York: Macmillian.

Katz, L., \& Robinson, C. (1991). Foster-care drift - A risk assessment matrix. Child Welfare, 70(3), 347-358. 
Katz. L., Spoonemore, N., \& Robinson, C. (1994). Concurrent Planning: From Permanency planning to permanency action, Lutheran Social Services of Washington and Idaho.

Kemp, S.P., \& Bodonyi, J.M. (2000). Infants who stay $n$ foster care: Child characteristics and permanency outcomes of legally free children first placed as infants. Child and Family Social Work, 5, 95-106.

Kemp, S.P., \& Bodonyi, J.M. (2002). Beyond termination: Length of stay and predictors of permanency for legally free children. Child Welfare, 81(1), $58-87$.

Kentucky Administrative Regulation. (2001). 922, 1:330 Section 1, paragraph 4. Kentucky Revised Statutes. (2001). 605.120(3).

Kentucky Revised Statutes. (2001). 620.180(2a).

Kerlinger, F. Foundations of Behavioral Research, Third Edition. (1986). Fort Worth: Harcourt Brace College Publishers.

Kossoudji, S. (in press). Race and adoption in Michigan. In D.Mont and R. Avery. (Eds.). Public Agency adoption policy. Westport, CT: Greenwood Press. Lahti, J. (1982). A follow-up study of foster children in permanent placements. Social Service Review, 56, 556-571.

Landy, S., \& Munro, S. (1998), Shared parenting: assessing the success of a foster parent program aimed at family reunification. Child Abuse and Neglect, 22(4), 305-318. 
Landsverk, J., Davis, I., Granger, W., Newton, K., \& Johnson, I. (1996). Impact of child psychosocial functioning on reunification from out of home placement. Children and Youth Services Review, 18, 447-462.

Lawder, E.A., Poulin, J.E., \& Andrews, R.G. (1986). A study of 185 foster children 5 years after placement. Child Welfare, 61(3), 241-251.

Leathers, S.J. (2002). Parental visiting and family reunification: Could inclusive practice make a difference. Child Welfare, 81(4), 595-617.

Lino, Mark. (2002). Expenditures on children in families, 2001 Annual Report U.S. Department of Agriculturee, Center for Nutrition Policy and Promotion. Miscellaneous Publication No. 1528-2001.

Lipner, R., \& Goertz, B. (1996). Child Welfare priorities and expenditures. WMemo. 2(8), 1. Washington, DC: American Public Human Services Association.

Littner, N. (1975). The importance of the natural parents to the child in placement. Child Welfare, 54, 175-181.

Maas, H., \& Engler, R. (1959). Children in need of parents. New York: Macmillian Press.

Magura, S. (1979). Trend analysis in foster care. Social Work Research and Abstracts, 15, 29-36.

Mallon, G.P., Aledort, N., \& Ferrera, M. (2002). There's no place like home: Achieving safety, permanency, and well-being for Lesbian and Gay adolescents in out-of-home care settings. In Contemporary Issues in Permanency Planning, 307-339. 
Millham, S., Bullock, R., Hosie, K., \& Haak, M. (1986). Lost in care: The problem of maintaining links between children in care and their families. Aldershot, UK: Gower.

Milner, J. L. (1987). An ecological perspective on duration of foster care. Child Welfare, 62(2), 113-123.

Murphy, H.B. (1968). Predicting duration of foster care. Child Welfare, 47, 76-84. Multiethnic Placement Act of 1994. Public Law 103-382, U.S.C. 108 Stat. 3518. Sections 551- 553. (1995).

National Child Abuse and Neglect Datá System. (1993). Working paper 2:

1991Summary data component. Washington, DC: U.S. Department of Health and Human Services.

National Child Welfare Resource Center for Family-Centered Practice. (2003a). Best Practice: Next Practice, Family-Centered Child Welfare. The Mental Health Service Array, p. 15-16.

National Child Welfare Resource Center for Family-Centered Practice. (2003b).

Best Practice: Next Practice, Family-Centered Child Welfare. Attachment and Children's Mental Health, p. 7.

National Council of Juvenile and Family Court Judges. (1999). Judge's

Guidebook on Adoption and Other Permanent Homes for Children.

Technical Assistance Bulletin, Volume III, p.26.

Nicholson, J., \& Branch, A. (1994). Rehabilitation for parenting roles for people with serious mental illness. Psychosocial Rehabilitation Journal, 18, 109119. 
Nicholson, J., Geller, J.L., \& Fisher, W.H. (1996). "Sylvia Frumkin" has a baby: A case study for policymakers. Psychiatric Services, 47, 497-501.

Nicholson, J., Geller, J.L., Fisher, W.H., \& Dion, G.L. (1993). State policies and programs that address the needs of mentally ill mothers in the public sector. Hospital and Community Psychiatry, 44, 484-489.

Nugent, W.R., \& Glisson, C. (1999). Reactivity and responsiveness in children's services systems. Journal of Social Service Research, 25, 41-50.

Olsen, L. (1982). Services for minority children in foster care. Social Services Review, 56, 572-585.

Omibus Budget Reconciliation Act. (1993). Public Law 103-66.

Oyserman, D., \& Benbenishty, R. (1992). Keeping in touch: Ecological factors related to foster care visitation. Child and Adolescent Social Work Journal, 9(6), 541-554.

Oyserman, D., Mowbray, C.T., \& Zemencuk, J.K. (1994). Resources and supports for mothers with severe mentally illness. Health \& Social Work, $19,132-142$.

Pardeck, J. (1984). Multiple placement of children in foster family care: An empirical analysis. Social Work, 29, 506-509.

Pecora, P., Whitaker, J., Maluccio, A., Barth, R. (2000). The Child Welfare Challenge. Policy, Practice and Research. New York: Aldine De Gruyter. Pike, V. (1976). Permanent families for foster children: The Oregon Project. Children Today, 5, 22-25. 
Pike, V., Downs, S., Emlen, A., Downs, G., \& Case, D. (1977). Permanent planning for children in foster care: A handbook for social workers. Washington, DC: U.S. Department for Health, Education and Welfare. Publication No. (OHDS) 78-30124.

Pilowsky, D.J. (1985). Psychopathology among children placed in family foster care. Psychiatric Services, 46, 906-910.

Potter, C.C., \& Klein-Rothschild, S. (2002). Getting home on time: Predicting timely permanence for young children. Child Welfare, 81(2), 123-150.

Poulin, J. E. (1985). Long term foster care, natural family attachment and loyalty conflict. Journal of Social Service Research, 9, 17-29.

Proch, K., \& Howard, J. (1986). Parental visiting of children in foster care. Social Work, 31, 178-181.

Raske, M. (1997). Training child welfare workers for service to families with maternal mental illness. Urbana: University of Illinois at UrbanaChampaign, Children and Family Research Center.

Rosenthal, J. A. (1993). Outcomes of adoption of children with special needs. The future of children, 3(1), 1-88.

Rubin, A., \& Babbie, E. (1997). Research methods for social work, ( $3^{\text {rd }}$ ed.) Pacific Grove, CA: Brooks-Cole.

Rzepnicki, T., Schuerman, J. R., \& Johnson, P.R. (1997). Facing uncertainty: Reuniting high risk families. In J.D. Berrick, R.P. Barth \& N. Gilbert (Eds.), Child Welfare Research Review (Vol. 2) (pp. 229-251). New York: Columbia University Press. 
Sackett, R.S. (1991). Terminating parental rights of the handicapped. Family Law Quarterly, 25, 253.

Schatz, M.S., Bane, W. (1991). Empowering the parents of children in substitute care: A training model. Child Welfare, 70(6), p665-78.

Schetky, D.H., Angell, R., Morrison, C.V., \& Sack, W.H. (1979). Parents who fail: 51 cases of termination of parental rights. Journal of the American Academy of Child Psychiatry, 18, 366-393.

Schmidt-Tieszen, A., \& McDonald, T.P. (1998). Children who wait: Long term foster care or adoption? Childrên and Youth Services Review, 20, 13-28.

Schumacker, R. \& Lomax, R. (1996). A Beginner's Guide to Structural Equation Modeling. Mahway, New Jersey, Lawrence Erlbaum Associates Publishers.

Schwartz, I., Ortega, R., Guo, S., \& Fishman, G. (1994). Infants in nonpermanent placements. Social Services Review, 68(3), 405-416.

Seaberg, J. R., \& Tolley, E. S. (1986). Predictors of the length of stay in foster care. Social Work Research and Abstracts, 82,11-17.

Semidei, J., Radel, L..F., \& Nolan, C. (2001). Substance abuse and child welfare: Clear linkages and promising responses. Child Welfare, 80(2), 109-129.

Shapiro, D. (1976). Agencies and foster children. New York: Columbia University Press. 
Sheldon, J. (1997). 50,000 children are waiting: Permanency planning and termination of parental rights under the Adoption Assistance and Child Welfare Act of 1980. Boston College: Third World Law Journal, 17, 73100.

Sherman, E.A., Neuman, R., \& Shyne, A.W. (1973). Children adrift in foster car: A study of alternative approaches. New York: Child Welfare League of America, Inc., 1973.

Singleton Royce A., Jr., \& Straits, Bruce C. (1999). Approaches to social research , ( $3^{\text {rd }}$. ed $)$. New York: Oxford University Press.

Social Security Act, Title IV-E (1994). Public Law, 96-272, Section 479, 45 CFR 1355.40 Appendices A-F.

Statewide Automated Child Welfare Information System (SACWIS). (1993).

Federal Register 1993b, Interim final rule, 45 CFR, parts 1355 \& 1356.

Steib, S.D., \& Blome, W.W. (2003). Fatal error: The missing ingredient in child welfare reform: Part 1. Child Welfare, 47(6), p. 747-746.

Stein, T.J., \& Gambrill, E. D. (1977). Facilitating decision making in foster care: The Alameda Project. Social Services Review, 51, 502-513.

Stone, N.M. \& Stone, S.F. (1983). The prediction of successful foster placement. Social Casework, The Journal of Contemporary Social Work, 64(1), 11-17.

Sullivan, D. (2003). The Kentucky Foster Care Census: Measuring Child WellBeing in the Child Welfare System. Dissertation Abstracts International, 45, p. $1468-1623$, UMI Number: 3097952. 
Tatara, T. (1993). U.S. child substitute care flow data for FY 92 and current trends in the state child substitute care populations. VCIS Research Notes. Washington, DC: American Public Welfare Association.

Test, M.A., \& Berlin, S.B. (1981). Issues of special concern to chronically mentally ill women. Professional Psychology, 12, 135-145.

Thompson, A.H., \& Fuhr, D. (1992). Emotional disturbances in fifty children in the care of a child welfare system. Journal of Social Service Research, 15, $95-112$.

Tiddy, S.G. (1986). Creative cooperatiớn: Involving biological parents in long term foster care. Child Welfare, 65, 53-62.

Triseliotis, J. (2002). Long-term foster care or adoption? The evidence examined. Child and Family Social Work, 7, 23-33.

Turner, J. (1984). Reuniting children in foster care with their biological parents. Social Work.

Unites States Department of Health and Human Service. (1999). Child Welfare Outcome 1999 Annual Report. Retrieved on January 31, 2004 from (http://www.acf.hhs.gov/programs/cb/publications/cwo99/index.htm).

Unites States Department of Health and Human Service. (2000a). Child Welfare Outcome 2000 Annual Report. Retrieved on January 31, 2004 from (http://www.acf.hhs.gov/programs/cb/publications/cwo00/index.htm). 
United States Department of Health and Human Services, Administration for Children and Family (2000b). The AFCARS Report. Preliminary FY 2000 estimates. Retrieved December 9, 2003 from http://www.acf.hhs.gov/programs/cb/publications/afcars/ar1000.htm United States Department of Health and Human Services, Administration for Children and Family (2003a). The AFCARS Report. Preliminary FY 2001 estimates. Retrieved December 9, 2003 from http://www.acf.hhs.gov/programs/cb/publications/afcars/reports8.htm. United States Department of Health and Human Services, Administration for Children and Families (2003b). Children's Bureau Program Assessment for Child and Family Services Reviews and Title IV-E eligibility reviews fact sheet. Retrieved December 9, 2003 from http://www.act.hhs.gov/programs/cb/cwrp/geninfo/07200/sheet.htm.

United States Department of Health and Human Services. Administration for Children and Families (2003c). Findings from the Initial Child and Family Service Reviews 2001-2004. Retrieved January 19, 2005 from http://www.acf.hhs.gov/programs/cb/cwrp/results/statefindings/sld006.htm. United States Department of Health and Human Services, Administration for Children and Families (2003d). Summary of the Results of the 2001 and 2002 Child and Family Services Reviews. Retrieved July 15, 2003 from http://www.acf.hhs.gov/programs/cb/cwrp/2002cfsrresults.htm. 
United States Department of Health and Human Services, Administration for Children and Families (2003e). Kentucky Final Child and Family Services Review Report.

United States Statutes at Large, Treaties, and Proclamations of the United States of America, Vol.13 (Boston, 1886), pp.507-9.

Urquizza, A.J., Wirth, S.J., Petersen, M.S., \& Singer, V.A. (1994). Screening and evaluating abused and neglected children entering protective custody. Child Welfare, $73,155-171$.

Van Zyl, K. \& van Zyl, M.A.. (2000). Ré-conceptualizing learning readiness and standardizating the Learning Benefit Inventory. Unpublished manuscript.

Viswesvaran C. \& Oanes, D.S. (2000). Perspectives on models of job performance. International Journal of Selection and Assessment, 8(40, 216-226.

Wald, M.S., Carlsmith, J.M., \& Leiderman, P.H. (1988). Protecting abused and neglected children. Stanford, CA: Stanford University Press.

Warsh, R., Maluccio, A.N., \& Pine, B.A. (1994). Teaching Family Reunification A sourcebook. Washington, DC: Child Welfare League of America.

Wattenberg, E. (2001). When the rehabilitation ideal fails: A study of parental rights termination. Child Welfare, 80(4), 405-432.

Webb, S., \& Webb, B. (1927). English Local Government: English Poor Law History, Part I, The Old Poor Law. New York: Longmans, Green. 
Webster, D., Barth, R.P., Needell, B., \& Berrick, J.D. (1998). Foster care, treatment foster family care and group care in California: An empirical analysis of lengths of stay and exits. Presentation made to the California Association for Services to Children. San Diego: CA (May).

Weinstein, E. (1960). The self-image of the foster child. New York: Russell Stage Foundation.

Wells, L., \& Guo, S. (1999). Reunification and reentry of foster children. Children and Youth Services Review, 21(4), 273-294.

Wertheimer, R. (2002). Youth who "agee out" of foster care: Troubled lives, troubled prospects.

Westat Group, (2001). Assessing the context of permanency and reunification in the foster care system. Retrieved 09/17/03 from:

http://www.aspe.hhs.gov/hsp/fostercare-reunif01/executive.htm.

White, M.E., Albers, E., \& Bitonti, C. (1996). Factors in length of foster care: Worker activities and Parent-Child visitation. Journal of Sociology and Social Work, 23(2), 75-84.

Wulczyn, F. (1994). Status at birth and infant foster care placement in New York City. In: Child Welfare Research Review, Vol. 1, pp. 146-184. Columbia University Press, New York.

Wulczyn, F. (2001). The effect of population dynamics on performance management. Social Services Review, 74(2), 292-318.

Wulczyn, F., Orlebeke, B., \& Melamid, E. (2000). Measuring contract agency performance with administrative data. Child Welfare, 79(5) p. 457-475. 
Youakim vs. Miller. (1979). Supreme Court 440 United States, 125.

Zlotnick, J. (1998). Historical analysis of the implementation of federal policy. A case study of accessing Title IV-E funds to support social work education. Unpublished doctoral dissertation, University of Maryland, College Park, MD.

Zuravin, S.J. (1989).Suggestions for operationally defining child physical abuse and physical neglect. Paper prepared for meeting on Issues in the Longitudinal Study of Child Maltreatment, Toronto, Canada. Baltimore, MD: The School of Social Work and Community Planning. University of Maryland at Baltimore. 


\section{UIVERSITY of LOUISVLLE}

APPENDIX A

Participant ASSENT

I am invited to be in a research study being done by Dr. Anita Barbee and Pam Nolley Tungate, M.S.W. When a person is in a research study, they are called a "participant". I am invited because I am a foster child.

This means that I will be asked questions about my feelings and experiences in foster care. There are no known risks associated with this study to me. My social worker and the people who take care of me have been told that I am being interviewed and plans have been made to make sure I am safe if any part of the interview is uncomfortable for me.

This study will last approximately thirty minutes to one hour. The benefit to me for participating in this study is that I can share my opinion about the foster care system and give suggestions for making the system better. People who are responsible for the foster care system can learn a lot from foster children about services foster children need and want.

My social worker and the researcher will know that l'm in the study. If anyone else is given information about me, they will not know my name. A number will be used instead of my name.

I have been told about this study and know why it is being done and what to do. I know that my social worker(s) have agreed to let me be in the study. I also know that if I have any questions I can ask Dr. Barbee and Pam and they will answer my questions.

Signature of Participant

Date Signed

Signature of Investigator

Date Signed

Signature of Investigator

Date Signed 


\section{APPENDIX B}

\section{Guardian Informed Consent}

Introduction and Background Information

A foster child under your case management is being invited to participate in a research study. The study is being conducted by Dr. Anita Barbee and Pam Nolley Tungate, M.S.W.. The study is sponsored by University of Louisville, Department of Social Work. The study will take place at placement sites throughout the state of Kentucky. Your agency Internal Review Board has reviewed this request. Approval for the study is attached. The child will also be requested to sign an participant assent form that explains the study to them and advises them of the purpose and process of the study. Approximately 20 subjects will be invited to participate.

\section{Purpose}

The purpose of this research study is to determine what factors affect permanency for children. It is important to better understand the specific legacy these children have in order to determine: $a$. if trends exist that have been overlooked in regards to service delivery, $b$. if the current definition of permanency best meet all children's needs, $c$. if outcomes of safety and well being outcomes correlate with permanency outcomes, and d. how ASFA philosophy has affected practice for the child protection social worker and their families. By addressing these questions, this study will seek to improve understanding of child welfare's current status of permanency outcomes for children and to bridge information from CFSR reviews and past studies related to duration of care. This study will last from March 1, 2004 to March 2005.

\section{Procedures}

In this study, an ethnographic interview will be conducted with twenty randomly selected foster children who have spent at least four years in foster care since 1-1-1999. These interviews will last approximately thirty minutes. Qualitative research does not always follow the conventional rules of ethical data collection. This type of research is needed in circumstances where the population being studied may be may be especially vulnerable or where special problems exist in collecting data, such as through children. A series of questions will be asked of these children to determine their understanding of permanency. A portion of these questions will be multiple choice to compare these children's answers with data entered into the TWIST system regarding barriers to permanency exist for each child. Other questions will be open-ended and will be analyzed through content analysis. Common themes will be identified regarding children's responses related to their involvement in case decision making, attachment, permanency, and suggestions for improvement of service delivery.

Potential Risks

There are no foreseeable risks associated with this study. 
Legacy Children: Whose Legacy are They?

Subject Informed Consent

Page 2

Benefits

The possible benefits of this study include increased knowledge about factors that affect foster care. Child protection social workers need additional information about this subject due to CFSR and ASFA requirements. The information collected may not benefit you, the social worker, directly. The information learned in this study may be helpful to others, such as the foster children on your caseload.

Confidentiality

Although absolute confidentiality cannot be guaranteed, confidentiality will be protected to the extent permitted by law. The study sponsor, the Institutional Review Board (IRB), the Human Subjects Protection Program Office (HSPPO), or other appropriate agencies may inspect research records involved with this study. Should the data collected in this research study be published, your identity will not be revealed. Participants of the study will be identified by number only for purposes of data analysis and publication.

\section{Voluntary Participation}

The foster child's participation in this research study is voluntary. The child may refuse to answer any questions that make them feel comfortable. You are free to refuse to participate or withdraw your consent at any time without penalty or losing benefit to which you are otherwise entitled.

\section{Research Subject's Rights and Contact Persons}

You acknowledge that all your present questions have been answered in language you can understand and all future questions will be treated in the same manner. If you have any questions about the study, please contact Pam Nolley Tungate, 270-766-5026.

If you have any questions about your rights as a research subject, you may call the HSPPO at (502) 852-5188. You will be given the opportunity to discuss any questions about your rights as a research subject, in confidence, with a member of the IRB. The IRB is an independent committee composed of members of the University community, staff of the institutions, as well as lay members of the community not connected with these institutions. The IRB has reviewed this study.

\section{Consent}

You have discussed the above information and hereby consent to voluntarily participate in this study. You have been given a copy of the consent.

Signature of Subject

Signature of Investigator
Date Signed

$\overline{\text { Date Signed }}$ 


\section{APPENDIX C}

\section{WORKER QUESTIONNAIRE}

You are being invited to participate in a research study. The purpose of this study is to evaluate the effectiveness of child welfare training. This study is being conducted by Dr. Anita Barbee and Pam Nolley Tungate, M.S.W. and is sponsored by the Kent School of Social Work. Your participation is completely voluntary. You may refuse to participate or discontinue participation at any time without being subject to any penalty or losing any benefits to which you are otherwise entitled. If you agree to participate, you will complete this survey. The survey should take approximately ten minutes. You may decline to participate or to answer any specific question on this survey. There are no known risks to you for participation. However, the knowledge gained may benefit employees of the Cabinet for Families and Children as well as their clients, through the enhancement of training.

Individuals from the Kent School of Social Work and the University Human Studies Committee may inspect these records. Data may also be shared with Cabinet staff for the purpose of enhancing training and worker readiness. In all other respects, however, the data will be held in confidence to the extent permitted by law. Should the data be published, your identity will not be disclosed. By completing this questionnaire, you are indicating that all your present questions have been answered in language you can understand. All future questions will be treated in the same manner. If you have any questions about this study, you may contact the Pam Nolley Tungate at 270-766-5026. If you have any questions about your right as a research subject, you can contact the University Human Studies Committee at (502) 852-5188 or the Cabinet for Families and Children IRB at (502) 564-2767x4102. The committee has reviewed this study. By completing this questionnaire, you are agreeing to participate. Thank you! 
Place a number beside each question using the scoring key at the top of each section. Just enter the number that reflects your situation the best. The shaded area has been included to help you in selecting a number. Example:

ANSWER KEY

\begin{tabular}{|c|c|c|c|c|}
\hline $\begin{array}{c}\text { None of the } \\
\text { time } \\
1\end{array}$ & $\begin{array}{c}\text { A little of the } \\
\text { time } \\
2\end{array}$ & $\begin{array}{c}\text { Some of the } \\
\text { time } \\
3\end{array}$ & $\begin{array}{c}\text { A good part of } \\
\text { the time } \\
4\end{array}$ & All of the time \\
\hline
\end{tabular}

1. 4 I think of my vacation.

\section{DEMOGRAPHICS}

1. Educational background (check highest degree attained)

a. High School

b. GED

c. Associate's Degree

d. Bachelor's Degree in Sociaf Work

e. Bachelor's Degree in Other Field

f. Master's Degree in Social Work

2. Ethnic Origin

g. Master's Degree in Other Field

a. Caucasian

b. Hispanic/Latino

c. African American

d. Asian American

e. Other

3. Gender

a. Female

b. Male

4. Age:

5. Length of Employment with Cabinet (in months): 
APPENDIX D

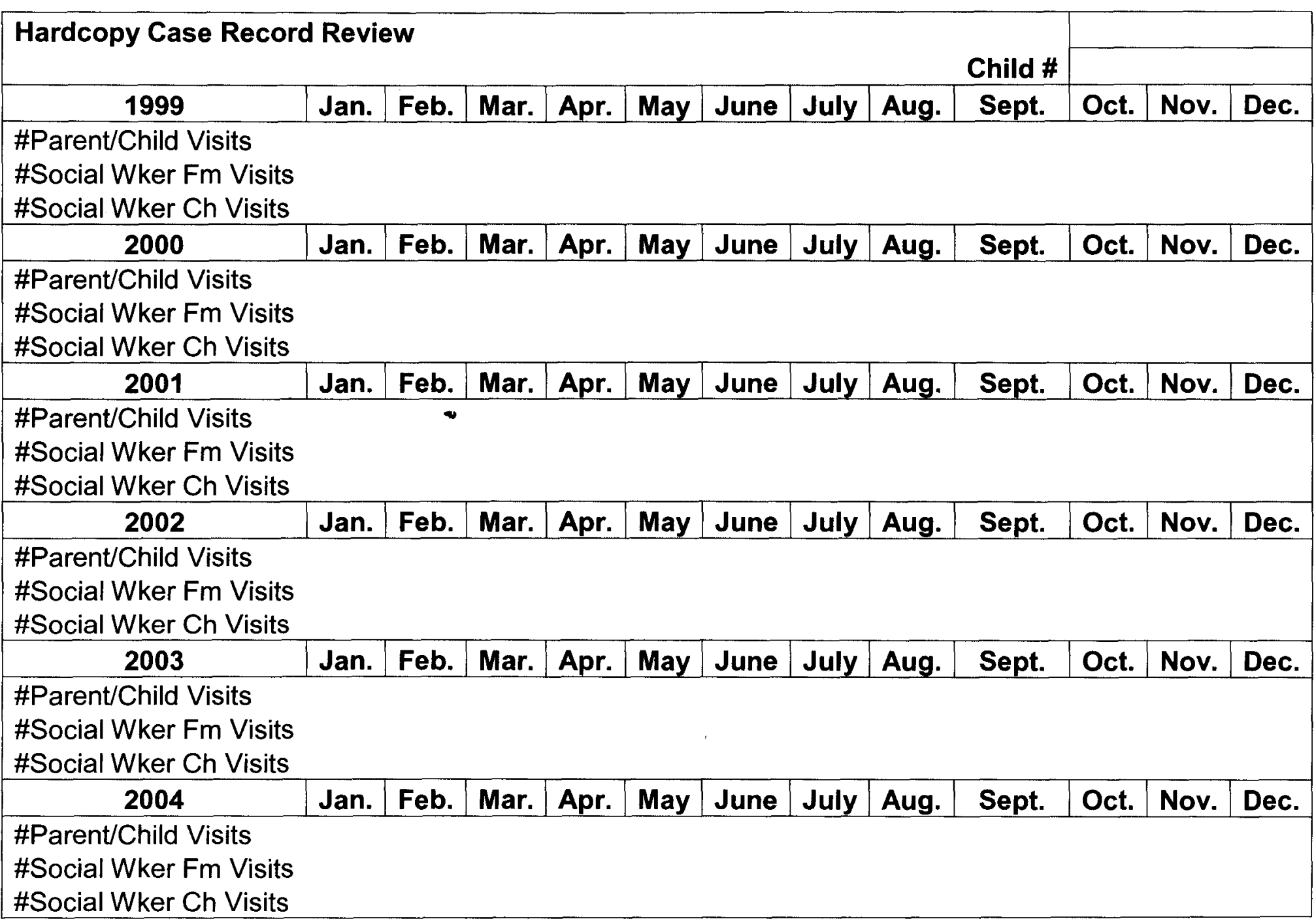




\section{APPENDIX E \\ Legacy Children Ethnographic Study \\ Interview Outline}

\section{Participant \#}

- How long have you been in foster care?

- Why are you in foster care?

- How many different placements have you had in the foster care system?

- Do you live in foster/adoptive home, foster home only, relatives' home, group home, hospital or a facility?

- What words would describe your Eurrent foster care placement?

- How does this placement compare to other placements you have had?

- How long do you expect to stay at your current placement?

- During the last year, how often has your social worker visited you? Circle One.

a. Weekly b. Twice a month c. At least once per month d. Once every two months e. Once every three months $f$. Less than once every three months

- Would you like your social worker to visit more often, less often, or about the same?

- During the last year, how often have you visited with your mother? Circle One a. Weekly b. Twice a month c. At least once per month d. Once every two months e. Once every three months $f$. Less than once every three months

- Would you like your mother to visit more often, less often, or about the same?

- During the last year, how often have you visited with your father? Circle One. a. Weekly b. Twice a month c. At least once per month d. Once every two months e. Once every three months $f$. Less than once every three months

- Would you like to visit with your father more often, less often or about the same?

- On a scale of 1 to 10 , with 1 being the lowest and 10 the highest, how would you describe the medical treatment you are currently receiving? Please explain your answer.

- On a scale of 1 to 10 , with 1 being the lowest and 10 the highest, how would you describe the counseling or mental health services you are currently being provided? Please explain your answer. 
- Do you attend conferences with your social worker and others where decisions are made concerning your future

- Are you asked your opinion regarding decisions affecting you?

- Of the following which is the current goal selected during your last case planning conference?

Return to Parent

Adoption

Permanent Relative Placement

Emancipation

Planned Permanent Living Arrangement

Unsure what my goal is

c

- Do you agree with this goal? (yes or no). Please explain your answer.

- Has your worker discussed Permanency with you? If so, what you think this means?

- What is the worse part about foster care?

- What is the best part about foster care?

- What suggestions do you have for improving the foster care system?

- Are there other questions that you feel should be asked to foster children that were not on this survey? If so, what are they? 
Rate the following on their ability to help children leave the foster care system.

$0=$ No effect on children permanently leaving foster care

$1=$ Little effect on children permanently leaving foster care

2 = Effective about half or some of the time

$3=$ Have the highest effect on children leaving the foster care system

\section{Social Workers}

\begin{tabular}{llll}
0 & 1 & 2 & 3 \\
\hline No & Low & Medium & High
\end{tabular}

Judges

\begin{tabular}{llll}
0 & 1 & 2 & 3 \\
\hline No & Low & Medium & High
\end{tabular}

\section{Foster Children}

\begin{tabular}{llcc}
0 & 1 & 2 & 3 \\
\hline No & Low & Medium & High
\end{tabular}

Mothers of foster children

\begin{tabular}{lccc}
0 & 1 & 2 & 3 \\
\hline No & Low & Medium & High
\end{tabular}

Fathers of foster children

\begin{tabular}{lccc}
0 & 1 & 2 & 3 \\
\hline No & Low & Medium & High
\end{tabular}

Foster parents

\begin{tabular}{lccc}
0 & 1 & 2 & 3 \\
\hline No & Low & Medium & High
\end{tabular}

Therapists

\begin{tabular}{lccc}
0 & 1 & 2 & 3 \\
\hline No & Low & Medium & High
\end{tabular}




\section{APPENDIX F}

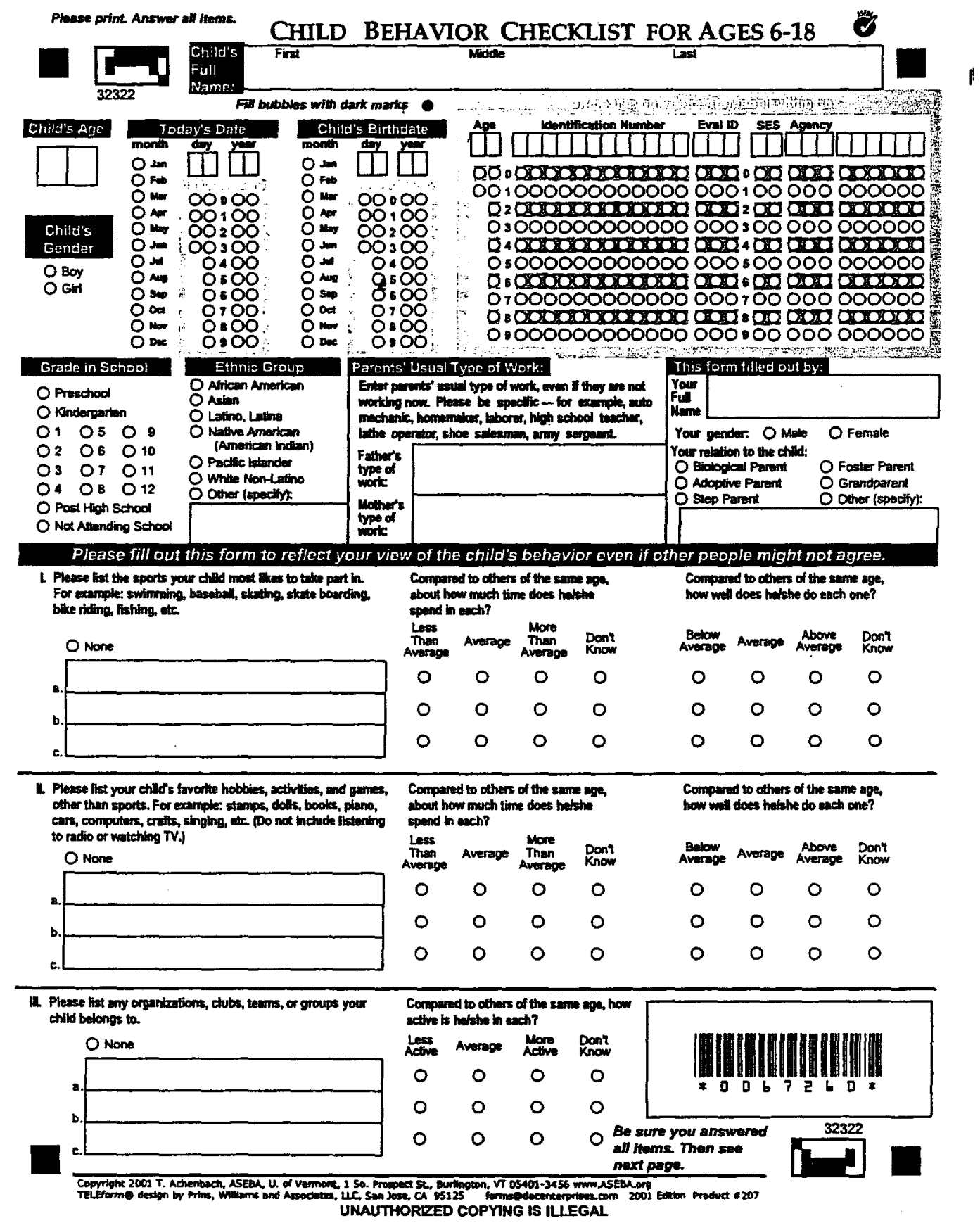


Please print Matse derk anates. Be sure to answer all hams.

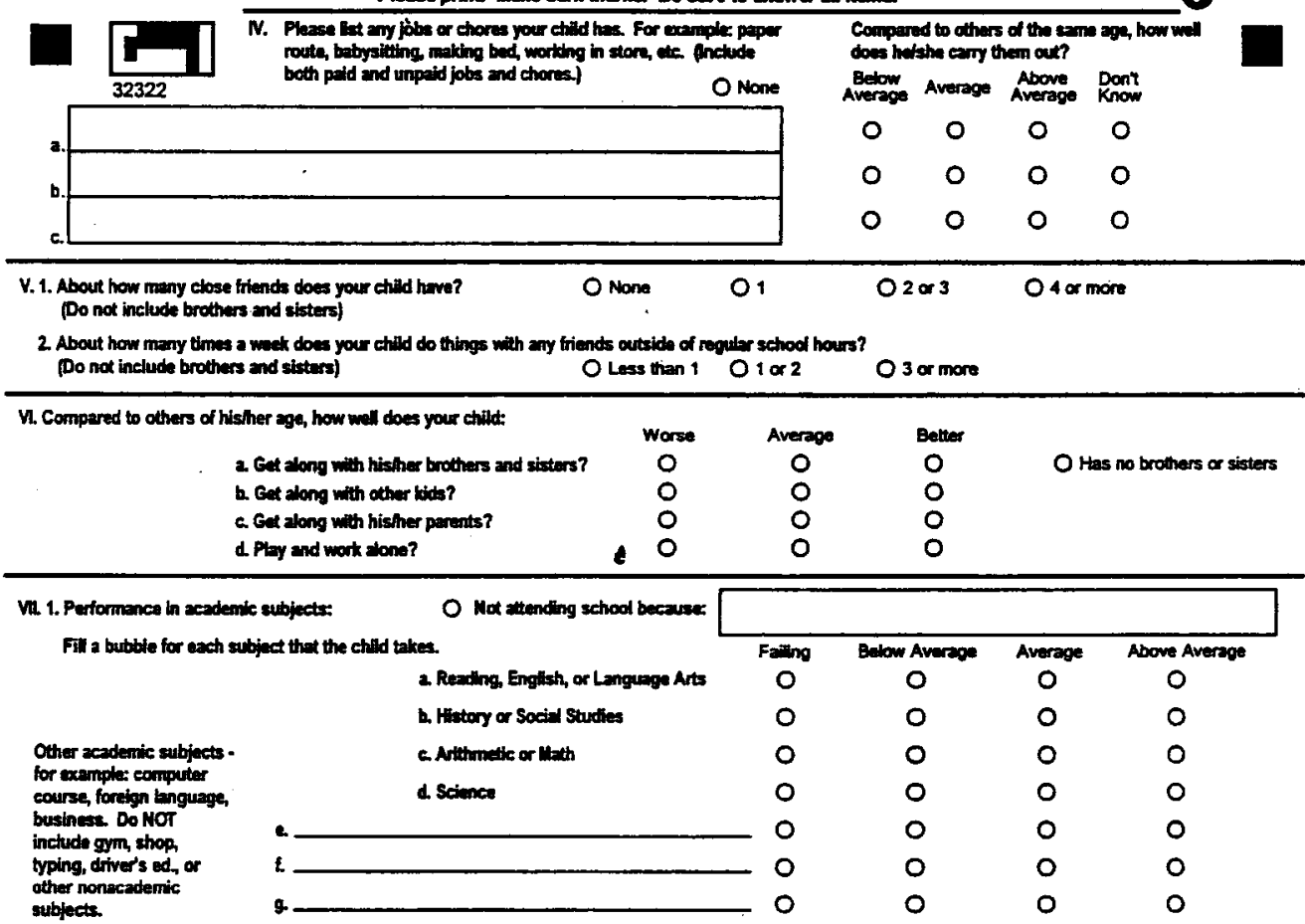

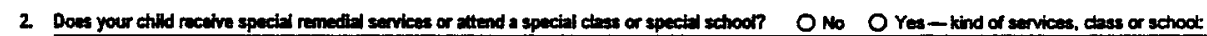

3. Hes your child ropeated ary gredes? ONo O Yes-grades and reasons:

4. Has your child had any acadenic or other probiems in actool? $O$ No $O$ Yes-please deachibe:

(1)

When did these problems start? Heve these problems endid? O No O Yes-when?

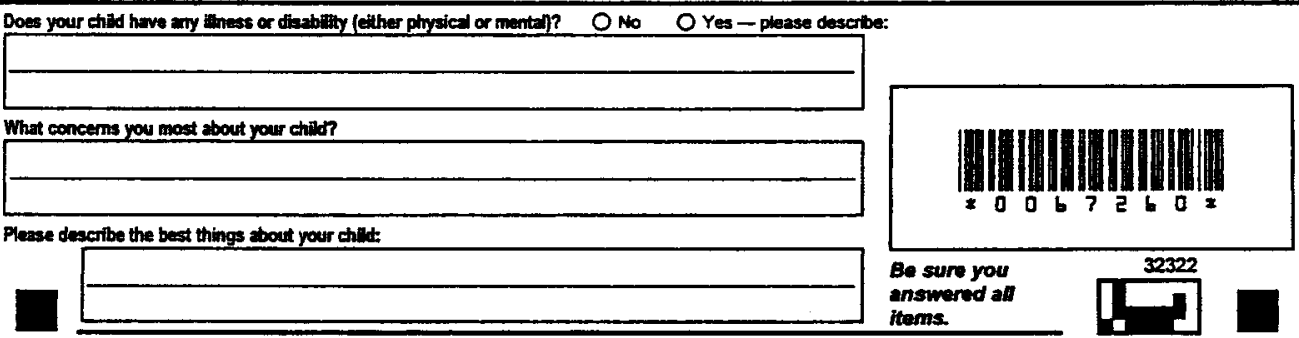

CBCL6-18 PAGE 2

UNAUTHORIZED COPYING IS ULEGAL 

bubble under 1 if the itern is samewhet or sometimes true of your child. If the item is not true of your child, fill in the bubble under $\boldsymbol{0}$. Please answer all items as well as you can, even if some do not seem to apply to your child.

OOO 1. Acts too young for hisher age 000 2. Drinks alcohol without parents' approval (describe):

012

\section{Argues a bot}

000 4. Falls to finish things he/she starts

000 5. There is very little that he/she enjoys

OOO 6. Bowel movements outside tollet

000 7. Bragging. boasting

000 8. Can't concentrate, can't pay attention for long

000 9. Can't get his/het mind off certain thoughts: obsessions (describe):

OO $0^{2}$ 10. Can't sit still, restless, or hyperactive

00011 . Clings to adults or too dependent

00012 Complains of loneliness

000 13. Confused or seems to be in a fog

000 14. Cries a lot

000 15. Cruel to animals

000 16. Cruelly, bullying, or meanness to athers

000 17. Daydreams or gets lost in his/her thoughts

OOO 18. Deliberatehy hams self or attempts suicide

000 19. Demands a lot of attention

000 20. Destroys his/her own things

000 21. Destroys things belonging to his/her family or others

OO 22. Disobedient at home

000 23. Disobedient at school

000 24. Doesn't eat well

$00 \bigcirc$ 25. Doesn't get along with other kids

000 26. Doesn't seem to feel guilty after misbehaving

000 27. Easily jealous

000 28. Breaks niles at home, school, or elsewhere

00029 . Fears certain animals, situations, or places, other than school (describe):

$012^{2}$

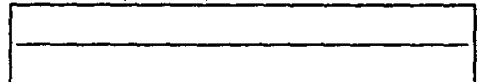

OOO 31. Fears he/she might think or do something bad 000 32. Feels he/she has to be perfect

000 33. Feels or complains that no one loves him/her

00034 . Feets others are out to get himher

000 35. Feets worthless or inferior

000 36. Gets hurt a lot, accident-prone
012

000 37. Gets in many fights

000 38. Gets teased a lot

00039 . Hangs around with others who get in trouble

00040 . Hears sounds or voices that aren't there (describe):

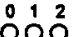

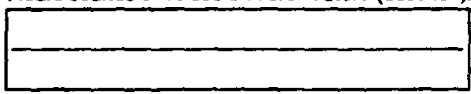

41. Imputsive or acts without thinking

000 42. Would rather be alone than with others

000 43. Lying or cheating

000 44. Bites finger nails

000 45. Nervous, highstrung, or tense

000 46. Nervous movements or twitching (describe)

0012 20 47. Nightmares

000 48. Not aked by other kids

000 49. Constipated, doesn't move bowels

000 50. Too fearful or anxious

000 51. Feels dizy or lightheaded

000 52. Feels too guity

000 53. Overeating

000 54. Overtired without good reason

000 55. Overweight

56. Physical problems without known medical cause.

O 12 a. Aches or pains (not stomach or headaches)

000 b. Headaches

000 c. Nausea, feels sick

000 d. Problems with eyes (not if corrected by glasses) (describe):

$\therefore z^{2}$

000 e. Rashes or other skin problems

000 f. Stomachaches

000 g. Vorniting, throwing up

000 h. Other (describe):

00122 57. Physicaly attacks people

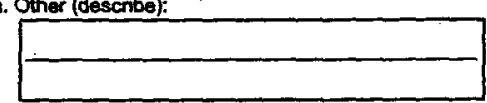

Be sure you

answered afl

items.

Then see

next page.

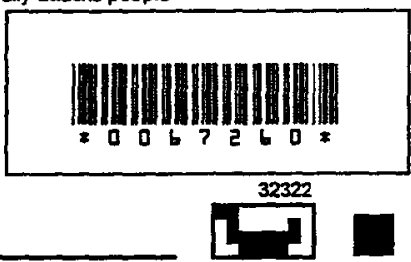


Please print. Woke dork marks. Be sure to answer all items.

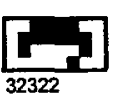

$0=$ Not True (as far as you know) 32322

$0_{0}^{1} \cos ^{2}$

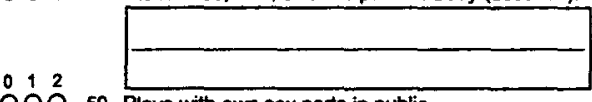

000 59. Plays with own sex parts in public

000 60. Plays with own sex parts too much

000 61. Poor school work

000 62. Poorly coordinated or clumsy

000 63. Prefers being with older kids

000 64. Prefers being with younger kids

000 65. Refuses to talk

000 66. Repeats certain acts over and over, compulsions (describe):

○̊ํํำ

67. Runs away from home

68. Screams a lot

00069 . Secretive, keeps things to self 00070 . Sees things that aren't there (describe):

0012 71. Self-conscious or easily embarrassed

000 72. Sets fires

000 73. Sexual probtems (describe):

$0^{1} \dot{O}^{2}$

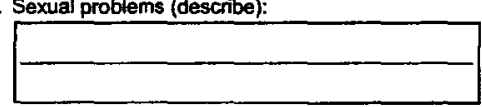

74. Showing off or downing

000 75. Too shy or timid

00076 . Sleeps less than most kids

00077 . Sleeps more than most kids during day and/or night (describe):

$01^{2}$

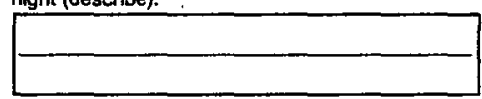

00078. Inattentive or easily distracted

000 79. Speech problem (describe):

$0_{0}^{0} 120$ 80. Stares blankly

000 81. Steals at home

000 82. Steals outside the home

000 83. Stores up too many things he/she doesn't need (describe):

O̊ำ

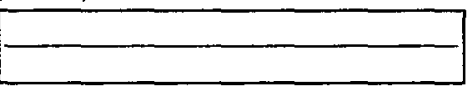

84. Strange behavior (describe):

2 = Very True or Often True

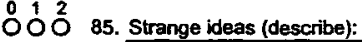

ㅇํㅇํำ

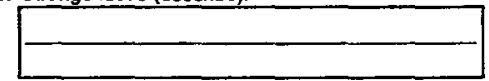

Stubborn, sullen, or irritable

87. Sudden changes in mood or feelings

000 88. Sulks a lot

OOO 89. Suspicious

00090 . Swearing or obscene language

000 91. Talks about killing self

000 92. Talks or walks in sleep (describe):

O̊ 120 93. Talks too much

OOO 94. Teases a lot

OOO 95. Temper tantrums or hot temper

000 96. Thinks about sex 100 much

OOO 97. Threatens people

000 98. Thumb-sucking

OOO 99. Smakes, chews, or sniffs tobacco

OOO 100. Trouble sleeping (describe):

012

OOO 101. Truancy, skips schoof

O 00102 . Underactive, stow moving, or lacks energy

OOO 103. Unhappy, sad, or depressed

$00 \bigcirc 104$. Unusually loud

000 105. Uses drugs for nonmedical purposes (don't

include alcohol or tobacco) (describe):

012

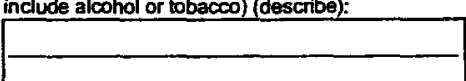

000 106. Vandalism

000107 . Wets self during the day

000 108. Wets the bed

000 109. Whining

000110 . Wishes to be of opposite sex

000111 . Withdrawn, doesn't get involved with others

000 112. Worries

113. Please write in any problems your child has that

อ̊ó were not listed above

O̊ํํำ

○ั0

Be sure you

answered all

items.
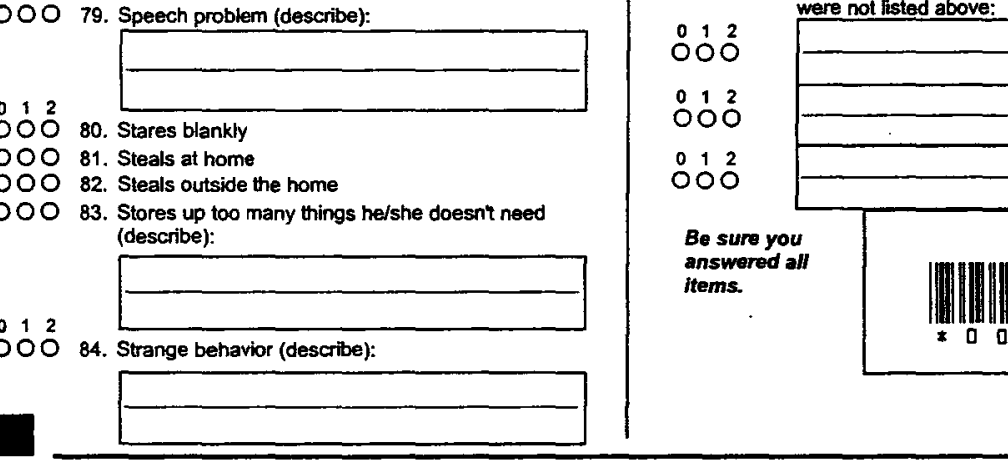

CBCL/6-18 PAGE

UNAUTHORIZED COPYING IS ILLEGAL 


\section{APPENDIX G}

\section{LEARNING BENEFIT INVENTORY}

\section{ANSWER KEY}

\begin{tabular}{|c|c|c|c|c|}
\hline $\begin{array}{c}\text { None of the } \\
\text { time } \\
1\end{array}$ & $\begin{array}{c}\text { A little of the } \\
\text { time } \\
2\end{array}$ & $\begin{array}{c}\text { Some of the } \\
\text { time } \\
3\end{array}$ & $\begin{array}{c}\text { A good part of } \\
\text { the time } \\
4\end{array}$ & \begin{tabular}{c} 
All of the time \\
\hline
\end{tabular}
\end{tabular}

\section{SECTION A}

1.

2.

3.

4.

5.

6.

7.

8.

9.

10.

11.

12.

13.

14.

15.

16.

17.

18.

19.

20.

21.

22.

23.

24.

25.

26.

27.

28.

29.

30.
Things I learn are useful.

It is easy for me to use what I know in new situations.

Experience helps me to learn new things.

Finding things out reminds me of things I already know.

I prefer to know how I am doing whenever I learn.

When I know how well or poorly I do, it is easy for me to change.

When what I know becomes outdated, I learn from scratch.

It frustrates me when I have made a mistake.

It helps me when others tell me how I am doing with something new.

It does not matter if I do well or poorly, I improve after finding out.

I enjoy learning.

I learn?

If I know something will help me to solve problems better, I will learn it.

Learning comes first in my life.

I enjoy the risks of trying to understand something.

I do my best to learn from changing circumstances.

When I am forced to do something for the first time, I try to learn quickly.

With new responsibilities, I try to master something new.

I decide when it is necessary for me to improve myself.

I decide what I should learn.

If I need information, I make a plan to get it.

I decide when to learn something new.

I judge my progress in learning better than others.

I know better than others how I should learn something.

My peers expect me to learn new things.

People at work encourage me to develop myself.

People I care about think I should try to know more or do things better.

My friends will disapprove if I do not strive to improve myself.

People that mean a lot to me expect me to learn.

My family understands when I set time aside to learn. 
31.

32.

33.

34.

35.
It frustrates me to learn things I cannot use immediately.

If I do not benefit from something, I do not make an attempt to learn it.

I learn for the sake of learning.

For me to do well, training must be practical.

I only learn if I think it will help me.

ANSWER KEY

\begin{tabular}{|c|c|c|c|c|}
\hline $\begin{array}{c}\text { None of the } \\
\text { time } \\
1\end{array}$ & $\begin{array}{c}\text { A little of the } \\
\text { time } \\
2\end{array}$ & $\begin{array}{c}\text { Some of the } \\
\text { time } \\
3\end{array}$ & $\begin{array}{c}\text { A good part of } \\
\text { the time } \\
4\end{array}$ & \begin{tabular}{c} 
All of the time \\
\hline
\end{tabular} \\
\hline
\end{tabular}

36.

37.

38.

39.

40.

\section{SECTION B}

1.

2.

3.

4.

5.

6.

7.

8.

9.

10.

11.

12.

13.

14.

15.

16.

17.

18.

19.

20.

21.

22.

23.

24.

25.

If something does not help me, I lose interest quickly.

When I think of learning, I panic.

I am tense when I learn.

I feel relaxed when I learn.

I become easily afraid of learning.

Experience is my best teacher.

I only learn if something is demonstrated.

Even if I think I will not succeed in training, I do my best to learn.

I find out how to do something if I know if is going to be difficult.

When I have time to spare, I try to do something better.

When I am bored, I improve my skills.

I learn to cope when my circumstances change.

The only way to solve problems better is to learn something new.

Improving my skills is more important than my many other commitments.

Through learning I am more able to do my job.

Learning helps me to be better in what I do.

I learn a great deal from changes in my life.

I have too many responsibilities in life to be concerned with learning.

I do my best to learn from changing circumstances.

Getting new knowledge is the most important thing in my life.

The only way to solve problems better is by learning.

My view of doing something well is all that counts.

I know better than anyone else what is best for my development.

I decide for myself what I should be able to do or need to know.

I hate being told what I should learn.

Most people in my life think one should never stop developing oneself.

Learning is a waste of time if on e is not rewarded for it.

It is a waste of time if one can not apply what one has learned.

One should always apply what one has learned immediately.

I only learn if $t$ it helps me to improve myself. 
I want to know as much as possible, even if it does not really help me.

27. Training should only help me perform better.

28. I feel I am in control of my learning.

29. My skills are useful to me in most situations.

30. Understanding one thing is useful in many situations. 


\section{APPENDIX H}

Place a number beside each adjective using the scoring key at the top of each section. Just enter the number that reflects your personality the best. The shaded area has been included to help you in selecting a number. ANSWER KEY

\begin{tabular}{|c|c|c|c|c|c|}
\hline $\begin{array}{r}\text { Stron } \\
\text { disag } \\
1\end{array}$ & $\begin{array}{l}\text { ngly } \\
\text { gree }\end{array}$ & $\begin{array}{c}\text { Disagree } \\
\quad 2\end{array}$ & $\begin{array}{c}\text { Neither agree } \\
\text { nor disagree } \\
3\end{array}$ & $\begin{array}{c}\text { Agree } \\
4\end{array}$ & $\begin{array}{c}\text { Strongly agree } \\
5\end{array}$ \\
\hline & & & 28 & 1) & \\
\hline 1. & bashful & & \multicolumn{3}{|l|}{ 21. moody } \\
\hline $2 . \overline{ }$ & \multicolumn{2}{|c|}{ bold } & \multicolumn{3}{|c|}{$22 . \quad$ organized } \\
\hline 3. & \multicolumn{2}{|c|}{ careless } & \multicolumn{3}{|c|}{ 23. philosophical } \\
\hline 4. & \multirow{2}{*}{\multicolumn{2}{|c|}{ cold }} & \multicolumn{3}{|c|}{ 24. _ practical } \\
\hline 5. & \multirow{2}{*}{\multicolumn{2}{|c|}{$\begin{array}{l}\text { complex } \\
\text { cooperative }\end{array}$}} & \multicolumn{3}{|l|}{ 25. _ quiet } \\
\hline 6. & & & \multicolumn{3}{|l|}{$26^{\circ} \ldots$ relaxed } \\
\hline 7. & \multicolumn{2}{|c|}{ creative } & \multicolumn{3}{|l|}{ 27. __ rude } \\
\hline 8. & \multicolumn{2}{|c|}{ deep } & \multirow{2}{*}{\multicolumn{3}{|c|}{$\begin{array}{l}28 . \\
29\end{array}$ - shy }} \\
\hline 9. & \multicolumn{2}{|c|}{ disorganized } & & & \\
\hline 10. & \multicolumn{2}{|c|}{ efficient } & \multicolumn{3}{|c|}{ 30. sympathetic } \\
\hline 11. & \multicolumn{2}{|c|}{ energetic } & \multicolumn{3}{|c|}{ 31. systematic } \\
\hline 12. & \multicolumn{2}{|c|}{ envious } & \multicolumn{3}{|c|}{ 32. talkative } \\
\hline 13. & \multicolumn{2}{|c|}{ extraverted } & \multicolumn{3}{|c|}{ temperamental } \\
\hline 14. & \multicolumn{2}{|c|}{ fretful } & \multicolumn{3}{|l|}{ 34. _ touchy } \\
\hline 15. & \multicolumn{2}{|c|}{ harsh } & \multicolumn{3}{|c|}{ 35.___ uncreative } \\
\hline 16. & \multicolumn{2}{|c|}{ imaginative } & \multicolumn{3}{|c|}{ unenvious } \\
\hline 17. & \multicolumn{2}{|c|}{ inefficient } & \multicolumn{3}{|c|}{ unintellectual } \\
\hline 18. & \multicolumn{2}{|c|}{ intellectual } & \multicolumn{3}{|c|}{ 38._ unsympathetic } \\
\hline 19. _. & \multirow{2}{*}{\multicolumn{2}{|c|}{$\begin{array}{l}\text { jealous } \\
\text { kind }\end{array}$}} & 39. __ warm & & \\
\hline 20. & & & 40. __ withd & & \\
\hline
\end{tabular}




\section{APPENDIX I}

\section{ANSWER KEY}

\begin{tabular}{|c|c|c|c|c|}
\hline $\begin{array}{c}\text { None of the } \\
\text { time } \\
1\end{array}$ & $\begin{array}{c}\text { A little of the } \\
\text { time } \\
2\end{array}$ & $\begin{array}{c}\text { Some of the } \\
\text { time } \\
3\end{array}$ & $\begin{array}{c}\text { A good part of } \\
\text { the time } \\
4\end{array}$ & $\begin{array}{c}\text { All of the time } \\
5\end{array}$ \\
\hline
\end{tabular}

\section{MY SUPERVISOR}

1.

2.

3.

4.

5.

6.

7.

8.

9.

10.

11.

12.

13.

14.

15.
Encourages me to use my training on the job.

Uses job aids to remind me of my training.

Expects me to use my training.

Set goals for me which are based on training.

Uses his/her training.

Gives me the opportunity to use my training.

Uses the Cabinet's terminology.

Let me discuss my training and learning with co-workers.

Discusses ways with me to use my training.

Involves me in decisions on aspects I have been trained on.

Expects me to describe new techniques learned to all my coworkers.

Asks me about problems in using my training.

Shows interest in what I have learned in training.

Eases work pressure to give me time to use my training.

Approves meetings between myself and the training instructor to discuss ways of using my training. 


\section{APPENDIX $J$}

Think of the person you are closest to (e.g., parent, sibling, romantic partner). Indicate the extent to which you agree or disagree with these statements. List the type of family member you are referring to .Just enter the number that reflects your feelings best. The shaded area has been included to help you in selecting a number.

ANSWER KEY

\begin{tabular}{|c|c|c|c|c|}
\hline $\begin{array}{c}\text { Strongly } \\
\text { disagree } \\
1\end{array}$ & $\begin{array}{c}\text { Disagree } \\
2\end{array}$ & $\begin{array}{c}\text { Neither agree } \\
\text { nor disagree } \\
3\end{array}$ & Agree & Strongly agree \\
\hline
\end{tabular}

1.

2.

3.

4.

5.

6.

7. -

8.

9.

10.

11.

12.

13.

14.

15.
I'm afraid that I will loose my family member's love.

I often wish that my family member's feelings were as strong as my feelings for them.

When my family member is out of sight; I worry that he/she might become involved with someone else.

I rarely worry about my family member leaving me.

Sometimes family members change their feelings about me for no apparent reason.

My desire to be very close sometimes scares people away.

I'm afraid that once a family member really gets to know me; he or she won't like who I really am.

It makes me mad that I don't get the affection and support I need from my family members.

I prefer to not show a family member how I feel deep down.

I am very comfortable being close to family members.

It helps to turn to my family member in times of need.

I tell my family member just about everything.

I am nervous when family members get too close too me.

I feel comfortable depending on family members.

My family member really understands me and my needs. 


\section{APPENDIX K}

Please answer the questions based on your general feelings towards mothers, other perpetrators, and children in your current caseload. Enter the number that best reflects your feelings toward each group.

ANSWER KEY

\begin{tabular}{|c|c|c|c|c|}
\hline $\begin{array}{c}\text { Strongly } \\
\text { disagree } \\
1\end{array}$ & $\begin{array}{c}\text { Disagree } \\
2\end{array}$ & $\begin{array}{c}\text { Neither agree } \\
\text { nor disagree } \\
3\end{array}$ & Agree & $\begin{array}{c}\text { Strongly } \\
\text { agree }\end{array}$ \\
\hline
\end{tabular}

Mothers Other Perpetrators Children

\section{Example $\underline{3}$}

1.

2.

3

4.

5. -

6.

7.

8. -

9.

10.

11.

12.

13.

14.

15.

16

17.

18.

19.

20.

21. $\underline{2}$

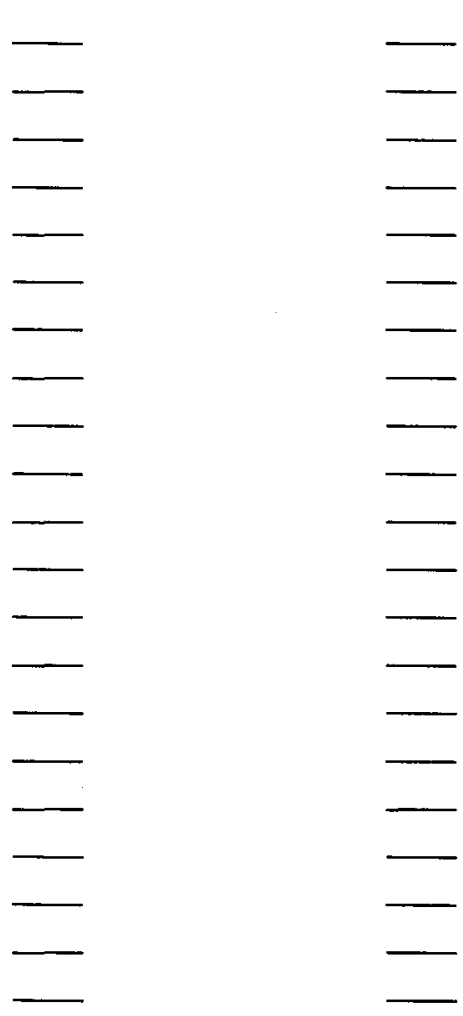

Honesty

alarmed tender grieved concerned softhearted impatient upset disgusted warm sympathetic worried angry compassionate pity disturbed moved disinterested perturbed/irritated distressed guilty resentful 


\section{APPENDIX L}

\section{CORRELATION MATRIX}

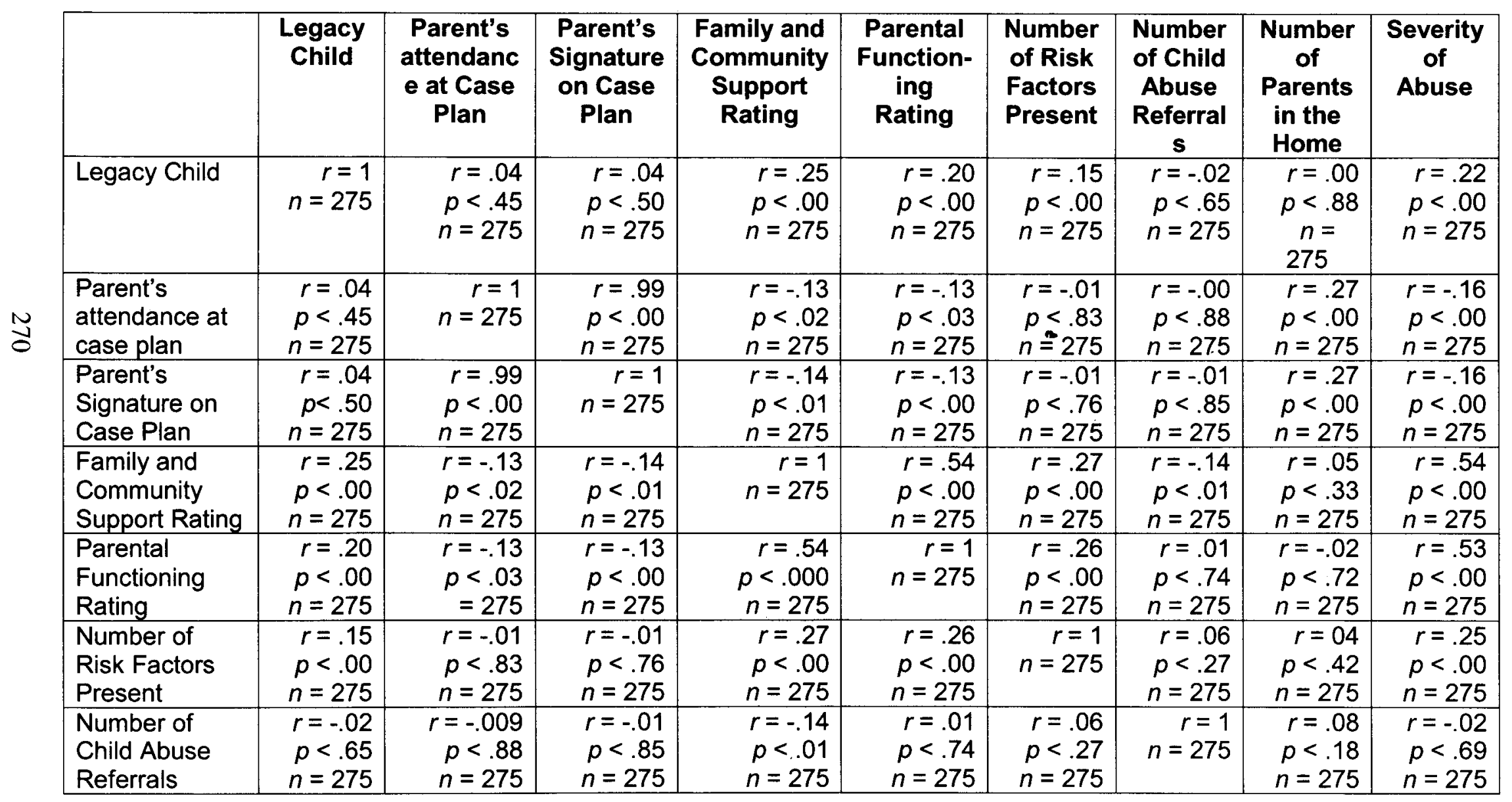




\begin{tabular}{|c|c|c|c|c|c|c|c|c|c|}
\hline & $\begin{array}{l}\text { Legacy } \\
\text { Child }\end{array}$ & $\begin{array}{c}\text { Parent's } \\
\text { attendanc } \\
\text { e at Case } \\
\text { Plan }\end{array}$ & $\begin{array}{c}\text { Parent's } \\
\text { Signature } \\
\text { on Case } \\
\text { Plan }\end{array}$ & $\begin{array}{c}\text { Family and } \\
\text { Community } \\
\text { Support } \\
\text { Rating }\end{array}$ & $\begin{array}{l}\text { Parental } \\
\text { Function- } \\
\text { ing } \\
\text { Rating }\end{array}$ & $\begin{array}{l}\text { Number } \\
\text { of Risk } \\
\text { Factors } \\
\text { Present }\end{array}$ & $\begin{array}{l}\text { Number } \\
\text { of Child } \\
\text { Abuse } \\
\text { Referral } \\
\text { s }\end{array}$ & $\begin{array}{c}\text { Number } \\
\text { of } \\
\text { Parents } \\
\text { in the } \\
\text { Home }\end{array}$ & $\begin{array}{c}\text { Severity } \\
\text { of } \\
\text { Abuse }\end{array}$ \\
\hline Child's Gender & $\begin{array}{l}r=-.01 \\
p<.77 \\
n=275\end{array}$ & $\begin{array}{c}r=.02 \\
p<.65 \\
n=275\end{array}$ & $\begin{array}{c}r=.02 \\
p<.64 \\
n=275\end{array}$ & $\begin{array}{c}r=-.02 \\
p<.63 \\
n=275\end{array}$ & $\begin{array}{l}r=.00 \\
p<.88 \\
n=275\end{array}$ & $\begin{array}{c}r=.01 \\
p<.87 \\
n=275\end{array}$ & $\begin{array}{c}r=-.01 \\
p<.81 \\
n=275\end{array}$ & $\begin{array}{l}r=-.06 \\
p<.26 \\
n=275\end{array}$ & $\begin{array}{l}r=-.02 \\
p<.65 \\
n=275\end{array}$ \\
\hline $\begin{array}{l}\text { CBCL Level } \\
\text { At entry }\end{array}$ & $\begin{array}{c}r=.06 \\
p<.94 \\
n=154\end{array}$ & $\begin{array}{c}r=-.15 \\
p<.15 \\
n=154\end{array}$ & $\begin{array}{r}r=-.119 \\
p<.14 \\
n=154\end{array}$ & $\begin{array}{l}r=-.03 \\
p<.62 \\
n=154\end{array}$ & $\begin{array}{l}r=-2.0 \\
p<.01 \\
n=154\end{array}$ & $\begin{array}{c}r=-02 \\
p<.80 \\
n=154\end{array}$ & $\begin{array}{c}r=.06 \\
p<.40 \\
n=154\end{array}$ & $\begin{array}{c}r=-.13 \\
p<.09 \\
n=275\end{array}$ & $\begin{array}{l}r=-.08 \\
p<.32 \\
n=153\end{array}$ \\
\hline $\begin{array}{l}\text { Child } \\
\text { Developmental } \\
\text { Level at Entry }\end{array}$ & $\begin{array}{c}r=.33 \\
p< \\
.00 \\
n=275\end{array}$ & $\begin{array}{c}r=.06 \\
p<.30 \\
n=275\end{array}$ & $\begin{array}{c}r=.05 \\
p<.34 \\
n=275\end{array}$ & $\begin{array}{c}r=.35 \\
p<.00 \\
n=275\end{array}$ & $\begin{array}{c}r=.25 \\
p<.00 \\
n=275\end{array}$ & $\begin{array}{c}r=.09 \\
p<.12 \\
n=275\end{array}$ & $\begin{array}{c}r=.11 \\
p<.06 \\
n=275\end{array}$ & $\begin{array}{c}r=.06 \\
p<.25 \\
n=275\end{array}$ & $\begin{array}{c}r=.25 \\
p<.00 \\
n=275\end{array}$ \\
\hline $\begin{array}{l}\text { Number of } \\
\text { Moves }\end{array}$ & $\begin{array}{c}r=.48 \\
p<.00 \\
n=275\end{array}$ & $\begin{array}{c}r=.01 \\
p<.81 \\
n=275\end{array}$ & $\begin{array}{c}r=.01 \\
p<.85 \\
n=275\end{array}$ & $\begin{array}{c}r=.07 \\
p<.22 \\
n=275\end{array}$ & $\begin{array}{l}r=-.00 \\
p<.88 \\
n=275\end{array}$ & $\begin{array}{l}r \times .01 \\
p<.80 \\
n=275\end{array}$ & $\begin{array}{c}r=.04 \\
p<.48 \\
n=275\end{array}$ & $\begin{array}{l}r=-.03 \\
p<.52 \\
n=275\end{array}$ & $\begin{array}{c}r=.10 \\
p<.08 \\
n=275\end{array}$ \\
\hline $\begin{array}{l}\text { Days between } \\
\text { Case Plans }\end{array}$ & $\begin{array}{c}r=.78 \\
p<.00 \\
n=275\end{array}$ & $\begin{array}{c}r=.02 \\
p<.72 \\
n=275\end{array}$ & $\begin{array}{c}r=.01 \\
p<.76 \\
n=275\end{array}$ & $\begin{array}{c}r=.20 \\
p<.00 \\
n=275\end{array}$ & $\begin{array}{c}r=.16 \\
p<.00 \\
n=275\end{array}$ & $\begin{array}{c}r=.16 \\
p<.00 \\
n=275\end{array}$ & $\begin{array}{l}r=-.02 \\
p<.68 \\
n=275\end{array}$ & $\begin{array}{c}r=-.01 \\
p<.85 \\
n=275\end{array}$ & $\begin{array}{c}r=.15 \\
p<.00 \\
n=275\end{array}$ \\
\hline $\begin{array}{l}\text { Permanency } \\
\text { Goal }\end{array}$ & $\begin{array}{c}r=-.14 \\
p<.01 \\
n=275\end{array}$ & $\begin{array}{c}r=.01 \\
p<.81 \\
n=275\end{array}$ & $\begin{array}{c}r=.01 \\
p<.78 \\
n=275\end{array}$ & $\begin{array}{c}r=-.13 \\
p<.02 \\
n=275\end{array}$ & $\begin{array}{c}r=.01 \\
p<.85 \\
n=275\end{array}$ & $\begin{array}{l}r=-.03 \\
p<.58 \\
n=275\end{array}$ & $\begin{array}{c}r=.07 \\
p<.23 \\
n=275\end{array}$ & $\begin{array}{c}r=.-.04 \\
p<.44 \\
n=275\end{array}$ & $\begin{array}{l}r=-.17 \\
p<.00 \\
n=275\end{array}$ \\
\hline $\begin{array}{l}\text { Social } \\
\text { Worker's } \\
\text { Educational } \\
\text { Degree }\end{array}$ & $\begin{array}{c}r=-.01 \\
p<.77 \\
n=275\end{array}$ & $\begin{array}{c}r=.01 \\
p<.86 \\
n=275\end{array}$ & $\begin{array}{c}r=-.04 \\
p<.49 \\
n=275\end{array}$ & $\begin{array}{c}r=-.04 \\
p<.45 \\
n=275\end{array}$ & $\begin{array}{l}r=-.03 \\
p<.55 \\
n=275\end{array}$ & $\begin{array}{c}r=-.04 \\
p<.47 \\
n=275\end{array}$ & $\begin{array}{c}r=.006 \\
p<.38 \\
n=275\end{array}$ & $\begin{array}{c}r=.10 \\
p<.07 \\
n=275\end{array}$ & $\begin{array}{l}r=-.03 \\
p<.54 \\
n=275\end{array}$ \\
\hline $\begin{array}{l}\text { Social } \\
\text { Worker's } \\
\text { Months of } \\
\text { Experience }\end{array}$ & $\begin{array}{c}r=-.15 \\
p<.02 \\
n=227\end{array}$ & $\begin{array}{c}r=.07 \\
p<.29 \\
n=227\end{array}$ & $\begin{array}{c}r=.07 \\
p<.28 \\
n=227\end{array}$ & $\begin{array}{c}r=-.02 \\
p<.74 \\
n=227\end{array}$ & $\begin{array}{c}r=-.04 \\
p<.50 \\
n=227\end{array}$ & $\begin{array}{c}r=-.04 \\
p<.47 \\
n=227\end{array}$ & $\begin{array}{c}r=.02 \\
p<.72 \\
n=227\end{array}$ & $\begin{array}{l}r=.05 \\
p<.39 \\
n=227\end{array}$ & $\begin{array}{c}r=-.02 \\
p<.69 \\
n=227\end{array}$ \\
\hline
\end{tabular}




\begin{tabular}{|c|c|c|c|c|c|c|c|c|c|}
\hline & $\begin{array}{l}\text { Legacy } \\
\text { Child }\end{array}$ & $\begin{array}{c}\text { Parent's } \\
\text { attendanc } \\
\text { e at Case } \\
\text { Plan }\end{array}$ & $\begin{array}{c}\text { Parent's } \\
\text { Signature } \\
\text { on Case } \\
\text { Plan }\end{array}$ & $\begin{array}{c}\text { Family and } \\
\text { Community } \\
\text { Support } \\
\text { Rating }\end{array}$ & $\begin{array}{l}\text { Parental } \\
\text { Function- } \\
\text { ing } \\
\text { Rating }\end{array}$ & $\begin{array}{c}\text { Number } \\
\text { of Risk } \\
\text { Factors } \\
\text { Present }\end{array}$ & $\begin{array}{c}\text { Number } \\
\text { of Child } \\
\text { Abuse } \\
\text { Referral } \\
\text { s }\end{array}$ & $\begin{array}{c}\text { Number } \\
\text { of } \\
\text { Parents } \\
\text { in the } \\
\text { Home }\end{array}$ & $\begin{array}{c}\text { Severity } \\
\text { of } \\
\text { Abuse }\end{array}$ \\
\hline $\begin{array}{l}\text { Number of } \\
\text { Parents in the } \\
\text { Home }\end{array}$ & $\begin{array}{c}r=.00 \\
p<.88 \\
n=275\end{array}$ & $\begin{array}{c}r=.27 \\
p<.00 \\
n=275\end{array}$ & $\begin{array}{c}r=.27 \\
p<.00 \\
n=275\end{array}$ & $\begin{array}{c}r=.05 \\
p<.33 \\
n=275\end{array}$ & $\begin{array}{c}r=-.02 \\
p<.72 \\
n=275\end{array}$ & $\begin{array}{c}r=04 \\
p<.42 \\
n=275\end{array}$ & $\begin{array}{c}r=.08 \\
p<.18 \\
n=275\end{array}$ & $\begin{array}{r}r=1 \\
n=275\end{array}$ & $\begin{array}{l}r=.02 \\
p<.69 \\
n=275\end{array}$ \\
\hline
\end{tabular}




\begin{tabular}{|c|c|c|c|c|c|c|c|c|c|}
\hline & $\begin{array}{l}\text { Legacy } \\
\text { Child }\end{array}$ & $\begin{array}{c}\text { Parent's } \\
\text { attendanc } \\
\text { e at Case } \\
\text { Plan }\end{array}$ & $\begin{array}{c}\text { Parent's } \\
\text { Signature } \\
\text { on Case } \\
\text { Plan }\end{array}$ & $\begin{array}{c}\text { Family and } \\
\text { Community } \\
\text { Support } \\
\text { Rating }\end{array}$ & $\begin{array}{c}\text { Parental } \\
\text { Function- } \\
\text { ing } \\
\text { Rating }\end{array}$ & $\begin{array}{l}\text { Number } \\
\text { of Risk } \\
\text { Factors } \\
\text { Present }\end{array}$ & $\begin{array}{l}\text { Number } \\
\text { of Child } \\
\text { Abuse } \\
\text { Referral } \\
\text { s }\end{array}$ & $\begin{array}{l}\text { Number } \\
\text { of } \\
\text { Parents } \\
\text { in the } \\
\text { Home }\end{array}$ & $\begin{array}{c}\text { Severity } \\
\text { of } \\
\text { Abuse }\end{array}$ \\
\hline $\begin{array}{l}\text { Severity of } \\
\text { Abuse Rating }\end{array}$ & $\begin{array}{c}r=.22 \\
p<.00 \\
n=275\end{array}$ & $\begin{array}{c}r=-.16 \\
p<.00 \\
n=275\end{array}$ & $\begin{array}{l}r=-.16 \\
p<.00 \\
n=275\end{array}$ & $\begin{array}{c}r=.54 \\
p<.00 \\
n=275\end{array}$ & $\begin{array}{c}r=.53 \\
p<.00 \\
n=275\end{array}$ & $\begin{array}{l}r=.25 \\
p<.00 \\
n=275\end{array}$ & $\begin{array}{c}r=-.02 \\
p<.69 \\
n=275\end{array}$ & $\begin{array}{c}r=.02 \\
p<.69 \\
n=275\end{array}$ & $\begin{array}{r}r=1 \\
n=275\end{array}$ \\
\hline Neglect & $\begin{array}{l}r=-.15 \\
p<.00 \\
n=275\end{array}$ & $\begin{array}{l}r=-.02 \\
p<.71 \\
n=275\end{array}$ & $\begin{array}{l}r=-.02 \\
p<.71 \\
n=275\end{array}$ & $\begin{array}{l}r=-.05 \\
p<.33 \\
n=275\end{array}$ & $\begin{array}{l}r=.03 \\
p<.57 \\
n=275\end{array}$ & $\begin{array}{l}r=.02 \\
p<.69 \\
n=275\end{array}$ & $\begin{array}{l}r=.11 \\
p<.05 \\
n=275\end{array}$ & $\begin{array}{c}r=-.03 \\
p<.62 \\
n=275\end{array}$ & $\begin{array}{l}r=.03 \\
p<.59 \\
n=275\end{array}$ \\
\hline Sexual Abuse & $\begin{array}{l}r=.14 \\
p<.01 \\
n=275\end{array}$ & $\begin{array}{c}r=.02 \\
p<.68 \\
n=275\end{array}$ & $\begin{array}{c}r=.02 \\
p<.68 \\
n=275\end{array}$ & $\begin{array}{c}r=.04 \\
p<.22 \\
n=275\end{array}$ & $\begin{array}{c}r=-.03 \\
p<.58 \\
n=275\end{array}$ & $\begin{array}{c}r=.03 \\
p<.61 \\
n=275\end{array}$ & $\begin{array}{c}r=.11 \\
p<.06 \\
n=275\end{array}$ & $\begin{array}{c}r=.01 \\
p<.84 \\
n=275\end{array}$ & $\begin{array}{l}r=.09 \\
p<.12 \\
n=275\end{array}$ \\
\hline $\begin{array}{l}\text { Physical } \\
\text { Abuse }\end{array}$ & $\begin{array}{c}r=.09 \\
p<.13 \\
n=275\end{array}$ & $\begin{array}{c}r=.02 \\
p<.68 \\
n=275\end{array}$ & $\begin{array}{l}r=.02 \\
p<.74 \\
n=275\end{array}$ & $\begin{array}{c}r=-.04 \\
p<.44 \\
n=275\end{array}$ & $\begin{array}{c}r=.00 \\
p<.94 \\
n=275\end{array}$ & $\begin{array}{l}r=.00 \\
p<.99 \\
n=275\end{array}$ & $\begin{array}{c}r=.19 \\
p<.001 \\
n=275\end{array}$ & $\begin{array}{c}r=-.00 \\
p<.95 \\
n=275\end{array}$ & $\begin{array}{c}r=.01 \\
p<.81 \\
n=275\end{array}$ \\
\hline Dependency & $\begin{array}{l}r=.06 \\
p<.25 \\
n=275\end{array}$ & $\begin{array}{l}r=-.16 \\
p<.00 \\
n=275\end{array}$ & $\begin{array}{l}r=-.16 \\
p<.00 \\
n=275\end{array}$ & $\begin{array}{c}r=.02 \\
p<.71 \\
n=275\end{array}$ & $\begin{array}{c}r=.-02 \\
p<.65 \\
n=275\end{array}$ & $\begin{array}{l}r=-.07 \\
p<.19 \\
n=275\end{array}$ & $\begin{array}{c}r=-.06 \\
p<.28 \\
n=275\end{array}$ & $\begin{array}{c}r=.08 \\
p<.14 \\
n=275\end{array}$ & $\begin{array}{c}r=-.01 \\
p<.83 \\
n=275\end{array}$ \\
\hline $\begin{array}{l}\text { Emotional } \\
\text { Abuse }\end{array}$ & $\begin{array}{l}r=-.03 \\
p<.52 \\
n=275\end{array}$ & $\begin{array}{r}r=-.04 \\
p<.42 \\
N=275\end{array}$ & $\begin{array}{l}r=-.04 \\
p<.44 \\
n=275\end{array}$ & $\begin{array}{c}r=-.10 \\
p<.07 \\
n=275\end{array}$ & $\begin{array}{c}r=-.14 \\
p<.01 \\
n=275\end{array}$ & $\begin{array}{l}r=-.03 \\
p<.54 \\
n=275\end{array}$ & $\begin{array}{c}r=.13 \\
p<.03 \\
n=275\end{array}$ & $\begin{array}{c}r=.04 \\
p<.48 \\
n=275\end{array}$ & $\begin{array}{c}r=-.07 \\
p<.20 \\
n=275\end{array}$ \\
\hline Sibling Group & $\begin{array}{c}r=.26 \\
p<.00 \\
n=275\end{array}$ & $\begin{array}{c}r=-.06 \\
p<.25 \\
n=275\end{array}$ & $\begin{array}{c}r=-.06 \\
p<.25 \\
n=275\end{array}$ & $\begin{array}{c}r=.06 \\
p<.31 \\
n=275\end{array}$ & $\begin{array}{c}r=.53 \\
p<.00 \\
n=275\end{array}$ & $\begin{array}{c}r=.03 \\
p<.54 \\
n=275\end{array}$ & $\begin{array}{c}r=.15 \\
p<.01 \\
n=275\end{array}$ & $\begin{array}{c}r=-.03 \\
p<.59 \\
n=275\end{array}$ & $\begin{array}{c}r=.11 \\
p<.04 \\
n=275\end{array}$ \\
\hline $\begin{array}{l}\text { Child's age at } \\
\text { Entry }\end{array}$ & $\begin{array}{c}r=.05 \\
p<.37 \\
n=275\end{array}$ & $\begin{array}{c}r=-.00 \\
p<.97 \\
n=275\end{array}$ & $\begin{array}{c}r=-.00 \\
p<.97 \\
n=275\end{array}$ & $\begin{array}{c}r=-.04 \\
p<.45 \\
n=275\end{array}$ & $\begin{array}{c}r=-.12 \\
p<.04 \\
n=275\end{array}$ & $\begin{array}{c}r=.04 \\
p<.48 \\
n=275\end{array}$ & $\begin{array}{r}r=.21 \\
p<.000 \\
n=275\end{array}$ & $\begin{array}{c}r=-.11 \\
p<.05 \\
n=275\end{array}$ & $\begin{array}{c}r=-.01 \\
p<.83 \\
n=275\end{array}$ \\
\hline Child's Race & $\begin{array}{l}r=-.16 \\
p<.00 \\
n=275\end{array}$ & $\begin{array}{l}r=-.19 \\
p<.00 \\
n=275\end{array}$ & $\begin{array}{l}r=-.19 \\
p<.00 \\
n=275\end{array}$ & $\begin{array}{c}r=.07 \\
p<.21 \\
n=275\end{array}$ & $\begin{array}{c}r=.07 \\
p<.24 \\
n=275\end{array}$ & $\begin{array}{l}r=-.06 \\
p<.30 \\
n=275\end{array}$ & $\begin{array}{l}r=-.19 \\
p<.00 \\
n=275\end{array}$ & $\begin{array}{c}r=.11 \\
p<.06 \\
n=275\end{array}$ & $\begin{array}{c}r=.11 \\
p<.06 \\
n=275\end{array}$ \\
\hline
\end{tabular}




\begin{tabular}{|c|c|c|c|c|c|c|c|c|c|}
\hline & $\begin{array}{l}\text { Legacy } \\
\text { Child }\end{array}$ & $\begin{array}{c}\text { Parent's } \\
\text { attendanc } \\
\text { e at Case } \\
\text { Plan }\end{array}$ & $\begin{array}{c}\text { Parent's } \\
\text { Signature } \\
\text { on Case } \\
\text { Plan }\end{array}$ & $\begin{array}{l}\text { Family and } \\
\text { Community } \\
\text { Support } \\
\text { Rating }\end{array}$ & $\begin{array}{l}\text { Parental } \\
\text { Function- } \\
\text { ing } \\
\text { Rating }\end{array}$ & $\begin{array}{l}\text { Number } \\
\text { of Risk } \\
\text { Factors } \\
\text { Present }\end{array}$ & $\begin{array}{c}\text { Number } \\
\text { of Child } \\
\text { Abuse } \\
\text { Referral } \\
\text { s } \\
\end{array}$ & $\begin{array}{c}\text { Number } \\
\text { of } \\
\text { Parents } \\
\text { in the } \\
\text { Home }\end{array}$ & $\begin{array}{c}\text { Severity } \\
\text { of } \\
\text { Abuse }\end{array}$ \\
\hline Child's Gender & $\begin{array}{c}r=-.01 \\
p<.77 \\
n=275\end{array}$ & $\begin{array}{c}r=.02 \\
p<.65 \\
n=275\end{array}$ & $\begin{array}{c}r=.02 \\
p<.64 \\
n=275\end{array}$ & $\begin{array}{c}r=-.02 \\
p<.63 \\
n=275\end{array}$ & $\begin{array}{c}r=.00 \\
p<.88 \\
n=275\end{array}$ & $\begin{array}{c}r=.01 \\
p<.87 \\
n=275\end{array}$ & $\begin{array}{c}r=-.01 \\
p<.81 \\
n=275\end{array}$ & $\begin{array}{c}r=-.06 \\
p<.26 \\
n=275\end{array}$ & $\begin{array}{c}r=-.02 \\
p<.65 \\
n=275\end{array}$ \\
\hline $\begin{array}{l}\text { CBCL Level } \\
\text { At entry }\end{array}$ & $\begin{array}{c}r=.06 \\
p<.94 \\
n=154\end{array}$ & $\begin{array}{l}r=-.15 \\
p<.15 \\
n=154\end{array}$ & $\begin{array}{r}r=-.119 \\
p<.14 \\
n=154\end{array}$ & $\begin{array}{c}r=-.03 \\
p<.62 \\
n=154\end{array}$ & $\begin{array}{c}r=-2.0 \\
p<.01 \\
n=154\end{array}$ & $\begin{array}{c}r=-02 \\
p<.80 \\
n=154\end{array}$ & $\begin{array}{c}r=.06 \\
p<.40 \\
n=154\end{array}$ & $\begin{array}{c}r=-.13 \\
p<.09 \\
n=275\end{array}$ & $\begin{array}{l}r=-.08 \\
p<.32 \\
n=153\end{array}$ \\
\hline $\begin{array}{l}\text { Child } \\
\text { Developmental } \\
\text { Level at Entry }\end{array}$ & $\begin{array}{c}r=.33 \\
p< \\
.00 \\
n=275\end{array}$ & $\begin{array}{c}r=.06 \\
p<.30 \\
n=275\end{array}$ & $\begin{array}{c}r=.05 \\
p<.34 \\
n=275\end{array}$ & $\begin{array}{c}r=.35 \\
p<.00 \\
n=275\end{array}$ & $\begin{array}{c}r=.25 \\
p<.00 \\
n=275\end{array}$ & $\begin{array}{c}r=.09 \\
p<.12 \\
n=275\end{array}$ & $\begin{array}{c}r=.11 \\
p<.06 \\
n=275\end{array}$ & $\begin{array}{c}r=.06 \\
p<.25 \\
n=275\end{array}$ & $\begin{array}{c}r=.25 \\
p<.00 \\
n=275\end{array}$ \\
\hline $\begin{array}{l}\text { Number of } \\
\text { Moves }\end{array}$ & $\begin{array}{c}r=.48 \\
p<.00 \\
n=275\end{array}$ & $\begin{array}{c}r=.01 \\
p<.81 \\
n=275\end{array}$ & $\begin{array}{c}r=.01 \\
p<.85 \\
n=275\end{array}$ & $\begin{array}{c}r=.07 \\
p<.22 \\
n=275\end{array}$ & $\begin{array}{l}r=-.00 \\
p<.88 \\
n=275\end{array}$ & $\begin{array}{l}r=.01 \\
p \approx .80 \\
n=275\end{array}$ & $\begin{array}{c}r=.04 \\
p<.48 \\
n=275\end{array}$ & $\begin{array}{l}r=-.03 \\
p<.52 \\
n=275\end{array}$ & $\begin{array}{c}r=.10 \\
p<.08 \\
n=275\end{array}$ \\
\hline $\begin{array}{l}\text { Days between } \\
\text { Case Plans }\end{array}$ & $\begin{array}{c}r=.78 \\
p<.00 \\
n=275\end{array}$ & $\begin{array}{c}r=.02 \\
p<.72 \\
n=275\end{array}$ & $\begin{array}{c}r=.01 \\
p<.76 \\
n=275\end{array}$ & $\begin{array}{c}r=.20 \\
p<.00 \\
n=275\end{array}$ & $\begin{array}{c}r=.16 \\
p<.00 \\
n=275\end{array}$ & $\begin{array}{c}r=.16 \\
p<.00 \\
n=275\end{array}$ & $\begin{array}{l}r=-.02 \\
p<.68 \\
n=275\end{array}$ & $\begin{array}{l}r=-.01 \\
p<.85 \\
n=275\end{array}$ & $\begin{array}{l}r=.15 \\
p<.00 \\
n=275\end{array}$ \\
\hline $\begin{array}{l}\text { Permanency } \\
\text { Goal }\end{array}$ & $\begin{array}{c}r=-.14 \\
p<.01 \\
n=275\end{array}$ & $\begin{array}{c}r=.01 \\
p<.81 \\
n=275\end{array}$ & $\begin{array}{c}r=.01 \\
p<.78 \\
n=275\end{array}$ & $\begin{array}{l}r=-.13 \\
p<.02 \\
n=275\end{array}$ & $\begin{array}{c}r=.01 \\
p<.85 \\
n=275\end{array}$ & $\begin{array}{l}r=-.03 \\
p<.58 \\
n=275\end{array}$ & $\begin{array}{c}r=.07 \\
p<.23 \\
n=275\end{array}$ & $\begin{array}{c}r=. .04 \\
p<.44 \\
n=275\end{array}$ & $\begin{array}{l}r=-.17 \\
p<.00 \\
n=275\end{array}$ \\
\hline $\begin{array}{l}\text { Social } \\
\text { Worker's } \\
\text { Educational } \\
\text { Degree } \\
\end{array}$ & $\begin{array}{l}r=-.01 \\
p<.77 \\
n=275\end{array}$ & $\begin{array}{c}r=.01 \\
p<.86 \\
n=275\end{array}$ & $\begin{array}{l}r=-.04 \\
p<.49 \\
n=275\end{array}$ & $\begin{array}{l}r=-.04 \\
p<.45 \\
n=275\end{array}$ & $\begin{array}{l}r=-.03 \\
p<.55 \\
n=275\end{array}$ & $\begin{array}{l}r=-.04 \\
p<.47 \\
n=275\end{array}$ & $\begin{array}{c}r=.006 \\
p<.38 \\
n=275\end{array}$ & $\begin{array}{c}r=.10 \\
p<.07 \\
n=275\end{array}$ & $\begin{array}{l}r=-.03 \\
p<.54 \\
n=275\end{array}$ \\
\hline $\begin{array}{l}\text { Social } \\
\text { Worker's } \\
\text { Months of } \\
\text { Experience }\end{array}$ & $\begin{array}{l}r=-.15 \\
p<.02 \\
n=227\end{array}$ & $\begin{array}{c}r=.07 \\
p<.29 \\
n=227\end{array}$ & $\begin{array}{l}r=.07 \\
p<.28 \\
n=227\end{array}$ & $\begin{array}{l}r=-.02 \\
p<.74 \\
n=227\end{array}$ & $\begin{array}{l}r=-.04 \\
p<.50 \\
n=227\end{array}$ & $\begin{array}{l}r=-.04 \\
p<.47 \\
n=227\end{array}$ & $\begin{array}{c}r=.02 \\
p<.72 \\
n=227\end{array}$ & $\begin{array}{l}r=.05 \\
p<.39 \\
n=227\end{array}$ & $\begin{array}{c}r=-.02 \\
p<.69 \\
n=227\end{array}$ \\
\hline
\end{tabular}




\begin{tabular}{|c|c|c|c|c|c|c|c|c|c|}
\hline & $\begin{array}{c}\text { Legacy } \\
\text { Child }\end{array}$ & $\begin{array}{l}\text { Parent's } \\
\text { attendanc } \\
\text { e at Case } \\
\text { Plan }\end{array}$ & $\begin{array}{c}\text { Parent's } \\
\text { Signature } \\
\text { on Case } \\
\text { Plan }\end{array}$ & $\begin{array}{l}\text { Family and } \\
\text { Community } \\
\text { Support } \\
\text { Rating }\end{array}$ & $\begin{array}{l}\text { Parental } \\
\text { Function- } \\
\text { ing } \\
\text { Rating }\end{array}$ & $\begin{array}{l}\text { Number } \\
\text { of Risk } \\
\text { Factors } \\
\text { Present }\end{array}$ & $\begin{array}{c}\text { Number } \\
\text { of Child } \\
\text { Abuse } \\
\text { Referral } \\
\text { s }\end{array}$ & $\begin{array}{c}\text { Number } \\
\text { of } \\
\text { Parents } \\
\text { in the } \\
\text { Home }\end{array}$ & $\begin{array}{c}\text { Severity } \\
\text { of } \\
\text { Abuse }\end{array}$ \\
\hline $\begin{array}{l}\text { Mean monthly } \\
\text { worker/parent } \\
\text { visits }\end{array}$ & $\begin{array}{c}r=-.19 \\
p<.00 \\
n=275\end{array}$ & $\begin{array}{c}r=.42 \\
p<.00 \\
n=275\end{array}$ & $\begin{array}{c}r=.42 \\
p<.00 \\
n=275\end{array}$ & $\begin{array}{l}r=-.12 \\
p<.03 \\
n=275\end{array}$ & $\begin{array}{l}r=-.06 \\
p<.31 \\
n=275\end{array}$ & $\begin{array}{c}r=-.02 \\
p<.68 \\
n=275\end{array}$ & $\begin{array}{c}r=.009 \\
p<.89 \\
n=275\end{array}$ & $\begin{array}{l}r=.21 \\
p<.00 \\
n=275\end{array}$ & $\begin{array}{l}r=-.17 \\
p<.00 \\
n=275\end{array}$ \\
\hline $\begin{array}{l}\text { Mean monthly } \\
\text { social } \\
\text { worker/child } \\
\text { visits }\end{array}$ & $\begin{array}{l}r=-.22 \\
p<.00 \\
n=275\end{array}$ & $\begin{array}{c}r=.27 \\
p<.00 \\
n=275\end{array}$ & $\begin{array}{l}r=.27 \\
p<.00 \\
n=275\end{array}$ & $\begin{array}{l}r=-.11 \\
p<.05 \\
n=275\end{array}$ & $\begin{array}{l}r=-.10 \\
p<.09 \\
n=275\end{array}$ & $\begin{array}{c}r=.00 \\
p<.97 \\
n=275\end{array}$ & $\begin{array}{c}r=.03 \\
p<.51 \\
n=275\end{array}$ & $\begin{array}{c}r=.13 \\
p<.02 \\
n=275\end{array}$ & $\begin{array}{l}r=-.15 \\
p<.01 \\
n=275\end{array}$ \\
\hline $\begin{array}{l}\text { Proximity of } \\
\text { placement }\end{array}$ & $\begin{array}{c}r=.04 \\
p<.44 \\
n=275\end{array}$ & $\begin{array}{c}r=.12 \\
p<.04 \\
n=253\end{array}$ & $\begin{array}{c}r=.12 \\
p<.04 \\
n=253\end{array}$ & $\begin{array}{c}r=-.05 \\
p<.34 \\
n=253\end{array}$ & $\begin{array}{c}r=.00 \\
p<.90 \\
n=253\end{array}$ & $\begin{array}{c}r=.08 \\
p<.19 \\
n=253\end{array}$ & $\begin{array}{c}r=.01 \\
p<.85 \\
n=275\end{array}$ & $\begin{array}{c}r=-.02 \\
p< \\
.69 \\
n=275\end{array}$ & $\begin{array}{c}r=-.11 \\
p<.06 \\
n=275\end{array}$ \\
\hline $\begin{array}{l}\text { Number of } \\
\text { social workers } \\
\text { assigned to the } \\
\text { case }\end{array}$ & $\begin{array}{c}r=.47 \\
p<.00 \\
n=275\end{array}$ & $\begin{array}{c}r=.03 \\
p<.58 \\
n=275\end{array}$ & $\begin{array}{l}r=.03 \\
p<.55 \\
n=275\end{array}$ & $\begin{array}{l}r=-.19 \\
p<.00 \\
n=275\end{array}$ & $\begin{array}{r}r=-.16 \\
p<.005 \\
n=275\end{array}$ & $\begin{array}{l}r=-.09 \\
p<.13 \\
n=275\end{array}$ & $\begin{array}{l}r=.04 \\
p<.47 \\
n=275\end{array}$ & $\begin{array}{c}r=.05 \\
p<.34 \\
n=275\end{array}$ & $\begin{array}{l}r=-.19 \\
p<.00 \\
n=275\end{array}$ \\
\hline $\begin{array}{l}\text { Degree of } \\
\text { supervisor }\end{array}$ & $\begin{array}{c}r=.15 \\
p<.01 \\
n=275\end{array}$ & $\begin{array}{l}r=-.03 \\
p<.54 \\
n=275\end{array}$ & $\begin{array}{l}r=-.04 \\
p<.49 \\
n=275\end{array}$ & $\begin{array}{c}r=.11 \\
p<.05 \\
n=275\end{array}$ & $\begin{array}{l}r=.06 \\
p<.28 \\
n=275\end{array}$ & $\begin{array}{c}r=.02 \\
p<.68 \\
n=275\end{array}$ & $\begin{array}{l}r=-.01 \\
p<.00 \\
n=275\end{array}$ & $\begin{array}{l}r=-.04 \\
p<.43 \\
n=275\end{array}$ & $\begin{array}{l}r=.06 \\
p<.28 \\
n=275\end{array}$ \\
\hline $\begin{array}{l}\text { Average } \\
\text { monthly } \\
\text { amount spent } \\
\text { on child's care }\end{array}$ & $\begin{array}{l}r=-.14 \\
p<.01 \\
n=275\end{array}$ & $\begin{array}{l}r=-.00 \\
p<.87 \\
n=275\end{array}$ & $\begin{array}{c}r=-.10 \\
p<.87 \\
n=275\end{array}$ & $\begin{array}{c}r=.002 \\
p<.97 \\
n=275\end{array}$ & $\begin{array}{l}r=-.13 \\
p<.02 \\
n=275\end{array}$ & $\begin{array}{c}r=-.08 \\
p<.17 \\
n=275\end{array}$ & $\begin{array}{c}r=-.04 \\
p<.42 \\
n=275\end{array}$ & $\begin{array}{c}r=.01 \\
p<.75 \\
n=275\end{array}$ & $\begin{array}{l}r=-.01 \\
p<.78 \\
n=275\end{array}$ \\
\hline $\begin{array}{l}\text { Type of } \\
\text { placement }\end{array}$ & $\begin{array}{c}r=.16 \\
p<.00 \\
n=275\end{array}$ & $\begin{array}{l}r=-.10 \\
p<.75 \\
n=275\end{array}$ & $\begin{array}{l}r=-.02 \\
p<.70 \\
n=275\end{array}$ & $\begin{array}{c}r=.04 \\
p<.46 \\
n=275\end{array}$ & $\begin{array}{c}r=-.08 \\
p<.17 \\
n=275\end{array}$ & $\begin{array}{c}r=-.15 \\
p<.01 \\
n=275\end{array}$ & $\begin{array}{c}r=.06 \\
p<.29 \\
n=275\end{array}$ & $\begin{array}{c}r=-.13 \\
p<.02 \\
n=275\end{array}$ & $\begin{array}{c}r=.02 \\
p<.70 \\
n=275\end{array}$ \\
\hline $\begin{array}{l}\text { Type of court } \\
\text { system }\end{array}$ & $\begin{array}{c}r=.07 \\
p<.21 \\
n=275\end{array}$ & $\begin{array}{c}r=-.02 \\
p<.72 \\
n=275\end{array}$ & $\begin{array}{c}r=-.01 \\
p<.75 \\
n=275\end{array}$ & $\begin{array}{c}r=-.05 \\
p<.72 \\
n=275\end{array}$ & $\begin{array}{c}r=-.08 \\
p<.17 \\
n=275\end{array}$ & $\begin{array}{c}r=-.07 \\
p<.20 \\
n=275\end{array}$ & $\begin{array}{r}r=-.16 \\
p<.005 \\
n=275\end{array}$ & $\begin{array}{c}r=.15 \\
p<.01 \\
n=275\end{array}$ & $\begin{array}{l}r=-.06 \\
p<.25 \\
n=275\end{array}$ \\
\hline
\end{tabular}




\begin{tabular}{|c|c|c|c|c|c|c|c|c|c|}
\hline & $\begin{array}{c}\text { Legacy } \\
\text { Child }\end{array}$ & $\begin{array}{c}\text { Parent's } \\
\text { attendanc } \\
\text { e at Case } \\
\text { Plan }\end{array}$ & $\begin{array}{c}\text { Parent's } \\
\text { Signature } \\
\text { on Case } \\
\text { Plan }\end{array}$ & $\begin{array}{c}\text { Family and } \\
\text { Community } \\
\text { Support } \\
\text { Rating }\end{array}$ & $\begin{array}{l}\text { Parental } \\
\text { Function- } \\
\text { ing } \\
\text { Rating }\end{array}$ & $\begin{array}{l}\text { Number } \\
\text { of Risk } \\
\text { Factors } \\
\text { Present }\end{array}$ & $\begin{array}{c}\text { Number } \\
\text { of Child } \\
\text { Abuse } \\
\text { Referral } \\
\text { s }\end{array}$ & $\begin{array}{c}\text { Number } \\
\text { of } \\
\text { Parents } \\
\text { in the } \\
\text { Home }\end{array}$ & $\begin{array}{c}\text { Severity } \\
\text { of } \\
\text { Abuse }\end{array}$ \\
\hline $\begin{array}{l}\text { Number of } \\
\text { months until } \\
\text { tpr }\end{array}$ & $\begin{array}{l}r=-.71 \\
p<.00 \\
n=136\end{array}$ & $\begin{array}{c}r=.12 \\
p<.15 \\
n=136\end{array}$ & $\begin{array}{c}r=.12 \\
p<.16 \\
n=136\end{array}$ & $\begin{array}{c}r=.17 \\
p<.04 \\
n=136\end{array}$ & $\begin{array}{c}r=.27 \\
p<.00 \\
n=136\end{array}$ & $\begin{array}{c}r=.20 \\
p<.01 \\
n=136\end{array}$ & $\begin{array}{c}r=.28 \\
p<.00 \\
n=136\end{array}$ & $\begin{array}{c}r=.13 \\
p<.12 \\
n=136\end{array}$ & $\begin{array}{l}r=.19 \\
p<.02 \\
n=136\end{array}$ \\
\hline $\begin{array}{l}\text { Mean number } \\
\text { of monthly } \\
\text { parent/child } \\
\text { visits }\end{array}$ & $\begin{array}{l}r=-.21 \\
p<.00 \\
n=275\end{array}$ & $\begin{array}{c}r=.07 \\
p<.18 \\
n=275\end{array}$ & $\begin{array}{c}r=.070 \\
p<.18 \\
n=275\end{array}$ & $\begin{array}{l}r=-.11 \\
p<.05 \\
n=275\end{array}$ & $\begin{array}{r}r=-.002 \\
p<.97 \\
n=275\end{array}$ & $\begin{array}{l}r=-.03 \\
p<.54 \\
n=275\end{array}$ & $\begin{array}{c}r=.13 \\
p<.03 \\
n=275\end{array}$ & $\begin{array}{c}r=.04 \\
p<.43 \\
n=275\end{array}$ & $\begin{array}{l}r=-.14 \\
p<.01 \\
n=275\end{array}$ \\
\hline
\end{tabular}




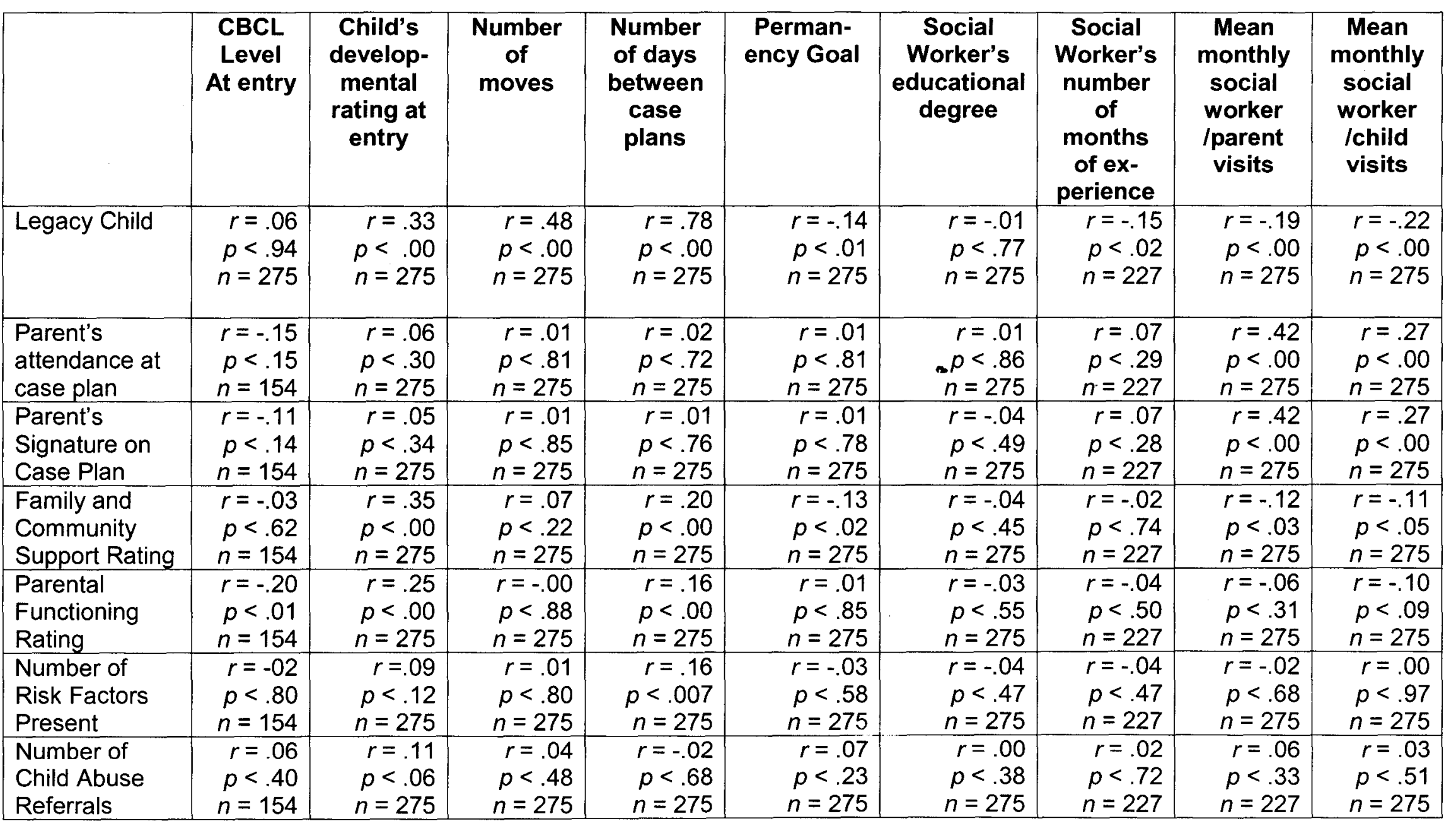




\begin{tabular}{|c|c|c|c|c|c|c|c|c|c|}
\hline & \begin{tabular}{|c|} 
CBCL \\
Level \\
At entry
\end{tabular} & $\begin{array}{c}\text { Child's } \\
\text { develop- } \\
\text { mental } \\
\text { rating at } \\
\text { entry }\end{array}$ & $\begin{array}{c}\text { Number } \\
\text { of } \\
\text { moves }\end{array}$ & $\begin{array}{l}\text { Number } \\
\text { of days } \\
\text { between } \\
\text { case } \\
\text { plans }\end{array}$ & $\begin{array}{l}\text { Perman- } \\
\text { ency Goal }\end{array}$ & $\begin{array}{c}\text { Social } \\
\text { Worker's } \\
\text { educational } \\
\text { degree }\end{array}$ & $\begin{array}{c}\text { Social } \\
\text { Worker's } \\
\text { number } \\
\text { of } \\
\text { months } \\
\text { of ex- } \\
\text { perience }\end{array}$ & $\begin{array}{c}\text { Mean } \\
\text { monthly } \\
\text { social } \\
\text { worker } \\
\text { /parent } \\
\text { visits }\end{array}$ & $\begin{array}{c}\text { Mean } \\
\text { monthly } \\
\text { social } \\
\text { worker } \\
\text { /child } \\
\text { visits }\end{array}$ \\
\hline $\begin{array}{l}\text { Number of } \\
\text { Parents in the } \\
\text { Home }\end{array}$ & $\begin{array}{c}r=-.13 \\
p<.09 \\
n=275\end{array}$ & $\begin{array}{c}r=.35 \\
p<.00 \\
n=275\end{array}$ & $\begin{array}{l}r=-.03 \\
p<.52 \\
n=275 \\
\end{array}$ & $\begin{array}{l}r=-.01 \\
p<.85 \\
n=275\end{array}$ & $\begin{array}{c}r=. .04 \\
p<.44 \\
n=275\end{array}$ & $\begin{array}{r}r=.10 \\
p<.07 \\
n=275\end{array}$ & $\begin{array}{l}r=.05 \\
p<.39 \\
n=227\end{array}$ & $\begin{array}{r}r=.21 \\
p<.00 \\
n=275\end{array}$ & $\begin{array}{c}r=.13 \\
p<.02 \\
n=275\end{array}$ \\
\hline $\begin{array}{l}\text { Severity of } \\
\text { Abuse Rating }\end{array}$ & $\begin{array}{c}r=-.08 \\
p<.32 \\
n=153\end{array}$ & $\begin{array}{r}r=.25 \\
p<.00 \\
n=275\end{array}$ & $\begin{array}{l}r=.10 \\
p<.08 \\
n=275 \\
\end{array}$ & $\begin{array}{r}r=.15 \\
p<.00 \\
n=275\end{array}$ & $\begin{array}{l}r=-.17 \\
p<.00 \\
n=275\end{array}$ & $\begin{array}{r}r=-.03 \\
p<.54 \\
n=275 \\
\end{array}$ & $\begin{array}{l}r=-.02 \\
p<.69 \\
n=227\end{array}$ & $\begin{array}{c}r=-.17 \\
p<.00 \\
n=275\end{array}$ & $\begin{array}{l}r=-.15 \\
p<.01 \\
n=275 \\
\end{array}$ \\
\hline Neglect & $\begin{array}{c}r=-.09 \\
p<.24 \\
n=154\end{array}$ & $\begin{array}{c}r=-.08 \\
p<.14 \\
n=275\end{array}$ & $\begin{array}{r}r=157 \\
p<.009 \\
n=275\end{array}$ & $\begin{array}{l}r=-.78 \\
p<.000 \\
n=275\end{array}$ & $\begin{array}{l}r=.01 \\
p<.80 \\
n=275\end{array}$ & $\begin{array}{r}r=.10 \\
p<.08 \\
n=275\end{array}$ & $\begin{array}{r}r=.01 \\
p<.77 \\
n=227\end{array}$ & $\begin{array}{l}r=.05 \\
p<.41 \\
n=275\end{array}$ & $\begin{array}{c}r=.06 \\
p<.28 \\
n=275\end{array}$ \\
\hline Sexual Abuse & $\begin{array}{l}r=.05 \\
p<.49 \\
n=154\end{array}$ & $\begin{array}{r}r=.11 \\
p<.05 \\
n=275\end{array}$ & $\begin{array}{c}r=.12 \\
p<.03 \\
n=275\end{array}$ & $\begin{array}{c}r=.08 \\
p<.15 \\
n=275\end{array}$ & $\begin{array}{c}r=-.10 \\
p<.09 \\
n=275\end{array}$ & $\begin{array}{r}r=.03 \\
p<.59 \\
n=275 \\
\end{array}$ & $\begin{array}{c}r=.02 \\
p<.67 \\
n=227\end{array}$ & $\begin{array}{c}r=.02 \\
p<.64 \\
n=275\end{array}$ & $\begin{array}{c}r=.02 \\
p<.72 \\
n=275\end{array}$ \\
\hline Physical Abuse & $\begin{array}{c}r=.12 \\
p<.13 \\
n=154\end{array}$ & $\begin{array}{c}r=-.02 \\
p<.64 \\
n=275\end{array}$ & $\begin{array}{c}r=.08 \\
p<.13 \\
n=275\end{array}$ & $\begin{array}{c}r=.04 \\
p<.43 \\
n=275\end{array}$ & $\begin{array}{c}r=.-06 \\
p<.27 \\
n=275\end{array}$ & $\begin{array}{c}r=-.001 \\
p<.98 \\
n=275\end{array}$ & $\begin{array}{l}r=.09 \\
p<.16 \\
n=227\end{array}$ & $\begin{array}{c}r=-.01 \\
p<.81 \\
n=275\end{array}$ & $\begin{array}{c}r=-.00 \\
p<.91 \\
n=275\end{array}$ \\
\hline Dependency & $\begin{aligned} r & =.01 \\
p & <.80 \\
n & =154\end{aligned}$ & $\begin{array}{c}r=-.08 \\
p<.71 \\
n=275\end{array}$ & $\begin{array}{c}r=-.06 \\
p<.32 \\
n=275\end{array}$ & $\begin{array}{c}r=-.03 \\
p<.57 \\
n=275\end{array}$ & $\begin{array}{c}r=-.11 \\
p<.50 \\
n=275\end{array}$ & $\begin{array}{r}r=-.13 \\
p<02 \\
n=275 \\
\end{array}$ & $\begin{array}{c}r=-.06 \\
p<.36 \\
n=275\end{array}$ & $\begin{array}{c}r=-12 \\
p<.04 \\
n=275\end{array}$ & $\begin{array}{c}r=-.12 \\
p<.04 \\
n=275\end{array}$ \\
\hline $\begin{array}{l}\text { Emotional } \\
\text { Abuse }\end{array}$ & $\begin{array}{c}r=-.06 \\
p<.39 \\
n=154\end{array}$ & $\begin{array}{c}r=-.03 \\
p<.56 \\
n=275\end{array}$ & $\begin{array}{c}r=-.10 \\
p<.09 \\
n=275\end{array}$ & $\begin{array}{c}r=-.06 \\
p<.32 \\
n=275\end{array}$ & $\begin{array}{c}r=.06 \\
p<.28 \\
n=275\end{array}$ & $\begin{array}{c}r=-.04 \\
p<.50 \\
n=275\end{array}$ & $\begin{array}{l}r=-.05 \\
p<.38 \\
n=227\end{array}$ & $\begin{array}{c}r=.04 \\
p<.50 \\
n=275\end{array}$ & $\begin{aligned} & r=.00 \\
& p<.91 \\
& n=275\end{aligned}$ \\
\hline Siblings & $\begin{array}{c}r=-.20 \\
p<.01 \\
n=154\end{array}$ & $\begin{array}{r}r=.20 \\
p<.001 \\
n=275\end{array}$ & $\begin{array}{c}r=.11 \\
p<.06 \\
n=275\end{array}$ & $\begin{array}{r}r=.20 \\
p<.001 \\
n=275\end{array}$ & $\begin{array}{l}r=.04 \\
p<.47 \\
n=275\end{array}$ & $\begin{array}{c}r=-.04 \\
p<.48 \\
n=275 \\
\end{array}$ & $\begin{array}{l}r=-.07 \\
p<.26 \\
n=227\end{array}$ & $\begin{array}{c}r=.03 \\
p<.53 \\
n=275\end{array}$ & $\begin{array}{c}r=-.04 \\
p<.46 \\
n=275\end{array}$ \\
\hline
\end{tabular}




\begin{tabular}{|c|c|c|c|c|c|c|c|c|c|}
\hline & $\begin{array}{c}\text { CBCL } \\
\text { Level } \\
\text { At entry }\end{array}$ & $\begin{array}{l}\text { Child's } \\
\text { develop- } \\
\text { mental } \\
\text { rating at } \\
\text { entry }\end{array}$ & $\begin{array}{c}\text { Number } \\
\text { of } \\
\text { moves }\end{array}$ & $\begin{array}{c}\text { Number } \\
\text { of days } \\
\text { between } \\
\text { case } \\
\text { plans }\end{array}$ & $\begin{array}{l}\text { Perman- } \\
\text { ency Goal }\end{array}$ & $\begin{array}{c}\text { Social } \\
\text { Worker's } \\
\text { educational } \\
\text { degree }\end{array}$ & $\begin{array}{l}\text { Social } \\
\text { Worker's } \\
\text { number } \\
\text { of } \\
\text { months } \\
\text { of ex- } \\
\text { perience }\end{array}$ & $\begin{array}{c}\text { Mean } \\
\text { monthly } \\
\text { social } \\
\text { worker } \\
\text { /parent } \\
\text { visits }\end{array}$ & $\begin{array}{l}\text { Mean } \\
\text { monthly } \\
\text { social } \\
\text { worker } \\
\text { /child } \\
\text { visits }\end{array}$ \\
\hline $\begin{array}{l}\text { Child's age at } \\
\text { Entry }\end{array}$ & $\begin{array}{c}r=.32 \\
p<.00 \\
n=154\end{array}$ & $\begin{array}{c}r=.09 \\
p<.11 \\
n=275\end{array}$ & $\begin{array}{c}r=.14 \\
p<.01 \\
n=275\end{array}$ & $\begin{array}{c}r=-.01 \\
p<.78 \\
n=275\end{array}$ & $\begin{array}{c}r=.25 \\
p<.00 \\
n=275\end{array}$ & $\begin{array}{c}r=-.00 \\
p<.81 \\
n=275\end{array}$ & $\begin{array}{l}r=.15 \\
p<.01 \\
n=227\end{array}$ & $\begin{array}{c}r=-.07 \\
p<.19 \\
n=275\end{array}$ & $\begin{array}{c}r=.01 \\
p<.75 \\
n=275\end{array}$ \\
\hline Child's Race & $\begin{array}{c}r=.22 \\
p<.00 \\
n=154\end{array}$ & $\begin{array}{c}r=-.01 \\
p<.80 \\
n=175\end{array}$ & $\begin{array}{c}r=-.05 \\
p<.34 \\
n=275\end{array}$ & $\begin{array}{c}r=-.13 \\
p<.02 \\
n=275\end{array}$ & $\begin{array}{l}r=-.03 \\
p<.55 \\
n=275\end{array}$ & $\begin{array}{c}r=-.05 \\
p<.37 \\
n=275\end{array}$ & $\begin{array}{l}r=.08 \\
p<.19 \\
n=227\end{array}$ & $\begin{array}{l}r=-.17 \\
p<.00 \\
n=275\end{array}$ & $\begin{array}{l}r=-.12 \\
p<.04 \\
n=275\end{array}$ \\
\hline Child's Gender & $\begin{array}{c}r=.05 \\
p<.49 \\
n=275\end{array}$ & $\begin{array}{c}r=-.03 \\
p<.15 \\
n=275\end{array}$ & $\begin{array}{c}r=-.02 \\
p<.64 \\
n=275\end{array}$ & $\begin{array}{c}r=-.06 \\
p<.32 \\
n=275\end{array}$ & $\begin{array}{c}r=.09 \\
p<.10 \\
n=275\end{array}$ & $\begin{array}{c}r=.14 \\
p<.05 \\
r=275\end{array}$ & $\begin{array}{c}r=.14 \\
p<.33 \\
n=275\end{array}$ & $\begin{array}{c}r=.06 \\
p<.29 \\
n=275\end{array}$ & $\begin{array}{c}r=.14 \\
p<.01 \\
n=275\end{array}$ \\
\hline $\begin{array}{l}\text { Number of } \\
\text { Moves }\end{array}$ & $\begin{array}{c}r=.31 \\
p<.00 \\
n=154\end{array}$ & $\begin{array}{c}r=.26 \\
p<.00 \\
n=275\end{array}$ & $\begin{array}{r}r=1 \\
n=275\end{array}$ & $\begin{array}{c}r=.43 \\
p<.00 \\
n=275\end{array}$ & $\begin{array}{l}r=-.15 \\
p<.00 \\
n=275\end{array}$ & $\begin{array}{c}r=-.03 \\
p<.54 \\
n=275\end{array}$ & $\begin{array}{l}r=-.05 \\
p<.37 \\
n=227\end{array}$ & $\begin{array}{l}r=-.15 \\
p<.01 \\
n=275\end{array}$ & $\begin{array}{c}r=-.12 \\
p<.04 \\
n=275\end{array}$ \\
\hline $\begin{array}{l}\text { Days between } \\
\text { Case Plans }\end{array}$ & $\begin{array}{c}r=.05 \\
p<.51 \\
n=154\end{array}$ & $\begin{array}{r}r=.28 \\
p<.000 \\
n=275\end{array}$ & $\begin{array}{r}r=.43 \\
p<.000 \\
n=275\end{array}$ & $\begin{array}{r}r=1 \\
n=275\end{array}$ & $\begin{array}{l}r=-.21 \\
p<.00 \\
n=275\end{array}$ & $\begin{array}{c}r=-.03 \\
p<.54 \\
n=275\end{array}$ & $\begin{array}{l}r=-.13 \\
p<.05 \\
n=227\end{array}$ & $\begin{array}{l}r=-.24 \\
p<.00 \\
n=275\end{array}$ & $\begin{array}{c}r=-.26 \\
p<.00 \\
n=275\end{array}$ \\
\hline $\begin{array}{l}\text { Permanency } \\
\text { Goal }\end{array}$ & $\begin{array}{l}r=-.10 \\
p<.19 \\
n=275\end{array}$ & $\begin{array}{c}r=-.07 \\
p<.20 \\
n=275\end{array}$ & $\begin{array}{c}r=-.15 \\
p<.00 \\
n=275\end{array}$ & $\begin{array}{c}r=-.21 \\
p<.00 \\
n=275\end{array}$ & $\begin{array}{r}r=1 \\
n=275\end{array}$ & $\begin{array}{c}r=-.03 \\
p<.57 \\
n=275\end{array}$ & $\begin{array}{c}r=.17 \\
p<.00 \\
n=227\end{array}$ & $\begin{array}{c}r=.04 \\
p<.44 \\
n=275\end{array}$ & $\begin{array}{c}r=.10 \\
p<.07 \\
n=275\end{array}$ \\
\hline
\end{tabular}




\begin{tabular}{|c|c|c|c|c|c|c|c|c|c|}
\hline & $\begin{array}{c}\text { CBCL } \\
\text { Level } \\
\text { At entry }\end{array}$ & $\begin{array}{l}\text { Child's } \\
\text { develop- } \\
\text { mental } \\
\text { rating at } \\
\text { entry }\end{array}$ & $\begin{array}{c}\text { Number } \\
\text { of } \\
\text { moves }\end{array}$ & $\begin{array}{c}\text { Number } \\
\text { of days } \\
\text { between } \\
\text { case } \\
\text { plans }\end{array}$ & $\begin{array}{l}\text { Perman- } \\
\text { ency Goal }\end{array}$ & $\begin{array}{c}\text { Social } \\
\text { Worker's } \\
\text { educational } \\
\text { degree }\end{array}$ & $\begin{array}{c}\text { Social } \\
\text { Worker's } \\
\text { number } \\
\text { of } \\
\text { months } \\
\text { of ex- } \\
\text { perience }\end{array}$ & $\begin{array}{c}\text { Mean } \\
\text { monthly } \\
\text { social } \\
\text { worker } \\
\text { /parent } \\
\text { visits }\end{array}$ & $\begin{array}{c}\text { Mean } \\
\text { monthly } \\
\text { social } \\
\text { worker } \\
\text { /child } \\
\text { visits }\end{array}$ \\
\hline $\begin{array}{l}\text { Social } \\
\text { Worker's } \\
\text { Educational } \\
\text { Degree }\end{array}$ & $\begin{array}{c}r=-.02 \\
p<.77 \\
n=154\end{array}$ & $\begin{array}{c}r=-.17 \\
p<.00 \\
n=275\end{array}$ & $\begin{array}{c}r=-.03 \\
p<.54 \\
n=275\end{array}$ & $\begin{array}{l}r=-.03 \\
p<.54 \\
n=275\end{array}$ & $\begin{array}{c}r=-.03 \\
p<.57 \\
n=275\end{array}$ & $\begin{array}{r}r=1 \\
n=275\end{array}$ & $\begin{array}{l}r=-.06 \\
p<.31 \\
n=275\end{array}$ & $\begin{array}{c}r=.09 \\
p<.10 \\
n=275\end{array}$ & $\begin{array}{c}r=.04 \\
p<.43 \\
n=275\end{array}$ \\
\hline $\begin{array}{l}\text { Social } \\
\text { Worker's } \\
\text { Months of } \\
\text { Experience }\end{array}$ & $\begin{array}{c}r=.07 \\
p<.39 \\
n=122\end{array}$ & $\begin{array}{c}r=.03 \\
p<.61 \\
n=227\end{array}$ & $\begin{array}{c}r=-.05 \\
p<.37 \\
n=227\end{array}$ & $\begin{array}{c}r=-.13 \\
p<.05 \\
n=227\end{array}$ & $\begin{array}{c}r=.17 \\
p<.00 \\
n=227\end{array}$ & $\begin{array}{c}r=-.06 \\
p<.31 \\
n=275\end{array}$ & $\begin{array}{r}r=1 \\
n=227\end{array}$ & $\begin{array}{c}r=.06 \\
p<.33 \\
n=227\end{array}$ & $\begin{array}{c}r=.18 \\
p<.005 \\
n=227\end{array}$ \\
\hline $\begin{array}{l}\text { Mean monthly } \\
\text { social worker } \\
\text { /parent visits }\end{array}$ & $\begin{array}{l}r=-.20 \\
p<.01 \\
n=154\end{array}$ & $\begin{array}{l}r=-.09 \\
p<.10 \\
n=275\end{array}$ & $\begin{array}{l}r=-.15 \\
p<.01 \\
n=275\end{array}$ & $\begin{array}{l}r=-.24 \\
p<.00 \\
n=275\end{array}$ & $\begin{array}{c}r=.04 \\
p<.44 \\
n=275\end{array}$ & $\begin{array}{c}r=.09 \\
p<.10 \\
n=275\end{array}$ & $\begin{array}{l}r=.06 \\
p<.33 \\
n=227\end{array}$ & $\begin{array}{r}r=1 \\
n=275\end{array}$ & $\begin{array}{l}r=.70 \\
p<.00 \\
n=275\end{array}$ \\
\hline $\begin{array}{l}\text { Mean monthly } \\
\text { social } \\
\text { worker/child } \\
\text { visits }\end{array}$ & $\begin{array}{c}r=-.05 \\
p<.54 \\
n=154\end{array}$ & $\begin{array}{c}r=-.07 \\
p<.23 \\
n=275\end{array}$ & $\begin{array}{c}r=-.12 \\
p<.04 \\
n=275\end{array}$ & $\begin{array}{c}r=-.26 \\
p<.00 \\
n=275\end{array}$ & $\begin{array}{c}r=.10 \\
p<.07 \\
n=275\end{array}$ & $\begin{array}{c}r=.04 \\
p<.43 \\
n=275\end{array}$ & $\begin{array}{c}r=.18 \\
p<.00 \\
n=227\end{array}$ & $\begin{array}{c}r=.70 \\
p<.00 \\
n=275\end{array}$ & $\begin{array}{r}r=1 \\
n=275\end{array}$ \\
\hline $\begin{array}{l}\text { Proximity of } \\
\text { placement }\end{array}$ & $\begin{array}{l}r=-.03 \\
p<.67 \\
n=146\end{array}$ & $\begin{array}{c}r=.03 \\
p<.57 \\
n=253\end{array}$ & $\begin{array}{c}r=.10 \\
p<.10 \\
n=253\end{array}$ & $\begin{array}{c}r=.03 \\
p<.59 \\
n=253\end{array}$ & $\begin{array}{c}r=.13 \\
p<.02 \\
n=253\end{array}$ & $\begin{array}{c}r=.05 \\
p<.38 \\
n=253\end{array}$ & $\begin{array}{l}r=-.09 \\
p<.17 \\
n=227\end{array}$ & $\begin{array}{c}r=.11 \\
p<.05 \\
n=253\end{array}$ & $\begin{array}{l}r=.01 \\
p<.87 \\
n=253\end{array}$ \\
\hline $\begin{array}{l}\text { Number of } \\
\text { social workers } \\
\text { assigned to the } \\
\text { case }\end{array}$ & $\begin{array}{c}r=-.03 \\
p<.63 \\
n=154\end{array}$ & $\begin{array}{l}r=-.25 \\
p<.00 \\
n=275\end{array}$ & $\begin{array}{c}r=-.28 \\
p<.00 \\
n=275\end{array}$ & $\begin{array}{c}r=-.58 \\
p<.00 \\
n=275\end{array}$ & $\begin{array}{c}r=.15 \\
p<.01 \\
n=275\end{array}$ & $\begin{array}{c}r=-.00 \\
p<.88 \\
n=275\end{array}$ & $\begin{array}{c}r=.03 \\
p<.60 \\
n=227\end{array}$ & $\begin{array}{c}r=.39 \\
p<.00 \\
n=275\end{array}$ & $\begin{array}{c}r=.37 \\
p<.00 \\
n=275\end{array}$ \\
\hline $\begin{array}{l}\text { Degree of } \\
\text { supervisor }\end{array}$ & $\begin{array}{l}r=-.08 \\
p<.29 \\
n=154\end{array}$ & $\begin{array}{c}r=.02 \\
p<.67 \\
n=275\end{array}$ & $\begin{array}{c}r=.02 \\
p<.63 \\
n=275\end{array}$ & $\begin{array}{c}r=.07 \\
p<.24 \\
n=275\end{array}$ & $\begin{array}{l}r=-.01 \\
p<.86 \\
n=275\end{array}$ & $\begin{array}{c}r=.04 \\
p<.64 \\
n=275\end{array}$ & $\begin{array}{l}r=-.18 \\
p<.00 \\
n=227\end{array}$ & $\begin{array}{l}r=-.06 \\
p<.27 \\
n=275\end{array}$ & $\begin{array}{c}r=-.05 \\
p<.38 \\
n=275\end{array}$ \\
\hline
\end{tabular}




\begin{tabular}{|c|c|c|c|c|c|c|c|c|c|}
\hline & $\begin{array}{c}\text { CBCL } \\
\text { Level } \\
\text { At entry }\end{array}$ & $\begin{array}{l}\text { Child's } \\
\text { develop- } \\
\text { mental } \\
\text { rating at } \\
\text { entry }\end{array}$ & $\begin{array}{c}\text { Number } \\
\text { of } \\
\text { moves }\end{array}$ & $\begin{array}{c}\text { Number } \\
\text { of days } \\
\text { between } \\
\text { case } \\
\text { plans }\end{array}$ & $\begin{array}{l}\text { Perman- } \\
\text { ency Goal }\end{array}$ & $\begin{array}{c}\text { Social } \\
\text { Worker's } \\
\text { educational } \\
\text { degree }\end{array}$ & $\begin{array}{c}\text { Social } \\
\text { Worker's } \\
\text { number } \\
\text { of } \\
\text { months } \\
\text { of ex- } \\
\text { perience }\end{array}$ & $\begin{array}{c}\text { Mean } \\
\text { monthly } \\
\text { social } \\
\text { worker } \\
\text { /parent } \\
\text { visits }\end{array}$ & $\begin{array}{c}\text { Mean } \\
\text { monthly } \\
\text { social } \\
\text { worker } \\
\text { /child } \\
\text { visits }\end{array}$ \\
\hline $\begin{array}{l}\text { Average } \\
\text { monthly } \\
\text { amount spent } \\
\text { on child's care }\end{array}$ & $\begin{array}{l}r=.26 \\
p<.00 \\
n=154\end{array}$ & $\begin{array}{c}r=-.01 \\
p<.83 \\
n=275\end{array}$ & $\begin{array}{c}r=.27 \\
p<.00 \\
N=275\end{array}$ & $\begin{array}{c}r=-.02 \\
p<.74 \\
n=275\end{array}$ & $\begin{array}{l}r=-.13 \\
p<.03 \\
n=275\end{array}$ & $\begin{array}{c}r=.01 \\
p<.77 \\
n=275\end{array}$ & $\begin{array}{c}r=.13 \\
p<.04 \\
n=227\end{array}$ & $\begin{array}{l}r=-.02 \\
p<.62 \\
n=275\end{array}$ & $\begin{array}{c}r=.03 \\
p<.56 \\
n=275\end{array}$ \\
\hline $\begin{array}{l}\text { Type of } \\
\text { placement }\end{array}$ & $\begin{array}{l}r=.24 \\
p<.00 \\
n=154\end{array}$ & $\begin{array}{c}r=.10 \\
p<.08 \\
n=275\end{array}$ & $\begin{array}{l}r=.32 \\
p<.00 \\
n=275\end{array}$ & $\begin{array}{r}r=.24 \\
p<.000 \\
n=275\end{array}$ & $\begin{array}{c}r=-.21 \\
p<.000 \\
n=275\end{array}$ & $\begin{array}{c}r=-.03 \\
p<.54 \\
n=275\end{array}$ & $\begin{array}{l}r=-.02 \\
p<.74 \\
n=227\end{array}$ & $\begin{array}{l}r=-.07 \\
p<.19 \\
n=275\end{array}$ & $\begin{array}{l}r=-.02 \\
p<.66 \\
n=275\end{array}$ \\
\hline $\begin{array}{l}\text { Type of court } \\
\text { system }\end{array}$ & $\begin{array}{l}r=.21 \\
p<.00 \\
n=154\end{array}$ & $\begin{array}{l}r=-.07 \\
p<.20 \\
n=275\end{array}$ & $\begin{array}{c}r=-.00 \\
p<.91 \\
n=275\end{array}$ & $\begin{array}{l}r=-.06 \\
p<.29 \\
n=275\end{array}$ & $\begin{array}{l}r=-.03 \\
p<.58 \\
n=275\end{array}$ & $\begin{array}{c}r=-.06 \\
p<.31 \\
n=275\end{array}$ & $\begin{array}{c}r=.07 \\
p<.28 \\
n=275\end{array}$ & $\begin{array}{l}r=-.08 \\
p<.15 \\
n=275\end{array}$ & $\begin{array}{l}r=-.09 \\
p<.29 \\
n=275\end{array}$ \\
\hline $\begin{array}{l}\text { Number of } \\
\text { months until tpr }\end{array}$ & $\begin{array}{c}r=-.11 \\
p<.25 \\
n=136\end{array}$ & $\begin{array}{r}r=.35 \\
p<.000 \\
n=275\end{array}$ & $\begin{array}{r}r=.27 \\
p<.001 \\
n=136\end{array}$ & $\begin{array}{r}r=.62 \\
p<.001 \\
n=136\end{array}$ & $\begin{array}{c}r=.13 \\
p<.10 \\
n=136\end{array}$ & $\begin{array}{c}r=.03 \\
p<.71 \\
n=136\end{array}$ & $\begin{array}{c}r=-.19 \\
p<.04 \\
n=136\end{array}$ & $\begin{array}{c}r=-.09 \\
p<.28 \\
n=136\end{array}$ & $\begin{array}{c}r=.02 \\
p<.78 \\
n=136\end{array}$ \\
\hline $\begin{array}{l}\text { Mean number } \\
\text { of monthly } \\
\text { parent/child } \\
\text { visits }\end{array}$ & $\begin{array}{c}r=.11 \\
p<.14 \\
n=154\end{array}$ & $\begin{array}{l}r=-.08 \\
p<.17 \\
n=275\end{array}$ & $\begin{array}{l}r=-.14 \\
p<.01 \\
n=275\end{array}$ & $\begin{array}{c}r=-.27 \\
p<.000 \\
n=275\end{array}$ & $\begin{array}{c}r=.06 \\
p<.31 \\
n=275\end{array}$ & $\begin{array}{c}r=-.05 \\
p<.40 \\
n=275\end{array}$ & $\begin{array}{c}r=.14 \\
p<.03 \\
n=227\end{array}$ & $\begin{array}{r}r=.23 \\
p<.000 \\
n=275\end{array}$ & $\begin{array}{r}r=.31 \\
p<.000 \\
n=275\end{array}$ \\
\hline
\end{tabular}




\begin{tabular}{|c|c|c|c|c|c|c|c|c|}
\hline & $\begin{array}{c}\text { Proximity } \\
\text { of } \\
\text { placement }\end{array}$ & $\begin{array}{l}\text { Number } \\
\text { of social } \\
\text { workers } \\
\text { assigned } \\
\text { to the } \\
\text { case }\end{array}$ & $\begin{array}{l}\text { Degree of } \\
\text { Supervisor }\end{array}$ & $\begin{array}{c}\text { Average } \\
\text { monthly } \\
\text { amount } \\
\text { spent } \\
\text { on } \\
\text { child's } \\
\text { care }\end{array}$ & $\begin{array}{c}\text { Type of } \\
\text { placement }\end{array}$ & $\begin{array}{l}\text { Type of } \\
\text { court } \\
\text { system }\end{array}$ & $\begin{array}{c}\text { Number } \\
\text { of } \\
\text { months } \\
\text { until tpr }\end{array}$ & $\begin{array}{c}\text { Mean } \\
\text { number of } \\
\text { monthly } \\
\text { parent/child } \\
\text { visits }\end{array}$ \\
\hline Legacy Child & $\begin{array}{c}r=.04 \\
p<.44 \\
n=275\end{array}$ & $\begin{array}{c}r=.47 \\
p<.00 \\
n=275\end{array}$ & $\begin{array}{c}r=.15 \\
p<.01 \\
n=275\end{array}$ & $\begin{array}{c}r=-.14 \\
p<.01 \\
n=275\end{array}$ & $\begin{array}{c}r=.16 \\
p<.00 \\
n=275\end{array}$ & $\begin{array}{c}r=.07 \\
p<.21 \\
n=275\end{array}$ & $\begin{array}{l}r=-.71 \\
p<.00 \\
n=136\end{array}$ & $\begin{array}{l}r=-.21 \\
p<.00 \\
n=275\end{array}$ \\
\hline $\begin{array}{l}\text { Parent's } \\
\text { attendance at } \\
\text { case plan }\end{array}$ & $\begin{array}{c}r=.12 \\
p<.04 \\
n=253\end{array}$ & $\begin{array}{c}r=.03 \\
p<.58 \\
n=275\end{array}$ & $\begin{array}{c}r=-.03 \\
p<.54 \\
n=275\end{array}$ & $\begin{array}{l}r=-.00 \\
p<.87 \\
n=275\end{array}$ & $\begin{array}{l}r=-.10 \\
p<.75 \\
n=275\end{array}$ & $\begin{array}{l}r=-.02 \\
p<.72 \\
n=275\end{array}$ & $\begin{array}{c}r=.12 \\
p<.15 \\
n=136\end{array}$ & $\begin{array}{c}r=.07 \\
p<.18 \\
n=275\end{array}$ \\
\hline $\begin{array}{l}\text { Parent's } \\
\text { Signature on } \\
\text { Case Plan }\end{array}$ & $\begin{array}{c}r=.12 \\
p<.04 \\
n=253\end{array}$ & $\begin{array}{c}r=.03 \\
p<.55 \\
n=275\end{array}$ & $\begin{array}{l}r=-.04 \\
p<.49 \\
n=275\end{array}$ & $\begin{array}{c}r=-.10 \\
p<.87 \\
n=275\end{array}$ & $\begin{array}{l}r=-.02 \\
p<.70 \\
n=275\end{array}$ & $\begin{array}{l}r=-.01 \\
p<.75 \\
n=275\end{array}$ & $\begin{array}{c}r=.12 \\
p<.16 \\
n=136\end{array}$ & $\begin{array}{l}r=.070 \\
p<.18 \\
n=275\end{array}$ \\
\hline $\begin{array}{l}\text { Family and } \\
\text { Community } \\
\text { Support Rating }\end{array}$ & $\begin{array}{l}r=-.05 \\
p<.34 \\
n=253\end{array}$ & $\begin{array}{c}r=-.19 \\
p<.001 \\
n=275\end{array}$ & $\begin{array}{c}r=.11 \\
p<.05 \\
n=275\end{array}$ & $\begin{array}{c}r=.002 \\
p<.97 \\
n=275\end{array}$ & $\begin{array}{c}r=.04 \\
p<.46 \\
n=275\end{array}$ & $\begin{array}{c}r=.17 \\
p<.04 \\
n=136\end{array}$ & $\begin{array}{c}r=.17 \\
p<.04 \\
n=136\end{array}$ & $\begin{array}{l}r=-.11 \\
p<.05 \\
n=275\end{array}$ \\
\hline $\begin{array}{l}\text { Parental } \\
\text { Functioning } \\
\text { Rating }\end{array}$ & $\begin{array}{c}r=.00 \\
p<.90 \\
n=253\end{array}$ & $\begin{array}{r}r=-.16 \\
p<.005 \\
n=275\end{array}$ & $\begin{array}{c}r=.06 \\
p<.28 \\
n=275\end{array}$ & $\begin{array}{c}r=-.13 \\
p<.02 \\
n=275\end{array}$ & $\begin{array}{l}r=-.08 \\
p<.17 \\
n=275\end{array}$ & $\begin{array}{l}r=-.08 \\
p<.17 \\
n=275\end{array}$ & $\begin{array}{c}r=.27 \\
p<.00 \\
n=136\end{array}$ & $\begin{array}{l}r=-.00 \\
p<.97 \\
n=275\end{array}$ \\
\hline $\begin{array}{l}\text { Number of Risk } \\
\text { Factors } \\
\text { Present }\end{array}$ & $\begin{array}{c}r=.08 \\
p<.19 \\
n=253\end{array}$ & $\begin{array}{c}r=-.09 \\
p<.13 \\
n=275\end{array}$ & $\begin{array}{c}r=.02 \\
p<.68 \\
n=275\end{array}$ & $\begin{array}{c}r=-.08 \\
p<.17 \\
n=275\end{array}$ & $\begin{array}{l}r=-.15 \\
p<.01 \\
n=275\end{array}$ & $\begin{array}{l}r=-.07 \\
p<.20 \\
n=275\end{array}$ & $\begin{array}{c}r=.20 \\
p<.01 \\
n=136\end{array}$ & $\begin{array}{l}r=-.03 \\
p<.54 \\
n=275\end{array}$ \\
\hline $\begin{array}{l}\text { Number of } \\
\text { Child Abuse } \\
\text { Referrals }\end{array}$ & $\begin{array}{l}r=.01 \\
p<.85 \\
n=275\end{array}$ & $\begin{array}{c}r=.04 \\
p<.47 \\
n=275\end{array}$ & $\begin{array}{l}r=-.01 \\
p<.005 \\
n=275\end{array}$ & $\begin{array}{l}r=-.04 \\
p<.42 \\
n=275\end{array}$ & $\begin{array}{l}r=.06 \\
p<.29 \\
n=27\end{array}$ & $\begin{array}{l}r=-.16 \\
p<.00 \\
n=275\end{array}$ & $\begin{array}{c}r=.28 \\
p<.00 \\
n=136\end{array}$ & $\begin{array}{c}r=.13 \\
p<.03 \\
n=275\end{array}$ \\
\hline $\begin{array}{l}\text { Number of } \\
\text { Parents in the } \\
\text { Home }\end{array}$ & $\begin{array}{l}r=-.02 \\
p<.69 \\
n=275\end{array}$ & $\begin{array}{c}r=.05 \\
p<.34 \\
N=275\end{array}$ & $\begin{array}{l}r=-.04 \\
p<.43 \\
n=275\end{array}$ & $\begin{array}{c}r=.01 \\
p<.75 \\
n=275\end{array}$ & $\begin{array}{l}r=-.13 \\
p<.02 \\
n=275\end{array}$ & $\begin{array}{c}r=.15 \\
p<.01 \\
n=275\end{array}$ & $\begin{array}{c}r=.13 \\
p<.12 \\
n=136\end{array}$ & $\begin{array}{c}r=.04 \\
p<.43 \\
n=275\end{array}$ \\
\hline
\end{tabular}




\begin{tabular}{|c|c|c|c|c|c|c|c|c|}
\hline & $\begin{array}{c}\text { Proximity } \\
\text { of } \\
\text { placement }\end{array}$ & $\begin{array}{c}\text { Number } \\
\text { of social } \\
\text { workers } \\
\text { assigned } \\
\text { to the } \\
\text { case }\end{array}$ & $\begin{array}{l}\text { Degree of } \\
\text { Supervisor }\end{array}$ & $\begin{array}{c}\text { Average } \\
\text { monthly } \\
\text { amount } \\
\text { spent } \\
\text { on } \\
\text { child's } \\
\text { care } \\
\end{array}$ & $\begin{array}{c}\text { Type of } \\
\text { placement }\end{array}$ & $\begin{array}{l}\text { Type of } \\
\text { court } \\
\text { system }\end{array}$ & $\begin{array}{l}\text { Number } \\
\text { of } \\
\text { months } \\
\text { until tpr }\end{array}$ & $\begin{array}{c}\text { Mean } \\
\text { number of } \\
\text { monthly } \\
\text { parent/child } \\
\text { visits }\end{array}$ \\
\hline Child's Race & $\begin{array}{l}r=-.15 \\
p<.01 \\
n=253\end{array}$ & $\begin{array}{l}r=-.00 \\
p<.94 \\
n=275\end{array}$ & $\begin{array}{l}r=-.04 \\
p<.42 \\
n=275\end{array}$ & $\begin{array}{c}r=.00 \\
p<.94 \\
n=275\end{array}$ & $\begin{array}{c}r=-.05 \\
p<.35 \\
n=275\end{array}$ & $\begin{array}{c}r=.39 \\
p<.00 \\
n=275\end{array}$ & $\begin{array}{l}r=-.19 \\
p<.02 \\
n=136\end{array}$ & $\begin{array}{l}r=-.09 \\
p<.10 \\
n=275\end{array}$ \\
\hline Child's Gender & $\begin{array}{l}r=.11 \\
p<.07 \\
n=275\end{array}$ & $\begin{array}{c}r=.04 \\
p<.42 \\
n=275\end{array}$ & $\begin{array}{r}r=.00 \\
p<.88 \\
n=275\end{array}$ & $\begin{array}{l}r=-.08 \\
p<.15 \\
n=275\end{array}$ & $\begin{array}{l}r=-.07 \\
p<.23 \\
n=275\end{array}$ & $\begin{array}{l}r=-.06 \\
p<.28 \\
n=275\end{array}$ & $\begin{array}{r}r=.07 \\
p<.38 \\
n=136\end{array}$ & $\begin{aligned} r & =.10 \\
p & <.09 \\
n & =275\end{aligned}$ \\
\hline CBCL Level & $\begin{array}{r}r=.03 \\
p<.67 \\
n=.146\end{array}$ & $\begin{array}{l}r=-.03 \\
p<.63 \\
n=154\end{array}$ & $\begin{array}{l}r=-.08 \\
p<.29 \\
n=275\end{array}$ & $\begin{array}{l}r=.26 \\
p<.00 \\
n=154\end{array}$ & $\begin{array}{c}r=.24 \\
p<.00 \\
n=154\end{array}$ & $\begin{aligned} & r=.21 \\
& p<.00 \\
& n=154\end{aligned}$ & $\begin{array}{l}r=-.11 \\
p<.25 \\
n=154\end{array}$ & $\begin{array}{r}r=.11 \\
p<.14 \\
n=154\end{array}$ \\
\hline $\begin{array}{l}\text { Child } \\
\text { Developmental } \\
\text { Level at Entry }\end{array}$ & $\begin{array}{c}r=.03 \\
p<.57 \\
n=253\end{array}$ & $\begin{array}{l}r=-.25 \\
p<.000 \\
n=275\end{array}$ & $\begin{array}{r}r=.02 \\
p<.67 \\
n=275\end{array}$ & $\begin{array}{r}r=-.01 \\
p<.83 \\
n=275\end{array}$ & $\begin{array}{c}r=.32 \\
p<.00 \\
n=275\end{array}$ & $\begin{array}{l}r=. .07 \\
p<.20 \\
n=275\end{array}$ & $\begin{array}{r}r=.35 \\
p<.00 \\
n=275\end{array}$ & $\begin{array}{r}r=-.08 \\
p<.17 \\
n=275\end{array}$ \\
\hline $\begin{array}{l}\text { Number of } \\
\text { Moves }\end{array}$ & $\begin{array}{r}r=.10 \\
p<.10 \\
n=253\end{array}$ & $\begin{array}{l}r=-.28 \\
p<.00 \\
n=275\end{array}$ & $\begin{array}{l}r=.02 \\
p<.63 \\
n=275\end{array}$ & $\begin{array}{l}r=.27 \\
p<.00 \\
n=275\end{array}$ & $\begin{array}{c}r=.32 \\
p<.00 \\
n=275\end{array}$ & $\begin{array}{c}r=-.00 \\
p<.91 \\
n=275\end{array}$ & $\begin{array}{l}r=.27 \\
p<.00 \\
n=136\end{array}$ & $\begin{array}{l}r=-.14 \\
p<.01 \\
n=275\end{array}$ \\
\hline $\begin{array}{l}\text { Days between } \\
\text { Case Plans }\end{array}$ & $\begin{array}{l}r=.03 \\
p<.59 \\
n=253\end{array}$ & $\begin{array}{l}r=-.58 \\
p<.00 \\
n=275\end{array}$ & $\begin{array}{l}r=.07 \\
p<.24 \\
n=275\end{array}$ & $\begin{array}{l}r=-.02 \\
p<.74 \\
n=275\end{array}$ & $\begin{array}{l}r=.24 \\
p<.00 \\
n=275\end{array}$ & $\begin{array}{c}r=-.06 \\
p<.29 \\
n=275\end{array}$ & $\begin{array}{c}r=.62 \\
p<.00 \\
n=136\end{array}$ & $\begin{array}{l}r=-.27 \\
p<.00 \\
n=275\end{array}$ \\
\hline $\begin{array}{l}\text { Permanency } \\
\text { Goal }\end{array}$ & $\begin{array}{c}r=.13 \\
p<.02 \\
n=253\end{array}$ & $\begin{array}{l}r=.15 \\
p<.01 \\
n=275\end{array}$ & $\begin{array}{l}r=-.01 \\
p<.86 \\
n=275\end{array}$ & $\begin{array}{l}r=-.13 \\
p<.03 \\
n=275\end{array}$ & $\begin{array}{l}r=-.21 \\
p<.00 \\
n=275\end{array}$ & $\begin{array}{c}r=.03 \\
p<.58 \\
n=275\end{array}$ & $\begin{array}{c}r=.13 \\
p<.10 \\
n=136\end{array}$ & $\begin{aligned} & r=.06 \\
& p<.31 \\
& n=275\end{aligned}$ \\
\hline $\begin{array}{l}\text { Social Worker's } \\
\text { Educational } \\
\text { Degree }\end{array}$ & $\begin{array}{r}r=.05 \\
p<.38 \\
n=253\end{array}$ & $\begin{array}{r}r=-.00 \\
p<.88 \\
n=275\end{array}$ & $\begin{array}{c}r=.04 \\
p<.64 \\
n=275\end{array}$ & $\begin{array}{c}r=.01 \\
p<.77 \\
n=275\end{array}$ & $\begin{array}{c}r=-.03 \\
p<.54 \\
n=275\end{array}$ & $\begin{array}{r}r=-.06 \\
p<.31 \\
n=275\end{array}$ & $\begin{array}{c}r=.03 \\
p<.71 \\
n=136\end{array}$ & $\begin{array}{r}r=-.05 \\
p<.40 \\
n=275\end{array}$ \\
\hline
\end{tabular}




\begin{tabular}{|c|c|c|c|c|c|c|c|c|}
\hline & $\begin{array}{c}\text { Proximity } \\
\text { of } \\
\text { placement }\end{array}$ & $\begin{array}{l}\text { Number } \\
\text { of social } \\
\text { workers } \\
\text { assigned } \\
\text { to the } \\
\text { case }\end{array}$ & $\begin{array}{l}\text { Degree of } \\
\text { Supervisor }\end{array}$ & $\begin{array}{c}\text { Average } \\
\text { monthly } \\
\text { amount } \\
\text { spent } \\
\text { on } \\
\text { child's } \\
\text { care }\end{array}$ & $\begin{array}{c}\text { Type of } \\
\text { placement }\end{array}$ & $\begin{array}{l}\text { Type of } \\
\text { court } \\
\text { system }\end{array}$ & $\begin{array}{l}\text { Number } \\
\text { of } \\
\text { months } \\
\text { until tpr }\end{array}$ & $\begin{array}{c}\text { Mean } \\
\text { number of } \\
\text { monthly } \\
\text { parent/child } \\
\text { visits }\end{array}$ \\
\hline $\begin{array}{l}\text { Social Worker's } \\
\text { Months of } \\
\text { Experience }\end{array}$ & $\begin{array}{l}r=-.09 \\
p<.17 \\
n=227\end{array}$ & $\begin{array}{c}r=.03 \\
p<.60 \\
n=227\end{array}$ & $\begin{array}{l}r=-.18 \\
p<.00 \\
n=227\end{array}$ & $\begin{array}{c}r=.13 \\
p<.04 \\
n=227\end{array}$ & $\begin{array}{l}r=-.02 \\
p<.74 \\
n=227\end{array}$ & $\begin{array}{c}r=.07 \\
p<.28 \\
n=275\end{array}$ & $\begin{array}{c}r=-.19 \\
p<.04 \\
n=136\end{array}$ & $\begin{array}{c}r=.14 \\
p<.03 \\
n=227\end{array}$ \\
\hline $\begin{array}{l}\text { Mean monthly } \\
\text { social worker } \\
\text { /parent visits }\end{array}$ & $\begin{array}{c}r=.11 \\
p<.05 \\
n=253\end{array}$ & $\begin{array}{c}r=.39 \\
p<.00 \\
n=275\end{array}$ & $\begin{array}{l}r=-.06 \\
p<.27 \\
n=275\end{array}$ & $\begin{array}{l}r=-.02 \\
p<.62 \\
n=275\end{array}$ & $\begin{array}{c}r=-.07 \\
p<.19 \\
n=275\end{array}$ & $\begin{array}{c}r=-.08 \\
p<.15 \\
n=275\end{array}$ & $\begin{array}{l}r=-.09 \\
p<.28 \\
n=136\end{array}$ & $\begin{array}{c}r=.23 \\
p<.00 \\
n=275\end{array}$ \\
\hline $\begin{array}{l}\text { Mean monthly } \\
\text { social } \\
\text { worker/child } \\
\text { visits }\end{array}$ & $\begin{array}{c}r=.01 \\
p<.87 \\
n=253\end{array}$ & $\begin{array}{c}r=.37 \\
p<.00 \\
n=275\end{array}$ & $\begin{array}{l}r=-.05 \\
p<.38 \\
n=275\end{array}$ & $\begin{array}{c}r=.03 \\
p<.56 \\
n=275\end{array}$ & $\begin{array}{l}r=-.02 \\
p<.66 \\
n=275\end{array}$ & $\begin{array}{l}r=-.09 \\
p<.29 \\
n=275\end{array}$ & $\begin{array}{c}r=.02 \\
p<.78 \\
n=136\end{array}$ & $\begin{array}{c}r=.31 \\
p<.00 \\
n=275\end{array}$ \\
\hline $\begin{array}{l}\text { Proximity of } \\
\text { placement }\end{array}$ & $\begin{array}{r}r=1 \\
n=275\end{array}$ & $\begin{array}{c}r=.01 \\
p<.87 \\
n=253\end{array}$ & $\begin{array}{c}r=.12 \\
p<.05 \\
n=253\end{array}$ & $\begin{array}{l}r=.09 \\
p<.12 \\
n=253\end{array}$ & $\begin{array}{l}r=.08 \\
p<.17 \\
n=253\end{array}$ & $\begin{array}{c}r=-.13 \\
p<.30 \\
n=253\end{array}$ & $\begin{array}{l}r=.00 \\
p<.97 \\
n=131\end{array}$ & $\begin{array}{c}r=.13 \\
p<.03 \\
n=253\end{array}$ \\
\hline $\begin{array}{l}\text { Number of } \\
\text { social workers } \\
\text { assigned to the } \\
\text { case }\end{array}$ & $\begin{array}{l}r=.04 \\
p<.47 \\
n=253\end{array}$ & $\begin{array}{r}r=1 \\
n=275\end{array}$ & $\begin{array}{l}r=-.06 \\
p<.30 \\
n=275\end{array}$ & $\begin{array}{l}r=-.03 \\
p<.62 \\
n=275\end{array}$ & $\begin{array}{l}r=-.07 \\
p<.22 \\
n=275\end{array}$ & $\begin{array}{c}r=-.04 \\
p<.43 \\
n=275\end{array}$ & $\begin{array}{l}r=-.45 \\
p<.00 \\
n=136\end{array}$ & $\begin{array}{c}r=.17 \\
p<.03 \\
n=275\end{array}$ \\
\hline $\begin{array}{l}\text { Degree of } \\
\text { supervisor }\end{array}$ & $\begin{array}{c}r=.12 \\
p<.05 \\
n=253\end{array}$ & $\begin{array}{l}r=-.06 \\
p<.30 \\
n=275\end{array}$ & $\begin{array}{r}r=1 \\
n=275\end{array}$ & $\begin{array}{l}r=-.01 \\
p<.76 \\
n=275\end{array}$ & $\begin{array}{l}r=.14 \\
p<.01 \\
n=275\end{array}$ & $\begin{array}{l}r=-.12 \\
p<.03 \\
n=275\end{array}$ & $\begin{array}{c}r=-.00 \\
p<.96 \\
n=136\end{array}$ & $\begin{array}{l}r=.06 \\
p<.29 \\
n=275\end{array}$ \\
\hline $\begin{array}{l}\text { Average } \\
\text { monthly } \\
\text { amount spent } \\
\text { on child's care }\end{array}$ & $\begin{array}{c}r=.09 \\
p<.12 \\
n=253\end{array}$ & $\begin{array}{l}r=-.03 \\
p<.62 \\
n=275\end{array}$ & $\begin{array}{l}r=-.01 \\
p<.76 \\
n=275\end{array}$ & $\begin{array}{r}r=1 \\
n=275\end{array}$ & $\begin{array}{c}r=.28 \\
p<.00 \\
n=275\end{array}$ & $\begin{array}{c}r=.04 \\
p<.48 \\
n=275\end{array}$ & $\begin{array}{l}r=-.27 \\
p<.00 \\
n=136\end{array}$ & $\begin{array}{l}r=-.00 \\
p<.98 \\
n=275\end{array}$ \\
\hline
\end{tabular}




\begin{tabular}{|c|c|c|c|c|c|c|c|c|}
\hline & $\begin{array}{c}\text { Proximity } \\
\text { of } \\
\text { placement }\end{array}$ & $\begin{array}{l}\text { Number } \\
\text { of social } \\
\text { workers } \\
\text { assigned } \\
\text { to the } \\
\text { case }\end{array}$ & $\begin{array}{l}\text { Degree of } \\
\text { Supervisor }\end{array}$ & $\begin{array}{c}\text { Average } \\
\text { monthly } \\
\text { amount } \\
\text { spent } \\
\text { on } \\
\text { child's } \\
\text { care } \\
\end{array}$ & $\begin{array}{c}\text { Type of } \\
\text { placement }\end{array}$ & $\begin{array}{l}\text { Type of } \\
\text { court } \\
\text { system }\end{array}$ & $\begin{array}{c}\text { Number } \\
\text { of } \\
\text { months } \\
\text { until tpr }\end{array}$ & $\begin{array}{c}\text { Mean } \\
\text { number of } \\
\text { monthly } \\
\text { parent/child } \\
\text { visits }\end{array}$ \\
\hline $\begin{array}{l}\text { Type of } \\
\text { placement }\end{array}$ & $\begin{array}{c}r=.08 \\
p<.17 \\
n=253\end{array}$ & $\begin{array}{l}r=-.07 \\
p<.22 \\
n=275\end{array}$ & $\begin{array}{r}r=.14 \\
p<.01 \\
n=275\end{array}$ & $\begin{array}{c}r=.28 \\
p<.00 \\
n=275\end{array}$ & $\begin{array}{r}r=1 \\
n=275\end{array}$ & $\begin{array}{l}r=.02 \\
p<.65 \\
n=275\end{array}$ & $\begin{array}{c}r=.08 \\
p<.30 \\
n=136\end{array}$ & $\begin{aligned} r & =-.05 \\
p & <.33 \\
n & =275\end{aligned}$ \\
\hline $\begin{array}{l}\text { Type of court } \\
\text { system }\end{array}$ & $\begin{array}{c}r=-.13 \\
p<.30 \\
n=253\end{array}$ & $\begin{array}{c}r=-.04 \\
p<.43 \\
n=275\end{array}$ & $\begin{array}{c}r=-.12 \\
p<.03 \\
n=275\end{array}$ & $\begin{array}{c}r=.04 \\
p<.48 \\
n=275\end{array}$ & $\begin{array}{c}r=.02 \\
p<.65 \\
n=275\end{array}$ & $\begin{array}{r}r=1 \\
n=275\end{array}$ & $\begin{array}{r}r=-.20 \\
p<01 \\
n=136\end{array}$ & $\begin{array}{c}r=.02 \\
p<.73 \\
n=275\end{array}$ \\
\hline $\begin{array}{l}\text { Number of } \\
\text { months until tpr }\end{array}$ & $\begin{array}{c}r=.00 \\
p<.97 \\
n=131\end{array}$ & $\begin{array}{l}r=-.45 \\
p<.00 \\
n=136\end{array}$ & $\begin{array}{c}r=-.00 \\
p<.96 \\
n=136\end{array}$ & $\begin{array}{l}r=-.27 \\
p<.00 \\
n=136\end{array}$ & $\begin{array}{c}r=.08 \\
p<.30 \\
n=136\end{array}$ & $\begin{array}{r}r=-.20 \\
p<01 \\
n=136\end{array}$ & $\begin{array}{r}r=1 \\
n=275\end{array}$ & $\begin{array}{c}r=.32 \\
p<.00 \\
n=275\end{array}$ \\
\hline $\begin{array}{l}\text { Mean number } \\
\text { of monthly } \\
\text { parent/child } \\
\text { visits }\end{array}$ & $\begin{array}{c}r=.13 \\
p<.03 \\
n=253\end{array}$ & $\begin{array}{c}r=.17 \\
p<.03 \\
n=275\end{array}$ & $\begin{array}{l}r=.06 \\
p<.29 \\
n=275\end{array}$ & $\begin{array}{l}r=-.00 \\
p<.98 \\
n=275\end{array}$ & $\begin{array}{r}r=-.05 \\
p<.33 \\
n=275\end{array}$ & $\begin{array}{c}r=.02 \\
p<.73 \\
n=275\end{array}$ & $\begin{array}{r}r=.32 \\
p<.00 \\
n=136\end{array}$ & $\begin{array}{r}r=1 \\
n=275\end{array}$ \\
\hline
\end{tabular}




\section{CURRICULUM VITAE \\ Pam Nolley Tungate \\ April, 2005}

\section{BIOGRAPHICAL DATA:}

Date of Birth:

Social Security Number:

Business Address:

E-mail Address:

Business/Cell Phone:

Home Address:

Home Phone:

\section{EDUCATIONAL BACKGROUND :}

Graduate:

\author{
University of Kentucky \\ Masters of Social Work Degree \\ Graduation Date: December 1991 \\ University of Louisville \\ Dealing with Sexually Reactive Children \\ Certification Program (12 Credit Hours) \\ Western Kentucky University \\ Enhancing Safety and Permanency
} 916 North Mulberry Street Elizabethtown, Kentucky 42701

pam.tungateE@ky.gov

34 Trotter Lane

Campbellsville, Kentucky 42718

(270) $789-4661$ 
Eastern Kentucky University

Chemical Dependency and Abuse Counselor Certification Program (15 Credit Hours)

University of Louisville Doctorate of Social Work Expected Graduation Date - May 2005

Undergraduate:

Campbellsville University Double Major: Social Work and Psychology Graduation Date: December 1990 Magna Cum Laude Graduate

\section{Professional Organizations and Honors:}

- University of Kentucky Scholarship Award Recipient

- Social Work Award, Campbejlsville University

- Senior Achievement Award for Excellence, Campbellsville University

- Rural Social Worker Scholarship Award, University of Kentucky

- Certified Social Worker License

- $110 \%$ Award - Cabinet for Families and Children

- Taylor Count Hospital Health Council

- Taylor County Elementary School Site Based Decision Making Council

- Qualified Mental Health/Mental Retardation Professional

- Kentucky Colonel, Commonwealth of Kentucky 2003

- Certified Public Manager Program (3 Credit Hours)

\section{RESEARCH INTERESTS:}

My primary research interest is child welfare outcomes. I have completed research studies in the following areas: the effects of ethnicity on duration of foster care, international adoption and international social work. I am particularly interested in policy development related to permanency for children in foster care.

\section{ACADEMIC POSITIONS}

Campbellsville University

University of Louisville
2000 to 2003 , Member of the Undergraduate Adjunct Faculty

2000-present, Field Practicum Supervisor Graduate School 


\section{PROFESSIONAL POSITIONS OF RESPONSIBILITY AND SERVICE TO THE PROFESSION AT LARGE:}

\section{SOCIAL WORK}

Cabinet for Health and Family Services, Lincoln Trail Region Clinical Associate: June 1999 to present. Responsibilities for overseeing policy and practice related to public child welfare in an eight county region of Kentucky.

Cabinet for Families and Children, Lincoln Trail Region. Family Services Offices Supervisor. December 1998 to June 1999. Supervised two public child welfare county offices.

Cabinet for Families and Children, Lake Cumberland Region. Social Services Treatment Specialist. January 1998 to December 1998. Provided specialized guidance to child welfare staff in a tén county area.

Cabinet for Families and Children, Social Services Clinician. June 1992 to December 1997. Provided front line child and adult protection services.

Regional Interagency Chairperson for Impact Plus services. June 2001 to present.

Member of the Cabinet for Families and Children Human Services Leadership Institute, 1999-2000.

Adanta Human Development Services, 1990 to 1992. Responsible for Disabled Children's Program, case management services for adult and child MR/DD clients and day treatment workshop service provider.

Family Home Health, 1990 to 1991. Provided medical social work services to home health clients.

Adanta Clinical Services, 1989 to 1991. Provided individual and group counseling services through community based mental health services. 


\section{COMMUNITY SERVICES:}

Red Cross Nursing Committees Chairperson, Campbellsville Chapter 1991.

Carver School of Social Work, Advisory Council, 2001-2002.

Campbellsville Youth Soccer Team Mom.

Taylor County Elementary School PTSO.

\section{References}

Libby Trager

Service Region Administrator

Cabinet for Health and Family Services

Lincoln Trail Region

916 North Mulberry Street

Elizabethtown, Kentucky 42701

Dr. April Vandeventer

Psychologists

Cabinet for Health and Family Services

Deputy Commissioner

916 North Mulberry Street

Elizabethtown, Kentucky 42701

Dr. Anita Barbee

University of Louisville

Kent School of Social Work

Belknap Campus

Louisville, Kentucky 40292 